SERVIÇO DE PÓS-GRADUAÇÃO DO ICMC-USP Data de Depósito: 08/04/2005

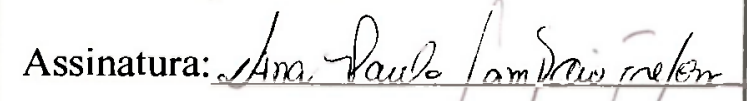

\title{
Contribuições para a extensão de informação capturada: \\ Metadados e Web Services.
}

\author{
Renata Paciência Godoy
}

Orientadora: Profa. Dra. Maria da Graça Campos Pimentel

Dissertação apresentada ao Instituto de Ciências Matemáticas e de Computação - ICMC-USP, para Defesa do Mestrado, como parte dos requisitos para obtenção do título de Mestre em Ciências de Computação e Matemática Computacional.

USP - São Carlos

Abril de $\mathbf{2 0 0 5}$ 
Aluno: Renata Paciência Godoy

A Comissão Julgadora:

Profa. Dra. Maria da Graça Campos Pimentel

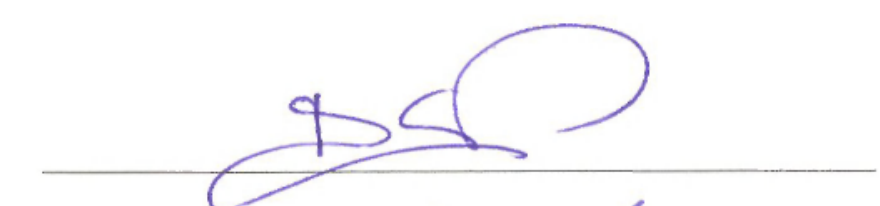

Prof. Dr. Caetano Traina Junior

Prof. Dr. Wilson Vicente Ruggiero

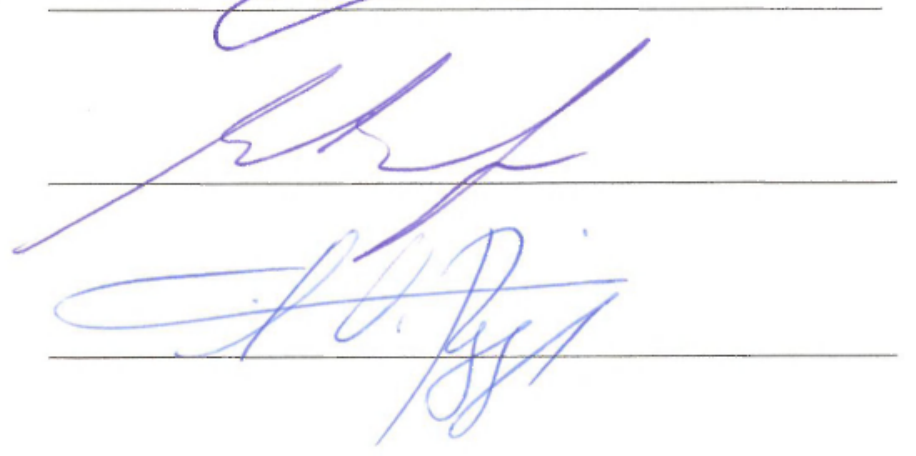




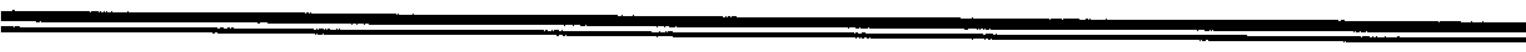

Dedicatória

Aos meus pais pelo carinho, incentivo, dedicação e amor incondicional Ao meu noivo pelo apoio e pela paciência 


\section{Agradecimentos}

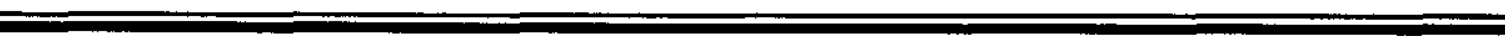

Agradeço a minha orientadora Graça Pimentel pelo apoio. além dos ensinamentos passados.

A Andrea, Renato, Patrão, Hélder, Renan, Valter, Laércio e aos outros amigos do Intermídia, minha sincera gratidão pelo apoio recebido e pela disposição em ajudar quando recorro a eles.

Deixo um agradecimento especial ao Renato, Patrão e Hélder pela ajuda neste projeto.

As minhas queridas amigas Adriane, Bia e Monica pelo incentivo e amizade.

A toda minha família que esteve sempre ao meu lado me alegrando e sem medir esforços para me ajudar. carinho

Aos meus irmãos, Eduardo e Lais, meu sincero obrigado pela ajuda, força, atenção $e$

Sou profundamente grata ao meu noivo, que sempre me confortou e me apoiou nas minhas decisões.

Impossivel não agradecer as pessoas mais especiais na minha vida: meus pais! Meu muito obrigado pelos esforços que fizeram e continuam fazendo, pela paciência, por sempre terem acreditado em mim e por nunca terem desistido de me apoiar. Muito obrigado! Amo vocês!

Finalmente, agradeço a Deus por sempre me dar força para enfrentar as dificuldades e pelo constante cuidado e socorro nas horas mais dificeis. Que Ele abençoe a todos. 
Resumo

A computação ubíqua é uma área de pesquisa que envolve a integração de tecnologia de forma transparente às atividades diárias das pessoas. Dois dos principais temas da computação ubiqua são aplicações de captura e acesso e a computação ciente de contexto. $O$ primeiro tema investiga o apoio à construção de aplicações que capturam informações relativas a uma experiência ao vivo com o objetivo de possibilitar posterior acesso à informação capturada, muitas vezes na forma de documentos Web. O segundo tema visa a facilitar a interação do usuário com o computador: cla descreve uma situação em que o dispositivo computacional está ciente das condições do usuário e adapta seu procedimento baseado em informações chamadas de informações de contexto.

Uma lacuna identificada em relação a aplicações de captura e acesso é que, muitas vezes, tais aplicações são desenvolvidas sem atenção para um possível reuso, por parte de outras aplicações, do material capturado. Nesse sentido, um problema tratado nesta dissertação é ausência de propostas de reuso de informações armazenadas por aplicações de captura e acesso. Em outras palavras, há a demanda pela incorporação de metadados à informação capturada, os quais viabilizam o intercâmbio c reuso das informações.

Nesse cenário, o trabalho tem por objetivo propor um mecanismo que permita incorporar metadados à informação capturada de modo que: quaisquer metadados manipulados sejam padronizados; metadados possam ser associados de modo automático a permitir intercâmbio; metadados possam ser adicionados sob demanda do usuário.

Como resultado das investigações, foram realizadas implementações que, partindo de informações capturadas pelo sistema de captura e acesso iClass, permitem a criação de objetos de aprendizagem de acordo com o padrão de metadados para objetos de aprendizagem SCORM tanto de modo automático como manual. fazendo uso de informações de contexto armazenadas no Web Service Context Kernel. Tanto o iClass como o Context Kernel são ambientes desenvolvidos no Laboratório Intermídia, no qual este trabalho foi realizado. 


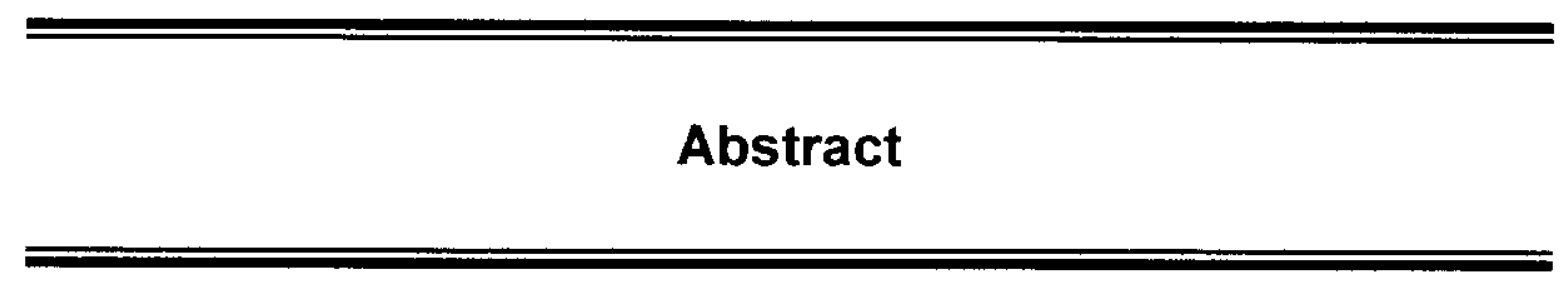

The ubiquitous computation is a research area that involves the integration of technology in a transparent way to the people's daily activities. Two of the main themes of the ubiquitous computation are capture applications and access and the aware computation of context. The first theme investigates the support to the construction of applications that capture relative information to a live experience with the objective of making possible subsequent access to the captured information, a lot of times in the form of documents Web. The second theme seeks to facilitate the user's interaction with the computer: it describes a situation in that the device of computation is aware of the uscr's conditions and it adapts his procedure based on called information of context information.

An identified gap in relation to capture applications and access is that, a lot of times, such applications are developed without attention for a possible reuse, on the part of other applications, of the captured material. In that sense, a problem treated in this dissertation is absence of proposals of reuse of information stored by capture applications and access. In other words, there is the demand for the metadata incorporation to the captured information, which make possible the exchange and reuse of the information.

In that scenery, the work has for objective to propose a mechanism to allow to incorporate metadata to the captured information so that: any manipulated metadata are standardized; metadata can be associated of automatic way to allow exchange; metadara can be added under the user's demand.

As a result of the investigations, they were accomplished implementations that, leaving of information captured by the capture system and access iClass, they allow the creation of learning objects in agreement with the metadata pattern for learning objects SCORM as much in an automatic way as manual, making use of context information stored in the Web Service Context Kernel. As much the iClass as Context Kernel they are ambient developed at the Laboratory Intermidia, in which this work was accomplished. 


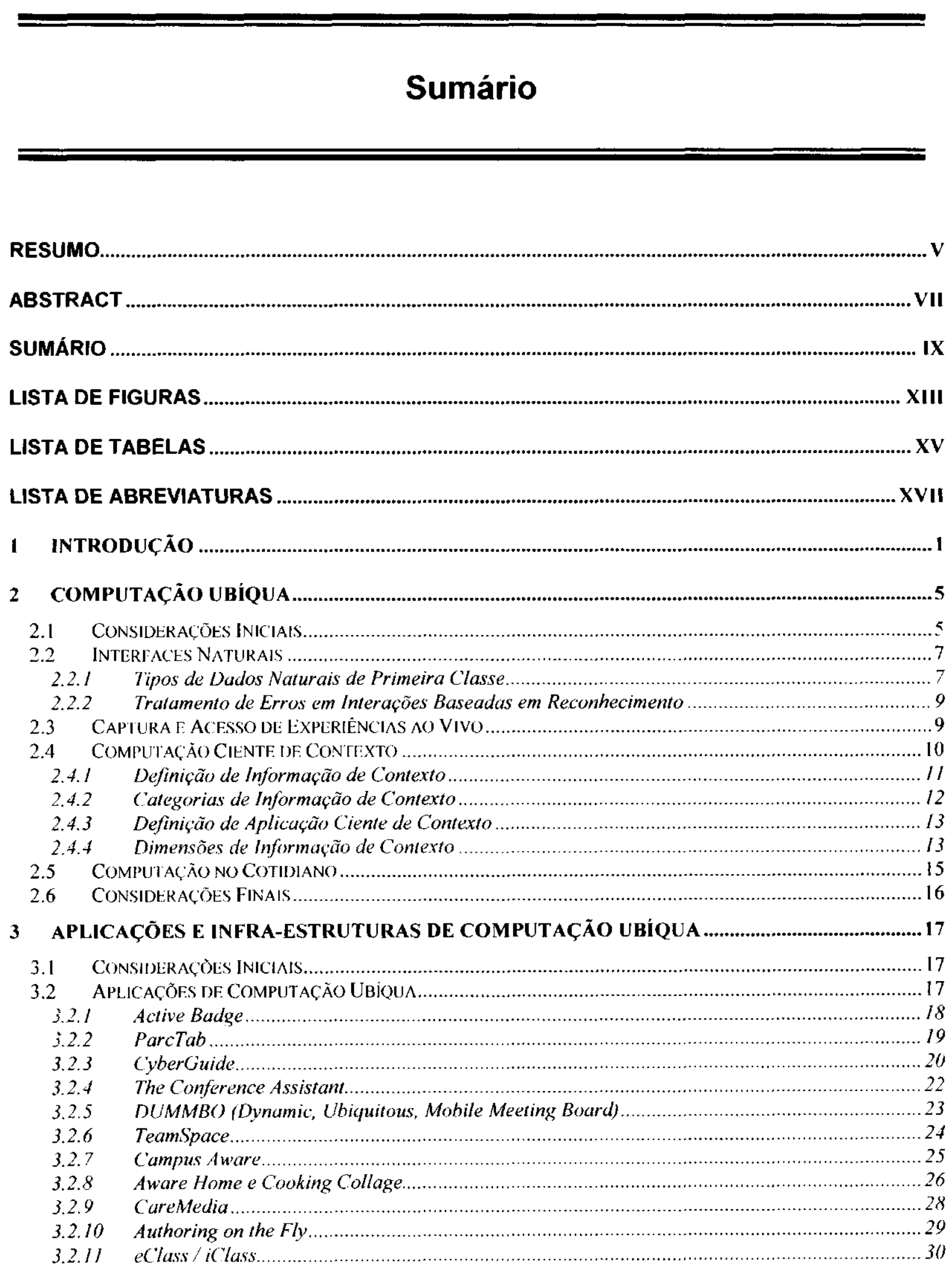




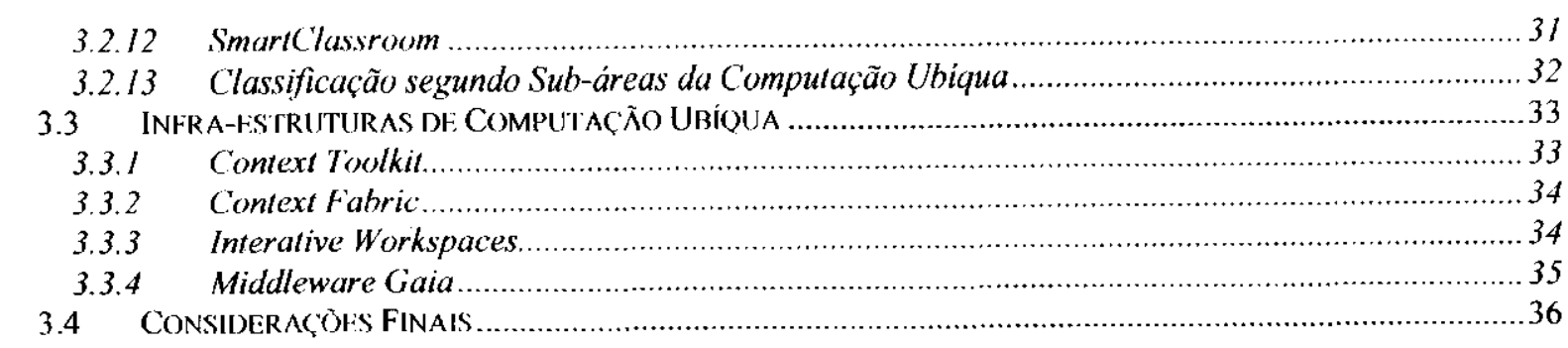

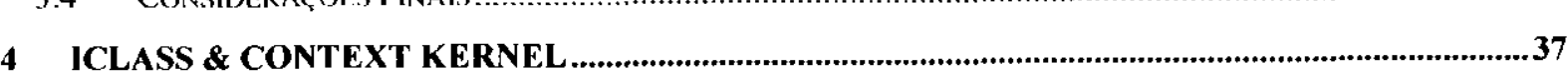

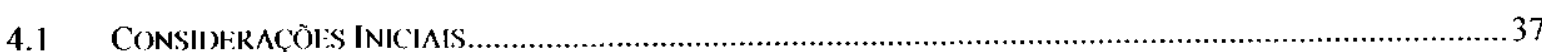

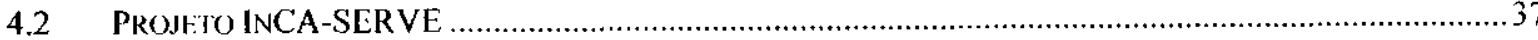

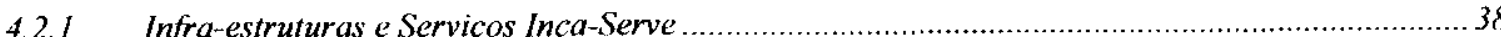

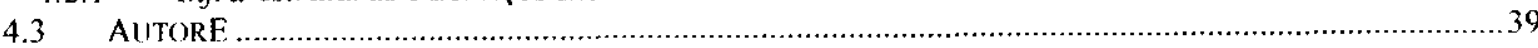

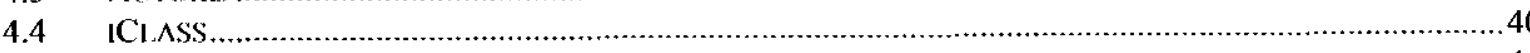

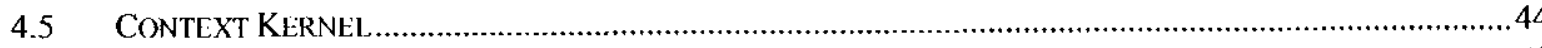

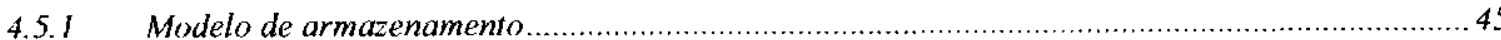

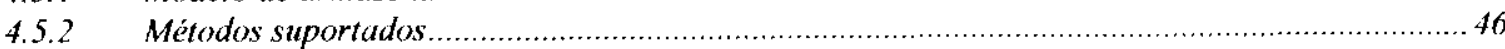

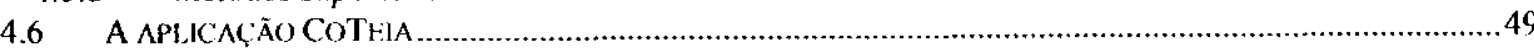

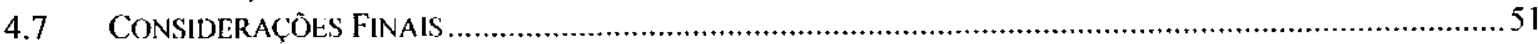

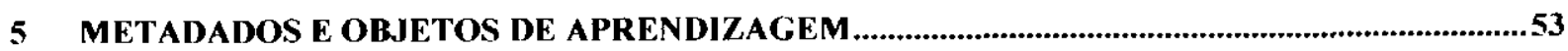

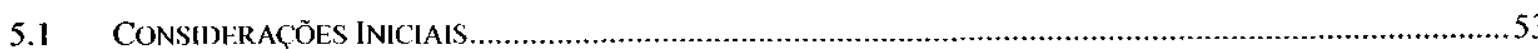

5.2 METADADOS

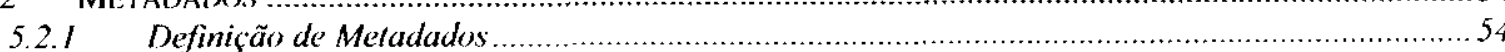

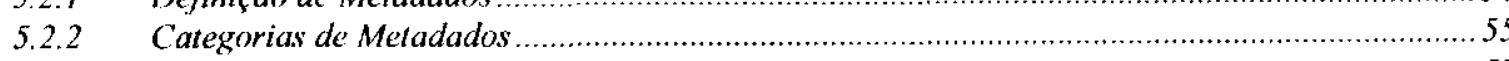

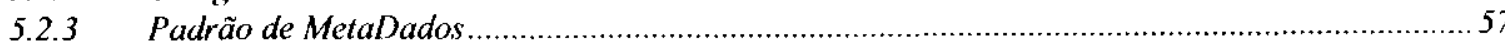

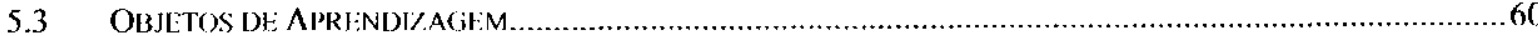

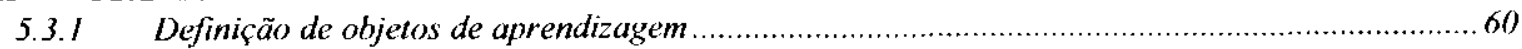

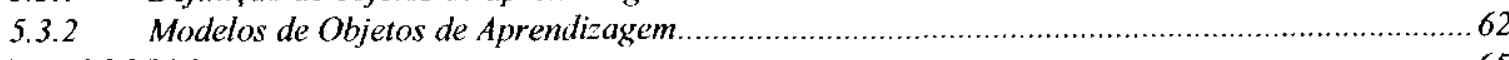

.

5.41 Requisitos para o SCORM

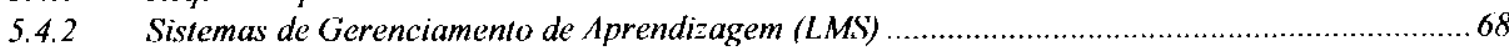

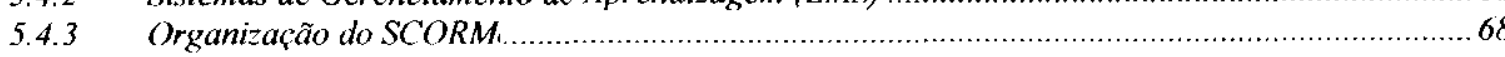

5.4.4 Componentes do Modelo de Conteúdo SCORM .................................................................. 70

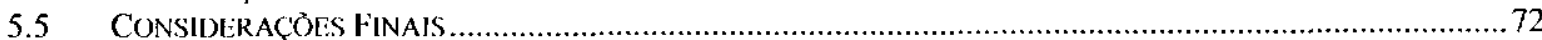

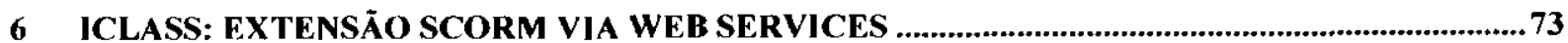

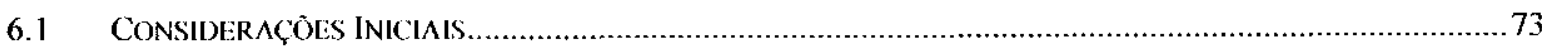

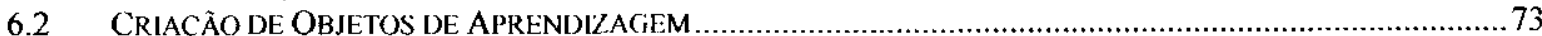

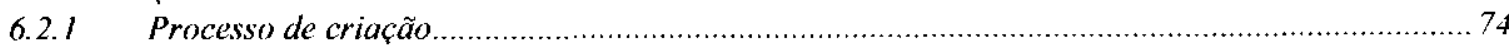

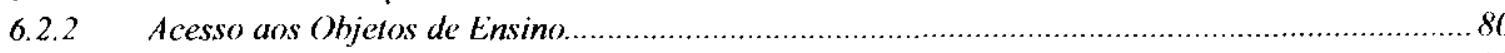

6.2.3 Procedimento de Validação dos Resultados ........................................................................ 82

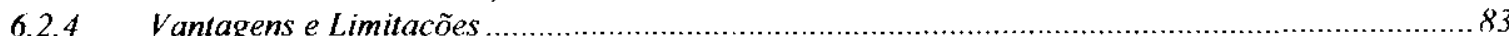

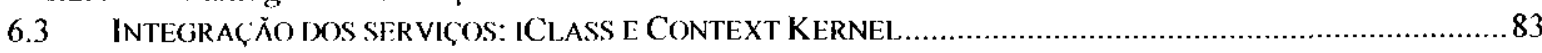

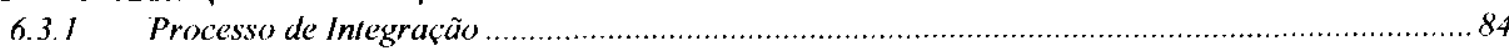

6.3.2 Vantagens e Limitaçẽes

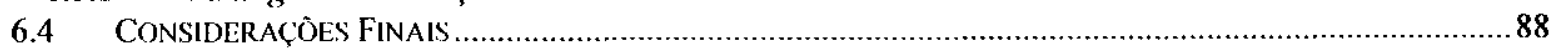

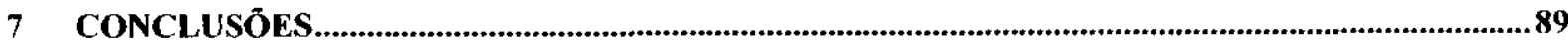

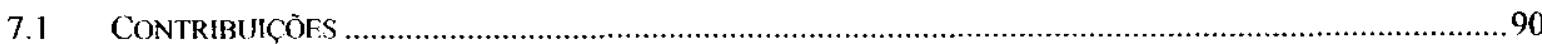

72 TRARALHOS FUTUROS

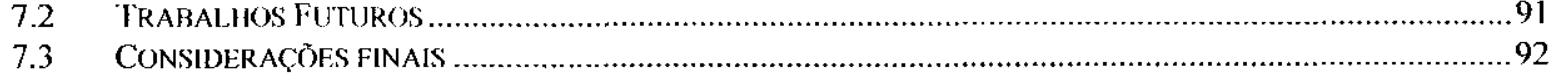

APÊNDICE A EMPACOTAMENTO DO CONTEÚDO SCORM.................................................................93

A.I COMPONENTES DO PACOTL DI: CONTEUUDO

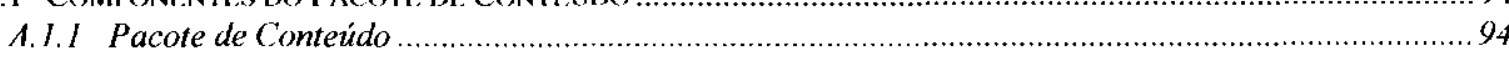

A.1.2 Manifesto

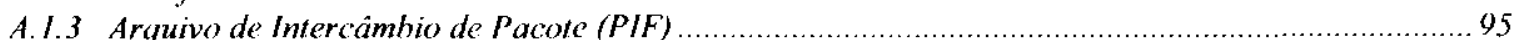


A.2 COMPONFNTFS DO MANIFFSTO

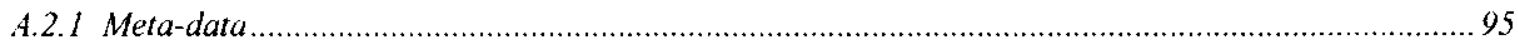

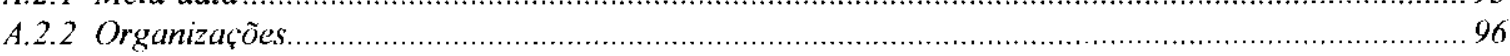

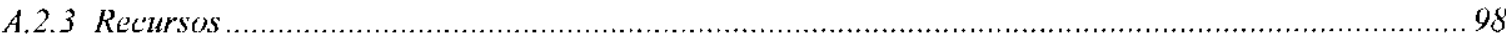

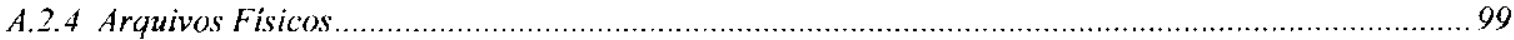

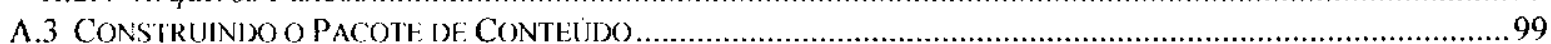

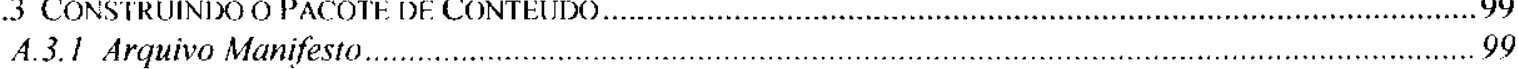

APÊNDICE B ESPECIFICAÇÕES DOS METADADOS SCORM ......................................................105

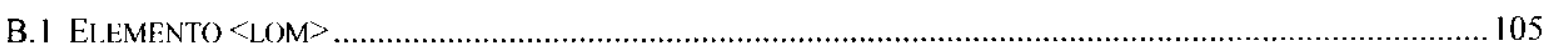

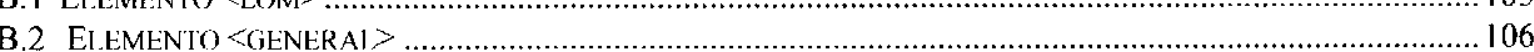

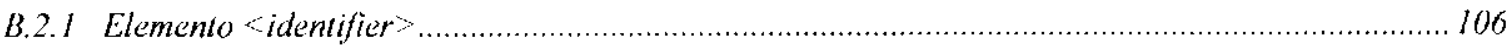

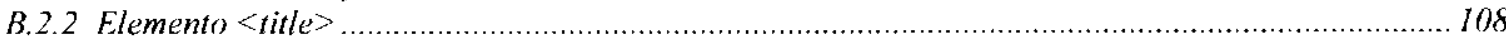

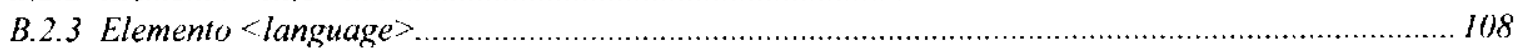

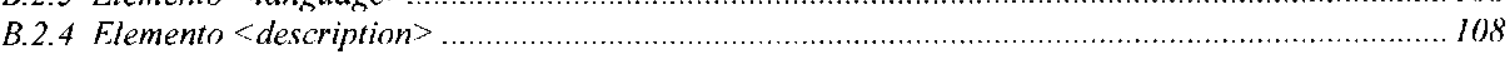

B.2.5 Elemento < kevword $>\quad .109$

B.2.6 Elemento <coverage $>\quad 109$

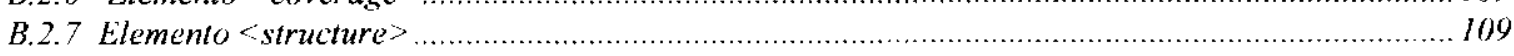

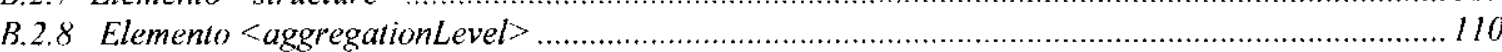

B.2.9 Exemplo com todos os elementos filhos do elemento <general> ..............................................111

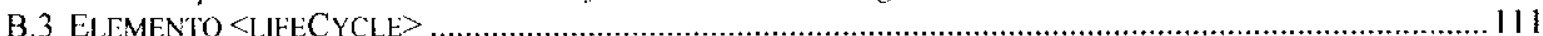

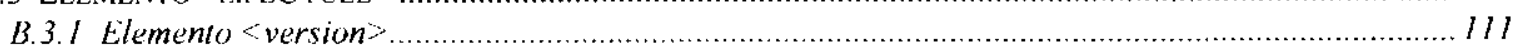

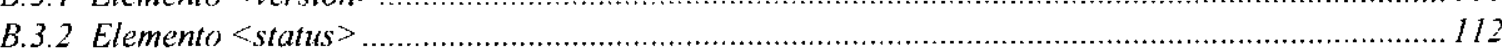

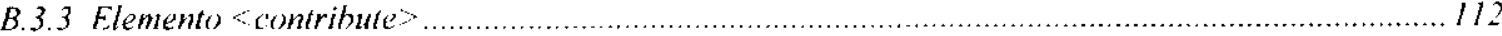

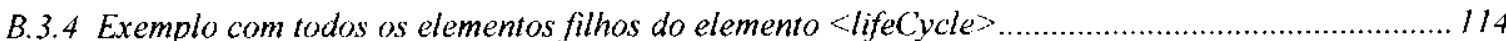

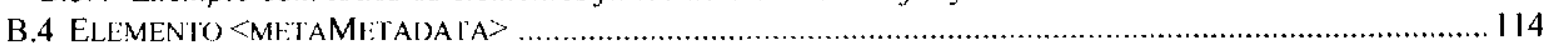

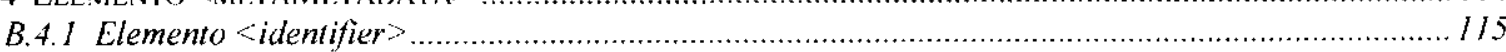

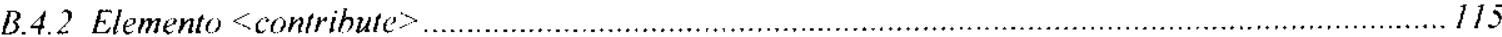

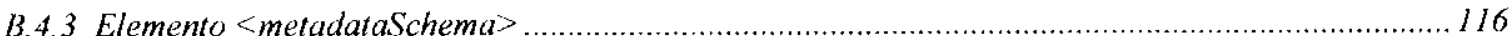

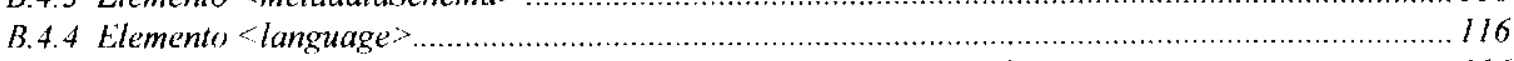

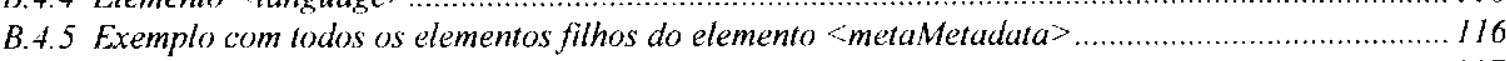

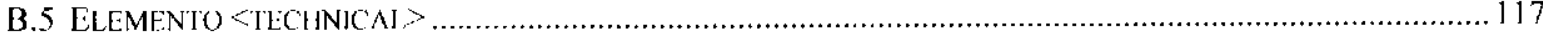

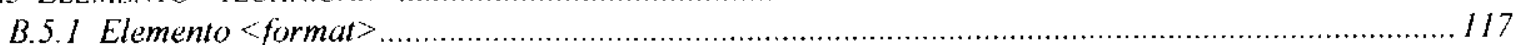

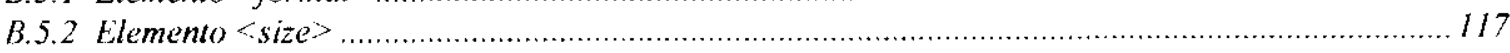

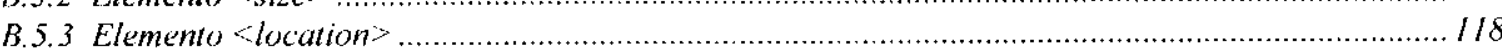

B.5.4 Elemento <requirement

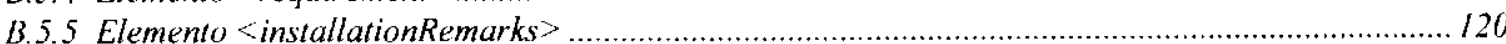

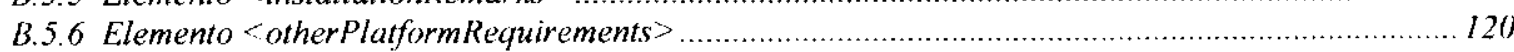

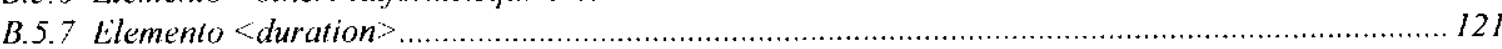

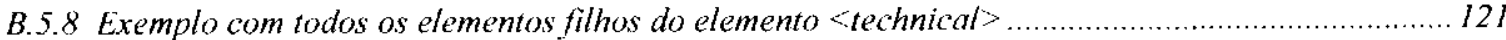

B.6 EIFMINTO <IDUCATIONAI>

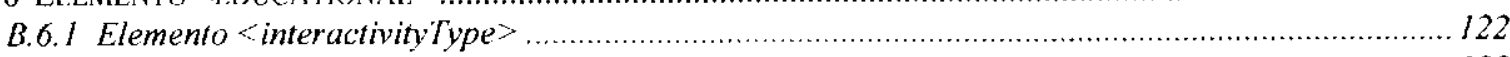

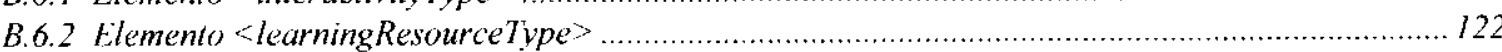

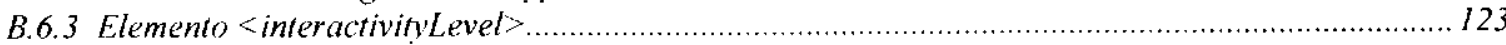

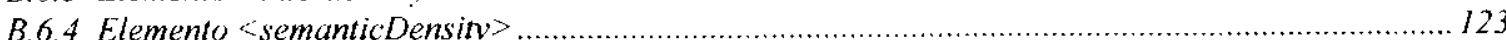

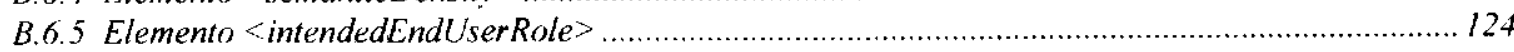

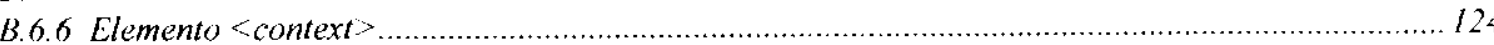

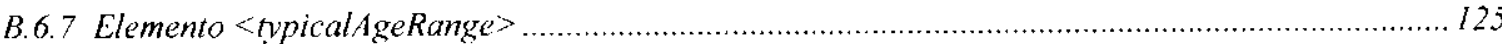

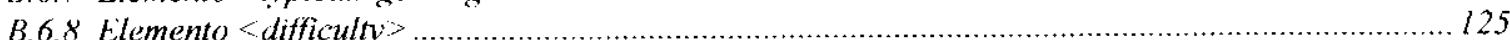

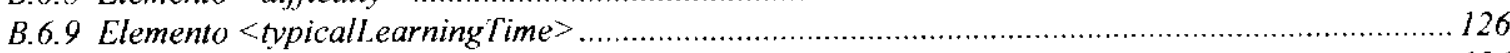

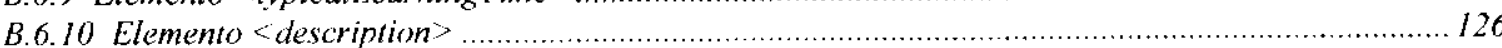

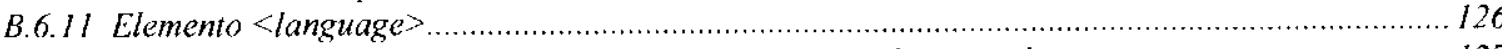

B.6. 12 Exemplo com todos os elementos filhos do elemento <educational $>$...................................... I27

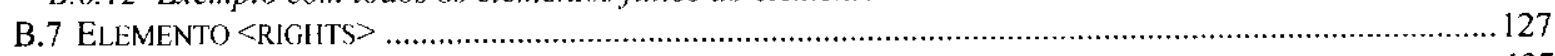

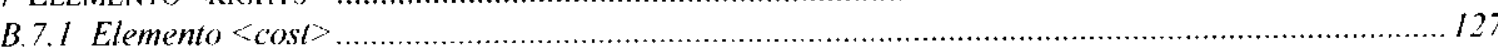

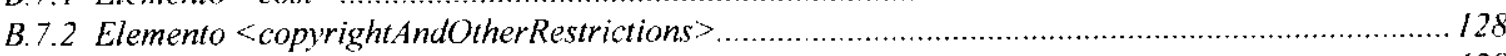

B.7.3 Elemento < description

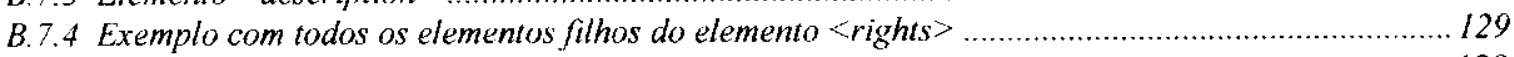

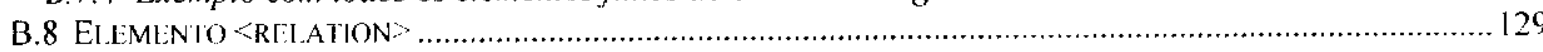




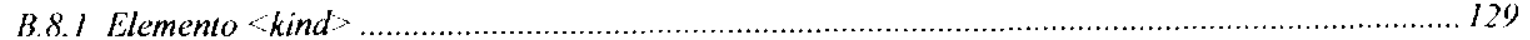

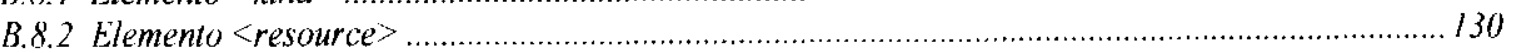

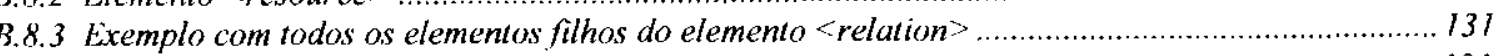

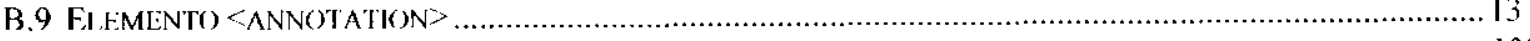

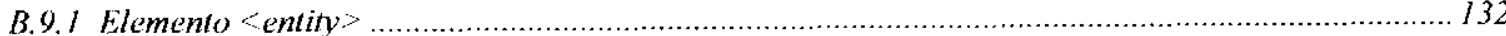

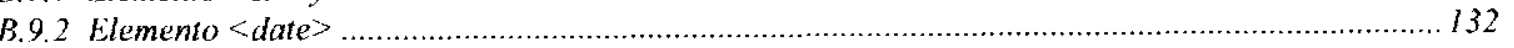

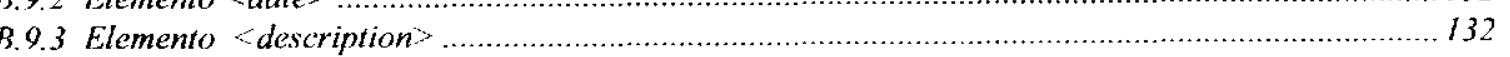

B.9.4 Exemplo com todos os elementos filhos do elemento cannotation

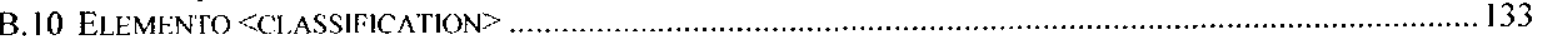

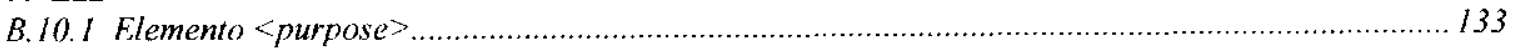

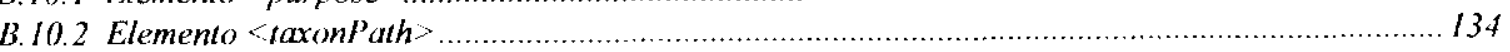

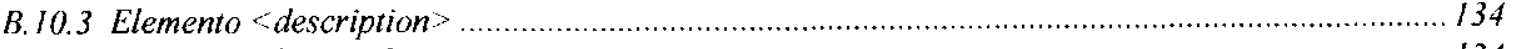

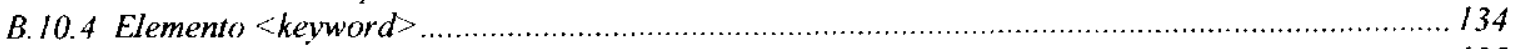

B. 10.5 Exemplo com todos os elementos filhos do elemento <classification > ..................................... 135

REFERÊNCIAS BIBLIOGRÁFICAS........................................................................................................137

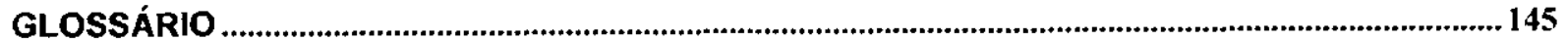




\section{Lista de Figuras}

Figura 2.1: Exemplos de dispositivos computacionais: (a) e (b) inch-scale, (c) foot-scale, (d) e (c) yard-scale...6 Figura 3.1: (a) Sensor do Active Badge, (b)Aplicação típica com a localização das pessoas [Want et al., 1992].

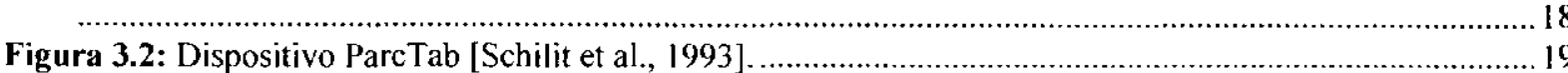

Figura 3.3: (a) Mapa do funcionamento do CyberGuide, (b) Interface com informações do sistema [A bowd et

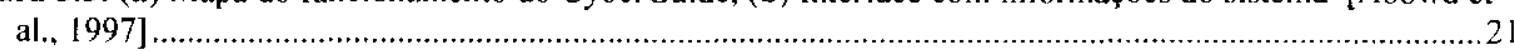

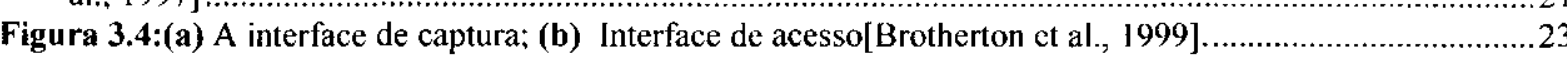

Figura 3.5:(a) Interface de Reuniões TeamSpace; (b) Interface do visualizador do TeamSpace [Richter et. Al.,2001]

Figura 3.6: (a) Palm com dados sobre a localização do usuário; (b) interface Web com o mapa do campus

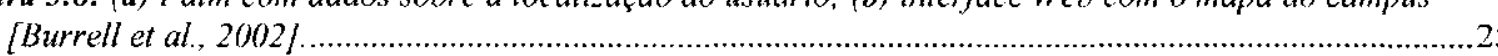

Figura 3.7: $\Lambda$ casa interativa e ciente de seus moradores, $A$ ware Home [Aware Home, 2003] .......................26

Figura 3.8: Sequiência de imagens de uma determinada ação [Mynatt \& Tran, 2002].....................................27

Figura 3.9: Sistema para detectar o movimento da atividade de se alimentar em uma sala de jantar. (a) mostra regiões de movimentos na sala de jantar, que é associado a cada pessoa; (b) As setas em vermelho indicam os movimentos das mãos relacionados à alimentação, enquanto que as áreas em azuis indicam a parte do corpo que está se movendo [Hauptmann et. al., 2004] ....................................................................28

Figura 3.10: Imagem visual de um vídeo de higiene pessoal. (a) mostra a atividade em si; b)mostra a análise do movimento, identificando os segmento correspondentes [Hauptmann et. al., 2004]....................................29

Figura 3.11: Sistema de captura no Authoring on the Fly usando uma SmartBoard [Muller \& Ottmann, 2000].30 Figura 3.12: Sistema de captura no Authoring on the Fly usando um tablet [Muller \& Ottmann, 2000]............30

Figura 3.13: Ambiente de sala de aula do SmartClassroom [Shi, et. Al.,2003] ..............................................32

Figura 4.1: Tela do Módulo de Preparação do AutorE [Sante, 2003] ................................................................40

Figura 4.2: A sala de aula do Projeto Classroom 2000 é equipada para capturar informação apresentada na lousa eletrônica (A), capturar o ambiente através de uma câmera de vídeo situada no fundo da sala (B), capturar áudio produzido pelo apresentador e pelos alunos através de microfones instalados no teto da sala (C) e capturar interações com navegadores Web (D). A tela central (E) é utilizada para exibir slides apresentados anteriormente [Abowd, 1999b]

Figura 43: Sala instrumentada com lousa eletrônica.

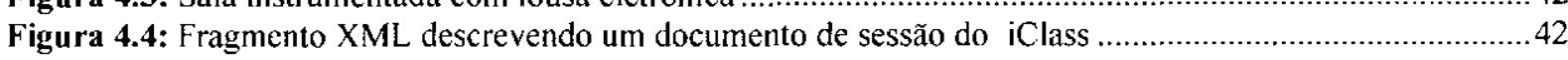

Figura 4.5: Documentos de apresentação do iClass: (a) Interface em SMIL, (b) Interface em HTML.................43

Figura 4.6: Navegação dos documentos de apresentação do iClass. (a) Índice de disciplinas. (b) Índice de aulas para uma disciplina

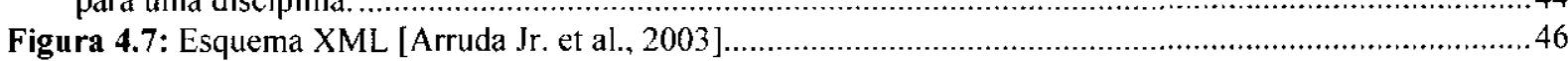

Figura 4.8: Pragmento XML descrevendo as informações da aplicação iClass. ..............................................46

Figura 4.9: Fragmento XML recebido pela aplicação resultante de sua aquisição de registro........................... 47

Figura 4.10: Fragmento XML. com as informações de contexto a serem armazenadas no Context Kernel através do método Put Data () [Arruda Jr. et al., 2003].

Figura 4.11: Fragmento XML que descreve uma regra de contexto a ser armazenadas no Context Kernel através do método PutRules () [Arruda Jr. et al 2003].

Figura 4.12: Fragmento XML que descreve uma consulla ao Context Kernel, , arravés do método Got Any () [Arruda.Jr. et al., 2003].

Figura 4.13: Fragmento XML que descreve uma possivel reposta à consulta ao Context Kernel. 


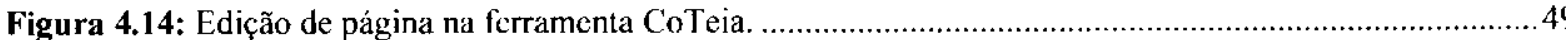

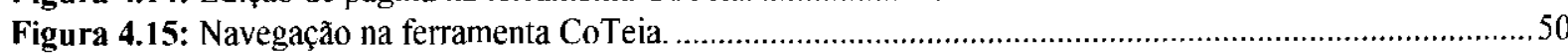

Figura 5.1: Fxemplo de uma descrição LOM [SCORM, 2004] ................................................................59

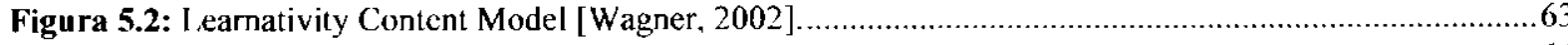

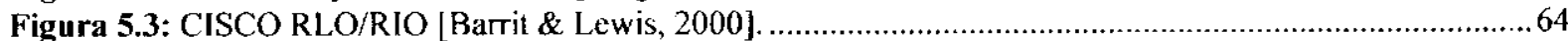

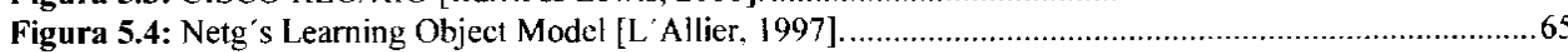

Figura 5.5: Organização de livros técnicos do SCORM [SCORM, 2004] .....................................................68

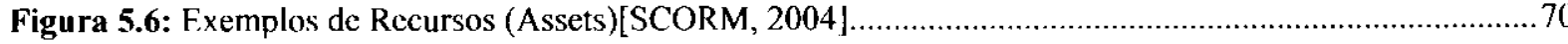

Figura 5.7: Exemplo de um SCO (Objeto de conteúdo compartilhável) [SCORM, 2004] ...............................71

Figura 5.8: Exemplo de uma Organização de Conteúdo [SCORM, 2004] ......................................................71

Figura 6.1: Seqüência de criação do objeto de aprendizagem. .................................................................75

Figura 6.2: Interface com link para a criação ou visualização dos objetos de aprendizagem.............................75

Figura 6.3: Interface de escolha entre a visualizaç̃o de um objeto de aprendizagem existente...

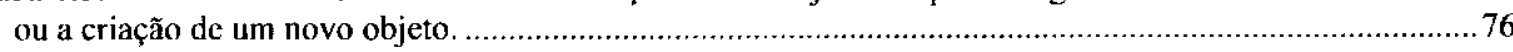

Figura 6.4: Interface referente à seleção de slides ...................................................................................... 76

Figura 6.5: Fragmento de exemplo de uma consulta XML através do método GetInverse ()...........................77

Figura 6.6: Fragmento XML de resposta ao método Getlnverse () ...........................................................78

Figura 6.7: Interface de criação de objetos de aprendizagem. Formulário para preenchimento dos

Figura 6.8: Interface de criação de objetos de aprendizagem. Formulário para preenchimento dos

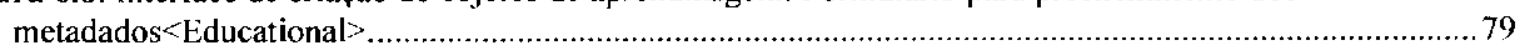

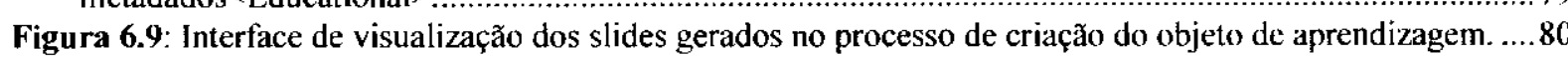

Figura 6.10: Exemplo de um arquivo imsmanifest.xml gerado ..................................................................

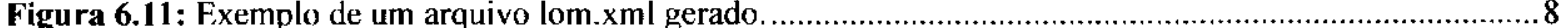

Figura 6.12: Sofware SCORM 2004 mostrando que o objeto de aprendizagem foi considerado válido..............82

Figura 6.13: Software TinyLMS mostrando a estruturação do objeto de aprendizagem criado...........................83

Figura 6.14: Integração entre os serviços. ............

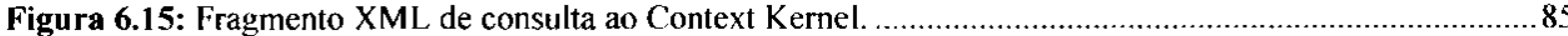

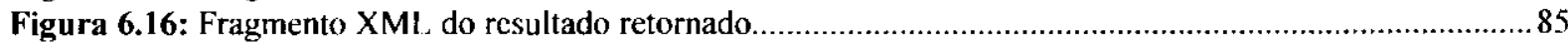

Figura 6.17:Interface no AutorF/iClass, mostrando os cursos e as aulas de determinado período do dia............86

Figura 6.18: Fragmento XML que será armazenado no Context Kernel......................................................88

Figu ra 6.19: Fragmento XML com a confirmação do resultado da criação. ....................................................8

Figura 6.20: Regra XML que será armazenado no Context Kernel, referente a URL da Coteia..........................87

Figura 6.21: Interface no AutorF/iClass para a criação da aula. ...................................................................87

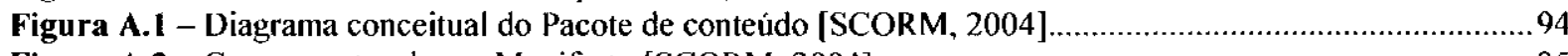

Figura A.2 - Componentes de um Manifesto [SCORM, 2004] ..............................................................

Figura A.3- Terminologia de Hierarquia de Conteúdo IMS [SCORM, 2004] .................................................97

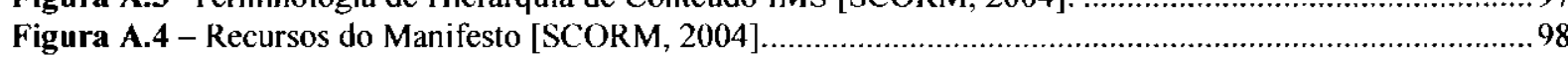

Figura A.5 - Composição do arquivo i msinda i fest . xm l . ........................................................................99 


\section{Lista de Tabelas}

Tabela 3.1: Classificação das aplicações em relação às sub-áreas da computação ubiquaa................................... 32 Tabela 5.1: Os elementos do padrão Dublin Core [DCMI, 2003a]. ..............................................................58

Tabela 5.2: LOMv1 .0 Base Schema [IEEE LTSC, 2002] ....................................................................5

Tabela 6.1: Especificações gerais em termos de tipo e valores de informações de contexto. 


\section{Lista de Abreviaturas}

$\begin{array}{ll}\text { ADL } & \text { Advanced Distributed Learning } \\ \text { AICC } & \text { Aviation Industry CBT Committee } \\ \text { API } & \text { Application Program Interface } \\ \text { ARIADNE } & \text { Alliance of Remote Instructional andAuthoring and Distribuition } \\ & \text { Networks for Europe } \\ \text { CAM } & \text { Content Aggregation Model } \\ \text { CB'T } & \text { Computer-Based Training } \\ \text { CDWA } & \text { Categories for the Description of Works of Art } \\ \text { CISE } & \text { Computer \& Information Science \& Engineering } \\ \text { CMI } & \text { Computer-Managed Instruction } \\ \text { CNPq } & \text { Conselho Nacional de Desenvolvimento Cientifico e Tecnológico } \\ \text { CSDGM } & \text { Content Standard for Digital Geospatial Metadata } \\ \text { DCMI } & \text { Dublin Core Metadata Initiative } \\ \text { dbXMI } & \text { Native XML Database } \\ \text { DoD } & \text { Department of Defense } \\ \text { DTD } & \text { Document Type Delinition } \\ \text { eXist } & \text { Open Source Native XML Database } \\ \text { GeorgiaTech } & \text { Georgia Institute of Technology } \\ \text { GILS } & \text { Global Information Locator Service } \\ \text { GPS } & \text { Global Positioning System } \\ \text { HCI } & \text { Human Computer-Interaction } \\ \text { HTML } & \text { HyperText Markup Languagc } \\ \text { IEEE } & \text { Institute of Eletrical and Eletronics Engineers } \\ \text { IETF } & \text { Internet Engineering Task Force } \\ \text { IMS } & \text { IMS Global Learning Consortium, Inc } \\ \text { InCA-SERVE } & \text { Infrastructure for Capture and Access AND Infrastructure for Store, } \\ & \text { Extend, Retricve and Visualize Evolutionary Information } \\ \end{array}$




$\begin{array}{ll}\text { JSP } & \text { JavaServer Pages } \\ \text { LMS } & \text { Learning Management System } \\ \text { LO } & \text { Learning Object } \\ \text { LOM } & \text { Learning Objects Metadata } \\ \text { LTSC } & \text { Iearning Technology Standards Committee } \\ \text { MPEG } & \text { Moving Picture Experts Group } \\ \text { NSF } & \text { National Science Foundation } \\ \text { OSTP } & \text { Office of Science and Technology Policy } \\ \text { PHIP } & \text { Personal Home Page } \\ \text { PIF } & \text { Package Interchange File } \\ \text { ProTeM-CC } & \text { Programa Temático Multiinstitucional em Ciência da Computaçâo } \\ \text { RIO } & \text { Reusable Information Object } \\ \text { RLO } & \text { Reusable Learning Object } \\ \text { RTE } & \text { Run Time Environment } \\ \text { SCO } & \text { Sharable Content Object } \\ \text { SCORM } & \text { Shareable Content Object Reference Model } \\ \text { SN } & \text { Sequencing and Navigation } \\ \text { RDF } & \text { Resource Description Framework } \\ \text { RFC } & \text { Request for Comments } \\ \text { SMIL } & \text { Synchronized Multimedia Integration Language } \\ \text { SOAP } & \text { Simple Object Access Protocol } \\ \text { TIDIA } & \text { Tecnologia da Informação no Desenvolvimento da Internet } \Lambda \text { vançada } \\ \text { URI } & \text { Universal Resource Identificator } \\ \text { URL } & \text { Universal Resource Name } \\ \text { XHTML } & \text { Extensible HyperText Markup Language } \\ \text { XML } & \text { Extensible Markup Language } \\ \text { XSD } & \text { XML Schema Definition } \\ \text { XSL } & \text { XML Stylesheet Language } \\ \text { XSLT } & \text { Extensible Server Pages } \\ \text { XSP } & \text { Xquery Language } \\ \text { WSDL } & \end{array}$




\section{Introdução}

A computação está cada vez mais difundida nos ambientes de trabalho, acadêmicos ou mesmo domésticos. Weiser [1991] vislumbrou uma forma pouco intrusiva de fazer uso do computador no cotidiano das pessoas. Segundo ele, pessoas e ambientes estariam envolvidos com recursos computacionais que forneceriam informações e serviços quando e onde eles os desejassem de forma transparente e natural. Weiser denominou computação ubíqua essa forma transparente de integrar tecnologia às atividades diárias das pessoas.

De acordo com Abowd e Mynatt [2000], dois dos principais temas da computação ubíqua são (a) aplicações de captura e acesso e (b) computação ciente de contexto ${ }^{1}$. O primeiro tema investiga o apoio à construção de aplicações de captura e acesso. Truong et al. [2001] definem captura e acesso como a tarefa de capturar informações relativas a uma expcriência ao vivo - experiências cm salas de aula, conferências acadêmicas, reuniões distribuídas, entre outras - com o objetivo de possibilitar posterior acesso à informação capturada, muitas vezes na forma de documentos Web. Alguns sistemas provêm suporte automatizado para capturar informações de câmeras e lousas eletrônicas, por exemplo, e para integração de várias apresentações (correspondentes a experiências ao vivo). Além disso, são oferecidos mecanismos de recuperação baseados em conteúdo, o qual pode ser acessado pelos usuários através de interfaces Web, como os sistemas Classroom 2000 [Abowd, 1999b],

${ }^{1}$ Para fins deste trabalho, o termo context será indicado como informaçôes de contexto e o termo context-aware computing como computação ciente de informações de contexto. Para brevidade, computação ciente de informações de contexto será tratada como computação ciente de contexto. 
Renata Paciència Godov-Dissertação de Mestrado - Pós-Graduação-- ICMC/USP - São Carlos

TeamSpace [Richter et. al., 2001], Authoring on the Fly [Muller \& Ottmann, 2000] e SmartClassroom [Shi et. al., 2003], por exemplo.

Outro tema importante na área de computação ubíqua investiga o fato de que informações de contexto devem ser exploradas $\mathrm{cm}$ aplicações de computação ubiqua para que o esforço do usuário seja reduzido. Segundo Dey \& Abowd [2000b], muitas aplicações não fazem bom uso de informações de contexto: o maior problema tem sido a ausência de suporte para a construção e a execução de aplicações de captura e acesso que fazem uso de informações de contexto. Abowd e Mynatt [2000] sugerem o suporte à obtenção de informações de contexto com base em cinco dimensões clássicas: who (identificação), where (localização), when (tempo), what (atividade) e why (motivação). Integrando os dois temas citados, Truong et al. [2001] propõem, para o domínio de aplicações de captura e acesso, a dimensão de contexto how para definir como os dados foram capturados e como podem ser acessados, e também discutem como aplicações fazem uso dessas dimensões.

Pesquisas recentes têm focado no desenvolvimento de serviços dedicados à captura, ao armazenamento e ao processamento de informações de contexto. Nesse contexto, o projeto InCA-SERVE ${ }^{2}$ [Pimentel \& Abowd 1999] foi proposto para implementar uma infra-estrutura de captura e acesso das informações associadas a experiências ao vivo, além de cuidar da parte de armazenamento, extensão, recuperação e visualização da informação. Esse projeto suporta a construção de aplicações e serviços como o iClass [Cattelan et al., 2003a; Cattelan et al., 2003b; Cattelan et al., 2003c;] e o Context Kernel [Arruda Jr, 2003; Arruda Jr. et. al, 2003]. O iClass [Cattelan et al., 2003a; Cattelan et al., 2003b] é uma aplicação de captura e accsso que permite acesso a material multimídia capturado em aulas presenciais no formato de hiperdocumentos Web. O Context Kernel, proposto por Arruda Jr. [2003], é um serviço que fornece armazenamento, extensão e recuperação de informações de contexto com base nas dimensões semânticas definidas por Abowd e Mynatt [2000] e Truong et al. [2001].

Uma lacuna identificada em relação a aplicações de captura e acesso é que, muitas vezes, tais aplicações são desenvolvidas sem atenção para um possível reuso, por parte de outras aplicações, do material capturado. Por exemplo, tanto no caso do iClass como no Classroom 2000 e no TeamSpace, entre outros, não houve preocupação em relação a isso. Nesse sentido, um problema tratado nesta dissertação é ausência de propostas de reuso de

\footnotetext{
${ }^{2}$ htpp://coweb.icme.usp.br/incaserve
} 
Renata Paciência Godoy - Dissertação de Mestrado - Pós-Graduação · ICMC/USP - São Carlos

informações armazenadas por aplicações de captura e acesso. Em outras palavras, há a demanda pela incorporação de metadados $^{3}$ à informação capturada, os quais viabilizam o intercâmbio e reuso das informações.

Entretanto, considerando que uma das características mais importantes de aplicações de captura e acesso é que apresentem um alto grau de automatização dos processos de captura de informação e geração de documentos associados [Abowd, 1999a], é importante que metadados necessários para intercâmbio e reuso possam ser associados à informação capturada de modo automático - pelo menos parcialmente. Por outro lado, dado que deve ser possível a usuários adicionar quaisquer metadados que julguem relevantes, a incorporação manual de metadados sob demanda do usuário também deve ser suportada.

Nesse cenário, o trabalho tem por objetivo propor um mecanismo que permita incorporar metadados à informação capturada de modo que: (a) quaisquer metadados manipulados sejam padronizados; (b) metadados possam ser associados de modo automático a permitir intercâmbio; (c) metadados possam ser adicionados sob demanda do usuário.

Considerando a demanda (a), é importante observar que sempre que reuso e intercâmbio sejam almejados, se faz necessária a utilização de padronizações reconhecidas pela comunidade interessada. No caso de aplicações no domínio educacional, são naturais a incorporação de metadados e a produção de objetos de aprendizagem a partir da informação capturada. Nesta dissertação em particular, foi investigado o padrão SCORM (Sharable Content (Object Reference Model) que, associado ao conteúdo do material de ensino, propicia o compartilhamento dessas informações entre sistemas que utilizem o mesmo padrão.

Considerando a demanda (b), é oportuno que a geração de metadados de modo automático leve em consideração informações de contexto relativas à aplicação de captura e acesso em questão. Em particular nesta dissertação, foi investigada a utilização do Context Kernel como provedor de informações de contexto para permitir a associação de informações de contexto de modo automático à informação capturada.

Já considerando a demanda (c), é importante que os usuários possam adicionar quaisquer metadados que julguem relevantes ao objeto de aprendizagem, devendo portanto

\footnotetext{
${ }^{3}$ Para este trabalho, o termo metadata será indicado como metadado, já que não foi encontrada tradução para o termo em inglês.
} 
Renata Paciència Godov Dissertação de Mestrado Pós-Graduação ICMC/USP-São Carlos

ser suportada a incorporação manual de metadados. Nesta dissertação em particular. foi investigada a utilização de interfaces $W e b$ para o provimento de formulários seqüenciais divididos em etapas, permitindo que o usuário possa navegar entre os formulários $\mathrm{e}$ verificar quais metadados são obrigatórios ou opcionais.

Como resultado das investigações reportadas acima, foram realizadas implementações que, partindo de informações capturadas pclo sistema iClass, permitem a criação de objetos de aprendizagem de acordo com o padrão SCORM tanto de modo automático como manual. No primeiro caso, metadados associados a informações de contexto são obtidos automaticamente a partir do Context Kernel. No segundo caso, informações adicionais podem ser incluídas explicitamente pelo usuário a partir de um conjunto de formulários que, especificados de acordo com o padrão SCORM, contém metadados considerados relevantes dada a utilização usual do sistema $i$ Class.

O restante desta dissertação está organizado como segue. No Capítulo 2 é apresentada uma visão geral da área de computação ubíqua, discutindo seus principais temas de pesquisa, em particular computação ciente de contexto e aplicações de captura e acesso. O Capítulo 3 apresenta um conjunto de aplicações representativas dos vários temas de pesquisa em computação ubíqua, classificando as aplicações em termos dos temas de pesquisa e identificando o uso de informações de contexto.

O Capítulo 4 apresenta infra-estruturas e serviços utilizados neste trabalho e que fornecem serviços dedicados à captura, ao armazenamento e ao processamento de informação. O Capítulo 5 apresenta uma revisão bibliográfica de metadados e objetos de aprendizagem, provendo definições, categorizações, padrões e modelos encontrados na literatura, com foco no modelo de conteúdo SCORM [SCORM, 2004].

No Capítulo 6 são detalhadas as implementações resultantes das investigações realizadas com o objetivo de estender as informações capturadas no iClass com metadados SCORM de modo automático e manual - que resultaram na extensão ${ }^{4}$ das facilidades providas pelo sistema iClass e o serviço Context Kernel. No Capitulo 7 são destacadas as contribuições e são discutidos trabalhos futuros. O Apêndice A e o Apêndice B apresentam detalhes de empacotamento SCORM e de metadados SCORM, respectivamente.

${ }^{4}$ Implementações realizadas pela autora e vários colaboradores. 


\section{Computação Ubíqua}

\subsection{Considerações Iniciais}

Computação Ubíqua é um tema relativamente novo. A principal referência a esse tema data de 1991 quando Mark Weiser, pesquisador do Xerox PARC, apresentou sua visão do que seria a computação ubíqua: tecnologia integrada ao ambiente de forma transparente para auxiliar atividades humanas [Weiser, 1991]. Na visão desse autor, pessoas e ambientes estariam envolvidos com recursos computacionais que forneceriam informações e serviços quando e onde eles os descjassem.

$\Lambda$ cvolução da computação tem envolvido a mudança de paradigmas relativos a como a interação entre humanos e computadores é realizada. Um dos mais recentes paradigmas é a computação ubíqua, onde a interação entre usuário e computador está mais distante do mouse e teclado, e mais próxima do mundo físico do usuário, ocorrendo de forma transparente e mais natural [Abowd et al., 2002].

Weiser [1991] previa a proliferação de dispositivos computacionais em três escalas: inch-scale (pequenos e usados em abundância nos ambientes e por usuarios), foot-scale (porte médio e de uso pessoal) e yard-scale (grandes e de uso coletivo). De fato, isto acabou acontecendo: dispositivos pessoais tais como pagers, telefones celulares, PDA's, tablets digitais e laptops tornaram-se comuns. Nesse mesmo contexto, lousas eletrônicas (dispositivos maiores) passaram a facilitar a comunicação em aulas, laboratórios e reuniões. Fxemplos de alguns dispositivos são mostrados na Figura 2.1. 


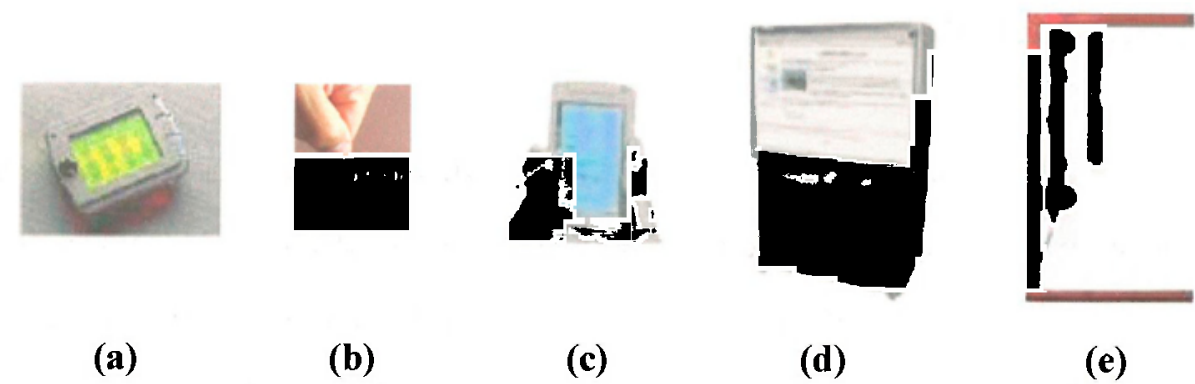

Figura 2.1: Exemplos de dispositivos computacionais: (a) e (b) inch-scale,(c) foot-scale, (d) e (e) yard-scale.

Segundo Weiser [1991], é necessário desenvolver novas aplicações para que esses novos dispositivos possam ser explorados. O desenvolvimento dessas aplicações está associado aos temas de pesquisa na área de computação ubíqua: interfaces naturais, computação ciente de contexto, captura e acesso de experiências ao vivo e computação no cotidiano Abowd \& Mynatt [2000], Abowd et al.[2002].

Em particular no contexto de engenharia de software, conforme Abowd [1999a], uma boa pesquisa na área de computação ubíqua deve satisfazer alguns critérios, como:

- as pesquisas devem ser baseadas nas aplicações;

- os sistemas devem seguir alguma noção de escala, que pode ser o espaço físico, o número de pessoas envolvidas, o número ou tipo de dispositivos, ou o tempo de uso da aplicação;

- o sistema deve se relacionar ao uso real e cotidiano;

- o uso do sistema deve ser avaliado para que se possa determinar o seu impacto nas atividades dos usuários.

Os dois últimos critérios são os mais importantes, pois juntos representam um forte desafio nas aplicações: a computação do cotidiano (everyday computing). Como aplicações de computação ubíqua começam a fazer parte do cotidiano, faz-se necessário prover disponibilidade de interação vinte e quatro horas por dia, sete dias por semana, auxiliando computacionalmente atividades informais e não-estruturadas comuns no dia-a-dia das pessoas.

Este capítulo tem como objetivo contextualizar a área de computação ubíqua e apresentar seus temas de pesquisa mais relevantes, como interfaces naturais, captura e acesso de experiências ao vivo, computação ciente de contexto e computação no cotidiano. 


\subsection{Interfaces Naturais}

A computação ubíqua inspira o desenvolvimento de aplicações não-centradas no paradigma teclado/mouse/display. A premissa básica para esse tipo de aplicação é adaptar as interfaces à forma segundo a qual os humanos interagem com o mundo físico. O objetivo de interfaces naturais é facilitar a comunicação entre usuários e computadores, visando suportar formas comuns de expressão humana c utilizar mais as ações implícitas nessa comunicação.

Interfaces que suportam formas naturais de comunicação como escrita manual, fàla e expressão gestual estão começando a substituir ou complementar elementos do paradigma de interfaces gráficas convencionais ${ }^{5}$. Essas novas interfaces facilitam o aprendizado e a usabilidade dos sistemas, já que não modificam drasticamente a forma como as atividades humanas são realizadas.

A comunidade de Interação Usuário-Computador (HCI - Human ComputerInteraction) vem trabalhando há vários anos no desenvolvimento de interfaces. O resultado desse trabalho inclui interfaces que suportam paradigmas de interação baseados em voz, em escrita manual, manipulação de artefatos eletrônicos (ou interfaces tangíveis) [Ishii \& Ullmer. 1997] e utilização de sensores em dispositivos computacionais, para manipulação física dos mesmos [Harrison et al., 1998]. A interação baseada em caneta, que nos anos 90 teve poucos resultados, tem demandado intensa pesquisa.

Para o desenvolvimento de interfaces naturais, são discutidos por Abowd \& Mynatt [2000] e Abowd et al. [2002] dois assuntos importantes: tipos de dados naturais de primeira classe e a questão do tratamento de erros em interações baseadas em reconhecimento.

\subsubsection{Tipos de Dados Naturais de Primeira Classe}

Para facilitar o desenvolvimento de aplicações com interfaces naturais, é necessário manipular outras formas de entrada de dados tão facilmente quanto entradas feitas de dispositivos comuns, como teclado e mouse [Abowd \& Mynatt, 2000]. [Abowd et al., 2002]. Os dados

\footnotetext{
${ }^{5} \mathrm{O}$ uso integrado de diversasformas naturais de comunicação tem sido investigado na área de interação multimodal [Oviatt, 1999].
} 
Renata Paciència Godoy - Dissertação de Mestrado --Pós-Graduação-ICMC/USP - São Carlos

provenientes das interfaces naturais, como áudio, vídeo, eletronic ink $k^{6}$ e informações sensoriais devem se tornar tipos de dados de primeira classe no desenvolvimento de sistemas interativos. Da mesma forma que programadores esperam que uma ferramenta de desenvolvimento de interfaces forneça um suporte básico para a manipulação de operações textuais e primitivas para a captura de interações via mouse e teclado, essas ferramentas devem contar com suporte básico à manipulação de linguagem natural e outras formas de entrada de dados, como áudio, vídeo e seqüências de ink.

Porém, tratar tais informações como objetos de primeira classe não é uma tarefa tão simples, como é o caso do tipo de dado ink, proveniente de interação baseada em caneta. As entradas provenientes desse dispositivo podem representar desenhos, marcações ou simplesmente rabiscos. Com isso, torna-se complexo o desenvolvimento de aplicações baseadas em técnicas de reconhecimento de escrita. Entretanto, para algumas aplicações não é necessário transformar o ink em texto, o que poderia até ser considerado intrusivo pelo usuário (isto é, a transformação de um dado em outro formato). Desta forma, concluiu-se que formas de manipular e trocar dados no formato ink ainda precisam de desenvolvimento e padronização [Abowd \& Mynatt, 2000].

Uma outra questão sobre os dados de tipo ink é a definição de quais operações devem estar associadas a esses dados. Fsse problema foi tratado por Abowd [1999b] no desenvolvimento do projeto Classroom 2000, que implementa um ambiente de computação ubíqua que permite a captura de material multimídia em uma sala de aula convencional, e a disponibilização e acesso desse material através da $W e b$. Esperava-se que as anotações feitas com a caneta pelo instrutor na lousa eletrônica pudessem ser associadas com o áudio e/ou vídeo da aula em questão. Foi usada a técnica de timestamping para associar as interações via caneta com o conteúdo de áudio e vídeo capurados e utilizada uma heurística temporal e espacial para agrupar as interações em uma palavra ou em um grupo de palavras. Porém, as técnicas de estruturação citadas necessitam de um esforço de padronização e disponibilização para que as aplicações desenvolvam interfaces baseadas em ink.

${ }^{6}$ Eletronic Ink ou simplesmente ink, é a tinta virtual presente nas anotações realizadas em dispositivos baseados em canetas, com PDAs, tablets, lousas eletronnicas, entre outros. 


\subsubsection{Tratamento de Erros em Interações Baseadas em Reconhecimento}

O tratamento de erros na entrada de dados não é um problema recente, mas o uso de interfaces naturais acentua erros já existentes e gera novos tipos de erros que estão ligados, principalmente, ao reconhecimento de linguagem natural e escrita manual.

Com isso, surgiram novas áreas de pesquisa para tratamento de erros em interfaces baseadas em reconhecimento. Abowd \& Mynatt [2000] e Abowd et al. [2002] destacam: (1) a redução de erros, que envolve pesquisas para melhorar a tecnologia de reconhecimento visando eliminar ou reduzir crros; (2) a descoberta de erros, onde antes do sistema ou do usuário tratar um erro, é necessário descobrir sua ocorrência; e (3) a infra-estrutura reutilizável para correção de erros, onde interfaces para manipulação de erros podem obter benefícios de ferramentas que forneçam uma biblioteca de técnicas de manipulação de erros para a entrada de dados baseada em reconhecimento.

\subsection{Captura e Acesso de Experiências ao Vivo}

Uma das principais características da computação ubiqua é que ela pode ser usada para capturar nossas experiências diárias e recuperar esses dados para serem usados mais tarde. $\Lambda \mathrm{s}$ pessoas gastam grande parte do seu tempo ouvindo e registrando eventos e/ou atividades dos quais participaram, seja no trabalho ou na educação, e depois, tentam recuperar os pedaços de informações mais importantes desses eventos.

Truong et al. [2001] definem captura e acesso como a tarefa de preservar a gravação de uma experiência vivida que é retomada em algum ponto futuro. A captura ocorre quando uma ferramenta gera um artefato que documenta a história do ocorrido. Esses artefatos, ou dados capturados são gravados como pedaços de informações que seguem um fluxo no tempo. As ferramentas que gravam as experiências são designadas dispositivos de captura; $\mathrm{e}$ as ferramentas usadas para rever essas experiências são chamadas dispositivos de acesso. Exemplos de alguns dispositivos para captura e acesso podem ser: caneta e papel ou câmeras e filmadoras, porém essas ferramentas só suportam um simples usuário durante a captura de informação, além de não registrarem todos os fatos ocorridos. 
Renata Paciência Godoy - Dissertação de Mestrado-Pós-Graduação-ICMC/USP - São Carlos

Como as pessoas não conseguem registrar todas as informações que estão ao seu redor, elas usam recursos como anotações e gravações de áudio e vídeo, além de armazenar dados no computador por meio de documentos tradicionais, hiperdocumentos ou arquivos de áudio e vídeo. Com isso, surgiram aplicações no sentido de tornar mais eficiente a captura e o posterior acesso à informação capturada, como experiências em salas de aula, encontros, conferências acadêmicas, reuniões distribuídas, experiências dentro de uma casa, entre outras.

Pesquisas relacionadas ao tema captura e acesso datam de 1985, quando Shmandt $\&$ Arons [1985] trabalharam na captura de áudio de chamadas telefônicas, fornecendo posterior acesso aos dados capturados através de facilidades que incluíam a geração de resumos das chamadas capturadas.

Focando na fase de pró-produção, alguns sistemas provêem suporte automatizado para a fusão de múltiplas câmeras, integração de várias apresentações de dados e mecanismos de recuperação baseados no conteúdo para ajudar o usuário na pesquisa das informações armazenadas nos repositórios. O resultado da pós-produção pode então ser acessado através de uma interface multimídia distribuída via $W e b$, como mostram os projeto Classroom 2000 [Abowd, 1999b] e Authoring on the Fly [Muller \& Ottmann, 2000], entre outros.

Várias aplicações de captura e acesso foram desenvolvidas ao longo dos anos, principalmente relacionadas à aulas e reuniões, que geralmente capturam informações de áudio, vídeo, ink e escrita manual em uma lousa eletrônica.

\subsection{Computação Ciente de Contexto}

A computação ciente de contexto consiste na relação entre atividades humanas e serviços computacionais no sentido de expandir e facilitar tais atividades. Ela descreve uma situação em que o dispositivo computacional está ciente das condições do usuário e modifica seu procedimento baseado nessas informações. Por exemplo, pode-se determinar que um telefone celular emita um sinal de aviso durante o horário de almoço, caso o sistema consiga determinar a localização do telefone e o horário em que o usuário costuma almoçar.

As informações de contexto do usuário podem ser totalmente ricas, como a localização física, estado psicológico e emocional, e assim por diante. O objetivo da computação ciente de contexto é explorar a informação de contexto usando informações 
Renata Paciência Godov - Dissertação de Mestrado - Pós-Graduação - ICMC/USP - São Carlos

relevantes sempre que necessárias para que a atenção do usuário seja reduzida. Combinada com as conclusões sobre as intenções do usuário, a computação ciente de contexto pode permitir uma melhora no desenvolvimento e confiabilidade da aplicação [Siewiorek, 2002].

Seres humanos têm total sucesso na transferência de idéias entre si. Isto se deve a muitos fatores, como a riqueza da linguagem que utilizam, o comum entendimento de como o mundo trabalha e o entendimento implícito das situações cotidianas. Infelizmente, essa habilidade de transferência de idéias não é obtida na interação humano - computador baseada em mouse-teclado-monitor, pois usuários têm um empobrecimento de mecanismos para entrada dos dados [Dey, 2001]. Conseqüentemente, aplicações não podem tirar total vantagem de informações de contexto no diálogo usuário-computador.

Dey \& Abowd [2000a] definem contexto como qualquer informação relevante sobre as entidades que participam da interação, inclusive os próprios usuário e computador. Surge a questão de como os desenvolvedores de aplicações proveriam informações de contexto para os computadores. As aplicações poderiam requisitar que os usuários dessem todas as informações relevantes para uma dada situação, entretanto, o objetivo da computação ciente de contexto é o de facilitar a interação com o computador. Forçá-los a aumentar a quantidade de informação é mais difícil e tedioso, além da maioria dos usuários não saber qual informação é relcvante.

Segundo Dey \& Abowd [2000a], o desenvolvimento de aplicações cientes de contexto deve obter informações de contexto de maneira automatizada, disponibilizando-as em um ambiente computacional em tempo de execução, e permitindo aos desenvolvedores de aplicações decidirem quais informações são relevantes $\mathrm{e}$ como lidar com elas.

\subsubsection{Definição de Informação de Contexto}

Dey \& Abowd [2000a] citam alguns autores que introduziram o termo informação de contexto, tais como Schilit \& Theimer [1994] e Ryan et al. [1997], que se referem a informações de contexto como informação referente à localização e à orientação do usuário, identificação das pessoas e objetos próximos ao usuário, hora do dia, estação do ano e temperatura. Outros autores definem informação de contexto baseada em sinônimos de informações de contexto, como o ambiente ou situação. Segundo Dey \& Abowd [2000a], 
Renata Paciência Godoy -Dissertação de Mestrado Pós-Graduação-ICMC/USP - São Carlos

alguns consideram informações de contexto como elementos pertencentes ao ambiente do usuário, como Brown [1996], enquanto outros consideram como a configuração da aplicação [Rodden et al., 1998].

Dey \& Abowd [2000a] definiram informações de contexto como "qualquer informação que possa ser usada para caracterizar uma entidade, onde uma cntidade pode ser uma pessoa, um lugar, ou um objeto que scja considerado relevante para a interação cntre o usuário e a aplicação, inclusive o usuário e o computador". Se uma informação pode ser usada para caracterizar a situação de um participante em uma interação, então essa informação é um contexto. Essa definição torna mais fácil para desenvolvedores de aplicações especificarem informações de contexto relevantes a uma dada aplicação.

\subsubsection{Categorias de Informação de Contexto}

A categorização de tipos de informações de contexto permitirá que desenvolvedores de aplicações possam escolher o tipo de informações de contexto que será mais útil na sua aplicação. Ryan et al [1997] sugeriram tipos de informações de contexto como localização, ambiente, identidade e tempo. Já Schlit et al. [1994] listaram como aspectos importantes de informações de contexto: onde o usuário está, com quem o usuário está e quais recursos estão próximos ao usuário. Baseado nisso. Dey \& Abowd [2000a] sugeriram os tipos de informações de contexto: localização, identidade, atividade e tempo. Essas categorias representam o tipo primário de informações de contexto para caracterizar a situação de uma cntidade. Por excmplo, dada a identidade de uma pessoa ou sua localização, pode-se obter muitas informações relacionadas, como o número do telefone, endereço, aniversário ou quais objetos e/ou pessoas estão perto da entidade. Com isso, nota-se que informações de contexto primárias de uma entidade, podem ser usadas para encontrar informações de contexto secundárias da própria entidade (e-mail) ou informações de contexto primárias de outras entidades relacionadas (como pessoas na mesma localização).

Essa categorização ajuda desenvolvedores a especificarem informações de contexto para usarem em suas aplicações, a estruturarem informações de contexto que eles usam e a pesquisarem por outras informações de contexto relevantes. As quatro informações de contexto primárias, who, where, what e when, indicam o tipo de informação necessária para caracterizar uma situação c como o contexto deve ser usado e organizado. 


\subsubsection{Definição de Aplicação Ciente de Contexto}

Pesquisadores de dois grandes centros de pesquisa em computação, o Olivetti Research Lab's, com seu Active Badge [Want et al., 1992], e o XEROX PARC, com seu PARCTab [Want et al., 1995], cstão entre os primeiros a desenvolver aplicações cientes de contexto baseadas na localização espacial. Esses dispositivos, com uma simples informação de contexto e a localização do usuário, possibilitaram implementações como transferências automáticas de chamadas telefồnicas e atualizações automáticas de mapas com as localizações de usuários de um escritório. Além disso, Schilit \& Theimer [1994] definiram aplicações ciente de contexto como softwares que se adaptam de acordo com a sua localização de uso, grupo de pessoas ou objetos próximos e as mudanças ocorridas com esses objetos ao passar do tempo.

Segundo Dey \& Abowd [2000a], vários termos surgiram como sinônimos para uma aplicação ciente de contexto, como adaptativa, reativa, dirigida a respostas, situada, sensível ao contexto e dirigida ao ambiente. A definição de aplicações cientes de contexto divide-se em duas categorias: as que usam informações de contexto e as que se adaptam a informações de contexto.

Dey \& Abowd [2000a] escolheram uma definição mais genérica para ciência de contexto, tomando a categoria de "adaptar-se ao contexto" que requer que o comportamento da aplicação seja modificado para ser considerado ciente de contexto. Baseando-se nos trabalhos de Ryan et al. [1997], definiram que um sistema é ciente de contexto caso utilize informação de contexto para prover informações ou serviços relevantes para os usuários, sendo que a relevância irá depender das tarefas dos mesmos.

\subsubsection{Dimensões de Informação de Contexto}

Para obter informações de localização, aplicações usam as facilidades providas por sistemas GPS - Global Positioning System - para prover navegação de carros em cidades e estradas ou a localização de usuários em ambientes, por exemplo. O sistema GPS também tem sido utilizado em sistemas de guias turisticos inteligentes capazes de escolher um vídeo ou áudio para ser exibido de acordo com informações de localização dadas através do GPS [Abowd et al., 1997]. 
Renata Paciência Godov - Dissertação de Mestrado-Pós-Graduação ICMCHSP - São Carlos

Outra importante forma de explorar informação contextual está nas técnicas de reconhecimento de objetos. Com essa técnica é possível reconhecer áreas em vídeos e imagens de forma a entender o contexto de uma cena ou de fotografia. Isso possibilita enriquecer apresentações com informações contextuais e realizar busca baseada em conteúdo sob fluxos de mídia contínua.

Porém, há muitas outras informações contextuais além de localização e identificação de pessoas e objetos. A maioria dos sistemas ciente de contexto ainda não incorpora noções de tempo, história, outras pessoas além do usuário, assim como muitas outras informações disponíveis nos ambientes. Embora ainda não exista uma definição completa de contexto, Abowd \& Mynatt [2000] e Abowd et al. [2002] descrevem como obter informações contextuais com base em cinco dimensões chamadas de "cinco $W$ 's":

- Who (quem): Sistemas focam suas interações na identidade de um usuário em particular, desconsiderando informações sobre outros usuários presentes no ambiente. Uma preocupação é em relação ao nủmero de pessoas envolvidas nas atividades computacionais. Os seres humanos realizam suas atividades e recordam de fatos passados com base na presença das pessoas que os vivenciaram. Sendo assim, o sistema deve prover informações de contexto de todas as pessoas envolvidas em uma determinada atividade, atendendo a todas as necessidades dos usuários;

- Where (onde): As informações de contexto de localização têm sido muito utilizadas por sistemas cientes de contexto. Pesquisas mostram um interesse particular na utilização dessa informação contextual associada a outras dimensões, como por exemplo, when (quando), com o intuito de prover novas funcionalidades a aplicações. É explorada a mobilidade dos usuários, possibilitando situações diferentes para os mesmos;

- When (quando): Informações de contexto temporais têm sido usadas apenas para indexar um registro capturado ou para informar por quanto tempo um usuário esteve em uma determinada localização. No entanto, o conhecimento das informações de contexto temporais permite projetar dispositivos e aplicações capazes de tirar proveito das informações contextuais existentes e fazer inferências, ajudando a interpretar as atividades humanas e estabelecer padrões de comportamento. Por exemplo, se um usuário visita um site por um curto espaço de tempo, pode-se deduzir que ele não teve 
Renata Paciência Godoy - Dissertação de Mestrado - Pós-Graduação - ICMC/LSP - São Carlos

interesse no que viu; ou se um usuário acessa o mesmo site diariamente no mesmo horário, pode-se concluir que provavelmente, no dia seguinte cle o fará novamente;

- What (o quê): Um grande problema é perceber e interpretar o que usuário está fazendo. Alguns sistemas assumem o que o usuário está fazendo em função do próprio projeto do sistema. No entanto, em sistemas onde várias atividades podem ser desenvolvidas, identificar o que um usuário está fazendo em um determinado momento pode ser uma tarefa complicada:

- Why (por quê): Mais desafiador do que perceber o que o usuário cstá fazendo, é entender o porquê de sua ação. Obter informações de contexto que possam caracterizar o estado de uma pessoa, como a temperatura do corpo, batimento cardíaco e pressão arterial, é talvez o maior desafio da computação sensível a contexto.

Devido à dificuldade de obter informações relativas à dimensão $W h y$, geralmente associa-se a dimensão What com uma sexta dimensão (How) para inferir informações sobre Why. Para aplicações específicas, como captura e aceso, a dimensão How é importante e pode definir como os dados foram capturados e como eles podem ser acessados [Troung et al., $2001]$.

\subsection{Computação no Cotidiano}

A computação no cotidiano (everyday computing) é uma nova área da computação ubíqua baseada nos eventos que acontecem em nossas vidas. A disponibilidade de acesso computacional deve ser constante; o tempo é fundamental e precisa ser representado nas interfaces de acesso. Abowd \& Mynatt [2000] e Abowd et al. [2002] definem algumas características das atividades cotidianas:

- não possuem início e fím claros: não há um início claro das atividades e nem um final. $\Lambda$ s aplicações devem fornecer visibilidade do estado corrente, liberdade de diálogo e simplicidade no acesso:

- interrupção é esperada;

- possuem múltiplas atividades operando concorrentemente: as aplicações devem permitir que os usuários monitorem suas atividades e possam retomá-las; 
Renata Paciência Godoy - Dissertação de Mestrado - Pós-Graduação -. ICMC/USP - São Carlos

- tempo é um discriminador importante: por exemplo. saber se a última conversa com o membro da família foi na última semana ou há cinco minutos é relevante para a aplicação;

- devem ser suportadas por um modelo associativo de informação: diferentemente do modelo hierárquico, permite que o acesso seja feito a partir de diferentes pontos de vista. Por exemplo, o usuário pode rever uma discussão na qual o participante chegou no meio da reunião.

As várias formas de interação no mundo real são implícitas na computação cotidiana, sendo uma área claramente relevante para a pesquisa de computação ubíqua.

\subsection{Considerações Finais}

Este capítulo apresentou o tema computação ubíqua, com seus sub-temas principais: interfaces naturais, computação ciente de contexto, captura e acesso de experiências ao vivo e computação no cotidiano. Como o trabalho desenvolvido foca nas informações de contexto no sentido de permitir que as aplicações scjam adaptadas à situação específica do usuário e na captura e acesso de experiências ao vivo no sentido de automatizá-las, o capitulo visou contextualizar de forma geral a área de computação ubíqua e detalhar as sub-áreas em que o trabalho está inserido.

A síntese da história da computação ubíqua demonstrou a ocorrência de várias características. A computação ciente de contexto demonstrou a promessa de fazer as interações entre os usuários e os serviços de forma mais transparente e natural, e para isto, é preciso usar o contexto implícito do ambiente físico e eletrônico para determinar um procedimento correto em um serviço. Observou-se também, que as aplicações podem trabalhar melhor quando são informadas apropriadamente sobre o contexto em seu uso.

Além disso, é preciso prover serviços automatizados para facilitar a captura e armazenamento de experiências ao vivo, para o uso posterior. Finalmente, é preciso disponibilizar esses serviços constantemente para os usuários. 


\section{Aplicações e Infra-estruturas de Computação Ubíqua}

\subsection{Considerações Iniciais}

Um dos temas em computação ubiqua investiga a construção de dispositivos e aplicações para apoiar a captura automatizada de experiências ao vivo e futuros acessos a esses registros. Outro tema de pesquisa é computação ciente de contexto, que têm mostrado o valor do uso de informações de contexto em aplicações interativas, já que seu uso permite que aplicações sejam adaptadas à situação específica do usuário, provendo aumento de benefícios para este. Aplicações de computação ubíqua envolvendo os temas captura e acesso e computação ciente de contexto são descritas na Seção 3.2.

Pesquisas recentes têm focado o desenvolvimento de suporte para serviços dedicados à captura, armazenamento e processamento de informação, como as infra-estruturas do Context Toolkit [Salber et al., 1999] e Context Fabric [Hong \& Landay, 2001], e o middleware Gaia [Hess et al., 2002], detalhadas na Seção 3.3.

\subsection{Aplicaçōes de Computação Ubíqua}

Neste tópico é apresentado um conjunto de aplicações representativas dos vários temas de pesquisa em computação ubíqua. O objetivo é mostrar que, apesar de nem sempre classificados como tal na literatura, a maioria das aplicações faz uso tanto de informação de contexto como de processo de captura e acesso de informações. 


\subsubsection{Active Badge}

A localização e a coordenação eficientes de um grupo de pessoas em uma grande empresa são tarefas complexas. Um exemplo é em um escritório, onde recepcionistas são responsáveis por determinar a localização dos membros da empresa. Uma solução existente para a localização pessoal é o sistema de pager onde um sinal é enviado para o destinatário mas que, embora útil, na prática ainda há circunstâncias em que não é ideal, pois nesse caso é o procurado que deve informar onde, de fato, se encontra. O mesmo se aplica ao uso de telefonia celular.

Pesquisadores do Laboratório de Pesquisa Olivetti [Want et al., 1992] propuseram o Active Badge System como um sistema para localizar e identificar pessoas e objetos dentro da área onde é instalado. O sistema apresenta como componentes principais:

- active badge: é o dispositivo que transmite sinais infravermelhos, cada um associado a uma pessoa ou objeto a localizar, que permite ao portador mover-se dentro da área controlada pelo Active Badge System;

- sensor: é o dispositivo receptor de raios infravermelhos o qual é associado a uma localização.

Cada indivíduo com seu active badge transmite, a cada dez segundos, um sinal de raios infravermelhos, consistindo de um código de identificação único e de identificação do status do badge, que é detectado pelos sensores. Essa informação é enviada através da rede e armazenada em uma base de dados para posterior processamento. A Figura 3.1a ilustra o sensor e a Figura 3.1b uma aplicação indicando a localização e dados das pessoas.

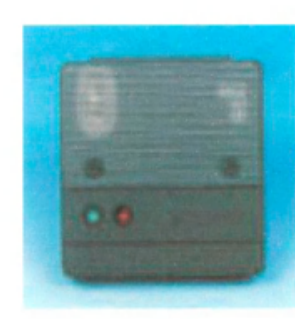

(a)

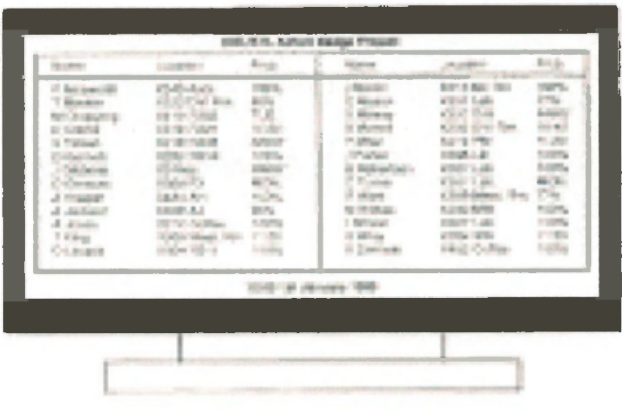

(b)

Figura 3.1: (a) Sensor do Active Badge, (b)Aplicação típica com a localização das pessoas [Want et al., 1992]. 
O sistema pode ter uma área de aplicação muito mais extensa, tais como: controle de acessos á determinadas árcas, controle de dispositivos de forma automática (por exemplo, redirccionamento de chamadas telefônicas), auxiliar $\mathrm{cm}$ emergências médicas e em controle de visitantes.

O Active Badge System é: (a) uma aplicação de computação no cotidiano, pois é comum no nosso dia-a-dia tarcfas tais como a localização de uma pessoa $\mathrm{cm}$ um ambiente; (b) uma aplicação de captura e acesso, pois as informações emitidas pelos sensores são gravadas e há o acesso a elas por aplicações específicas; e (c) uma aplicação ciente de contexto, pois utiliza informações contextuais, como who (destinguir a pessoa procurada), where (onde cla se encontra), e when (quando cla esteve no local).

\subsubsection{ParcTab}

O ParcTab foi desenvolvido pelo Laboratório de Ciência da Computação da então XEROX PARC [Schilit et al., 1993]. O ParcTab é um pequeno dispositivo portátil de entrada de informação (PDA) com tela sensivel ao toque. Assume-se que está sempre conectado a uma infra-estrutura de rede e utiliza o infravermelho como tecnologia de comunicação sem fio.

O ParTab foi desenvolvido para ser usado dentro do ambiente de um escritório. $\mathrm{O}$ objetivo foi criar um pequeno dispositivo que pudesse ser carregado por toda parte em um dia de trabalho. Devido a isso, o dispositivo foi desenvolvido com um baixo peso, tamanho e consumo de energia. () tab possui um conjunto de fontes para escrever textos, funções que permitem ler e escrever em armazenamento externo, gerar sons e setar parâmetros para processamentos. Por estarem interconectados, os tahs podem ir além das funcionalidades de simples calculadoras ou agendas eletrônicas, podendo ser usados, por exemplo, como crachás eletrônicos. A Figura 3.2 ilustra o dispositivo Parclab [Schilit et al., 1993].

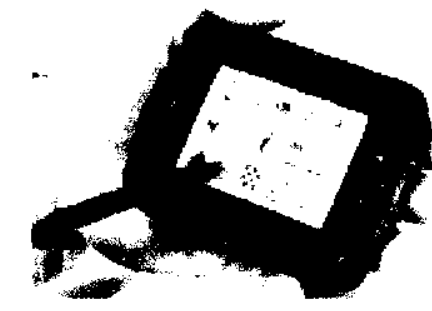

Figura 3.2: Dispositivo ParcTab [Schilit et al., 1993]. 
Renata Paciencia Godoy - Dissertação de Mestrado - Pós-Giraduação - ICMC/USP - São Carlos

Há três tipos de componentes de software no sistema: gateways, agentes e aplicaçôes. Os gateways enviam e recebem pacotes de dados através dos sinais infravermelhos. Cada tab é representado por um agente, responsável por rastrear sua localização. $\Lambda$ plicações são projetadas para fazer uso de pouca banda e pequena área de display.

Um grande número de aplicações ParcTab foi construido para explorarcm os problemas no acesso da informação ubíqua, o uso de interfaces baseadas $\mathrm{cm}$ canetas e o controle do ambiente. Algumas aplicações são:

- Controle do ambiente: um tab pode ser usado como controle remoto, como por exemplo, para controlar as luzes e temperatura de uma dada localização;

- Tempo: oferece as condições atuais do tempo do local em que o usuário está;

- Dicionários e calendários.

O ParcTab é: (a) uma aplicação de interfaces naturais, pois a interface utilizada se adapta à forma segundo a qual os humanos interagem com o mundo físico, através de canetas, por exemplo; (b) uma aplicação de captura c acesso, pois informações são gravadas e há o acesso a elas através da rede; e (c) uma aplicação ciente de contexto, pois utiliza informações contextuais, como where (localização dos objetos ou usuário), when (informações de horário ou dia) e what (o que deve ser utilizado na aplicação).

\subsubsection{CyberGuide}

Quando um turista visita uma localidade não familiar, é útil que ele tenha alguma informação para prover dados sobre sua localização. Um serviço de informação muito efetivo é o guia turístico humano, que fornece informações sobre a área e também é capaz de responder a questões espontâneas fora do contexto preparado.

Aplicações para um ambiente móvel devem tomar vantagem da informação contextual, como a localização, para oferecer melhores serviços para os usuários. Pesquisadores da GeorgiaTech criaram o projeto CyberGuide [Abowd et al., 1997], um serviço de guia turístico eletrônico que faz uso de dispositivos móveis, tecnologia handheld (dispositivos que cabem na palma da mão), localização espacial e serviços de comunicação. 
A informação de localização é fornecida por GPS para informar à aplicação onde o usuário está localizado. Esse conhecimento da localidade, assim como o histórico de suas localizações passadas, são usadas para prover maiores quantidades de serviços similares aos de um guia turístico real. O sistema é dividido em alguns componentes que fornecem os seguintes serviços:

- Cartografia (componente de mapas): tem o conhecimento do ambiente fisico, como a localização de construções, lugares ou caminhos que o turista pode seguir;

- Biblioteca (componente de informação): provê acesso a toda informação que o turista possa encontrar durante sua visita;

- Navegador (componente de localização): informa onde o usuário está;

- Mensageiro (componente de comunicação): provê envio/recebimento de informações.

O objetivo da aplicação é reconhecer onde o turista está (através do navegador e da cartografia), o que ele está olhando (através da biblioteca), poder predizer e responder questões que ele possa apresentar (através da biblioteca) e prover habilidade de interagir com outras pessoas do ambiente (através do mensagciro). Como cenário de aplicação, o CyberGuide pode ser usado por turistas, como guias pessoais, guias em museus e em cidades históricas, como dicionário tradutor e ainda suportar a interação de grupos em salas de aula. A Figura 3.3a mostra o mapa do funcionamento do CyberGuide e a Figura 3.3b a visualização das informações [Abowd et al., 1997].

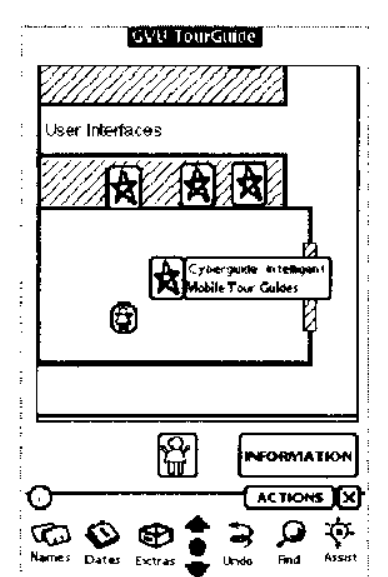

(a)

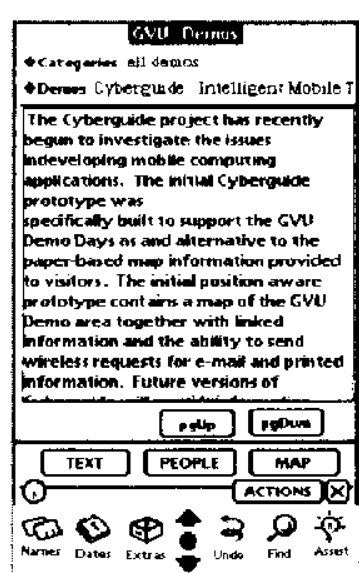

(b)

Figura 3.3: (a) Mapa do funcionamento do CyberGuide, (b) Interface com informações do sistema [Abowd et al., 1997] 
Renata Paciência Godoy - Dissertação de Mestrado - Pós-Graduação - ICMC/USP - São Carlos

O CyberGuide é uma aplicação: (a) de computação no cotidiano, pois encontramos guias com freqüência e utilizamos seus conhecimentos para nos localizarmos; (b) de captura e acesso, pois as informações sobre os lugares a visitas devem ser capturadas e depois acessadas para informar ao usuário; além disso, a própria visita de um usuário podem ser capturadas e registradas para acesso postcrior; e (c) ciente de contexto, pois utiliza informações contextuais, como where (onde os lugares históricos se encontram), when (histórico das passagens do usuário pelo local) e what (quais são os lugares visitados).

\subsubsection{The Conference Assistant}

O Conference Assistant foi projetado para auxiliar pessoas a assistirem conferências que envolvem uma grande quantidade de atividades paralelas, como apresentações de artigos, demonstrações e reuniões de grupo.

O Conference Assistant [Dey et al., 1999] foi desenvolvido para ajudar usuários a decidirem qual atividade assistir, prover ciência das atividades de outros participantes, aumentar as interações tanto entre usuários como com o ambiente, auxiliar os usuários a fazerem anotações nas apresentações e ajudar na recuperação das informações depois da conclusão das atividades.

O sistema permite a usuários fazerem anotações das apresentações através de um PDA que é utilizado durante a conferência. Um usuário pode então registrar seus interesses pessoais nos temas da conferência e o nome das pessoas cujas apresentações deseja assistir. () sistema fornece uma cópia do calendário da conferência, incluindo os artigos contidos nas apresentações. Como espera-de que as apresentações sejam capturadas pela sala, não é necessário fazer anotações detalhadas, apenas alguns comentários. Depois de concluída a conferência, cada anotação do usuário pode ser integrada com as apresentações capaturadas nas salas. $O$ sistema também é ciente da localização, pois se o usuário mover-se durante a conferência, o sistema captura sua localização física e as apresentações, e o acesso às informações capturadas são dadas a partir desta localização.

O Conference Assistant é uma aplicação: (a) de captura e acesso, pois todos os dados referentes à conferência (como artigos e seminários) são armazenados para posterior acesso; e (b) ciente de contexto, pois utiliza informações contextuais, como who (quem é o palestrante 
e quem é o usuário), where (localização das palestras/seminários e do usuário), when (quando as atividades aconteceram) e what (o que foi capturado).

\subsubsection{DUMMBO (Dynamic, U Ubiquitous, Mobile Meeting Board)}

Nem todas as reuniões podem ser marcadas com antecedência, ocorrendo muitas vezes a partir de encontros casuais. $O$ assunto que será tratado durante essas reuniões não é conhecido, assim como também não se sabe quem está envolvido ou quanto tempo o encontro irá durar.

Para suportar tais reuniões informais que ocorrem a partir de encontros oportunísticos, foi criado o sistema $D U M M B O$ [Brotherton et al., 1999]. O sistema é composto de uma lousa eletrônica, de um sistema de som anexo à lousa e um laptop responsável pela codificação do áudio e registro das atividades realizadas sobre a lousa eletrônica. Quando alguém se aproxima da lousa e retira uma caneta para escrever, o sistema inicia a captura automaticamente. O sistema conta ainda com sensores capazes de detectar a presença de pessoas próximas à lousa e, mesmo que não haja interação, a sessão continua sendo registrada. A Figura 3.4a ilustra a interface de captura e a Figura 3.4b ilustra a interface de acesso do sistema $D U M M B O$.

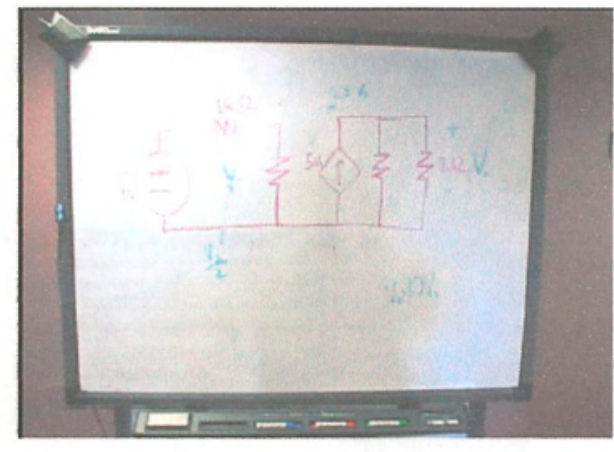

(a)

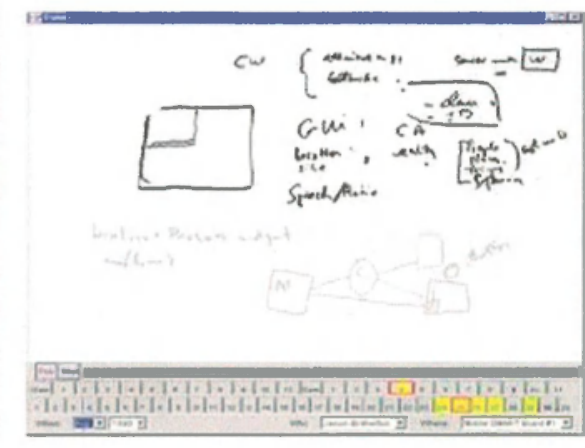

(b)

Figura 3.4:(a) A interface de captura; (b) Interface de acesso[Brotherton et al., 1999].

$\mathrm{O}$ acesso à informação capturada é realizado através de uma interface $W e b$, onde as informações contextuais são utilizadas para auxiliar na busca por conteúdo de interesse. $O$ usuário pode, por exemplo, dar informações como data e horário aproximados de uma reunião e a interface possibilita que as atividades realizadas na lousa eletrônica sejam exibidas de forma sincronizada com o áudio capturado. 
O DUMMBO é: (a) uma aplicação de captura e acesso, pois armazena informações referentes à reunião que serão recuperadas depois; e (b) uma aplicação ciente de contexto, pois utiliza informações contextuais, como who (quem são os usuários), where (localização das atividades), when (quando as atividades aconteceram) e what (o que foi capturado).

\subsubsection{TeamSpace}

A captura de informações de reuniões foi um assunto comum da pesquisa na comunidade relacionada à computação ubíqua para a década passada. Entretanto, a maioria das pesquisas focalizou em tecnologias para suportar não somente a captura, mas para alcançar e utilizar posteriormente o registro capturado dessas discussões ou reuniões. Para este propósito, Richter et. al. [2001] desenvolveram um sistema denominado TeamSpace para a captura da reunião como a parte de um sistema distribuído maior, onde exigências em relação ao tipo de dados capturados pudessem ser determinados com antecedência.

O TeamSpace é um sistema de trabalho colaborativo para gerenciar o processo de trabalho compartilhado e manter artefatos compartilhados em projetos distribuídos. A Figura 3.5a mostra uma interface do TeamSpace onde pode-se ver uma apresentação anotada, além de poder observar na parte esquerda da tela, a agenda, os itens de ação, as apresentações e os participantes. Já a Figura 3.5b mostra a interface do visualizador do TeamSpace, que integra todas as informações baseadas no tempo, utilizando timelines para navegação entre as reuniões.

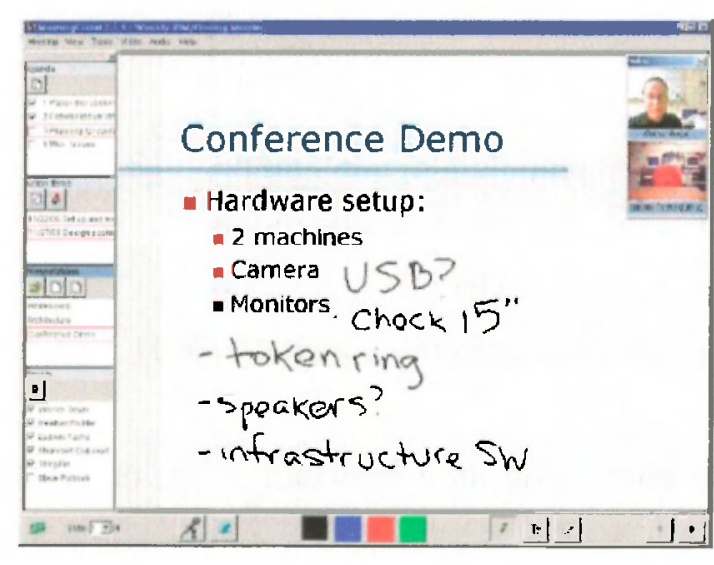

(a)

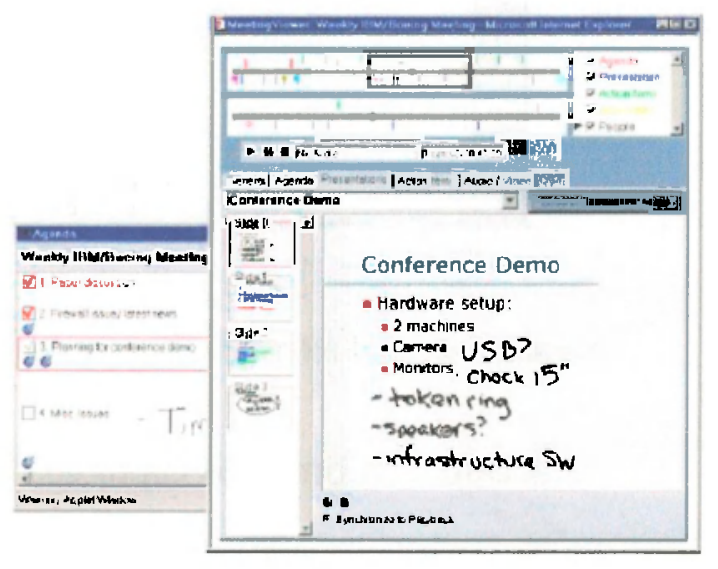

(b)

Figura 3.5:(a) Interface de Reuniões TeamSpace; (b) Interface do visualizador do TeamSpace [Richter et. Al.,2001]. 
O sistema TeamSpace é uma aplicação: (a) de interfaces naturais, porque suporta o uso de lousa eletrônica e tablets PCs; (b) de captura e acesso, pois registram as informações para depois serem acessadas; e (c) ciente de contexto, pois utilizam as informações de contexto, who (usuário), where (localização das aulas capturadas), when (quando aconteceu a captura) e what (o que foi capturado).

\subsubsection{Campus Aware}

Quando estudantes ingressam em universidades, estudantes locais os ajudam a conhecer melhor o campus. Surge então a questão de se essa experiência não poderia ser melhorada através de novas tecnologias para ajudar os estudantes a compartilharem seus conhecimentos e experiências com os novos alunos.

Nesse contexto, foi proposto o projeto Campus Aware [Burrell et al., 2002], um guia turístico para um campus universitário baseado na localização espacial. Esse guia permite que membros da universidade possam associar comentários a espaços físicos representados no sistema, sendo que os novos estudantes também podem questionar esses comentários feitos por eles. O sistema possui mapas para associar comentários a locais - esses mapas devem agregar os dados do usuário com localização da área, sendo que esses dados podem incluir as localizações visitadas e quanto tempo os usuários permaneceram em cada lugar.

O sistema é executado em um Palm para permitir mobilidade e também uso de GPS para uma localização apurada. A Figura 3.6a mostra um Palm com dados da localização do usuário e a Figura 3.6b uma interface Web mostrando o mapa do campus [Burrell et al., 2002].

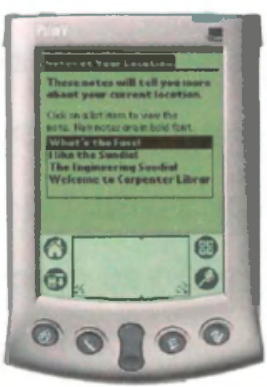

(a)

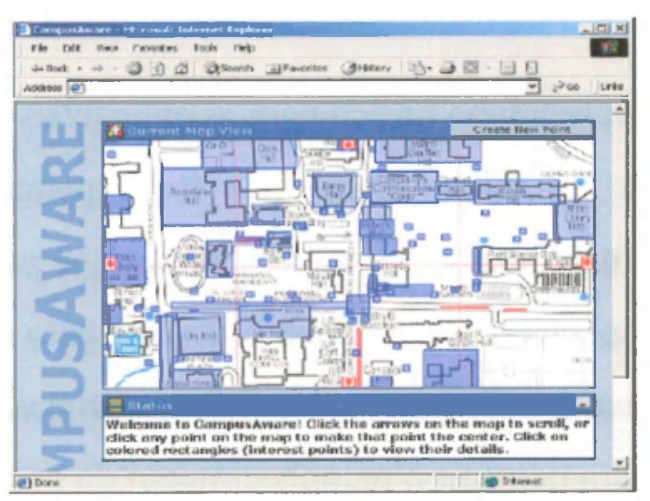

(b)

Figura 3.6: (a) Palm com dados sobre a localização do usuário; (b) interface Web com o mapa do campus [Burrell et al., 2002]. 
Em trabalhos futuros, desenvolvedores do projeto esperam evoluir em relação aos mapas, à escalabilidade do sistema, ao uso do sistema por diferentes tipos de usuários e ao uso de sistemas similares em outros ambientes.

O Campus Aware é uma aplicação: (a) de computação no cotidiano, pois estudantes sempre querem obter informações sobre o campus; (b) de interfaces naturais, já que a interface do Palm é baseada em caneta; (c) de captura e acesso, pois as informações sobre as dependências da faculdade são capturadas para posterior acesso; e (d) ciente de contexto, pois utiliza informações contextuais, como where (localização das dependências), when (histórico das passagens do usuário pelo local) e what (quais são as dependências).

\subsubsection{Aware Home e Cooking Collage}

A Aware Home Research Initiative [Aware Home, 2003] vem sendo desenvolvida por um grupo de pesquisadores do Georgia Institute of Technology com o objetivo de construir uma casa interativa e ciente de seus moradores, servindo de laboratório para aplicações de computação ubíqua. A Figura 3.7 ilustra a Aware Home.

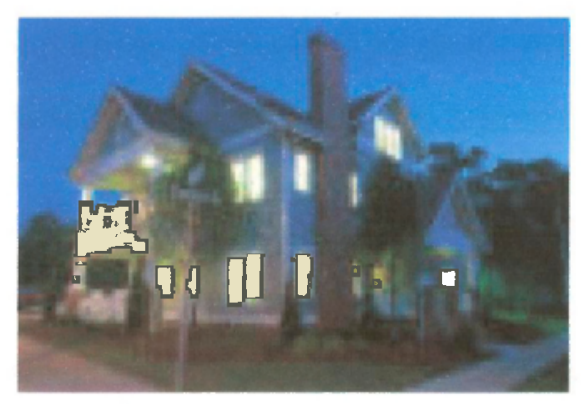

Figura 3.7: A casa interativa e ciente de seus moradores, Aware Home [Aware Home, 2003].

Um requisito básico para as aplicações da casa é a possibilidade de localização de seus ocupantes. Na Aware Home isso foi implementado fornecendo rádio transmissores a cada usuário $^{7}$, funcionando como identidades que podem ser localizadas pela casa. No entanto, isso permitiu apenas o conhecimento do aposento ocupado, o que deu início ao desenvolvimento de um sistema mais preciso baseado no processamento de imagens através de câmeras no teto da casa, para permitir o reconhecimento da posição de cada ocupante dentro de um aposento.

\footnotetext{
${ }^{7}$ Os rádios transmissores são pequenos e utilizados na roupa ou no calçado.
} 
Entre outros trabalhos, também estão em desenvolvimento métodos de reconhecimento de atividades, por exemplo, para perceber alguém lendo jornal, vendo TV ou cozinhando, além de técnicas de rastreamento de visão e reconhecimento de voz.

Cozinhar é uma sequência detalhada de instruções que exige atenção para os detalhes e tempo. Interrupções e esquecimentos ocasionais de memória, agravados pela tendência de realizar várias tarefas ao mesmo tempo, apresentam obstáculos para completar a atividade. Por exemplo, quando uma receita pede uma grande quantidade de materiais brancos (farinha, açúcar, sal), quando o usuário interrompe a atividade (para fazer outra atividade) e depois retorna, é difícil determinar o que já foi adicionado ou não.

Para apoiar usuários em tarefas cotidianas em uma cozinha foi desenvolvido o Cook's Collage [Mynatt \& Tran, 2002], um sistema ciente de contexto que captura informações transitórias de atividades recentes e as mostra em displays como sugestões visuais. Várias câmeras são embutidas no ambiente para capturar as imagens dentro da cozinha, que por sua vez é instrumentada com tecnologias sensitivas capazes de detectar quando certos itens são usados, ou onde as atividades estão ocorrendo. Quando o usuário trabalha na cozinha, esses sensores são disparados e usados para controlar a captura de imagens para criar a sequência das atividades recentes. Então, quando o usuário não se lembra da última atividade, ele pode confiar no ambiente para prover a informação. A Figura 3.8 ilustra uma sequência de imagens referentes a uma determinada ação, ajudando o usuário a saber o que iá foi feito ou não.

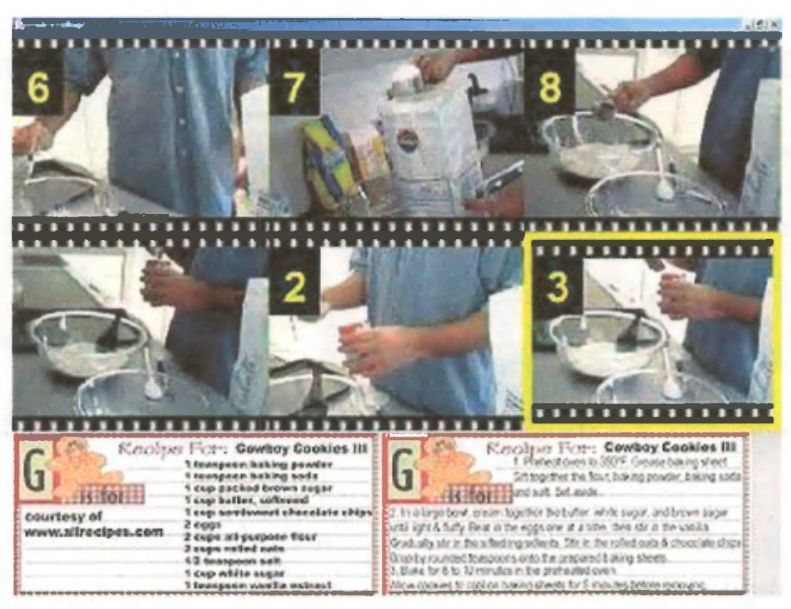

Figura 3.8: Sequência de imagens de uma determinada açâo [Mynatt \& Tran, 2002]. 
É relevante observar que muitas das aplicações em desenvolvimento na AwareHome são destinadas ao público idoso - que possui maiores demandas por apoio a processos cognitivos, entre outros.

O Cooking Collage é: (a) uma aplicação de interfaces naturais, pois o modo de interagir com o ambiente continua o mesmo, ou seja, a interface utilizada se adapta ao usuário; (b) uma aplicação de computação no cotidiano, pois sempre estamos em casa ou na cozinha fazendo as atividades que, neste caso, são monitoradas; (c) uma aplicação de captura e acesso, pois todas as informações referentes a uma atividade devem ser armazenadas e depois recuperadas para lembrar o usuário de sua última ação; e (d) uma aplicação ciente de contexto, pois utilizam todas as informações contextuais, who (quem é o usuário), where (localização das atividades), when (quando as atividades aconteceram), what (o que foi feito) e how (como foi feito).

\subsubsection{CareMedia}

O projeto CareMedia [Hauptmann et. al., 2004] faz o uso de captura de dados de áudio e vídeo para auxiliar na monitoração de atividades, podendo rastrear pessoas automaticamente, agrupando-as em determinadas ações e atividades. Por enfatizar a detecção de atividade de alimentação e de higiene pessoal, é um sistema para a monitoração da saúde do indivíduo. A

Figura 3.9 mostra como o sistema detecta o movimento da atividade de se alimentar e a

Figura 3.10 mostra a extração de uma característica visual de um vídeo de higiene pessoal.

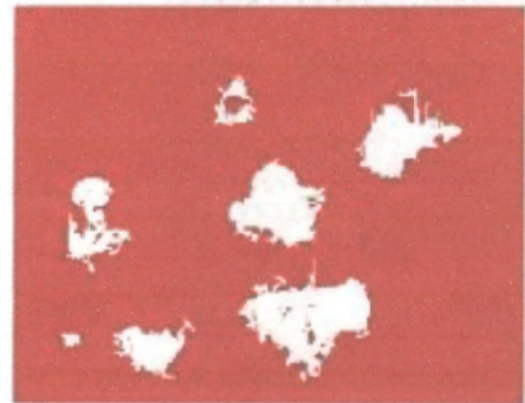

(a)

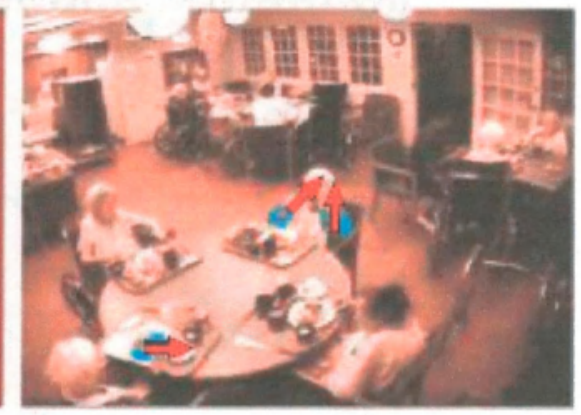

(b)

Figura 3.9: Sistema para detectar o movimento da atividade de se alimentar em uma sala de jantar. (a) mostra regiões de movimentos na sala de jantar, que é associado a cada pessoa; (b) As setas em vermelho indicam os movimentos das mãos relacionados à alimentação, enquanto que as áreas em azuis indicam a parte do corpo que está se movendo [Hauptmann et. al., 2004]. 


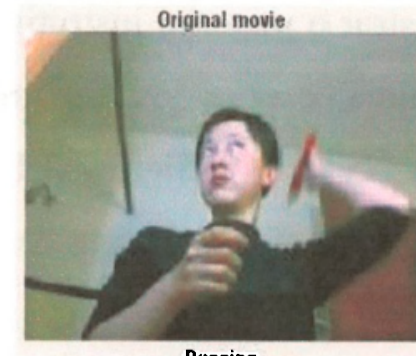

(a)

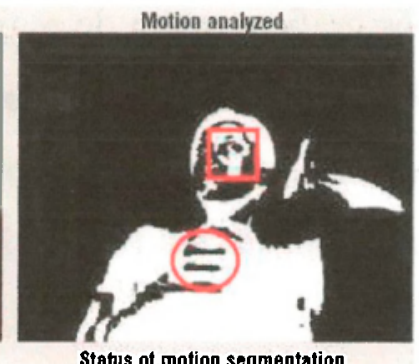

(b)

Figura 3.10: Imagem visual de um video de higiene pessoal. (a) mostra a atividade em si; b)mostra a análise do movimento, identificando os segmento correspondentes [Hauptmann et. al., 2004].

O projeto é uma aplicação: (a) de interfaces naturais, pois os humanos continuam interagindo com o mundo físico; (b) de captura e acesso, pois todas as informações referentes às atividades executadas são armazenadas; e (d) ciente de contexto, pois utilizam as informações contextuais, who (quem é o usuário), where (localização das pessoas no ambiente), when (quando ocorreram as atividades) e what (o que foi capturado).

\subsubsection{Authoring on the Fly}

O sistema Authoring on the Fly, como apresetado por Muller e Ottmann [2000], tem como principal característica a fusão entre as três atividades listadas:

- Captura e gravação de apresentações;

- Ensino via teleconferência;

- Posterior produção de material multimídia e educacional.

Esse sistema vem sendo utilizado em eventos de treinamento e educação ou em apresentações de modo general, onde sempre se têm os dados gravados para futuras reutilizações da maneira escolhida pelo usuário. O sistema permite a captura e o replay dos fluxos de dados capturados durante uma tele-apresentação, possuindo um texto integrado e um editor de gráficos para a preparação de páginas a serem carregadas em uma lousa eletrônica durante a fase de apresentação.

Antes da apresebtação, o conferencista ou o professor usa o sistema para produzir um material novo (como slides, por exemplo) ou para combinar material já existente, como imagens, textos ou animações. Na próxima fase, o sistema é usado para apresentar, fazer 
comentários e anotações gráficas, além de registrar o material instrutivo. Quando o processo de gravação é terminado, os dados de mídia capturados são usados para produzir automaticamente um documento integrado em HTML. A Figura 3.11 ilustra o sistema de captura usando uma SmartBoard e a Figura 3.12 ilustra o sistema de captura através de um tablet gráfico.

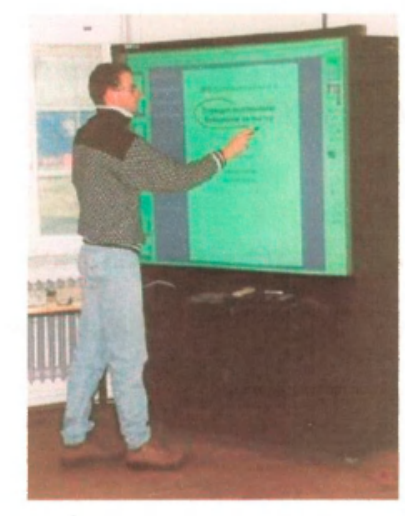

Figura 3.11: Sistema de captura no Authoring on the Fly usando uma SmartBoard [Muller \& Ottmann, 2000].

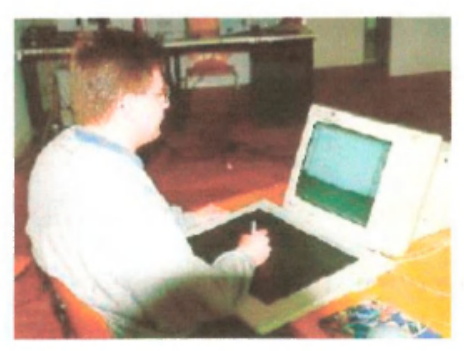

Figura 3.12: Sistema de captura no Authoring on the Fly usando um tablet [Muller \& Ottmann, 20007 .

O Authoring on the Fly é uma aplicação: (a) de interfaces naturais, pois com o uso da lousa eletrônica, a interface utilizada se adapta à forma segundo quais os humanos interagem com o mundo físico; (b) de computação no cotidiano, pois apresentações são eventos que ocorrem habitualmente; (c) de captura e acesso, pois todas as informações referentes a uma apresentação são armazenadas e depois acessadas; e (d) ciente de contexto, pois utilizam todas as informações contextuais, who (quem é o usuário), where (localização das aulas capturadas), when (quando as aulas foram dadas), what (o que foi capturado) e how (como foi capturado o slide ou áudio).

\subsubsection{1 eClass / iClass}

Com a introdução de novas tecnologias em sala de aula, por exemplo, apresentações multimídia, os estudantes passaram a receber uma carga de informação cada vez maior. Para tentar absorver todas as informações, o estudante precisa fazer diversas anotações, perdendo a oportunidade de discutir e prestar mais atenção à aula. Liberar o estudante dessas anotações foi o principal objetivo que motivou o desenvolvimento do projeto eClass, também chamado 
de Classroom 2000 [Abowd, 1999b]. O sistema iClass [Cattelan et al., 2003a; Cattelan et al., 2003b] é uma evolução do sistema eClass.

Tanto o eClass e o iClass são aplicações: (a) de interfaces naturais, pois a interface utilizada se adapta à forma segundo a qual os humanos interagem com o mundo fỉsico, através de canetas e borrachas, por exemplo; (b) de computação no cotidiano, pois aulas são eventos cotidianos, e que com esses sistemas podem ser capturadas para facilitar o estudo dos alunos; (c) de captura e acesso, pois informações referentes a uma aula (como slides, áudio ou vídeo) são armazenadas e depois acessadas para o estudo; e (d) ciente de contexto, pois utilizam informações contextuais, como who (quem é o usuário), where (localização das aulas capturadas), when (quando as aulas aconteceram), what (o que foi capturado) e how (como foi capturado o slide, áudio ou tinta eletrônica).

Como o trabalho apresentado nesta dissertação envolve o iClass, o detalhamento da aplicação é feito no próximo capítulo, para uma melhor contextualização do projeto.

\subsubsection{SmartClassroom}

Esta aplicação descrita por Shi et. al. [2003] é uma tentativa de estudar o impacto da utilização da computação ubíqua sobre métodos de ensino.

Para isso, foram e estão sendo construídos protótipos de ambiente de sala de aula com infra-estrutura de software necessária para a captura de toda a interação que ocorre entre o professor e seu ambiente de aula típico de uma universidade. Neste sistema, é também, motivação a redução da necessidade de anotações por parte do aluno, permitindo que o mesmo compreenda melhor a discussão da sala de aula. O SmartClassroom é baseado na transmissão síncrona da aula, que são autenticadas por reconhecimento de voz e interface. A Figura 3.13 ilustra o ambiente denominado de sala de aula do "futuro"[Shi, et. al., 2003].

O SmartClassroom é uma aplicação: (a) de interfaces naturais, pois a interface utilizada se adapta à forma a qual os humanos interagem com o mundo físico; (b) de computação no cotidiano, pois aulas são eventos corriqueiros; (c) de captura e acesso, pois todas as informações referentes a uma aula (como slides, áudio ou vídeo) são armazenadas e depois acessadas para o estudo; e (d) ciente de contexto, pois utilizam todas as informações contextuais, who (quem é o usuário, tanto professor como alunos), where (incluindo 
localização das aulas remotas), when (quando as aulas acontecem), what (o que foi capturado) e how (como foi capturado o slide, áudio ou tinta eletrônica).

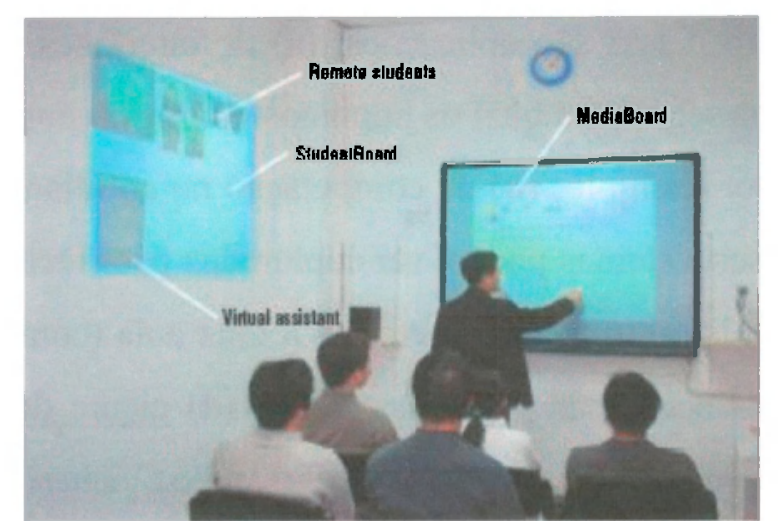

Figura 3.13: Ambiente de sala de aula do SmartClassroom [Shi, et. Al.,2003].

\subsubsection{Classificação segundo Sub-áreas da Computação Ubiqua}

A Tabela 3.1 sumariza o uso de computação de captura e acesso e a computação ciente de contexto nas aplicações atacadas. Além disso, todas as aplicações fazem uso de várias das dimensões de contexto: who, where, when, what e how.

\begin{tabular}{|l|c|c|c|c|c|c|c|c|c|}
\hline \multirow{2}{*}{ Aplicações } & \multicolumn{3}{|c|}{ Sub-áreas da Computação Ubíqua } & \multicolumn{5}{c|}{$\begin{array}{c}\text { Classificação segundo } \\
\text { dimensóes de contexto }\end{array}$} \\
\cline { 2 - 11 } & $\begin{array}{l}\text { Interface } \\
\text { Natural }\end{array}$ & $\begin{array}{c}\text { Captura } \\
\text { e acesso }\end{array}$ & $\begin{array}{l}\text { Computaçã } \\
\text { no Computacãa }\end{array}$ & $\begin{array}{c}\text { Cotidiano } \\
\text { Ciente de } \\
\text { Contexto }\end{array}$ & Who & Where & When & What & How \\
\hline Active Badge & & $\mathrm{X}$ & $\mathrm{X}$ & $\mathrm{X}$ & $\mathrm{X}$ & $\mathrm{X}$ & $\mathrm{X}$ & & \\
\hline ParcTab & $\mathrm{X}$ & $\mathrm{X}$ & & $\mathrm{X}$ & & $\mathrm{X}$ & $\mathrm{X}$ & $\mathrm{X}$ & \\
\hline CyberGuide & & $\mathrm{X}$ & $\mathrm{X}$ & $\mathrm{X}$ & & $\mathrm{X}$ & $\mathrm{X}$ & $\mathrm{X}$ & \\
\hline $\begin{array}{l}\text { The Conference } \\
\text { Assistant }\end{array}$ & & $\mathrm{X}$ & & $\mathrm{X}$ & $\mathrm{X}$ & $\mathrm{X}$ & $\mathrm{X}$ & $\mathrm{X}$ & \\
\hline DUMMBO & & $\mathrm{X}$ & & $\mathrm{X}$ & $\mathrm{X}$ & $\mathrm{X}$ & $\mathrm{X}$ & $\mathrm{X}$ & \\
\hline TeamSpace & $\mathrm{X}$ & $\mathrm{X}$ & & $\mathrm{X}$ & $\mathrm{X}$ & $\mathrm{X}$ & $\mathrm{X}$ & $\mathrm{X}$ & \\
\hline Campus Aware & $\mathrm{X}$ & $\mathrm{X}$ & $\mathrm{X}$ & $\mathrm{X}$ & & $\mathrm{X}$ & $\mathrm{X}$ & $\mathrm{X}$ & \\
\hline $\begin{array}{l}\text { Aware Home e } \\
\text { Cooking Collage }\end{array}$ & $\mathrm{X}$ & $\mathrm{X}$ & $\mathrm{X}$ & $\mathrm{X}$ & $\mathrm{X}$ & $\mathrm{X}$ & $\mathrm{X}$ & $\mathrm{X}$ & $\mathrm{X}$ \\
\hline CareMedia & $\mathrm{X}$ & $\mathrm{X}$ & & $\mathrm{X}$ & $\mathrm{X}$ & $\mathrm{X}$ & $\mathrm{X}$ & $\mathrm{X}$ & \\
\hline $\begin{array}{l}\text { Authoring } \\
\text { on the Fly }\end{array}$ & $\mathrm{X}$ & $\mathrm{X}$ & $\mathrm{X}$ & $\mathrm{X}$ & $\mathrm{X}$ & $\mathrm{X}$ & $\mathrm{X}$ & $\mathrm{X}$ & $\mathrm{X}$ \\
\hline Eclass / iClass & $\mathrm{X}$ & $\mathrm{X}$ & $\mathrm{X}$ & $\mathrm{X}$ & $\mathrm{X}$ & $\mathrm{X}$ & $\mathrm{X}$ & $\mathrm{X}$ & $\mathrm{X}$ \\
\hline SmartClassroom & $\mathrm{X}$ & $\mathrm{X}$ & $\mathrm{X}$ & $\mathrm{X}$ & $\mathrm{X}$ & $\mathrm{X}$ & $\mathrm{X}$ & $\mathrm{X}$ & $\mathrm{X}$ \\
\hline
\end{tabular}

Tabela 3.1: Classificação das aplicações em relaçao às sub-áreas da computação ubiqua. 


\subsection{Infra-estruturas de Computação Ubíqua}

Neste tópico são apresentadas pesquisas no tocante às infra-estruturas de suporte à ciência de contexto e aplicaçôes de captura e acesso, mostrando de um modo geral algumas iniciativas encontradas na literatura.

\subsubsection{Context Toolkit}

O Context Toolkit [Dey \& Abowd, 2000b; Salber et al, 1999] propõe um framework com mecanismos genéricos a fim de facilitar o desenvolvimento de aplicações cientes de contexto, além de fornecer padronização e generalização às aplicações, visando o reuso de métodos de desenvolvimento na construção de novas aplicações. O Context Toolkit consiste em três abstrações principais: widgets de contexto (componentes de interação), agregadores e interpretadores.

Widgets de contexto modelam a interação entre o usuário e o ambiente. Eles encapsulam a informação de contexto como atividade ou localização, provendo uma interface uniforme e transparente para os componentes das aplicações que utilizam essas informações. Agregadores de informações de contexto possuem todas as capacidades dos widgets, além de provêem habilidade de agregar informação de contexto das entidades do mundo real como usuários ou lugares. Os agregadores ligam as aplicações com os widgets, fornecendo mais transparência para o processo. Interpretadores de informações de contexto são usados para abstrair ou interpretar informação de contexto de baixo nível para alto nível. Por exemplo, dados como identificação, localização e tempo podem ser utilizados para abstrair que uma dada reunião esteja acontecendo.

No Context Toolkit, todos os componentes compartilham um mecanismo de comunicação comum (XMI sobre HTTP) que permite a transparência no processo de aquisição de informação de contexto. Todos os componentes são executados independentes do uma aplicação, permitindo usá-los em várias aplicações. Assim, o Context Toolkit provê captura, armazenamento, conversão, agregação, acesso c distribuição de informação de contexto para aplicações. 
Renata Paciência Godoy - Dissertação de Mestrado. Pós-Graduał̧ão ICMC/USP - São Carlos

\subsubsection{Context Fabric}

O Context Fabric [Hong \& Landay, 2001] é um serviço de infra-estrutura para aplicações ciente de contexto com foco no modelo de armazenamento para informações de contexto distribuídas. Através de abstrações uniformes c serviços confiáveis para as operações, a infraestrutura pode facilitar o desenvolvimento de aplicações mesmo com as mudanças do conjunto de dispositivos e sensores.

O primeiro benefício do Context Fabric é que ele pode ser usado independentemente da plataforma de hardware, sistemas operacionais e linguagem de programação. Através de formatos padrões de dados e protocolos de rede, a infra-estrutura pode suportar uma grande quantidade de dispositivos e aplicações. O segundo benefício é que provê uma camada de middleware com um nivel uniforme de abstração onde os sensores, serviços, e dispositivos e aplicações ficam separados, possibilitando que ele seja trocado independentemente (sem afetar nenhum outro) e dinamicamente (mesmo que outro esteja em exccução). $O$ terceiro benefício é que aplicações cientes de contexto são mais fáceis de serem desenvolvidas, já que podem ser compartilhadas.

\subsubsection{Interative Workspaces}

O projeto Interactive Workspaces (IW) [Johanson et al., 2002] explora novas possibilidades para pessoas trabalharem juntas em um ambiente de alta tecnologia. O projeto visa aumentar a interação humana com monitores de alta resolução e a integração de aplicações móveis.

Foram construídas algumas versões do protótipo do Interactive Workspace denominada iRoom, sendo composto por três lousas eletrônicas sensíveis ao toque, câmeras, microfones, suporte a rede $L A N$ e outros dispositivos de interação que são usados simultaneamente no Workspace, onde um é acessível por todos os outros. Para isso, há um framework para prover uma plataforma de suporte. Da perspectiva da interação usuáriocomputador, a interface é customizada para diferentes monitores e possibilita diferentes modalidades de entrada e saída de dados, como a escrita e a fala.

$\Lambda$ infra-estrutura do sistema é chamada iROS (Interactive Room Operating System), contendo três subsistemas: Event Heap, Data Heap e iCrafier. O Event Heap provê um repositório central para que todas as aplicações possam enviar eventos. O Data Heap facilita a 
movimentação das informações, permitindo que qualquer aplicação possa armazenar seus dados no ambiente associado. Além disso, armazena o formato da informação e possibilita a transformação dos dados para o melhor formato suportado pela aplicação que está recuperando a informação. () iCrafter permite que usuários escolham serviços e retorna a melhor interface para o usuário.

\subsubsection{Middleware Gaia}

A infra-estrutura de middleware Gaia [Hess et al., 2002] foi desenvolvida para prover suporte ao Espaço Virtual do Usuário (User Virtual Space), uma abstração que inclui dados, consultas a essas informações e dispositivos associados aos usuários. A infra-estrutura é sempre ativa e não depende de dispositivos específicos; desloca-se com os usuários; e mapeia informações de contextos e consultas para o ambiente de computação ubíqua do usuário de acordo com o contexto atual.

A construção do Espaço Virtual do Usuário enfrentou alguns desafios, como:

- Gerenciamento de contexto: as informações de contexto podem efetuar mudanças nas aplicações para adaptar-se ao ambiente do usuário, visando lacilitar o uso do ambiente compulacional;

- Ligação (binding): as aplicações devem ser constituídas de modo que elas sejam particionadas e mapeadas para o recurso mais apropriado de acordo com as informações de contexto físico, configurações pessoais e outros atributos;

- Mobilidade: afeta a arquitetura da aplicação, pois requer habilidade de migrar parte de seus componentes em tempo de execução. A mobilidade do usuário também implica na disponibilidade das informações, além do usuário não dever se sobrecarregar com as configurações, preferências ou dados das aplicações;

- Adaptabilidade: os desenvolvedores das aplicações não devem se preocupar com a complexidade das conversões dos formatos dos dados, deixando a cargo do sistema adaptar as informações de contexto para o formato descjado. 
O Espaço Virtual do Usuário mantém várias informações para cada usuário, que podem estar em servidores distribuidos constituindo os dados, configurações e preferências das aplicações.

\subsection{Consideraçōes Finais}

O trabalho apresentado nesta dissertação envolve a associação de metadados baseados em informação de contexto à informação capturada $\mathrm{cm}$ aplicações da captura $\mathrm{c}$ acesso. Para mostrar a atualidade e abrangência do problema, este capitulo apresentou aplicações representativas dos temas de pesquisa de computação ubíqua e mostrou que todas as aplicações entre as apresentadas usam captura e acesso e informações de contexto. Além disso, mostrou de um modo geral algumas infra-estruturas encontradas na literatura. 


\section{4 iClass \& Context Kernel}

\subsection{Considerações Iniciais}

O trabalho reportado nesta dissertação identificou a importância do reuso de informações capturadas por aplicações de captura e acesso e propõe que sejam associados metadados a essas informações - tanto de forma automática, com a exploracação de informações de contexto, como de forma manual, com a exploração de interfaces Web. Para exemplificar essa proposta, o trabalho envolveu a associação de metadados ao sistema iClass, fazendo uso de informações de contexto obtidas do Context Kernel. Deste modo, este capítulo apresenta esses sistemas no contexto do projeto no qual eles foram propostos.

\subsection{Projeto InCA-SERVE}

$O$ projeto InCA-SERVE ${ }^{\ngtr}$ envolveu uma parceria entre o Georgia Institute of Technology (GATech), sob supervisão do Dr. Gregory Abowd, e o Instituto de Ciências Matemáticas e de Computação (ICMC), sob supervisão da Dra. Maria da Graça Campos Pimentel. Esse projeto foi financiado por um programa de cooperação internacional entre a NSF/CISE nos EUA e o $\mathrm{CNPq} /$ ProTeM-CC no Brasil.

O Projeto InCA-SERVE prevê a construção das infra-estruturas InCA e SERVE. A InCA (Infrastructure for Capture and Access) trata da implementação da infra-cstrutura de 
Renata Paciência Godoy Dissertação de Mestrado . Pós-Graduação- ICMCUSP - São Carlos

captura e acesso de informações associadas à experiências ao vivo. A SERVE (Infrastructure for Store, Extend, Retrieve and Visualize Evolutionary information) cuida da parte de armazenamento, extensão, recuperação e visualização de informação evolucionária [Pimente] \& Abowd 1999].

As infra-estruturas InCA e SERVE provêem um conjunto de serviços de captura, acesso, armazenamento, extensão, recuperação e visualização da informação, pcrmitindo a construção de aplicações que suportem atividades de ensino e reuniões. Elas ainda são padronizadas $\mathrm{em} \mathrm{XML,} \mathrm{permitindo} \mathrm{uma} \mathrm{grande} \mathrm{integração} \mathrm{entre} \mathrm{as} \mathrm{aplicações.}$

\subsubsection{Infra-estruturas e Serviços Inca-Serve}

A INCA (Infrastructure for Capture and Access Applications) [Truong \& Abowd, 2002] [Truong \& Abowd, 2004] e a xINCA (Extended Infrastructure for Capture and Access Applications) [Cattelan, 2004] são infra-estruturas genéricas, escritas cm linguagem Java com arquiteturas cliente/servidor, que promovem suporte por meio de interfaces e módulos para as aplicações de captura e acesso. A xINCA estende a INCA com base em funcionalidades recorrentes de aplicações de captura e acesso. Utilizando módulos e abstrações da INCA, a xINCA provê componentes de software reutilizáveis responsáveis pelas funcionalidades de áudio, vídeo, chat, Web browsing e lousa eletrônica.

Para que a xINCA tenha uma arquitetura extensível, cada componente deve ter um esquema de dados estruturando toda a informação produzida, além da aplicação ter que possuir um esquema de dados para a sessão que combinem todos os esquemas dos componentes. Essas funcionalidades são obtidas pelo serviço StRES (Storing, Retrieving and Extending Service) [Baldochi et. al., 2002; Baldochi et. al., 2003; Baldochi et. al., 2004], que provê módulos para manipulação de forma transparente da informação produzida por aplicações de captura e acesso.

Pode-se citar ainda a infra-estrutura INDU [Rocha, 2004], que captura sessões privadas em plataformas PDAs. Além disso, existem alguns serviços, como: o serviço de autoria AutorE [Sante, 2003; Pimentel et. al, 2003] para preparar sessões de captura; o serviço GroupNote [Izeki, 2001], que estende o conteúdo capturado de anotações colaborativas e o

${ }^{8}$ htpp://coweb.icme:sciusp.hr/incaserve 
Renata Paciência Godoy - Dissertação de Mestrado - Pós-Graduação-ICMCLUSP - São Carlos

serviço WLS [Bulcão Neto, 2001], para estender o conteúdo capturado por meio de ligações hipermídia. De particular relevância para o trabalho reportado nesta dissertação, os serviços AutorE [Sante, 2003; Sante et. al, 203], Context Kernel [Arruda Jr, 2003; Arruda Jr. et al, 2003] e iClass [Cattelan et al., 2003a; Cattelan et al., 2003b], são detalhados neste capítulo.

As infra-estruturas e serviços têm forte relação entre si c pode-se dizer que são complementares com respeito à construção de aplicações de captura e acesso, que podem ser associados às fases de experiências de captura e acesso como segue:

- pré-produção (preparação): Autorl;

- gravação ao vivo (captura): INCA, xINCA, INDU, StRES;

- acesso: iClass;

- pós-produção (extensão): GroupNote, WLS e AutorE.

\subsection{Autore}

Antes de se capturar uma experiência ao vivo, é necessária a preparação das sessões de captura, que se dá através do sistema de autoria AutorE: [Sante, 2003; Sante et. al, 2003; Pimentel et. al, 2003], que permite criar sessões, inclusive com reuso de materiais previamente existentes.

O AutorE (Sistema de Autoria Evolucionário ${ }^{7}$ ) é um sistema aberto, estruturado, baseado em padrões XMI e utiliza a plataforma JavaServer Pages (JSP). Possui uma arquitetura simples, modular c com uma camada de acesso independente de dispositivos, que permite funcionalidades como a preparação, referência e expansão de sessões de autoria cm informação multimídia. O sistema permite: a) relacionar porções de uma sessão capturada com sessões anteriores; b) preparar uma nova sessão a partir de dados utilizados na preparação e/ou capturados em outras sessões; e c) criar novos documentos associados a sessões a partir de documentos já existentes [Sante ct. al, 2003].

No contexto de aplicações de captura e acesso, pode-se dizer que o AutorE é responsável pela fase de pré-produção (no caso, a preparação das aulas no ambiente i(lass) c

"Por evolucionário, Pimentel et. al [2001] referem-se à necessidade de integrar documentos capturados ou sessões diferentes porém relacionadas, e que se realizem periodicamente. 
pós-produção (extensão das aulas capturadas, no sentido de reutilizar slides já utilizados em outras aulas). Ou seja, no ambiente iClass por exemplo, o professor poderia utilizar o AutorE para criar uma nova aula de Hipermídia, utilizando para isso alguns slides que já tenham sido capturados no semestre anterior, adicionando também novos slides. Também seria possivel relacionar a aula dada à outra aula do semestre anterior, criando uma referência de forma a complementar o entendimento da aula. A Figura 4.1 apresenta uma tela típica do módulo de preparação do AutorE, utilizada para a escolha de material para reuso.

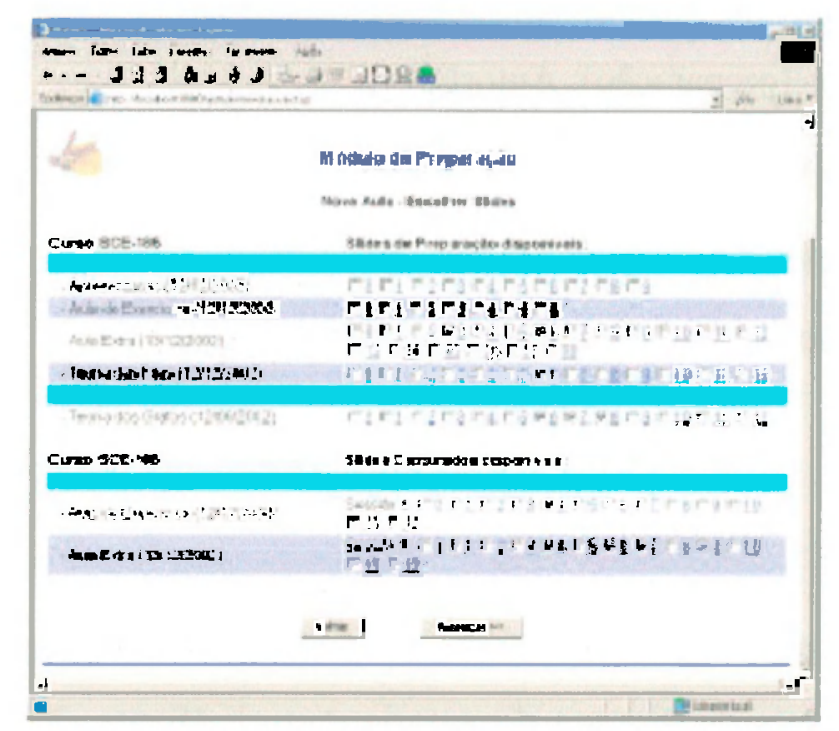

Figura 4.1: Tela do Módulo de Preparação do AutorE [Sante, 2003].

\section{4 iClass}

Com a introdução de novas técnicas de ensino em sala de aula, por exemplo, apresentações multimídia, os estudantes passaram a receber uma carga de informação cada vez maior. Para tentar processar todas as informações, o estudante precisa fazer diversas anotações, perdendo a oportunidade de discutir e prestar mais atenção à aula. Liberar o estudante da necessidade de realizar essas anotações foi o principal objetivo que motivou o desenvolvimento do projeto eClass, também chamado de Classroom 2000 [Abowd, 1999b].

O projeto Classroom 2000 foi desenvolvido no Georgia Institute of Technology. O projeto começou em julho de 1995 com a intenção de produzir um sistema capaz de fazer a captura automática de uma experiência ao vivo (uma aula com material multimídia), facilitando o acesso posterior a esses dados pelos estudantes e professores através da Web. 
Após preparar uma sessão de captura, pode-se iniciar a aula. Para a captura do material, o sistema utiliza uma sala de aula equipada com microfones, câmeras de vídeo, projetores e uma lousa eletrônica sensível ao toque que, conectada a um computador, permite armazenar as interações do usuário com a tela como escrita, desenho ou um clique em um botão. A Figura 4.2 ilustra uma sala de aula para a captura de aulas presenciais [Abowd, 1999b].

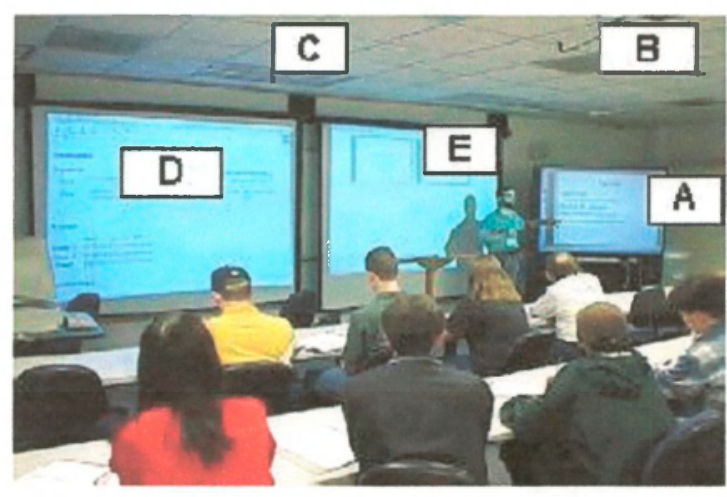

Figura 4.2: A sala de aula do Projeto Classroom 2000 é equipada para capturar informação apresentada na lousa eletrônica (A), capturar o ambiente através de uma câmera de video situada no fundo da sala (B), capturar áudio produzido pelo apresentador e pelos alunos através de microfones instalados no teto da sala (C) e capturar interações com navegadores Web (D). A tela central (E) é utilizada para exibir slides apresentados anteriormente [Abowd, 1999b].

Para gerar a interface de acesso Web ao material capturado, um conjunto de aplicações cliente-servidor é responsável pela integração e sincronização dos vários fluxos de informação capturados tendo como resultado um conjunto de hiperdocumentos. Cada aula é gravada como um único fluxo de áudio ou vídeo, e a interface de acesso disponibiliza diferentes formas para indexação das informações gravadas no decorrer da sessão.

O sistema iClass [Cattelan et al., 2003a; Cattelan et al., 2003c] é uma nova versão do sistema eClass, que vem sendo utilizado no ICMC $^{10}$ desde o 20 semestre de 2002 para captura de aulas. O sistema também foi implantado no GATech e nas Faculdades COC de Ribeirão Preto em 2003. A Figura 4.3 ilustra a sala de aula equipada com lousa eletrônica, projetor e computador em rede.

A captura e o armazenamento das sessões são fornecidas pelas infra-estruturas e serviços providos pelo projeto InCA-SERVE, onde a captura se dá com os componentes xINCA [Cattelan, 2004], por meio da infraestrutura INCA [Truong \& Abowd, 2002] [Truong \& Abowd, 2004] e o armazenamento ocorre com os módulos do serviço StRES [Baldochi et. 
al., 2003; Baldochi et. al., 2004]. A aplicação permite o posterior acesso ao material multimídia capturado no formato de hiperdocumentos Web [Andrade et. al, 2004a; Andrade et. al, 2004b; Ribas, 2004], construídas em XML para apresentar a aula capturada.

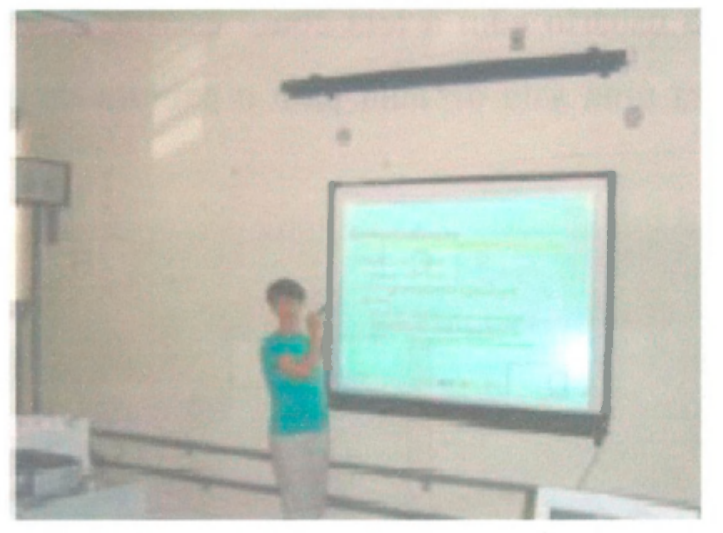

Figura 4.3: Sala instrumentada com lousa eletrônica

No iClass, o documento XML de sessão é estruturado como ilustrado no código XML da Figura 4.4, onde o elemento raiz session possui o atributo id que identifica a sessão e seus filhos podem ser divididos em elemento de contexto (context_info) e elementos referentes a outros componentes.

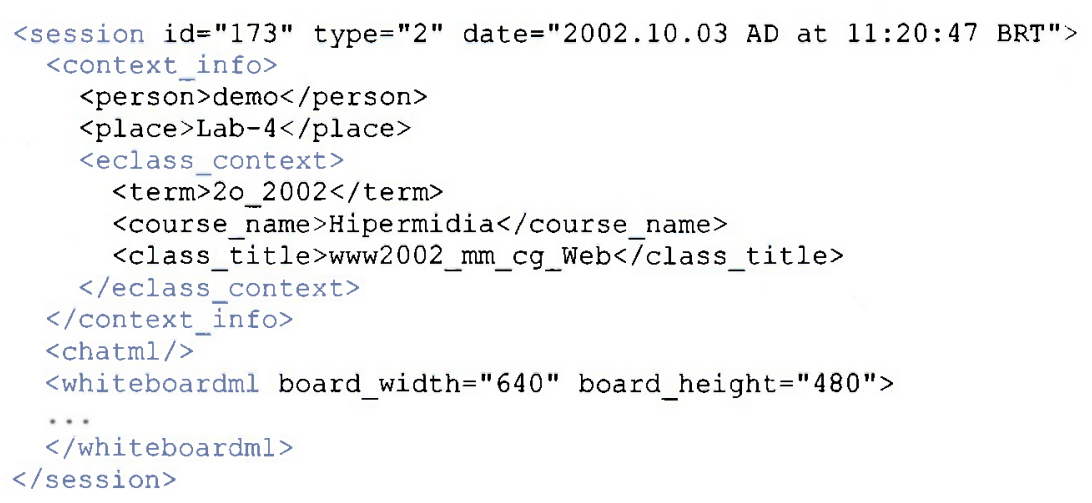

Figura 4.4: Fragmento XML descrevendo um documento de sessão do iClass

O documento XML da sessão é gerado após a captura, sendo armazenado no banco de dados XML nativo eXist ${ }^{11}$, passando antes por um processamento com três folhas de estilo XSLT que geram documentos SMIL, HTML e uma animação da aula mostrado num applet Java, possibilitando a visualização dos documentos em três opções. A Figura 4.5 exibe exemplo de documentos gerados para uma mesma sessão. $\mathrm{O}$ documento de apresentação em

${ }^{10}$ http://iclass.icmc.usp.br/

${ }^{\prime \prime}$ http://exist-db.org 
SMIL (Figura 4.5a) apresentam os slides e uma linha de tempo referindo-se a uma visita à um slide, enquanto que o documento em HTML (Figura 4.5b) possibilita a visualização de todos os slides em uma única página.

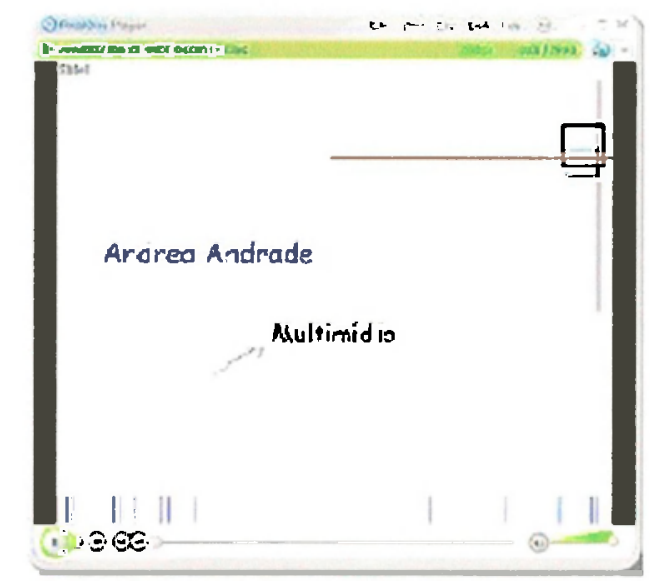

(a)

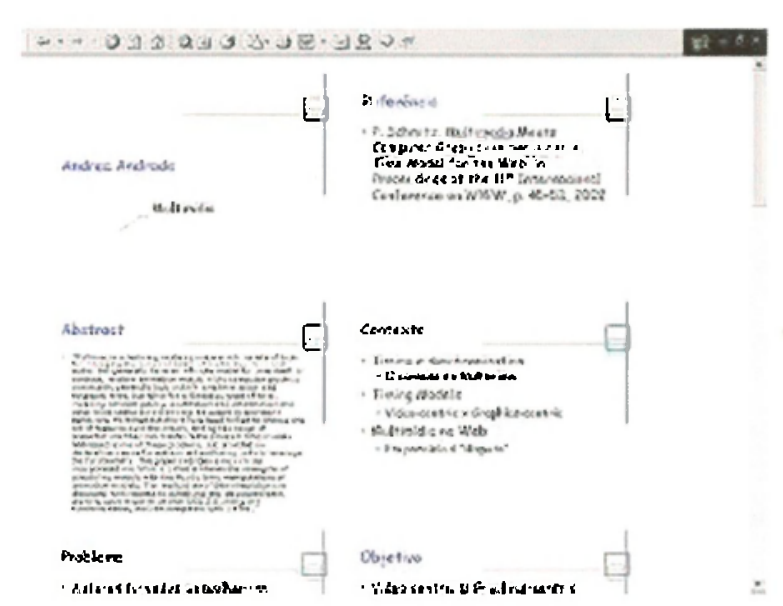

(b)

Figura 4.5: Documentos de apresentação do iClass: (a) Interface em SMIL, (b) Interface em HTML.

Para permitir a navegação referente aos documentos de apresentação gerados, foi implementada uma aplicação Web com a linguagem eXtensible Server Pages $(\mathrm{XSP})^{\mathrm{i} \hat{\iota}}$ do framework Apache Cocoon ${ }^{13}$ que faz consultas aos documentos de sessão armazenados [Ribas, 2004]. Essa aplicação Web permite a navegação entre os documentos de apresentação por meio de estruturas de acesso, como um índice de semestres, anos, disciplinas e um índice de aulas para uma dada disciplina. Na Figura 4.6a é mostrado o índice de disciplina e na Figura 4.6b o índice de aulas de uma disciplina.

Com relação à informação de contexto, o iClass utiliza:

- Dados do usuário: login e senha;

- Identificador de cada aulae: $i d$, título e curso;

- Localização: nome da sala de aula;

- Tipo dos objetos capturados: slides e escrita, áudio, login da Web;

- Tempo: criação de dados da sessão, período (semestre e ano) da disciplina e duração do tempo de cada visita a cada slide.

\footnotetext{
l" http://cocoon.apache.org/2.1/userdocs/xsp/index.html

${ }^{3}$ http://cocoon.apache.org/
} 


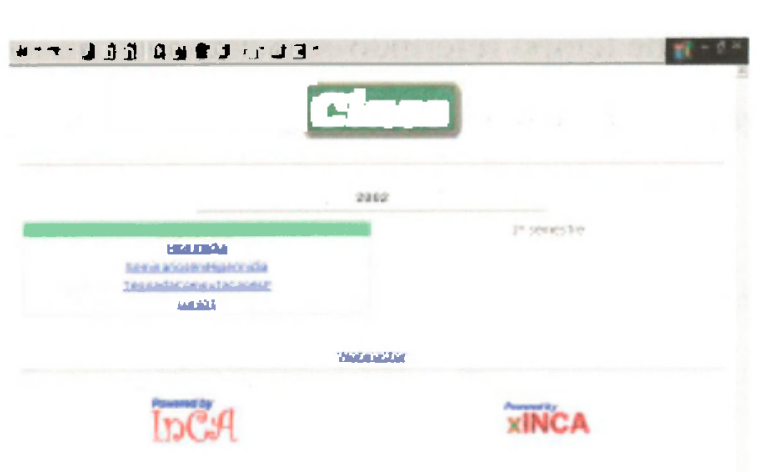

(a)

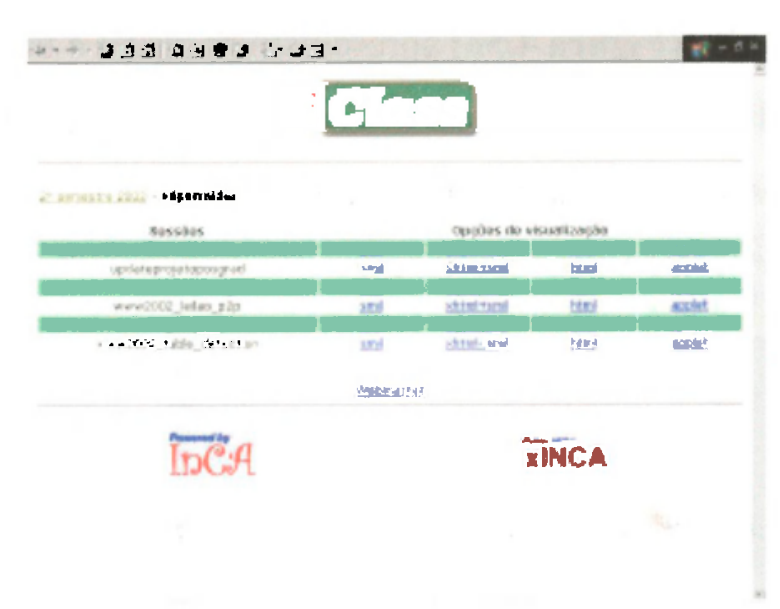

(b)

Figura 4.6: Navegação dos documentos de apresentação do iClass. (a) Indice de disciplinas. (b) Indice de aulas para uma disciplina.

\subsection{Context Kernel}

O Context Kernel [Arruda Jr. et al, 2003] é um Web Service que permite a aplicações manipular informações de contexto com base nas dimensões who (identificação), where (localização), when (localização temporal), what (atividade), why (motivação) e how (modo de captura e acesso) discutidas anteriormente no Capítulo 2.

Web Services [Stal et al., 2002] por sua vez, utilizam a infra-estrutura da Internet para prover comunicação transparente a aplicações e não dependem das diferenças da tecnologia de rede, dispositivos, sistemas operacionais e linguagens de programação. Web Services são baseados no protocolo HTTP e especificações baseadas no código aberto XML, como o SOAP (Simple Object Access Protocol) e WSDL (Web Service Descripition Language) [W3C, 2002].

A arquitetura básica de Web Services inclui tecnologias capazes de trocar mensagens e descrever serviços. Para a troca de mensagens, o Web Service pode usar o protocolo SOAP, que é simples e extensível. O protocolo SOAP define uma sintaxe baseada em XML, a semântica e a ordem das mensagens trocadas entre as aplicações e serviços, além de usar o HTTP como protocolo de comunicação. Um Web Service ainda pode tomar vantagem da especificação WSDL para definir a interface do serviço. 
Renata Paciência Godoy - Dissertação de Mestrado - Pós-Graduação - ICMC/USP - São Carlos

O Context Kernel possui um núcleo de operações que permite a comunicação transparente entre aplicações por meio de ambientes altamente heterogêneos em termos de hardware e software, fornecendo um conjunto básico de operações para armazenamento, processamento e recuperação de informações de contexto.

A manipulação de informações de contexto feita pelo Context Kernel se dá através da formalização, em XML, de um conjunto de operações associadas a essas dimensões. O Context Kernel classifica essas dimensões da seguinte forma:

- who, where, when e how são dimensões primitivas, pois podem ser armazenadas $\mathrm{e}$ recuperadas independentemente de outras dimensões;

- what e why são dimensões derivadas, pois são obtidas através do relacionamento com outras dimensões, primitivas ou derivadas.

\subsubsection{Modelo de armazenamento}

O Context Kernel armazena dimensões primitivas em uma tripla composta por type, value e um opcional qualifier. Por exemplo, a dimensão when pode ser representada por (type $=$ date, value $=2004-11-15$ 10:25:00, qualifier $=$ datetime .

Uma dimensão derivada é definida através de uma regra (rule) que contém pelo menos uma premissa (premise) e uma inferência (inference). Premissa é uma quádrupla contendo dimension, type, value e um opcional qualifier, como $($ dimension $=$ where, type - latitude, value $=22$ ). Inferência é um par contendo dimension e value, como (dimension $=$ what, value $=$ Campinas $)$. As premissas e as inferências podem conter informações de contexto e dimensões primitivas ou derivadas e as regras são inferidas pelas aplicações e armazenadas no Context Kernel para consultas.

Além disso, as regras são agrupadas em elementos XML denominados schemas e um contexto pode conter dimensões primitivas e esquemas. A Figura 4.7 apresenta um fragmento do vocabulário XML definido pelo Context Kernel. 


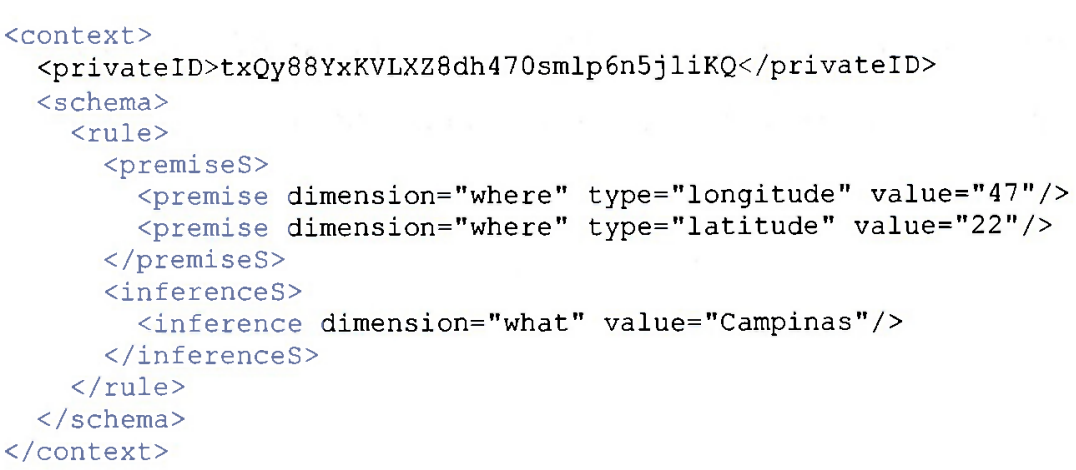

Figura 4.7: Esquema XML [Arruda Jr. et al., 2003].

\subsubsection{Métodos suportados}

O Context Kernel oferece três categorias de métodos: registro, armazenamento, consulta e recuperação. Eles são chamados pelas aplicações usando o protocolo SOAP encapsulando mensagens baseadas em XML.

Uma aplicação chama o método InfoApp () para se registrar como usuário do Context Kernel. A aplicação registra seu conjunto de metadados como: nome, uma descrição, seu endereço na Web, o número e data da sua última versão, o domínio (comercial, acadêmico, demonstração, gratuito ou versão para avaliação) e o endereço eletrônico dos seus desenvolvedores. O fragmento XML da Figura 4.8 descreve as informações da aplicação iClass [Cattelan et al., 2003a; Cattelan et al., 2003c] que devem ser enviadas ao método InfoApp ().

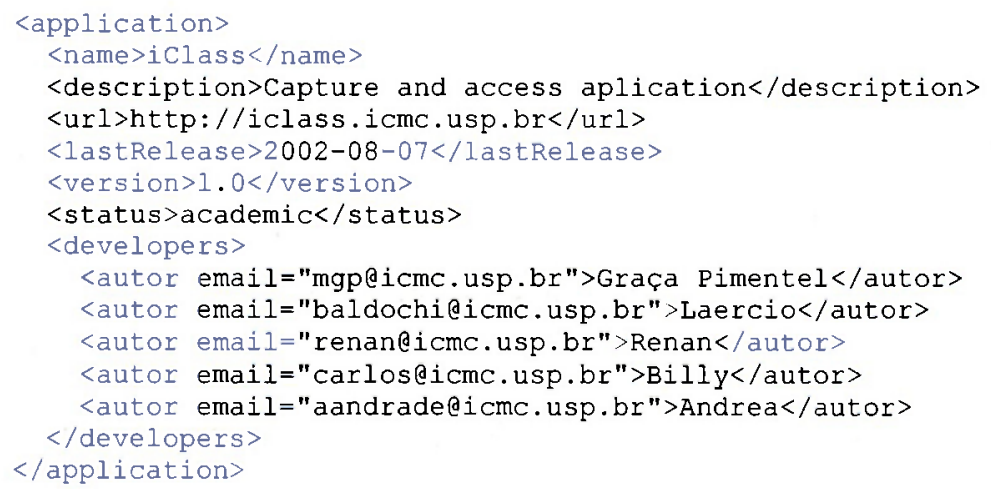

Figura 4.8: Fragmento XML descrevendo as informações da aplicação iClass.

Se as informações forem válidas, a aplicação é registrada e recebe dois identificadores, um público e um privado. O primeiro é usado para armazenar a informação de contexto e o segundo pode ser utilizado por outras aplicações quaisquer para acessar 
informações de contexto do Context Kernel. O fragmento XML da Figura 4.9 mostra uma mensagem de registro bem sucedido recebido pela aplicação.

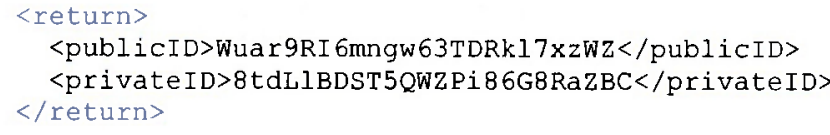

Figura 4.9: Fragmento XML recebido pela aplicação resultante de sua aquisição de registro.

O Context Kernel permite que aplicações possam armazenar informações primitivas e regras de contexto. O método PutData () permite a uma aplicação armazenar informações de contexto relativas às dimensões primitivas, enviando suas informações de contexto na forma de quádruplas "dimensão-tipo-valor-qualificador". No fragmento XML da Figura 4.10, a aplicação chama o método PutData() para armazenar "o usuário chamada Renata estava no Intermídia às 10 horas no dia 02 de março de 2005 ".

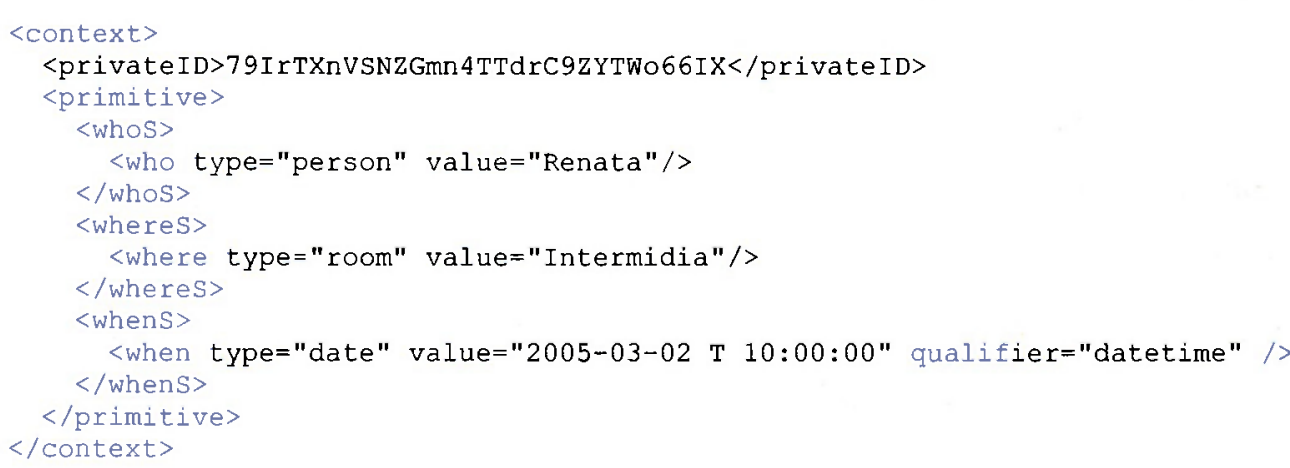

Figura 4.10: Fragmento XML com as informações de contexto a serem armazenadas no Context Kernel através do método PutData () [Arruda Jr. et al., 2003]

O método PutRules() permite o armazenamento de regras de contexto (informações de contexto relativo às dimensões primitivas e derivadas). $\mathrm{O}$ método requer que aplicações enviem um ou mais dados primitivos que fazem parte da premissa, ou um ou mais dados derivados que fazem parte da inferência da regra. No fragmento XML da Figura 4.11, uma aplicação está armazenando a seguinte regra: "a pessoa chamada Renata está na sala 3-009 todas as quartas-feiras assistindo a Seminários". A aplicação pode associar a expiração da data para suas regras; neste caso a regra é válida somente para o primeiro semestre de 2005. Quando a validade da data da regra acaba, ela continuará armazenada no servidor, e pode ser utilizado apenas para consultas. 


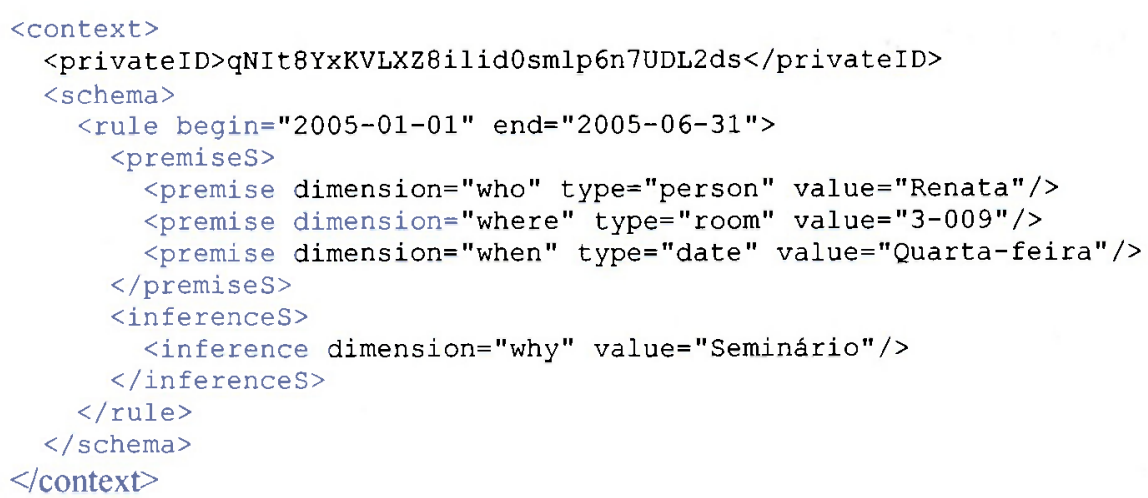

Figura 4.11: Fragmento XML que descreve uma regra de contexto a ser armazenadas no Context Kernel através do método Put Rules () [Arruda.Jr. et al., 2003]

Em relação a consultas, o Context Kernel torna disponível o método GetAny (), permitindo que aplicações recuperem informações de contexto baseadas no valor de premissas e inferências associadas às dimensões primitivas e derivadas. Com isso, é possível especificar respostas baseadas nas dimensões dessas premissas ou inferências. Uma consulta requer o identificador público da aplicação e uma especificação XML de consulta baseada nos operadores booleanos AND e OR. A aplicação ainda pode especificar o número máximo de respostas e quais as dimensões de resposta. No fragmento XML da Figura 4.12, uma aplicação quer saber "qual foi a última atividade que uma pessoa chamada Renata fez no Intermidia no dia 21 de Fevereiro de 2005".

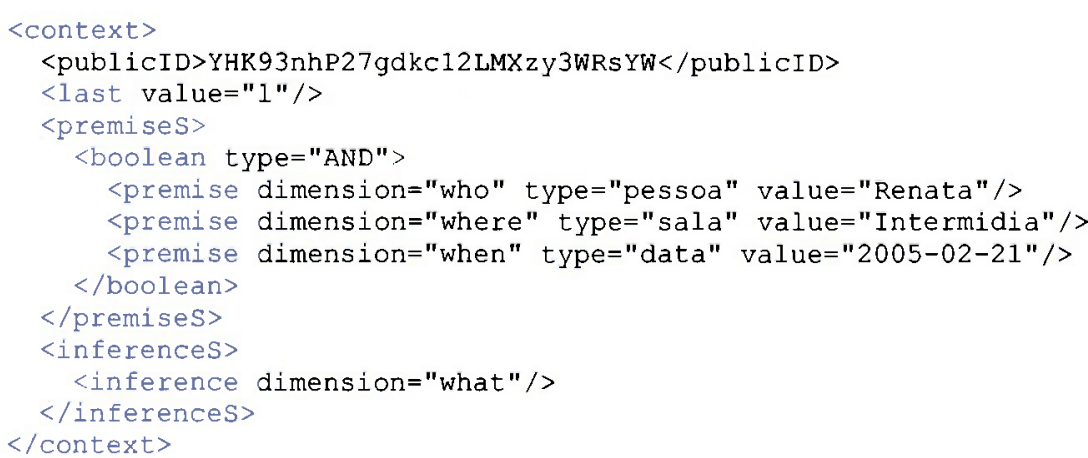

Figura 4.12: Fragmento XML que descreve uma consulta ao Context Kernel, , através do método GetAny () [Arruda Jr. et al., 2003].

O fragmento XML da Figura 4.13 mostra um possível retorno para a consulta da Figura 4.12.

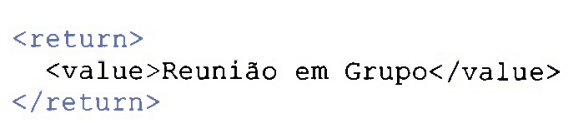

Figura 4.13: Fragmento XML que descreve uma possível reposta à consulta ao Context Kernel. 


\subsection{A aplicação CoTeia}

A CoTeia ${ }^{14}$ é uma ferramenta de hipermídia colaborativa para edição de páginas Web [Arruda Jr et al. 2002; Arruda Jr. \& Pimentel, 2001], que é uma evolução da Coweb. Esta por sua vez, foi usada como ferramenta colaborativa de apoio ao ensino por vários cursos no ano $2000 \mathrm{em}$ nosso instituto. Apoio esse, como: repositório de documentos para futuras pesquisas, escrita de artigos entre professores e alunos, páginas de disciplinas e projetos da graduação e pósgraduação para agendar reuniões de grupos e acompanhamento das atividades e aulas.

Através da utilização da Coweb pelos usuários, Macedo et al. [2001] identificaram algumas limitações na infra-estrutura, como a falta de controle de acesso, deficiência no controle de concorrência, a inexistência do reuso das informações e limitações de recursos de navegação. Sendo assim, foi criada uma nova ferramenta, denominada CoTeia [Arruda Jr \& Pimentel 2001] mantendo as características da ferramenta anterior, mas tentando suprir as deficiências encontradas.

A CoTeia é de fácil manuseio, pois o usuário edita as páginas no próprio navegador, sem precisar saber a linguagem de marcação, além das páginas não terem uma estrutura prédefinida. A Figura 4.14 apresenta uma edição de página na ferramenta CoTeia.

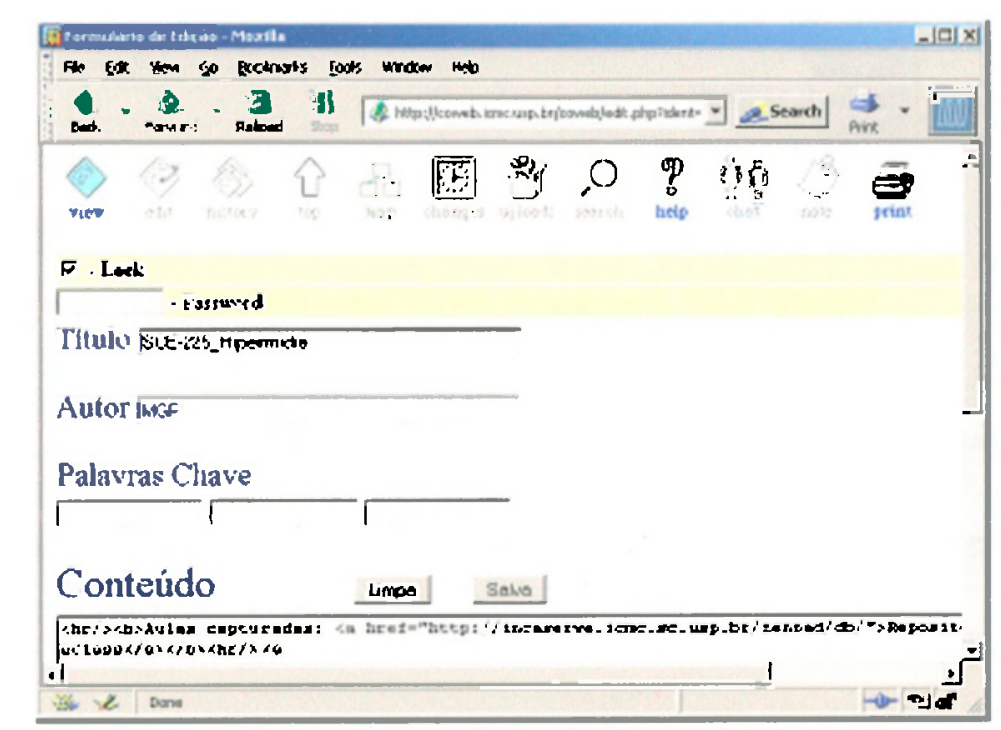

Figura 4.14: Edição de página na ferramenta CoTeia.

\footnotetext{
${ }^{14}$ http:// coweb.icmc.usp.br
} 
A ferramenta disponibiliza funcionalidades como:

- login, permitindo privilégios exclusivos ao administrador;

- help, para auxílio dos usuários;

- recent changes, identificando as últimas páginas modificadas;

- search, possibilitando a pesquisa por hiperdocumentos específicos;

- uploads / downloads de arquivos e anotações, permitindo uma colaboração ativa dos usuários;

- chats.

A Figura 4.15 mostra a navegação na ferramenta CoTeia.

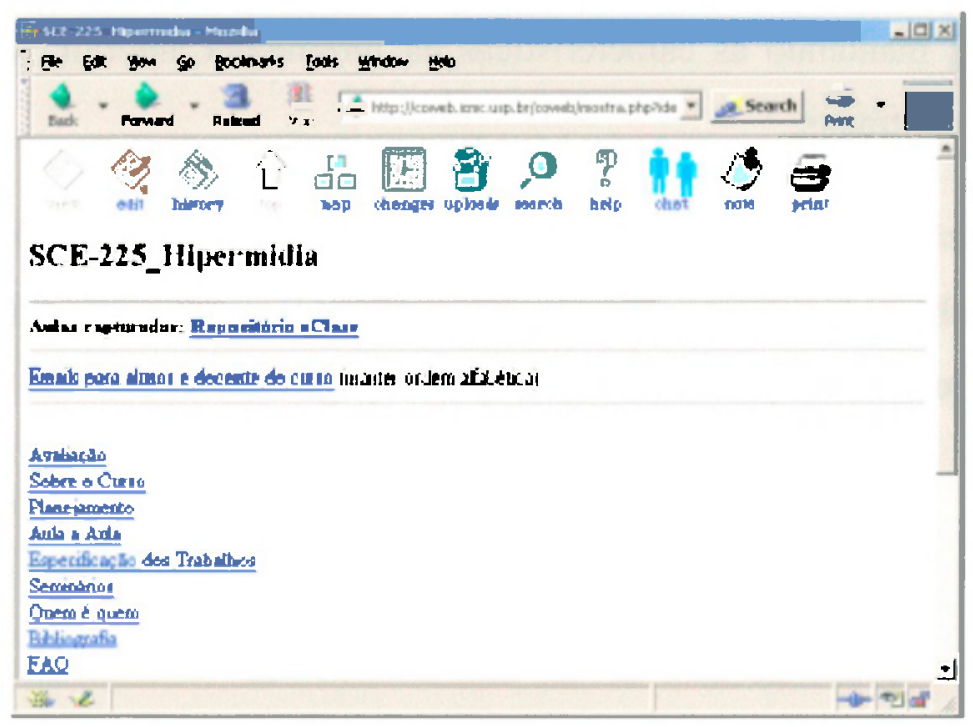

Figura 4.15: Navegação na ferramenta CoTeia.

Com relação à informação de contexto, a CoTeia utiliza:

- Dados do usuário: login, senha, e-mail, preferências e permissões;

- Identificador de páginas $W e b$ : identificador numérico e URI;

- Localização através do IP: computador remoto do usuário e servidor;

- Tempo: login e logout. 
Renata Paciência Godoy - Dissertação de Mestrado - Pós-Graduação-ICMC/USP - São Carlos

\subsection{Considerações Finais}

Este capítulo apresentou alguns serviços, especificando o projeto InCA-SERVE, que provê alguns serviços, como o Context Kernel e o iClass. Porém, o iClass não se preocupou para sua evolução e possível reuso em outros domínios. Nesse sentido, percebeu-se a necessidade de criar uma maneira de poder reusar essas informações, para que pudessem promover integração e troca de informação entre sistemas $W e b$.

Para exemplificar essa proposta, o trabalho envolveu a associação de metadados ao sistema iClass, fazendo uso de informações de contexto obtidas do Context Kernel. Sendo assim, o próximo capitulo mostra a importância do reuso dessas informações, incorporando metadados e transformando-as $\mathrm{em}$ objetos de aprendizagem. 


\section{Metadados e Objetos de Aprendizagem}

\subsection{Considerações Iniciais}

A Internet é uma inovação, e depois de mudar a maneira com que as pessoas se comunicam e fazem negócios, agora é a vez da mudança de paradigma na maneira em que as pessoas aprendem. Conseqüentemente, a mudança maior também pode estar vindo à maneira que materiais educacionais são projetados, desenvolvidos e entregues para aqueles que desejam aprender [Wiley, 2000].

A idéia de utilizar metadados surgiu no desenvolvimento de sistemas de informação para facilitar a descrição e descoberta de informação, que descrevem o conteúdo, gerenciamento, contexto e preservação dos dados [Böhm \& Rakow, 1994; Kashyap el al., 1995; Moura et al., 1998; Gilliland-Swetland 2000]. Para que esses metadados possam ser reusados em diferentes contextos, surgiram os objetos de aprendizagem.

O SCORM (Sharable Content Object Reference Model) é um modelo de conteúdo de objetos de aprendizagem, visando favorecer a criação de conteúdo de aprendizagem reutilizável como "objetos instrucionais" dentro de um framework para aprendizado baseado na Web. 


\subsection{Metadados}

O conceito de metadados tem um papel importante, não só porque permite uma descrição dos recursos disponíveis, mas também porque apóia uma variedade de funções que aqueles usuários esperam receber dos mecanismos de procura, como: localização, avaliação, seleção e recuperação dos dados [Moura et al., 1998].

\subsubsection{Definição de Metadados}

Metadados é um termo ubíquo que é compreendido de diferentes maneiras pelas diversas comunidades profissionais que projetam, criam, descrevem, preservam e usam sistemas de informação e recursos. Segundo Gilliland-Swetland [2000], uma maneira de se pensar em metadados é "a soma total do que uma pessoa pode dizer sobre qualquer objeto de informação cm qualquer nível de agregação". Nesse contexto, um objeto de informação é qualquer coisa que possa ser endereçada e manipulada por uma pessoa ou um sistema como uma entidade. $O$ objeto pode ser incluído como um único recurso ou pode ser um agregado de muitos recursos.

Em geral, todos os objetos de informações têm características que podem ser refletidas pelos metadados. São elas:

- Conteúdo: relacionado ao conteúdo ou característica do objeto;

- Contexto: indica características como: quem, o que, porque, aonde e como; são associados com a criação do objeto e não são essenciais ao objeto de informação;

- Estrutura: relacionada com a formalidade do conjunto de associações dentro ou entre os objetos de informação individuais e pode ser necessário ou não ao objeto de informação.

Em um ambiente onde um usuário pode ter acesso imediato a objetos de informação. metadados: certificam a autenticidade e o grau de perfeição do conteúdo; estabelecem e documentam o contexto do conteúdo (como aquele objeto se comporta, sua função e uso); identificam e exploram as relações estruturais que existem entre e dentro de objetos de informação; sua relação com outros objetos de informações e como deveria ser gerenciado. 
Renata Paciência Godoy - Dissertação de Mestrado - Pós-Graduação-ICMC/USP - São Carlos

A seguir, são descritas as principais classificações de metadados encontradas na literatura, mostrando a diversidade de categorias e evidenciando a abrangência dos aspectos que podem ser representados através dos metadados.

\subsubsection{Categorias de Metadados}

O uso de metadados é o principal fator para promover integração e troca de informação entre os recursos da Web. Fsta integração por sua vez, exige um mecanismo para representar informação semântica que suporta o relacionamento entre tipos de informação.

Algumas classificações de metadados têm sido apresentadas na literatura, como por exemplo, [Böhm \& Rakow. 1994] [Kashyap et al., 1995] [Moura et al., 1998] [GillilandSwetland, 2000$] \mathrm{j}$ com base em como metadados são obtidos ou na descrição de características funcionais. Issas classificações são importantes para entender e definir a natureza e a extensão dos metadados.

Kashyap et al. [1995] apresentam uma classificação baseada na natureza dos metadados em relação ao seu conteúdo, tipo de mídia ou recurso de informação. Nessa classificação são identificados três tipos de metadados, categorizados como:

- Metadados dependente de conteúdo: dependem somente do conteúdo do recurso, podendo ser extraídos automaticamente desse conteúdo;

- Metadados descritivo de conteúdo: associam termos descritivos com o conteúdo do recurso, mas não podem ser gerados automaticamente somente a partir do conteúdo;

- Metadados independente de conteúdo: não dependem do conteúdo do recurso, mas estão associados a ele.

Outra classilicação baseada nas características funcionais dos elementos de metadados é sugerida por Böhm \& Rakow [1994], que focam o uso de metadados no contexto de documentos multimidia. Seis categorias funcionais são identificadas:

- Metadados para representação de tipos de mídia: apresentam informações para representar dados multimidia, como linguagem, formato, codificação e técnicas de compressão; 
Renata Paciencia Godoy - Dissertação de Mestrado Pós-(Graduação . ICMC/USP - São Carlos

- Metadados descritivo de conteúdo: são usados para descrever o conteúdo de um documento multimídia e podem ser dependentes do tipo de mídia;

- Metadados para classificação de conteúdo: correspondem a informações adicionais que podem ser derivadas a partir do conteúdo do documento;

- Metadados para composição de documento: representam informações sobre os rclacionamentos entre os componentes do documento e o papel de cada componente no documento;

- Metadados para histórico de documento: provêem a informação que é relacionada ao histórico e ao status do documento:

- Metadados para localização de documento: permitem acesso aos dados multimídia.

Moura et al. [1998] apresentam uma classificação baseada nas características funcionais dos elementos de metadados, focando os tipos de componentes dos metadados. A categorização é feita em quatro grupos:

- Metadados para descoberta de recursos: representam o conjunto de termos necessários para descobrir e identificar recursos de informação na Web, como por exemplo, metadados para descrição de bibliografia, identificação única dos recursos, descrição do relacionamento dos recursos, entre outros.

- Metadados para disponibilidade de recursos: definem os termos e condições necessárias para o acesso e recuperação de recursos, sem considerar se a maneira é restrita ou irrestrita, como por exemplo, metadados para distribuição dos recursos, termos e condições para acesso e uso aos recursos, entre outros.

- Metadados para uso de recursos: são informações adicionais para permitir o uso adequado do recurso, como por exemplo, metadados para classificação do conteúdo dos recursos, descrição da qualidade dos recursos, entre outros.

- Metadados para administração e controle de recursos: provêem informaçôes para controlar e rastrear informações sobre o próprio recurso e sobre seus metadados, como por exemplo, metadados para controle de modificação dos recursos, histórico de uso dos recursos, entre outros. 
Renata Paciência Godoy - Dissertação de Mestrado - Pós-Graduação-ICMC/USP - São Carlos

Outra classificação baseada nas características funcionais dos elementos de metadados é sugerida por Gilliland-Swetland [2000]. As categorias dessa classificação são: a) Metadados administrativos, utilizados no gerenciamento e administração de recursos de informação; b) Metadados descritivos, usados para descrever ou identificar recursos de informação; c) Metadados de preservação, relacionados ao gerenciamento da preservação de recursos de informação; d) Metadados técnicos, relacionados ao funcionamento ou comportamento de um sistema; e e) Metadados de uso, relacionados ao nivel e ao tipo do uso de recursos de informação.

\subsubsection{Padrão de MetaDados}

Na literatura são encontrados vários esquemas de metadados, como o Dublin Core [DCMI 2003b] [ISO 2003], LOM [IEEE LISC 2002], MARC 21, Global Information Locator Service (GILS), Content Standard for Digital Geospatial Metadata (CSDGM), MPEG-7 o Categories for the Description of Works of Art (CDWA).

Esquemas como esses envolvem diversos esforços de padronização de vários grupos, cujo objetivo é a definição de conjuntos de atributos para descrever objetos de informação Esses esquemas também definem formatos apropriados para facilitar o intercâmbio de metadados entre as aplicações. Nesta Seção são detalhados apenas os dois primeiros. O Dublin Core é um padrão muito adotado para descrever recursos da Web; e o LOM é um dos resultados do trabalho colaborativo de diversas organizações envolvidas na definição de metadados para recursos de aprendizagem, e portanto de particular interesse para o trabalho reportado neste texto.

\subsubsection{DUBLIN Core}

O padrão de metadados Dublin Core (DC) [ISO, 2003] [DCMl, 2003b] é um simples conjunto de elementos para descrever a grande variedade de recursos de informações encontrados na Web, mantido pela Dublin Core Metadata Initiative (DCMI). No padrão Dublin Core, as descrições podem ser representadas em qualquer linguagem de codificação, como HTML, RDF/XML e XML. 
Renata Paciência Godoy - Dissertação de Mestrado-Pós-Graduação - ICMC/USP - São Carlos

O padrão Dublin Core inclui dois níveis: simples e qualificado. O primeiro é composto de quinze elementos e o nível qualificado inclui um elemento denominado "audience" e um grupo de elementos de refinamento para os elementos do nível simples [Hillmann, 2003]. Na Tabela 5.1 são listados o conjunto dos elementos do Dublin Core. Cada elemento é opcional e pode ser repetido; não há ordem predefinida para uso desses elementos.

\begin{tabular}{|c|c|c|}
\hline Nível & Elemento & Descrição \\
\hline \multirow{15}{*}{ Simples } & Title & O nome atribuído ao recurso. \\
\hline & Subject & O tópico ou tema do conteúdo do recurso. \\
\hline & Description & Uma descrição do conteúdo do recurso. \\
\hline & Type & A natureza ou gênero do conteúdo do recurso. \\
\hline & Source & Uma referência ao recurso de origem do recurso atual. \\
\hline & Relation & Uma referência a um recurso relacionado. \\
\hline & Coverage & $\begin{array}{l}\text { A extensão ou escopo do conteúdo do recurso, geralmente espacial } \\
\text { ou temporal. }\end{array}$ \\
\hline & Creator & Uma entidade responsável pela criação do conteúdo do recurso. \\
\hline & Publisher & Uma entidade por tornar o recurso disponível. \\
\hline & Contributor & $\begin{array}{l}\text { Uma entidade responsável por contribuir na criação do conteúdo do } \\
\text { recurso. }\end{array}$ \\
\hline & Rights & Informação sobre direitos mantidos sobre o recurso. \\
\hline & Date & Uma data associada a um evento no ciclo de vida do recurso. \\
\hline & Format & A materialização física ou digital do recurso. \\
\hline & Identifier & $\begin{array}{l}\text { Uma referência não ambigua ao recurso dentro de um determinado } \\
\text { contexto. }\end{array}$ \\
\hline & Language & Uma linguagem do conteúdo do recurso. \\
\hline Qualificado & Audience & Uma classe de entidades para a qual o recurso é útil ou destinado. \\
\hline
\end{tabular}

Tabela 5.1: Os elementos do padrão Dublin Core [DCMI. 2003a].

\subsubsection{LOM}

O IEEE Standard for Learning Object Metadata (LOM) [IEEE LTSC, 2002] é parte do padrão IEEE 1484 Learning Objects Metadata (IELE LOM), em desenvolvimento pelo IEEE Learning Technology Standards Committee (LTSC). O padrão LOM especifica um esquema conceitual de dados que define a estrutura de uma instância de metadados para um objeto de aprendizagem.

LOM tem um conjunto de atributos para que objetos de aprendizagem possam ser gerenciados, localizados c avaliados. Nesse conjunto, são incluídos atributos considerados importantes para descrever um objeto de aprendizagem (como autor, tipo e nome do objeto), e também os atributos para descrever seus aspectos educacionais (por exemplo, nível de dificuldade). Os atributos são divididos em nove categorias e classificados como elementos, que, juntos formam o LOMv1.0 Base Schema. A Tabela 5.2 mostra essa classificação. 


\begin{tabular}{|l|l|}
\hline General & Informações gerais que descrevem o objeto de aprendizagem como um todo. \\
\hline Life Cycle & $\begin{array}{l}\text { Caracteristicas relacionadas ao estado atual e ao histórico dos estados dos } \\
\text { objetos de aprendizagem e daqueles que fizeram parte na sua evolução. } \\
\text { Informações sobre a própria instância de metadados (não o objeto de } \\
\text { aprendizagem que a instância de metadados descreve). }\end{array}$ \\
\hline Technical & Requisitos e informações técnicas do objeto de aprendizagem. \\
\hline Educational & Características educacionais e pedagógicas do objeto de aprendizagem. \\
\hline Rights & $\begin{array}{l}\text { Informaçôes sobre os direitos de propriedade intelectual e as condições de } \\
\text { uso do objeto de aprendizagem }\end{array}$ \\
\hline Relation & $\begin{array}{l}\text { Características que especificam o relacionamento entre o objeto de } \\
\text { aprendizagem e outros objetos de aprendizagem relacionados. }\end{array}$ \\
\hline Annotation & $\begin{array}{l}\text { Comentários sobre o uso educacional do objeto de aprendizagem, além de } \\
\text { informação sobre quem e quando criou as anotações. }\end{array}$ \\
\hline Classification & $\begin{array}{l}\text { Descreve o objeto de aprendizagem em relação a um determinado sistema de } \\
\text { classificação. }\end{array}$ \\
\hline
\end{tabular}

Tabela 5.2: LOMv1.0 Base Schema /IEEE LTSC, 2002].

O modelo de dados do LOM é uma hierarquia de elementos de dados composta de elementos simples (os nós folhas da hierarquia) e elementos de agregação. Os elementos simples possuem valores, definidos por meio de um comjunto de valores e tipos de dados associados a esses elementos. Já os elementos de agregação não possuem valores. O conjunto de elementos do LOMv1.0 Base Schema pode ser estendido para satisfazer casos em que esses elementos não sejam adequados.

O IEEE LTSC está desenvolvendo um padrão para vincular o modelo de dados do IEEE LOM ao XML, isto é, especificar uma coleção de regras para a criação de instâncias de metadados codificadas em XML. [IEEE LTSC, 2004]. A Figura 5.1 exibe um exemplo do LOM codificada em XML, considerando-se apenas os elementos da categoria "General".

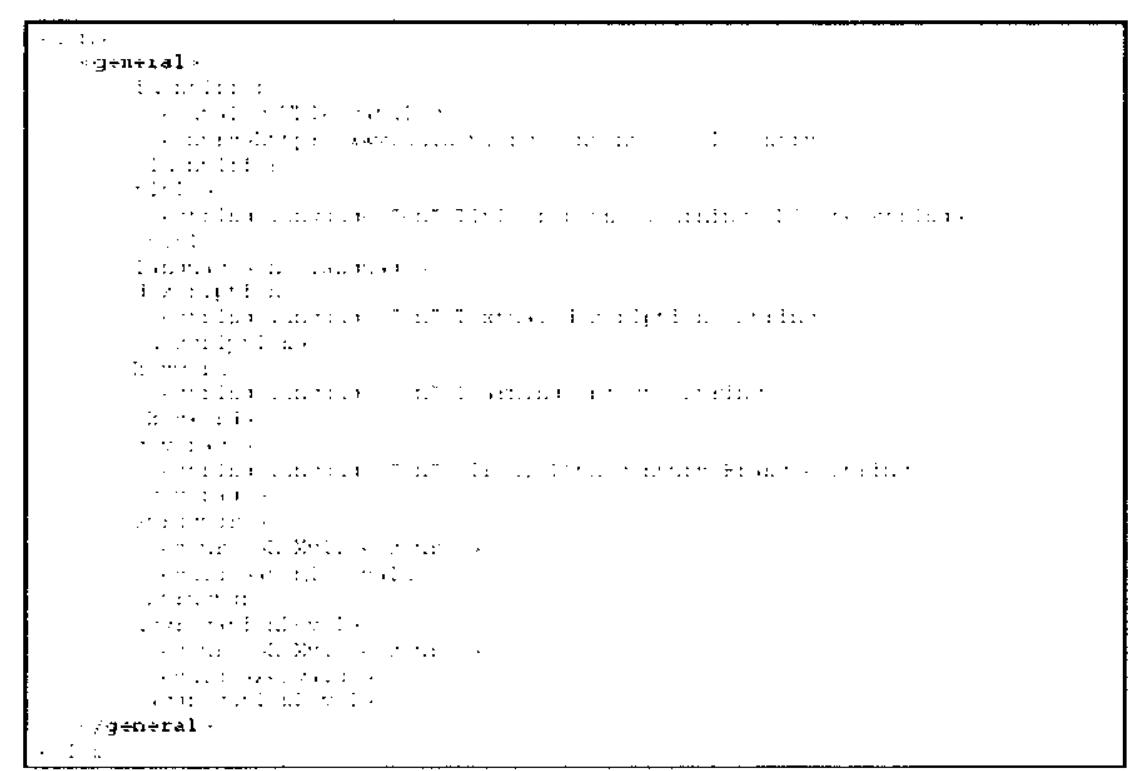

Figura 5.1: Exemplo de uma descrição LOM [SCORM, 2004]. 
Renata Paciencia Godoy Dissertação de Mestrado - Pós-Graduação- KMC/USP - São Carlos

\subsection{Objetos de Aprendizagem}

Objetos de aprendizagem são freqüentemente considerados como documentos tradicionais, no sentido de que é possível reutilizar um parágrafo ou uma oração de um documento por meio de simples cópia em outros documentos. Porém, é possível reusar o objeto de aprendizagem de uma maneira muito mais sofisticada se for possível reusar os componentes desses objetos [Duval \& Hodgins, 2003].

Dado que o foco de pesquisa e desenvolvimento de objetos de aprendizagem tem sido a maximização da reusabilidade, objetos de aprendizagem geralmente são entendidos como sendo recursos digitais, porque a maioria dos recursos não digitais pode ser usada por uma só pessoa de cada vez; ou seja, são "recursos competitivos" [Wiley, 2002]. Recursos digitais disponíveis em uma rede de computadores são "recursos não competitivos", pois podem ser utilizados simultaneamente por várias pessoas.

Como muitos objetos de aprendizagem não são textuais (como por exemplo, slides, animações ou vídeos), a sua localização $\mathrm{em}$ uma biblioteca digital pode ser uma tarefa difícil sem a ajuda de metadados. Wiley [2002] ainda reforça que metadados são recursos descritivos usados para indexar um recurso para descoberta posterior, como o autor do recurso, título e data de publicação.

\subsubsection{Definição de objetos de aprendizagem}

Objetos de aprendizagem são definidos como "qualquer entidade, digital ou não digital, que pode ser usada, reusada ou referenciada durante o aprendizado suportado pela tecnologia". Exemplos de objetos de aprendizagem incluem conteúdo multimídia, conteúdo instrutivo, objetivos de aprendizagem, software instrutivo e ferramentas de software, e as pessoas, organizações ou eventos referenciados durante a aprendizagem auxiliada pela tecnologia [IEEE LTSC, 2002].

Há várias definições de objetos de aprendizagem encontradas na literatura. Wiley [2000] definem objetos de aprendizagem como elementos de um novo tipo de instrução baseada em computador fundamentada no paradigma orientado a objeto da ciência da computação, onde os componentes podem ser reusados em múltiplos contextos. Dois anos 
depois, Wiley [2002] define objeto de aprendizagem como qualquer recurso digital que pode ser reusado para apoiar o aprendizado. O termo "objeto de aprendizagem" geralmente é aplicado a materiais educacionais projetados e criados em pequenas partes com a finalidade de maximizar o número de situações de aprendizado nas quais os recursos podem ser utilizados.

Ainda encontramos referências em que objetos de aprendizagem são definidos como a menor unidade de conteúdo capaz de ser reusado em diferentes cursos e contextos possiveis. Ip et.al [2002] definem objetos de aprendizagem como "um computador que entrega um módulo ou unidade, provendo uma experiência de aprendizagem significante em um contexto de aprendizagem planejado".

Ip et.al. [2001] discutem que uma distinção deveria ser feita entre "recursos de aprendizado" e "objetos de aprendizado" e que, para uma entidade digital se qualificar como um "objeto de aprendizado", é necessário mais do que somente anexar metadados de "objetos de aprendizado" à entidade digital - é necessário adquirir comportamento e ser adaptável.

Dois conceitos importantes em relação a objetos de aprendizagem são combinação e granularidade [Wiley, 2000]. Combinação refere-se à maneira em que os objetos são reunidos em estruturas maiores para facilitar a instrução, enquanto que granularidade refere-se ao "tamanho" do objeto de aprendizagem. O quão grande deve ser um objeto de aprendizagem é uma questão que sempre acontece, já que se o objeto for muito "grande", diminui a possibilidade de reusá-lo.

A comunidade de objetos de aprendizagem tem usado metáforas para explicar o conceito de objetos de aprendizagem. A mais conhecida é a metáfora do LEGO, que constrói blocos para descrever objetos de aprendizagem [Wiley, 2000]. As características são que os blocos são combináveis com qualquer outro; podem ser agregados da maneira que você escolher; além de serem tão divertidos e simples que mesmo as crianças podem os reunir.

O problema é que ela pode limitar a maneira de pensar das pessoas em relação aos objetos de aprendizagem. Wiley [2000] observou que uma combinação aleatória de objetos de aprendizagem podia não produzir necessariamente um material de curso instrucional e que nem todos os objetos de aprendizagem podiam ser combinados. Além disso, o modo nos quais objetos de aprendizagem podem ser combinados para facilitar o aprendizado são 
Renata Paciência Godoy - Disseriação de Mestrado - Pós-Graduação - KMC/USP - São Carlos

completamente dependentes de sua própria estrutura. Dessa maneira, os objetos de aprendizagem são semelhantes aos participantes de um processo de agrupamento molecular: cles só podem ser combinados com outros objetos de aprendizagem cuja estrutura é compatível com a deles [Wiley et al., 2000].

Sendo assim, Wiley [2000] introduziu a noção de "átomos" como uma metáfora, já que: a) nem todo átomo é combinável com outro; b) os átomos podem ser agrupados somente em estruturas descritas em sua estrutura interna; e c) algum treinamento é necessário para poder agrupar átomos. Com isso, nota-se que as diferenças são significantes e que o uso da metáfora do "átomo" é a mais oportuna.

\subsubsection{Modelos de Objetos de Aprendizagem}

Para contornar a variedade de granularidade, surgiram modelos de conteúdo de objetos de aprendizagem, que identificam tipos diferentes de objetos de aprendizagem e seus componentes. Eles provêem uma definição mais precisa do que são objetos de aprendizagem e nos permitem identificar seus componentes e propósitos [Duval \& Verbert, 2004].

Encontramos na literatura vários modelos de conteúdo de objetos de aprendizagem, como o Learnativity Content Model [Wagner, 2002], o Modelo de Agregação de Conteúdo SCORM [SCORM, 2004], o Modelo CISCO RI.O/RIO [Barrit \& Lewis, 2000] [CISCO, 2003] e o Modelo de objeto de aprendizagem NETg [L'Allier, 1995] [L'Allier, 1997], que serão apresentados a seguir.

\subsubsection{Learnativity Content Model}

Definir e entender objetos de aprendizagem é um desafio, pois eles precisam ser vistos dentro do contexto de um modelo conceitual que é baseado em uma hierarquia. Mostrando o relacionamento de construções de diferentes conteúdos, torna-se mais fácil a conceitualização de que elementos de conteúdo podem ser agupados, desmontados, c reagrupados.

O Learnativity Content Model [Wagner, 2002], mostrado na Figura 5.2 foi projetado para ajudar a visualizar como conteúdo pode ser organizado e mostra o relacionamento entre tipos e tamanhos variados de arquivos de dados que podem ser parte de qualquer objeto de aprendizagem ou aplicações de gerenciamento de conhecimento. 


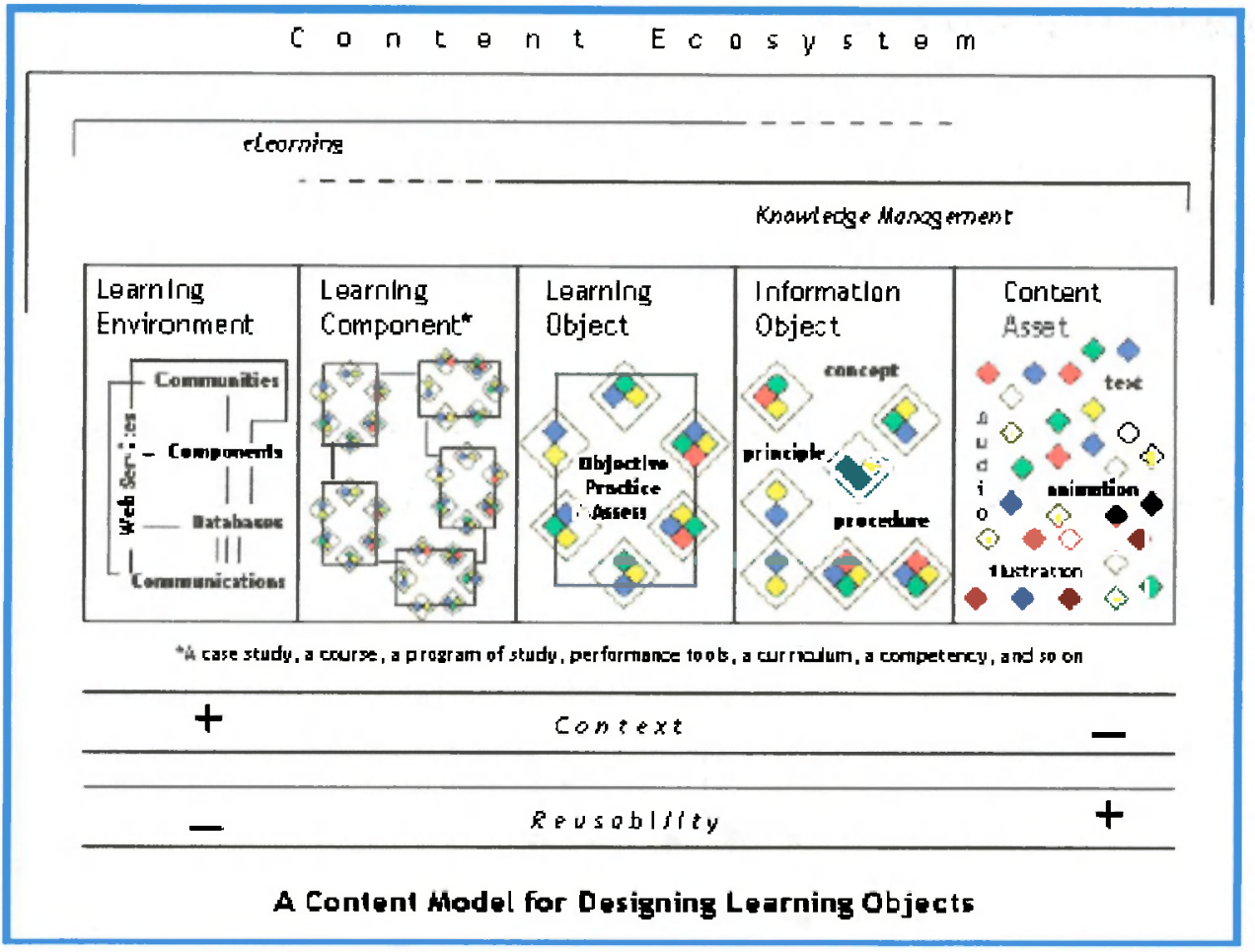

Figura 5.2: Learnativity Content Model [Wagner, 2002].

O modelo Learnativity Content Model apresenta a seguinte taxonomia:

- Content Assets: são arquivos mais granulares, ou seja, o menor nível do modelo. Incluem mídias como fotografias, ilustrações, arquivos de áudio e vídeo, entre outros;

- Objetos de informação: é o próximo nível do modelo, formado por um conjunto de Content Assets. São classificados como conceito, fato, processo, princípio, referência de comando, um exercício ou procedimento;

- Objetos de Aprendizagem: o terceiro nível do modelo, formado pela combinação de objetos de informação;

- Componentes de Aprendizagem: o quarto nível apresenta objetos de aprendizagem que podem ser sequenciados e agrupados para formar um objeto de aprendizagem maior, como lições e cursos;

- Ambientes de Aprendizagem: lições e cursos são agrupados em coleções maiores com funcionalidades adicionais, formando o último nível. 


\subsubsection{CISCO RLO/RIO Model}

Objetos de informação reutilizáveis (RIO) são pedaços de informações que são construídos ao redor de um único objetivo de aprendizagem. Cada RIO é composto de três componentes: itens de conteúdo, itens de prática e itens de avaliação, e podem ser classificados como conceito, fato, processo, princípio ou procedimento. Os RIOs individuais podem ser combinados para formar uma estrutura maior chamada objeto de aprendizagem reutilizável (RLO). A Figura 5.3 mostra o Modelo CISCO RLO/RIO [Barrit \& Lewis, 2000].

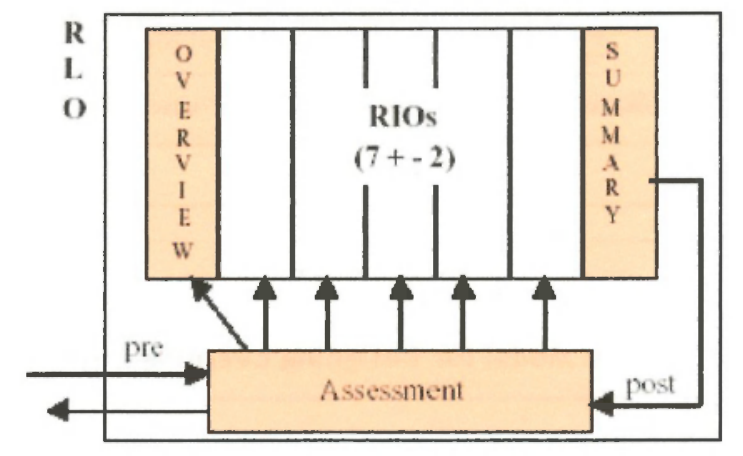

Figura 5.3: CISCO'RLO/RIO [Barrit \&' Lewis, 2000].

Um objeto de aprendizagem reutilizável (RLO) provê uma hierarquia de cinco níveis para garantir aos desenvolvedores estruturas consistentes em vários cursos. Os níveis são: curso, módulo, lição, tópico e sub-tópico [CISCO, 2003]. O RLO é composto por uma coleção de cinco a nove $(7 \pm 2)$ RIOs. Cada RLO ainda inclui revisão, resumo e avaliação.

\subsubsection{NETg s Learning Object Model}

L'Allier [1997] cita a conhecida frase: "Nós não podemos ver as árvores devido à floresta", para ilustrar o problema que pode acontecer quando olhamos um sistema complexo cuja estrutura básica está escondida na complexidade da sua própria estrutura. "A "floresta" tornase a única estrutura possível quando você não entende as "árvores"”, diz L'Allier [1997]. Igualmente, o modelo Netg's tem uma grande variedade de produtos que não podem ser usados potencialmente se sua estrutura básica e desenvolvimento não forem completamente entendidos.

O modelo tem uma hierarquia de quatro niveis: curso, unidade, lição e tópico. A Figura 5.4 ilustra a estrutura do modelo como uma matrix com as dimensãoes unidade, lição e tópico. 


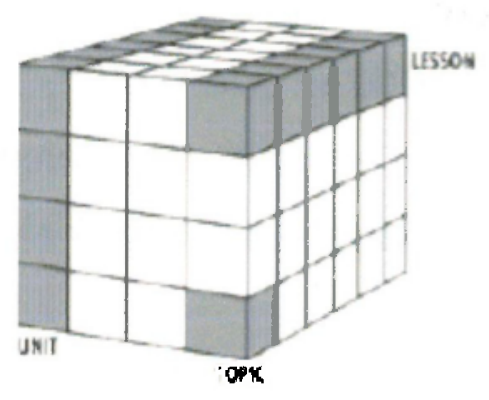

Figura 5.4: Netg's Learning Object Model [L'Allier, 1997].

Cada unidade, lição e tópico são definidas através de relacionamentos com outros componentes. Um curso contém unidades independentes; uma unidade contém lições independentes e uma lição contém tópicos independentes. Um tópico por sua vez, representa um objeto de aprendizagem independente que contém um único objetivo, uma atividade de aprendizado correspondente e uma avaliação.

A atividade de aprendizado apresenta uma complexidade contínua que permite ao desenvolvedor determinar o meio apropriado de ensinar a atividade. Os seis níveis apresentados na modelo de Bloom são: conhecimento, compreensão, aplicação, análise, síntese e evolução. A avaliação do objeto de aprendizagem pode ser feita de algumas maneiras, como questões de múltipla escolha, sequenciamento e simulação [L'Allier et al., 1995].

\subsection{SCORM}

O Departamento de Defesa (DoD) e o Escritório da Casa Branca de Ciência e Política de tecnologia (OSTP) lançou a iniciativa $\mathrm{ADL}^{15}$ - Aprendizagem Distribuída Avançada, cuja missão é prover acesso e treinamento para educação de mais alta qualidade, personalizada, a qualquer hora e em qualquer lugar.

Nesse contexto, surgiu o SCORM - Sharable Content Object Reference Model - visando favorecer a criação de conteúdo de aprendizagem reutilizável como "objetos instrucionais" dentro de um framework comum para aprendizado baseado na Web. O SCORM descreve esse framework provendo um conjunto de diretrizes, especificações e padrões com base no trabalho de várias especificações e-learning e corpos padrões.

${ }^{15}$ http://www.adlnet.org 
Renata Paciência Godoy - Dissertação de Mestrado-Pós-Graduação - ICMC/USP - São Carlos

Das muitas organizações que trabalham em especificações relacionadas a e-learning, quatro são fundamentais para o SCORM: ARIADNE ${ }^{16}, \mathrm{AICC}^{17}$, IEEE LTSC ${ }^{18} \mathrm{e} \mathrm{IMS}^{19}$. Adaptações de múltiplas fontes possibilitam interoperabilidade, acessibilidade, $\mathrm{e}$ reusabilidade de conteúdo de aprendizagem baseado na Web. As especificações e padrões que servem de base para o SCORM 2004 são:

- IEEE Data Model For Content Object Communication;

- IEEE ECMAScript Application Programming Interface for Content to Runtime Services Communication;

- IEEE Learning Object Metadata (LOM);

- IEEE Extensible Markup Language (XML) Schema Binding for Learning Object Metadata Data Model;

- IMS Content Packaging e IMS Simple Sequencing.

O SCORM descreve um modelo (Content Aggregation Model) para suportar instruções adaptativas baseadas nos objetivos dos estudantes, preferências, desempenho e outros fatores (como técnicas instrulivas). Além de boa compatibilidade com outras especificações de recursos de aprendizagem, o SCORM provê o Run-Time Environment (RTE), característica única que oferece um padrão para os $S C O$ (Sharable Content Object) se comunicarem com o LMS através do uso de uma API (interface de programa de aplicação) comum. Essa API é capaz de esconder detalhes de implementação de LMS dos SCOs e assim promover reusabilidade e interoperabilidade de recursos de aprendizagem lQu \& Nejdl, 20027 .

Com o SCORM, a ADL e outras organizações têm trabalhado para construir um "modelo de referência" comum para a fundação de aprendizado baseado na Web. Após alguns anos de experimentação e testes de aplicações, o SCORM confirma-se um modelo estável para alcançar a maioria dos requisitos (ilities) da ADL.

\footnotetext{
io http://www ariadne-eu.org

${ }^{17} \mathrm{http}: /$ www.aicc.org

${ }^{18} \mathrm{http} / /$ ltsc.ieee.org/

${ }^{19} \mathrm{http}: / / \mathrm{www}$.imsglobal.org/
} 
Renata Paciência Godov - Dissertação de Mestrado - Pós-Graduação -.. KMCLUSP - São Carlos

\subsubsection{Requisitos para o SCORM}

Há três critérios primários para um modelo de referência como o SCORM. Primeiro, deve ter diretrizes que possam ser entendidas e implementadas pelos desenvolvedores do conteúdo de aprendizado. Segundo, deve ser adotado, compreendido e usado por uma grande variedado de pessoas possível. Terceiro, deve permitir mapeamento de qualquer modelo específico para sistemas instrutivos para que possam se projetar e desenvolver [SCORM, 2004].

O SCORM assume alguns requisitos conhecidos como "ADL ilities", formando uma base na qual todas as mudanças e adições no padrão SCORM são baseadas:

- Acessibilidade: localizar e acessar componentes instrucionais de um local remoto e distribuí-los para outros locais;

- Adaptabilidade: personalizar instrução às necessidades dos indivíauos $\mathrm{e}$ organizações;

- Disponibilidade: aumentar a eficiência e produtividade, reduzindo o tempo e custos envolvidos na distribuição de instrução;

- Durabilidade: resistir à evolução de tecnologia e mudanças sem custo alto para reprojeto, reconfiguração ou recodificação;

- Interoperabilidade: habilidade dos componentes instrucionais desenvolvidos com um conjunto de ferramentas ou plataforma possam ser reusados em outro local com um conjunto diferente de ferramentas ou plataforma;

- Reusabilidade: flexibilidade para incorporar componentes instrucionais em múltiplas aplicações e contextos.

Alćm desses requisitos, outro conceito fundamental para SCORM é a afirmação que a Web provê melhor oportunidade para maximizar o acesso e reuso de conteúdo de aprendizagem, já que adota um conteúdo e formato de entrega comum. A função fundamental de um LMS no contexto de ADL, então, é administrar a experiência em tempo-real que o estudante tem com o conteúdo de aprendizagem. 
Renata Paciência Godoy - Dissertação de Mestrado - Pós-Graduação - ICMC/USP - São Carlos

\subsubsection{Sistemas de Gerenciamento de Aprendizagem (LMS)}

O termo Sistema de Gerenciamento de Aprendizagem (LMS) refere-se a um conjunto de funcionalidades projetadas para entregar, localizar, informar e gerenciar o conteúdo de aprendizagem, o progresso e as interações do estudante. O termo "LMS" pode ser aplicado para sistemas de gerenciamento simples ou em empreendimentos altamente complexos em ambientes distribuídos.

O SCORM suporta a noção de conteúdo de aprendizagem composta de pequenos e reutilizáveis objetos de conteúdo e agregados para formar unidades de instrução como cursos, módulos, capítulos, tarefas, entre outros - a agregação provê o contexto e suporta uma experiência de aprendizado. O LMS somente processa as regras definidas e não tem nenhum conhecimento sobre como o conteúdo é organizado.

\subsubsection{Organização do SCORM}

O SCORM é uma coleção de especificações e padrões que foram empacotadas numa coleção de "livros técnicos" que se agrupam em três principais tópicos: o "Modelo de agregação de conteúdo (CAM)", o "Ambiente de execução (RTE)" e "Sequenciamento e Navegação (SN)". O livro de visão geral (Overview) mostra a história e os objetivos da iniciativa ADL e SCORM, incluindo as especificações e padrões usados pelo SCORM. Também descreve como os vários livros de SCORM são relacionados um ao outro. A Figura 5.5 mostra a organização dos livros técnicos do SCORM.

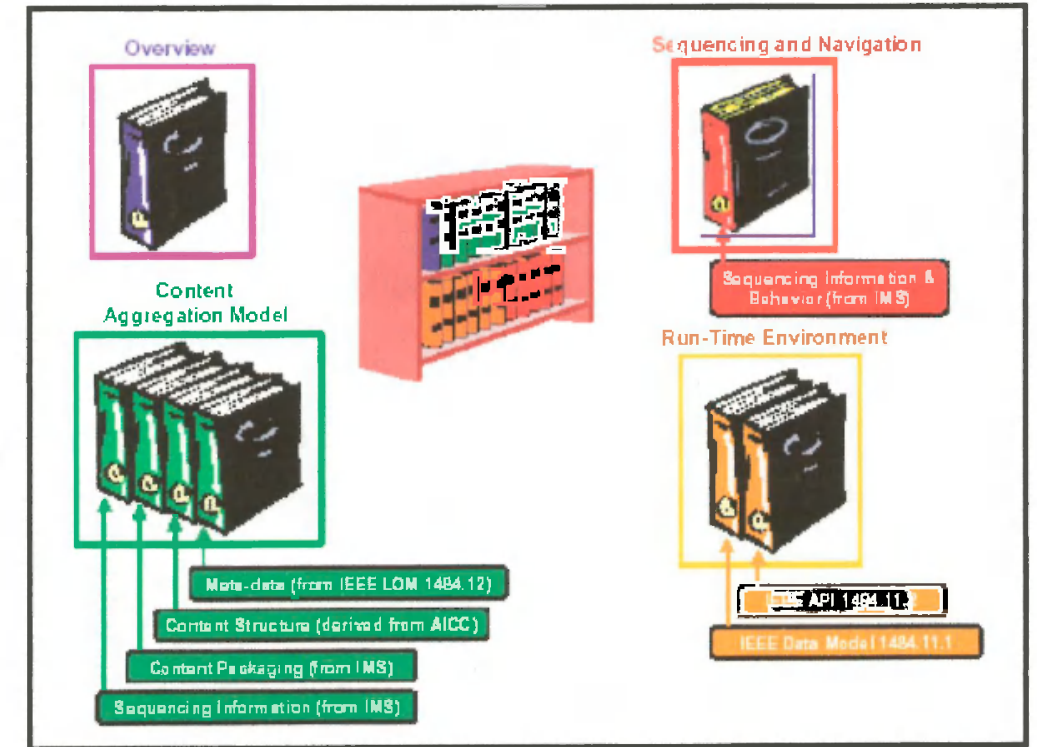

Figura 5.5: Organização de livros técnicos do SCORM [SCORM, 2004]. 
Renata Paciência Godoy · Dissertação de Mestrado-Pós-Graduação-ICMC/USP - São Carlos

\subsubsection{Livro do Modelo de agregação de conteúdo SCORM (CAM)}

O livro Content Aggregation Model (SCORM CAM) descreve os componentes usados em uma experiência de aprendizado, como empacotar esses componentes para troca de sistema, como descrever esses componentes para possibilitar a procura e descoberta, e como definir as regras de sequenciamento para os componentes. O C $\Lambda \mathrm{M}$ promove armazenamento consistente, nomeação, empacotamento, troca e descoberta de contcúdo.

O livro CAM também define responsabilidades e exigências por construir agregações de conteúdos (por exemplo curso, lições, módulos, etc). O livro contém informações para criar pacotes de conteúdo, aplicar metadados aos componentes presentes nesse pacote $\mathrm{e}$ aplicar detalhes de sequenciamento e de navegação no contexto desse pacote. Os Mctadados SCORM descrevem diferentes componentes do Modelo de conteúdo SCORM, como agregações de conteúdo, atividades, SCOs e Assets.

\subsubsection{Livro de ambiente de execução do SCORM (RTE)}

O livro Run-Time Environment (SCORM RTE) descreve os requisitos do Sistema de Gerenciamento de Aprendizagem (LMS) para gerenciar o ambiente de execução, como por exemplo: processo de lançamento de conteúdo, comunicação entre conteúdo e LMSs e unificação de elementos de modelo de dados usados para informar dados sobre o estudante. $O$ propósito do SCORM RTE é prover meios de interoperabilidade entre SCOs e LMSs, indiferente das ferramentas usadas para criar o conteúdo.

\subsubsection{Livro de Sequenciamento e Navegação do SCORM (SN)}

O livro Sequencing and Navigation (SCORM SN) apresenta os detalhes dos processos de seqüenciamento e navegação do SCORM, para incluir especificações de como um LMS avalia os pedidos de navegação e atividades relacionadas. O modelo SCORM SN descreve o fluxo de atividades de aprendizado em termos de Arvores de Atividades, baseado nos resultados das interações do estudante com objetos de aprendizagem. 


\subsubsection{Componentes do Modelo de Conteúdo SCORM}

O Modelo de Conteúdo SCORM descreve os componentes usados para construir experiências de aprendizado a partir de recursos de aprendizagem. O Modelo de Conteúdo também define como estes recursos de aprendizado são agregados em unidades de alto-nível de instrução. $\mathrm{O}$ Modelo de Conteúdo SCORM é composto de Assets (Recursos), SCOs (objetos de conteúdo compartilhável) e Organização de Conteúdo.

\subsubsection{Recursos (Assets)}

A forma mais básica de um recurso de aprendizagem é um recurso. Recursos são representações eletrônicas de mídia, como texto, imagens, som, objetos de conteúdo ou qualquer fragmento de dados que podem ser apresentados ao estudante. Recursos podem ser agrupados para construir outros recursos. Um recurso pode ser descrito com metadados de recurso para permitir pesquisa em repositórios. A Figura 5.6 mostra alguns exemplos de recursos.

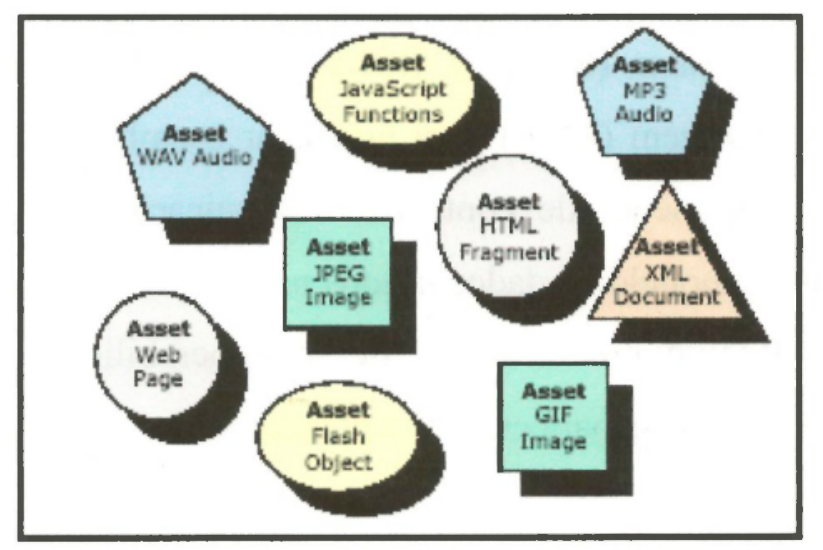

Figura 5.6: Exemplos de Recursos (Assets) [SCORM, 2004].

\subsubsection{Objeto de Conteúdo Compartilhável (SCO)}

Um SCO é uma coleção de um ou mais recursos que representam um único recurso de aprendizagem e que utiliza o SCORM RTE para se comunicar com um LMS. Um SCO representa o mais baixo nível de granularidade de um recurso de aprendizagem que é localizado por um LMS usando o Modelo de Dados do SCORM RTE. A Figura 5.7 mostra um exemplo de $S C O$ compostos por vários recursos. 


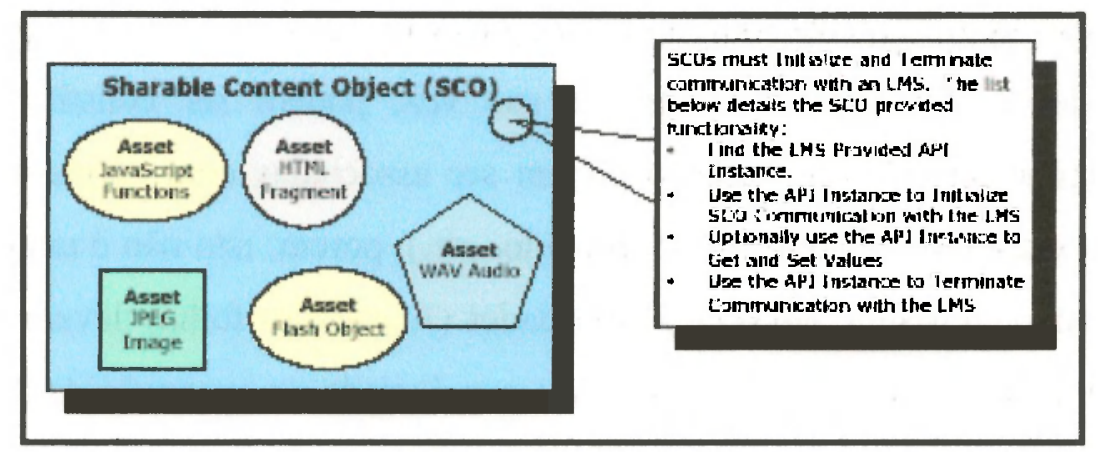

Figura 5.7: Exemplo de um SCO (Objeto de conteúdo compartilhável) [SCORM, 2004].

Para melhorar a reusabilidade. um SCO deveria ser independente de seu conteúdo de aprendizagem, podendo ser reusado em diferentes experiências de aprendizagem para cumprir diferentes objetivos de aprendizagem. SCOs são unidades pequenas, que podem ser reusadas por múltiplos contextos de aprendizagem. Os requisitos de reuso para uma organização devem pesar na decisão sobre o tamanho de SCOs. Um SCO pode ser descrito com metadados de SCO para permitir a pesquisa e descoberta em repositórios.

\subsubsection{Organização do Conteúdo}

A Organização do Conteúdo é um mapa que representa o uso planejado do conteúdo através de unidades estruturadas de instrução (atividades). O mapa mostra como as atividades se relacionam entre si. A Figura 5.8 mostra um exemplo de uma Organização de Conteúdo.

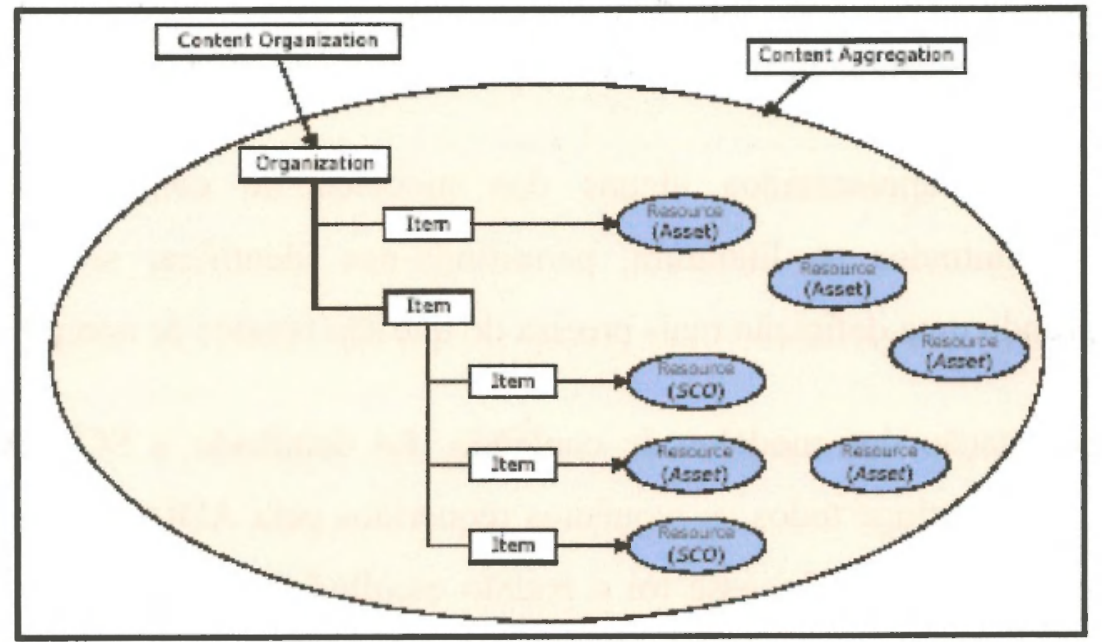

Figura 5.8: Exemplo de uma Organização de Conteúdo [SCORM, 2004] 
Renata Paciencia Godoy - Dissertação de Mestrado-Pós-Graduação - ICMC/USP - São Carlos

Atividades representadas em uma Organização de Conteúdo podem consistir $\mathrm{em}$ outras Atividades (sub-atividades), que por sua vez, podem ser constituídas de outras Atividades. Taxonomias de aprendizado podem ser associadas com níveis hierárquicos de Atividades (por exemplo, curso, capitulo, módulo, etc.), porém, isto não é uma exigência. As Atividades que não consistem em outras Atividades (Atividades folha) devem ter um recurso de aprendizagem associado (um SCO ou Asset) que é usado na execução da Atividade. Uma Atividade pode referenciar um metadados de atividade para permitir a pesquisa e descoberta em repositórios.

\subsubsection{Componentes de Metadados SCORM}

Os perfis de metadados SCORM representam um mapeamento e padrão indicado pelo IEEE Learning Technology Standards Committee (LTSC) Learning Object Metadata (LOM) [IELE I.TSC, 2002] para cada componente do Modelo de Conteúdo SCORM. A orientação deve ser aplicada a Assets, SCOs, atividades e organizações de conteúdo para descrevê-los de uma maneira consistente tal que eles possam ser identificados, categorizados, pesquisados e descobertos por sistemas.

\subsection{Considerações Finais}

Foi apresentada uma revisão bibliográfica com relação a metadados e objetos de aprendizagem. O levantamento das principais classificações encontradas na literatura mostrou que os metadados não só facilitam a descrição e a descoberta de informação, mas também descrevem conteúdo, gerenciamento, contexto e preservação dos dados.

Foram ainda apresentados alguns dos modelos de conteúdo de objetos de aprendizagem encontrados na literatura, permitindo-nos identificar seus componentes e propósitos, provendo uma definição mais precisa do que são objetos de aprendizagem.

$\mathrm{Na}$ apresentação dos modelos de conteúdo, foi detalhado o SCORM, por ser um modelo estável e que atinge todos os requisitos requeridos pela ADL (Advanced Distributed Learning). Por essa estabilidade, esse foi o padrão escolhido para o processo de criação de objetos de aprendizagem a partir de metadados. O empacotamento do conteúdo SCORM e as especificações dos metadados SCORM são detalhados nos Apêndices A e B, respectivamente. 


\section{6 iClass: Extensão SCORM via Web Services}

\subsection{Considerações Iniciais}

Este capítulo descreve implementações ${ }^{20}$ que, partindo de informações capturadas pelo sistema iClass, permitem a criação de objetos de aprendizagem de acordo com o padrão SCORM tanto de modo automático como manual. Sendo assim, o trabalho incluiu a investigação de mecanismos que permitissem incorporar metadados à informação capturada de modo que: (a) quaisquer metadados manipulados sejam padronizados; (b) metadados possam ser associados de modo automático; (c) metadados possam ser adicionados sob demanda do usuário.

\subsection{Criação de Objetos de Aprendizagem}

Os documentos que são gerados automaticamente pelo iClass são especificados no formato XML (Extensible Markup Language) permitindo que os documentos possam ser trocados entre aplicações que estão em conformidade com essá mesma especificação.

Considerando-se que os documentos gerados pelo iClass são de conteúdo educacional, julgou-se relevante que esse conteúdo também fosse disponibilizado em um formato para

${ }^{20}$ Realizadas com outros membros do grupo. As implementaçêes encontram-se na fase final, podendo ser acessadas em: http://mexcal.intermidia.icmc.usp.br:81/exist/iclass. 
objetos de aprendizagem, assim como o padrão SCORM, para que houvesse troca de informação e integração entre os recursos na $W e b$.

Foi reita então a associação dos metadados SCORM com o conteúdo gerado pelo iClass através de interfaces Weh, que permitem ao usuário (por exemplo, o professor) criar um objeto de aprendizagem de acordo com o padrão SCORM. Para automatizar parcialmente o preenchimento dos dados, foi feita uma integração com o Context Kernel, recuperando as informações de contexto referentes a cursos e a aulas.

A criação de objetos de aprendizagem é feita depois da aula ser aplicada e a disponibilização desses objetos é feita pelo sistema em interface $W e b$ através de arquivos (em formato comprimido .zip) contendo seus respectivos metadados e conteúdo (fornecidos pelo i(lass e Context Kernel).

A parte referente a implementação foi desenvolvida com a ajuda do mestrando Hélder Máximo Botter Ribas [Ribas, 2004], tendo utilizado o Tom ( $a t^{2 i}$ como servidor de páginas e o framework Apache Cocoon ${ }^{22}$ para desenvolvimento e publicação de páginas Web.

Através da linguagem Extensible Server Pages $(\mathrm{XSP})^{23}$ (linguagem XML baseada cm JSP, que permite indiretamente a inclusão de código Java na geração de páginas), o framework Apache Cocoon permite a geração dinâmica de conteúdo para a Internet através do conteúdo XML, que, passando por um processamento de folhas de estilo XSLT (XML Stylesheet Language Transformation), geram documentos em inúmeros formatos, como html, pdf ou plain text. O banco de dados utilizado foi o XML nativo eXist $t^{24}$ e para acesso aos dados armazenados foi utilizada a linguagem $X q u e r y^{25}$.

\subsubsection{Processo de criação}

Foi definida a criação de objetos de aprendizagem aproveitando-se o conjunto de aulas já armazenado no banco de dados do iClass, associando-os aos metadados SCORM através de interfaces Web. Além disso, foi feita a integração com o Context Kernel, recuperando as

21 htp:l/jakarta.apacheorg/

$\because$ htip://cocoun apache.org/

${ }^{23}$ http://cocoon apache.org/2.//userdocs/xsp/index.html

${ }^{24}$ hitp://exist-dh.org/

${ }^{25}$ http://www.w3.org/XML/Query 
informações de contexto referentes ao curso, como who, where, when, what e how. Com isso, ocorreu uma especificação da aula dada e a possibilidade de que novas aulas ou cursos possam estar utilizando esses objetos de aprendizagem. O processo de criação de objetos de aprendizagem se dá através da sequência mostrada na Figura 6.1.

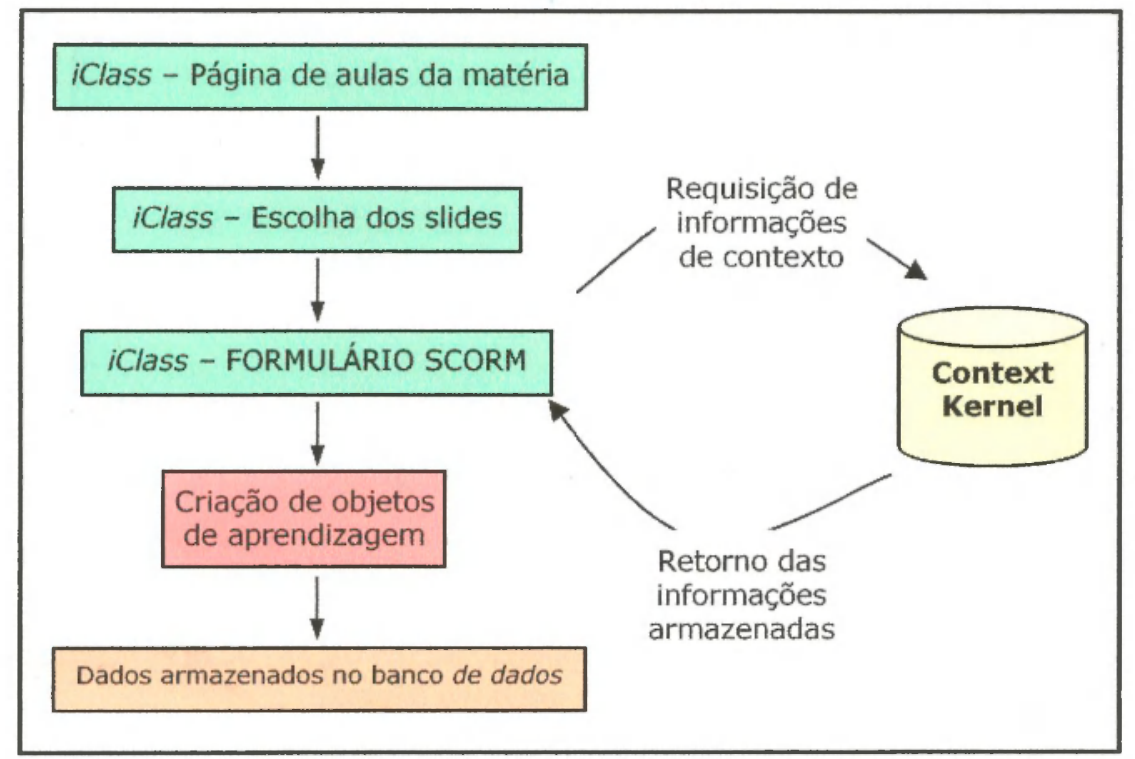

Figura 6.1: Sequência de criação do objeto de aprendizagem

A primeira página de acesso é feita baseada na página de acesso a aulas do iClass, com a inclusão de uma nova opção pra criar objetos de aprendizagem SCORM de uma determinada aula. Isso é feito através da crição de uma ligação (link) denominada "scorm", como mostrado na Figura 6.2.

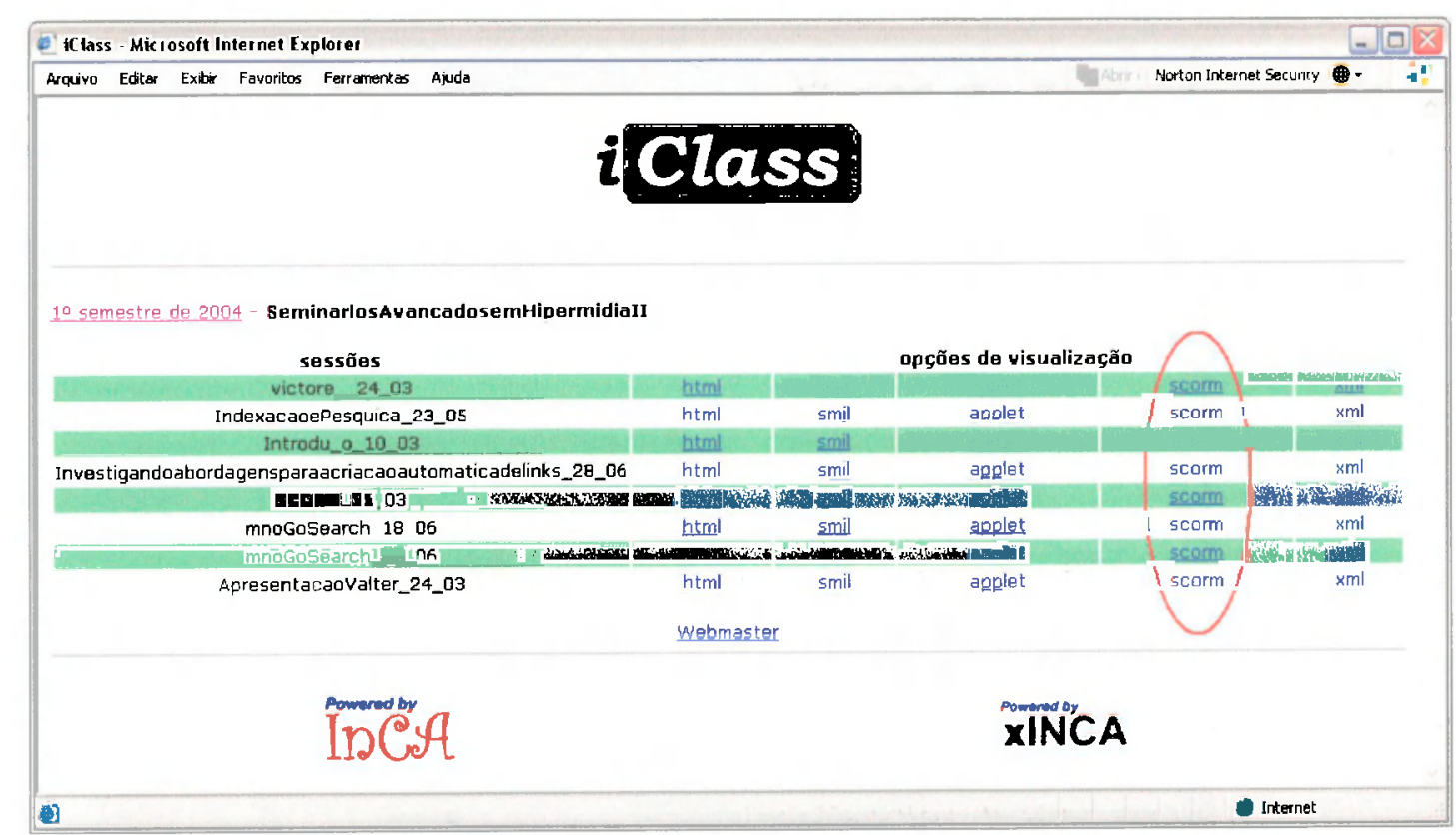

Figura 6.2: Interface com link para a criação ou visualização dos objetos de aprendizagem. 
Renata Paciência Godoy - Dissertação de Mestrado - Pós-Graduação - ICMC/USP - São Carlos

Essa ligação encaminha o usuário a uma nova página, onde são listados os objetos de aprendizagem já criados, e há opção para criar novos objetos, como mostra a Figura 6.3.

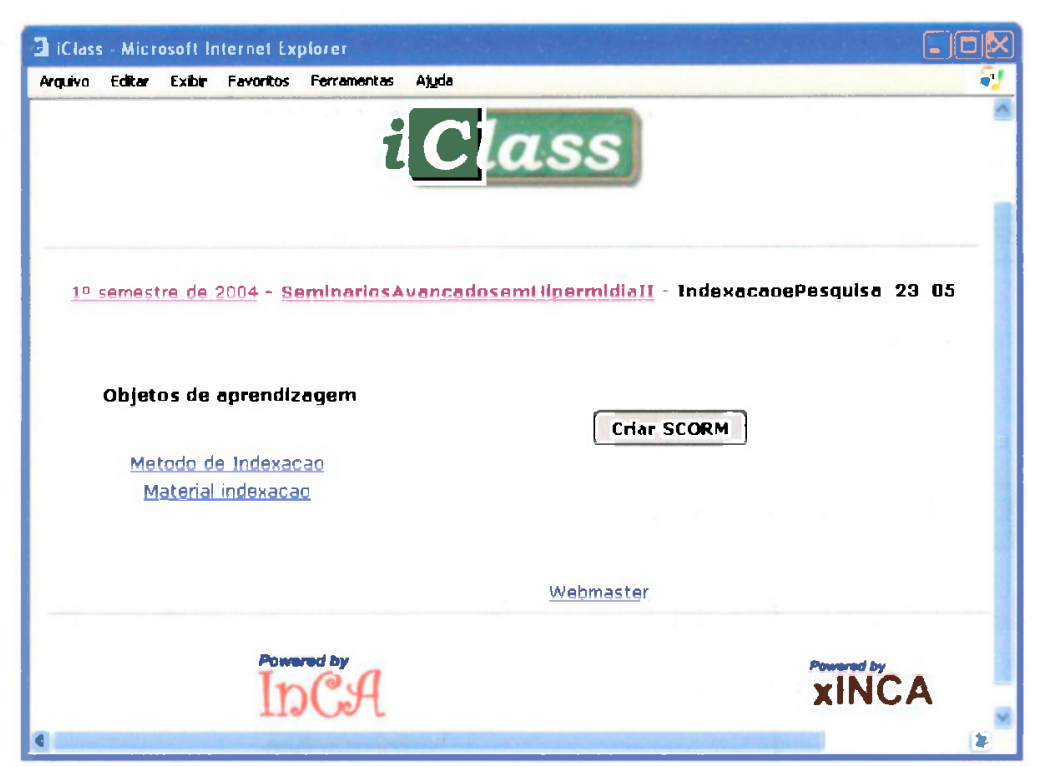

Figura 6.3: Interface de escolha entre a visualização de um objeto de aprendizagem existente ou a criação de um novo objeto.

Na criação de novos objetos (clicando sobre o botão "Criar scorm"), o usuário tem acesso a uma nova página, onde são mostrados os slides referentes à aula associados a um checkbox, como é mostrado na Figura 6.4. Desta maneira, o professor pode indicar quais slides devem fazer parte do objeto de aprendizagem que será gerado. Depois de selecionados os slides, o formulário é enviado e uma nova página para o preenchimento dos metadados $L O M$ demandados pelo padrão SCORM é fornecida.

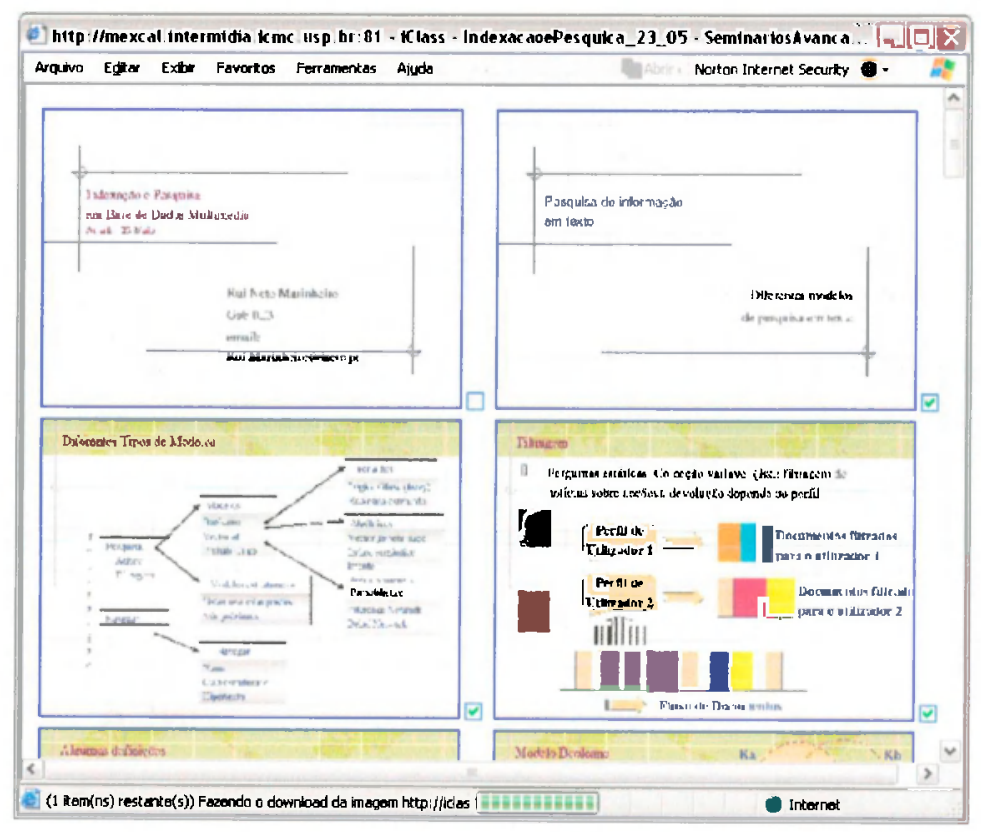

Figura 6.4: Interface referente à seleção de slides. 
Renata Paciência Godoy - Dissertação de Mestrado - Pós-Graduação - ICMC/USP - São Carlos

Antes da página do formulário ser exibida, o SCORM envia uma mensagem para o Context Kernel requisitando as informações de contexto referentes aquele curso ou aula. $\mathrm{O}$ Context Kernel retorna essas informações, que serão automaticamente incluídas no objeto de aprendizagem como metadados. As informações de contexto são preenchidas em alguns campos no formulário, referentes aos elementos $L O M$ como segue abaixo:

- <lifecycle $><$ contribute $><$ entity $>$ : através da dimensão de contexto who, informa o professor responsável pela aula;

- <metaMetadata $><$ contribute> <entity $>$ : através da dimensão de contexto who, informa o professor responsável pela aula;

- <rights $><$ description>: através de informações de contexto como who, fornece uma opção padrão representada por uma frase indicando informações adicionais, especificando por exemplo, quem contatar e em que endereço eletrônico;

- $<$ relation $><$ resource $><$ identifier $><$ entry $>$ : através da dimensão de contexto how, assume o valor da URL referente à página da aula na CoTeia se exisitir;

- <annotation><entity>: através da dimensão de contexto who, informa o professor responsável pela anotação;

- <annotation><description>: através das dimensões de contexto who, where, when e what, fornece uma opção padrão representada por uma frase indicando informações adicionais, especificando as informações necessárias para a descrição da anotação.

Exemplificando o item <relation $><$ resource $><$ identifier $><$ entry $>$, a informação é obtida no Context Kernel pelo método Getinverse() através da inferência what (com o identificador do curso) para obter a premissa com dimensão how com o valor da URL. A Figura 6.5 ilustra um exemplo do $X M L$ da consulta ao Context Kernel, e a Figura 6.6 ilustra o resultado obtido, que foi a URL da Coteia que contém informações sobre o curso.

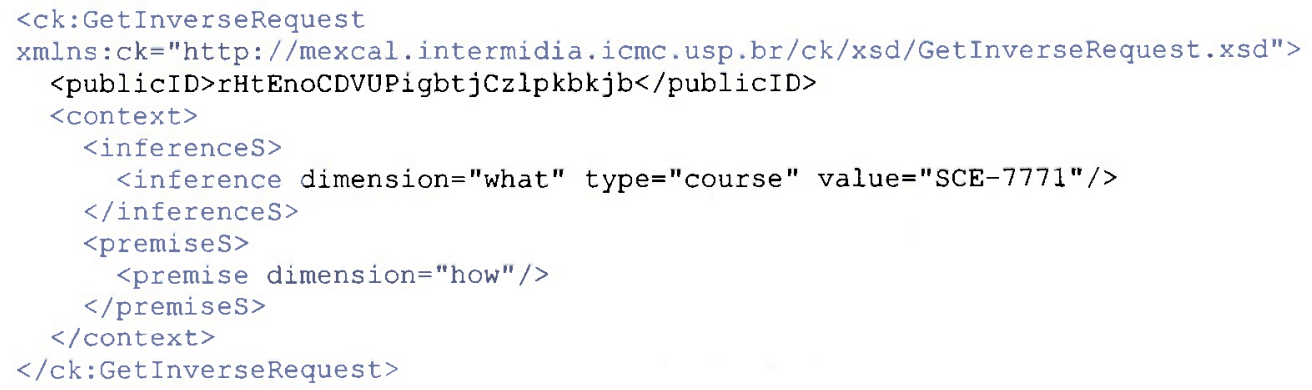

Figura 6.5: Fragmento de exemplo de uma consulta XML através do método GetInverse (). 


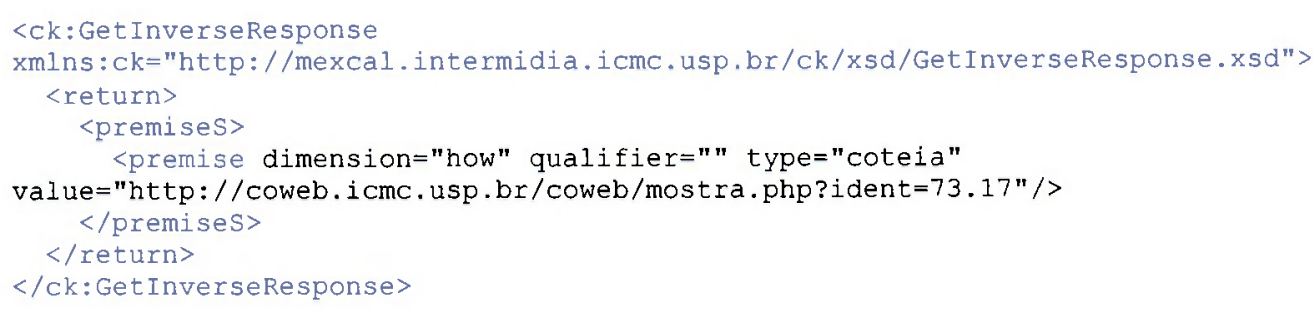

Figura 6.6: Fragmento XML de resposta ao método GetInverse O.

Na página do formulário para preenchimento dos metadados, o usuário deve preencher pelos menos os metadados considerados obrigatórios. O formulário é dividido em nove etapas, representando os nove elementos principais do LOM. Há ainda um help oferecendo informações do que representa cada elemento e qual sua utilidade. A Figura 6.7 apresenta a tela referente a criação de objetos de aprendizagem do elemento General e a Figura 6.8 apresenta a tela referente a criação de objetos de aprendizagem do elemento Educational.

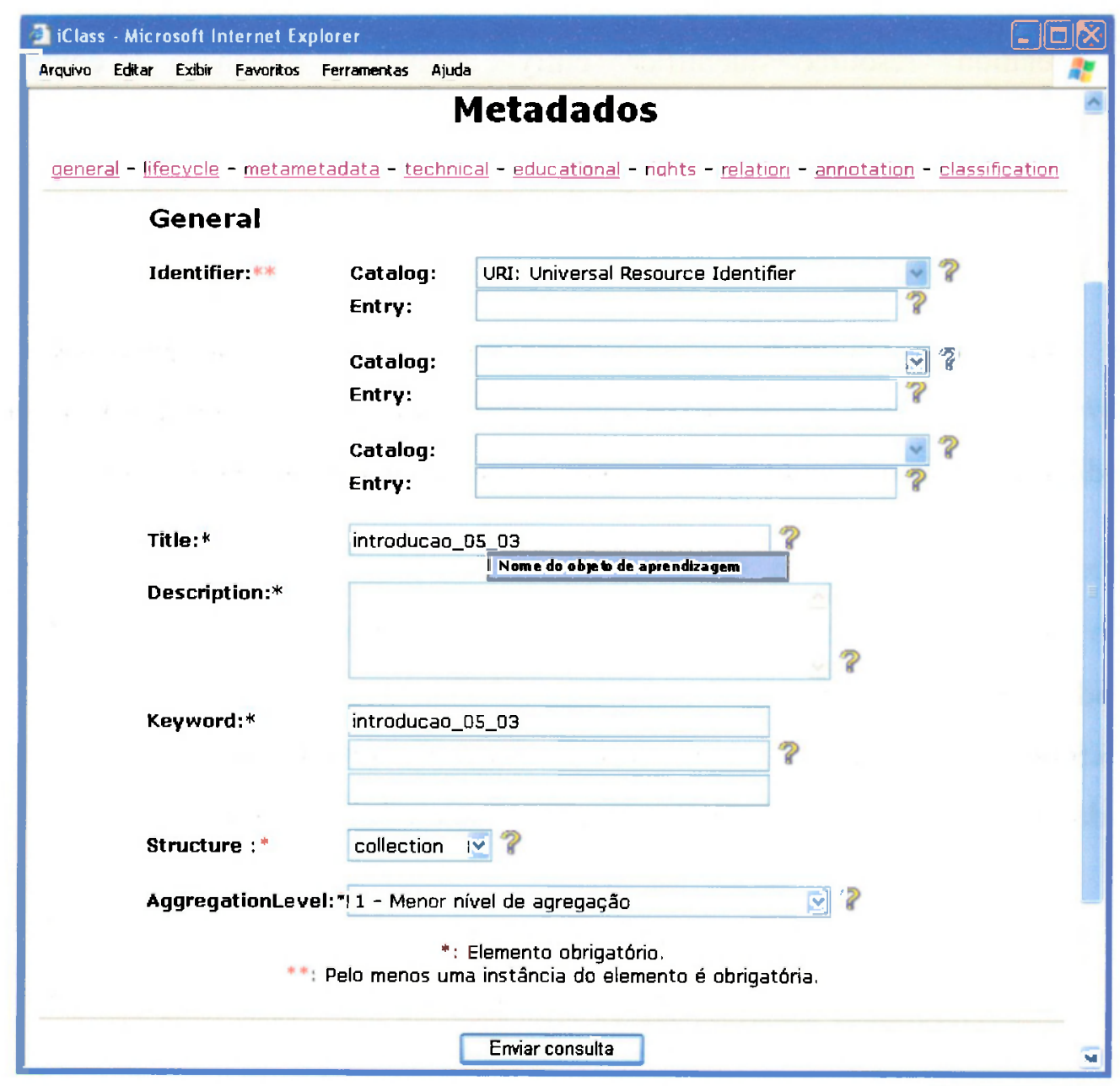

Figura 6.7: Interface de criação de objetos de aprendizagem. Formulário para preenchimento dos metadados $<$ General $>$. 


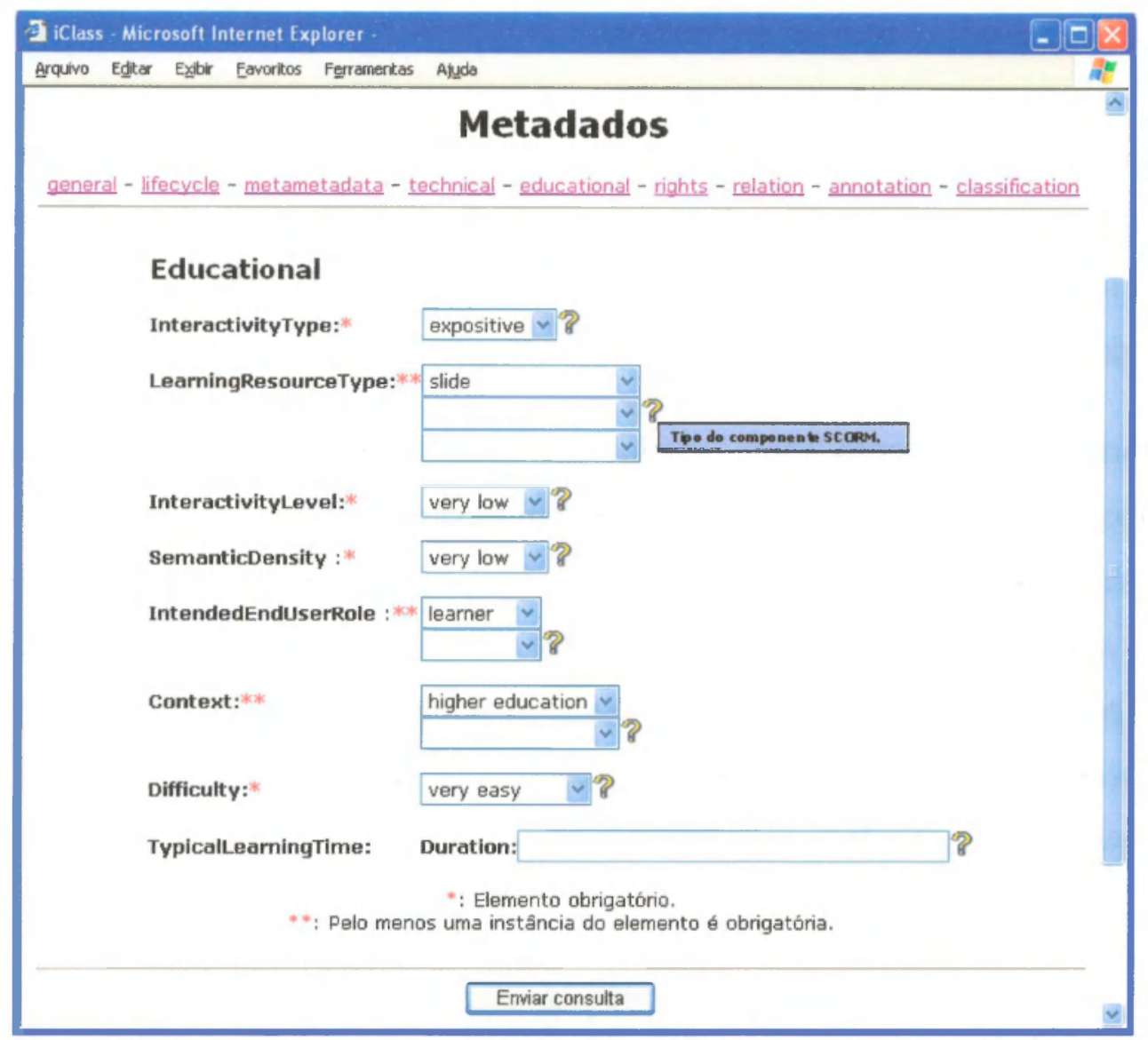

Figura 6.8: Interface de criação de objetos de aprendizagem. Formulário para preenchimento dos metadados $<$ Educational $>$.

Depois de o formulário ser preenchido, a consulta é enviada e os dados recolhidos são salvos dentro de um diretório existente no banco de dados eXist. O caminho desse arquivo é descrito da forma:/scorm/semestre_ano/matéria/aula, na qual o semestre, o ano, a matéria e a aula são referentes à aula salva. Esse diretório é subdividido em outros três diretórios:

- manifest: onde são salvos os dados referente aos slides escolhidos para a composição do imsmanifest.xml;

- lom: onde são salvos os metadados do objeto de aprendizagem;

- html: onde são salvas as páginas para a visualização dos slides.

Nesta versão, apenas as imagens são consideradas. Como trabalho futuro, deve ser suportada a extração do texto dos slides e anotações que os acompanhem. Todos os arquivos gerados são salvos com o mesmo nome nessas pastas, fazendo com que cada objeto de aprendizagem possua um nome único. Na geração dos objetos de aprendizagem, esses arquivos criados são comprimidos junto com os arquivos dos slides e os arquivos que definem os formatos permitidos pelo padrão SCORM. 


\subsubsection{Acesso aos Objetos de Ensino}

Os objetos de aprendizagem criados podem ser acessados através de uma página para sua apresentação, na mesma interface de acesso à criação dos objetos de aprendizagem, como mostrado na Figura 3.6. Cada objeto de aprendizagem é disponibilizado em um arquivo comprimido (.zip), com todos os arquivos que o compõem.

Para exemplificação, foi gerado um objeto de aprendizagem para a aula IndexacaoePesquisa_23_05 da matéria SeminariosAvancadosemHipermidiall, realizada no primeiro semestre de 2004. Nesta aula foram escolhidos os slides 2 e 3 . Através do arquivo do objeto de aprendizagem, o usuário pode utilizar um visualizador compatível com o padrão SCORM para ver quais slides foram transformados em objetos de ensino ou pode descompactar o arquivo e utilizar o arquivo denominado session. htm para visualizar os slides, como mostrado na Figura 6.9.

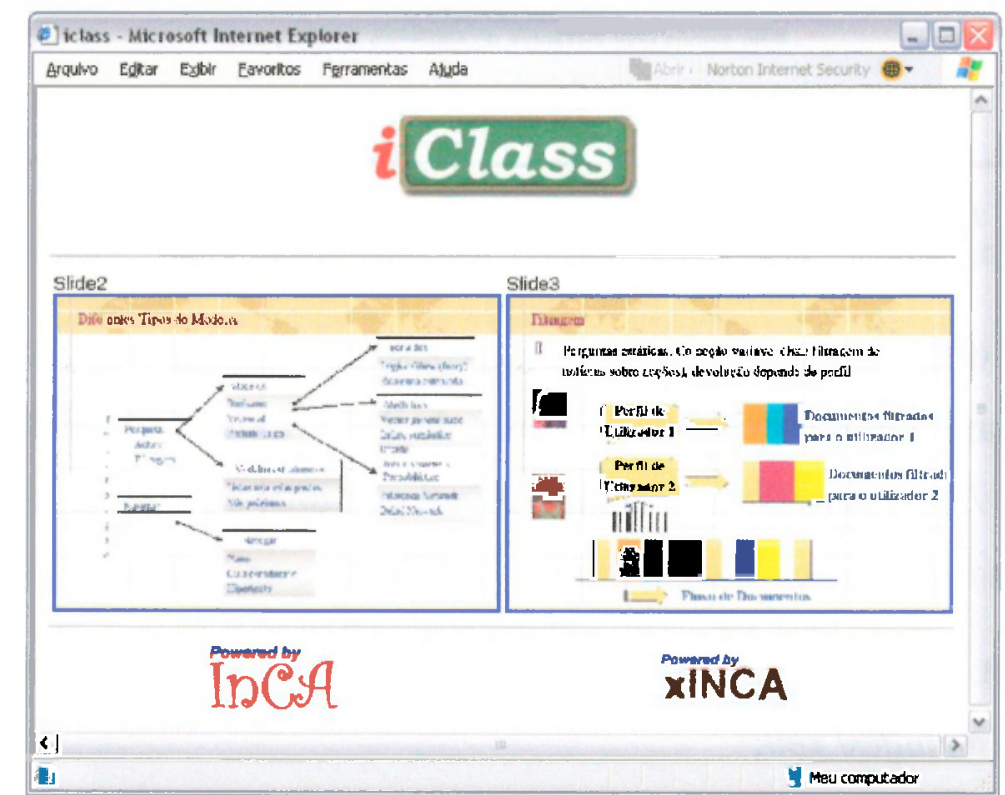

Figura 6.9: Interface de visualização dos slides gerados no processo de criação do objeto de aprendizagem.

Dentro do arquivo comprimido ainda encontram-se os arquivos: imsmanifest.xml e lom.xml. No imsmanifest.xml são salvos os dados referente aos slides escolhidos para a composição do objeto de aprendizagem, como mostra a Figura 6.10. e no lom.xml são salvos os metadados do objeto de aprendizagem gerado, como mostra a Figura 6.11. 
Renata Paciência Godoy - Dissertação de Mestrado - Pós-Graduação - ICMC/USP - São Carlos

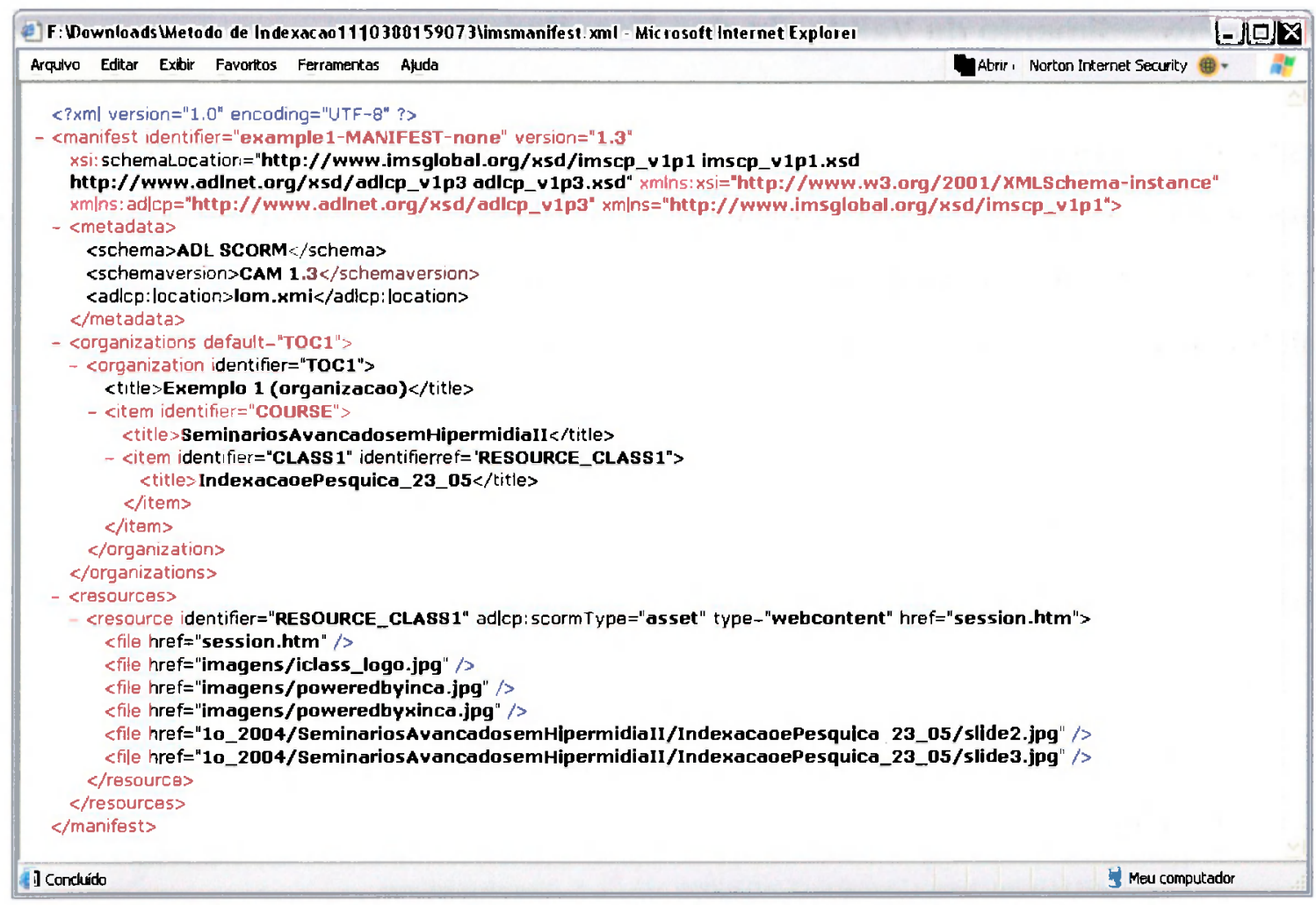

Figura 6.10: Exemplo de um arquivo imsmanifest.xml gerado

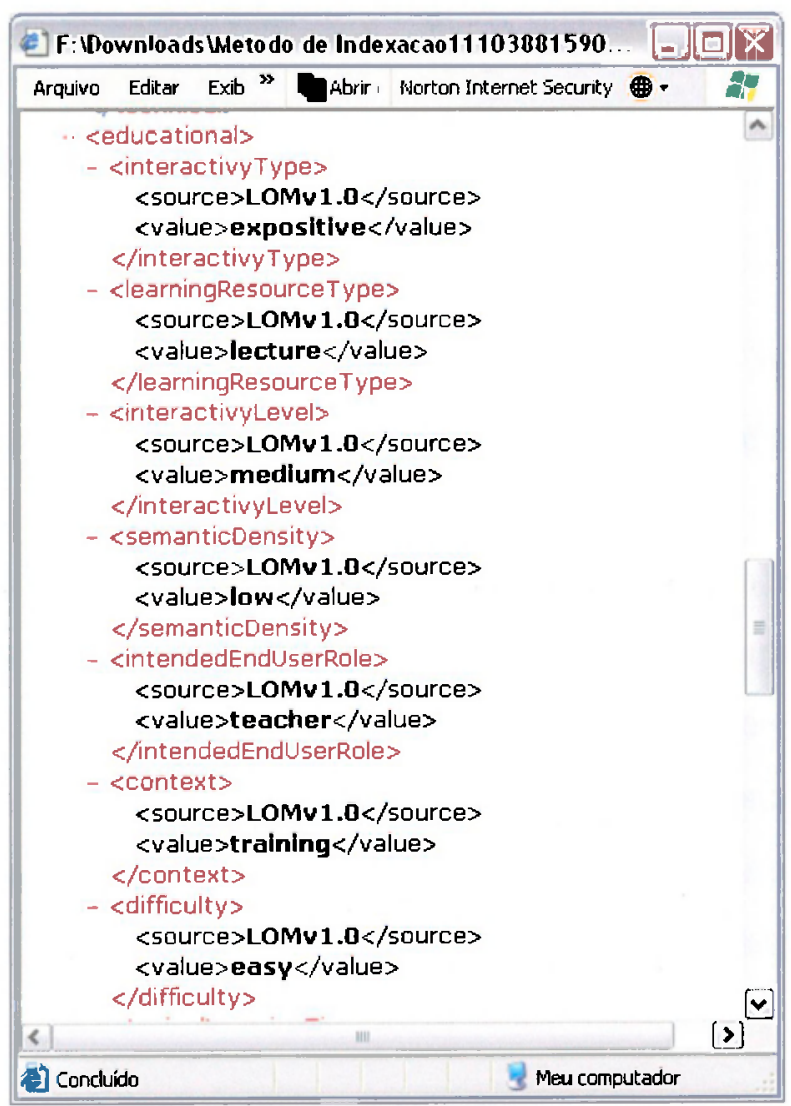

Figura 6.11: Exemplo de um arquivo lom.xml gerado 


\subsubsection{Procedimento de Validação dos Resultados}

Para realizar a validação dos arquivos criados no processo de aquisição dos objetos de aprendizagem, pode ser utilizado o software SCORM. 2004 Conformance Test Suite Version 1.3.1 (Self Test) ${ }^{26}$, desenvolvida pela $A D L$ para facilitar a criação de programas que geram conteúdo compatível com o SCORM. Mesmo se o conteúdo for considerado válido, o programa tem que ser auditado pela $A D L$ para poder ser, formalmente, considerado compatível com o padrão SCORM. A Figura 6.12 apresenta o sofware SCORM. 2004, mostrando que a validação ocorreu com sucesso e o objeto de aprendizagem correspondente foi considerado válido.

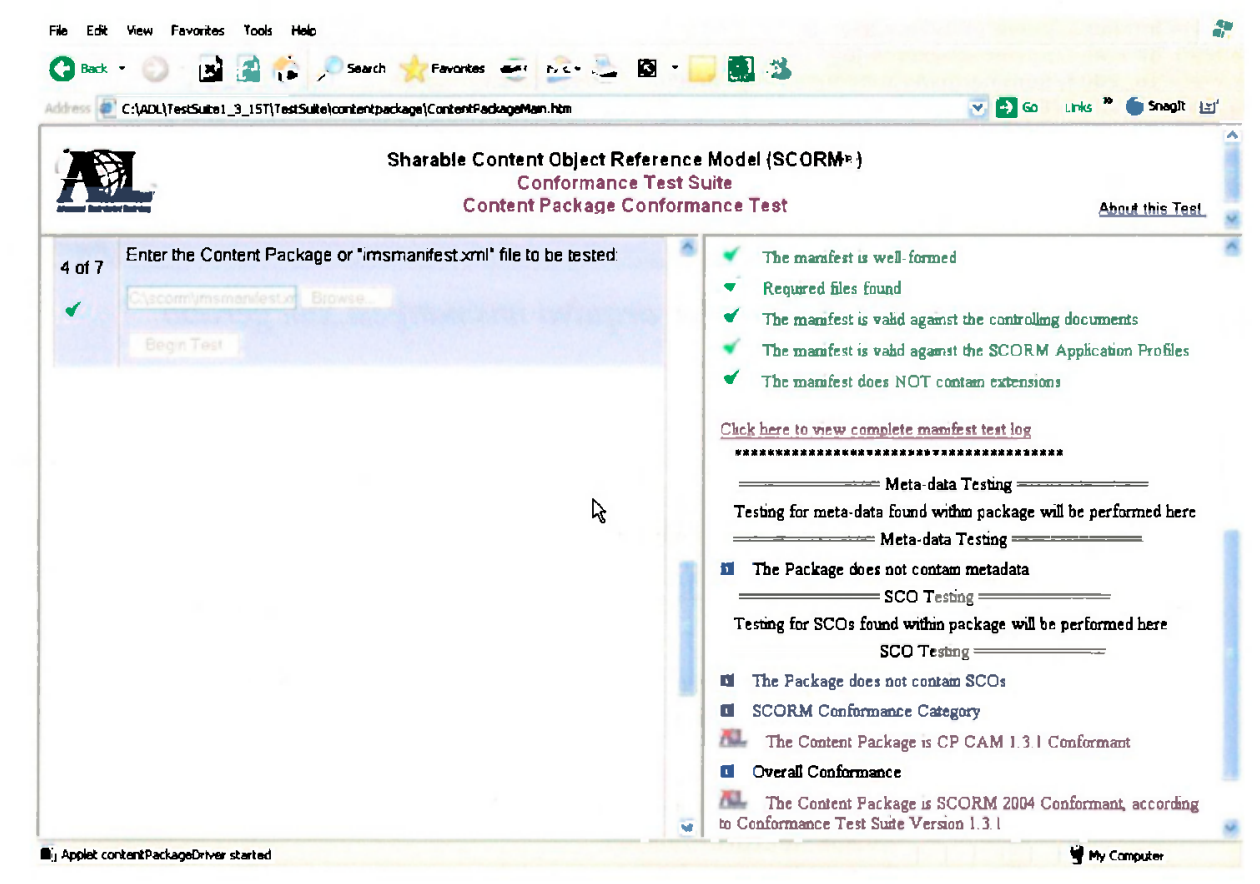

Figura 6.12: Sofware SCORM 2004 mostrando que o objeto de aprendizagem foi considerado válido

Os arquivos do objeto de aprendizagem são vistoriados pelo sistema de teste do SCORM a partir do arquivo imsmanifest.xml, que verifica se o arquivo está seguindo os padrões estabelecidos e se todos os arquivos estão nos seus respectivos diretórios. Nesse caso, verificam-se a existência dos arquivos de imagens, o arquivo html e os arquivos .xsd necessários para a execução do objeto de aprendizagem. Através do software TinyLMS é possível ver a estruturação do objeto de aprendizagem criado, como mostra a Figura 6.13.

${ }^{26}$ http://www.adlnet.org/ 


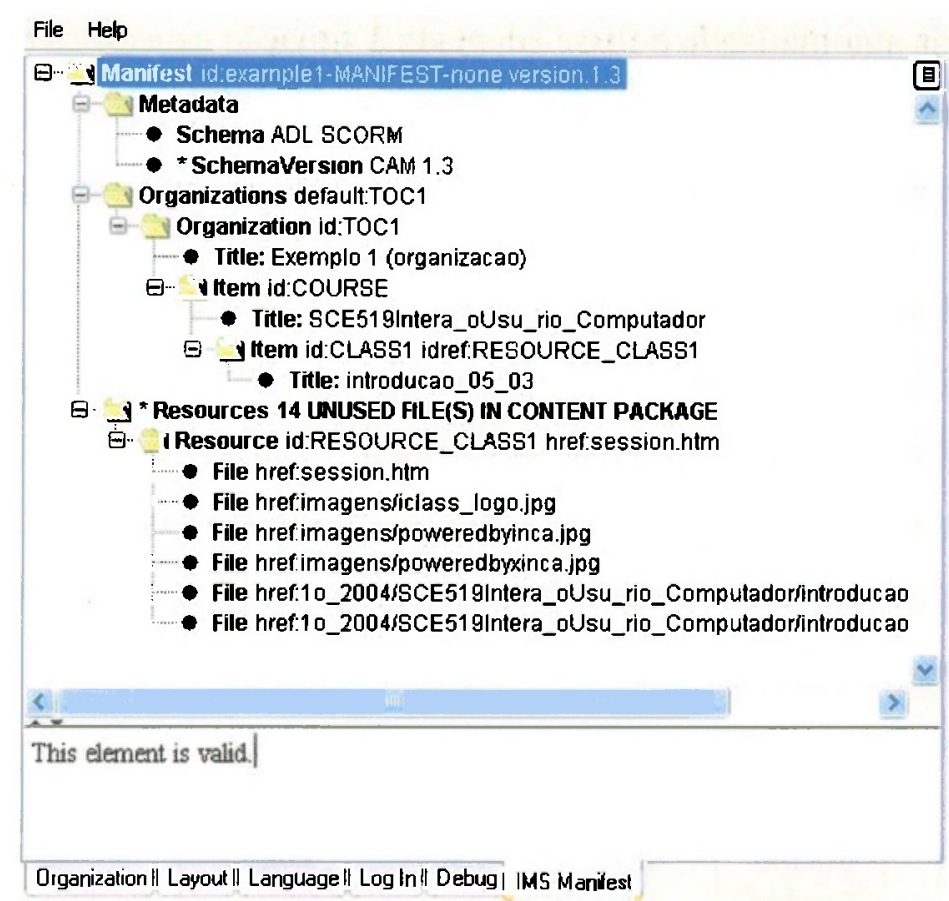

Figura 6.13: Software TinyLMS mostrando a estruturação do objeto de aprendizagem criado

\subsubsection{Vantagens e Limitações}

No processo de criação de objetos de aprendizagem, talvez a maior vantagem encontrada seja a de promover integração e troca de informação entre os recursos da Web. Ainda podemos citar que, através da incorporação de metadados e transformação em objetos de aprendizagem, há a possibilidade de reuso dessas informações, já que estão sendo padronizadas.

Uma das limitações encontradas foi que, no processo de criação de objetos de aprendizagem, na etapa do preenchimento do formulário referente aos metadados, seria importante explorar toda possível informação de contexto existente no ambiente iClass para uma maior integração e usabilidade do sistema. Porém, não foi possível o completo aproveitamento dessas informações, pois elas não estavam de acordo com os elementos exigidos pela padronização do $L O M$ do SCORM.

\subsection{Integração dos serviços: iClass e Context Kernel}

Com a preocupação do uso de informações de contexto em aplicações interativas, decidiu-se integrar o Context Kernel - já que permite às aplicações manipular informações de contexto com base nas dimensões who, where, when, what, why e how - à ferramenta iClass, para que 
a mesma ficasse mais automatizada e fosse adaptada à situação específica do usuário. Foi feita a integração dos serviços, mudando somente alguns pontos na interface, já que as mudanças maiores ocorreram na maneira de se recuperar a informação e como exibí-las.

A manipulação dessas informações de contexto feita pelo Context Kernel [Bulcão Neto et. al., 2004a; Bulcão Neto et. al., 2004b] se dá através da formalização em XML de um conjunto de operações associadas a essas dimensões ${ }^{27}$. Para que as informações de contexto pudessem ser utilizadas, foi verificado que tipo de informação poderia ser armazenado nas dimensões de contexto e quais valores seriam a eles associados. Essa especificação resultou numa especificação generalizada, como na Tabela 6.1 ilustrada abaixo.

\begin{tabular}{|c|c|c|c|c|c|}
\hline & Who & When & Where & What & How \\
\hline Type & $\begin{array}{c}\text { Papel do } \\
\text { usuário. } \\
\text { "teacher" }\end{array}$ & "date" & "room" & "course" & $\begin{array}{c}\text { "course" } \\
\text { "title" } \\
\text { "subject" }\end{array}$ \\
\hline $\begin{array}{c}\text { Valor } \\
\text { associado }\end{array}$ & Login & $\begin{array}{c}\text { Dia da } \\
\text { semana }\end{array}$ & $\begin{array}{c}\text { Valor fixo: } \\
\text { intermídia }\end{array}$ & $\begin{array}{c}\text { Nome do } \\
\text { curso }\end{array}$ & $\begin{array}{c}\text { Nome do curso; } \\
\text { Título do curso; } \\
\text { Assunto do curso. }\end{array}$ \\
\hline
\end{tabular}

Tabela 6.1: Especificações gerais em termos de tipo e valores de informações de contexto

\subsubsection{Processo de Integração}

O processo de integração é feito baseado na sequêencia mostrada na Figura 6.14.

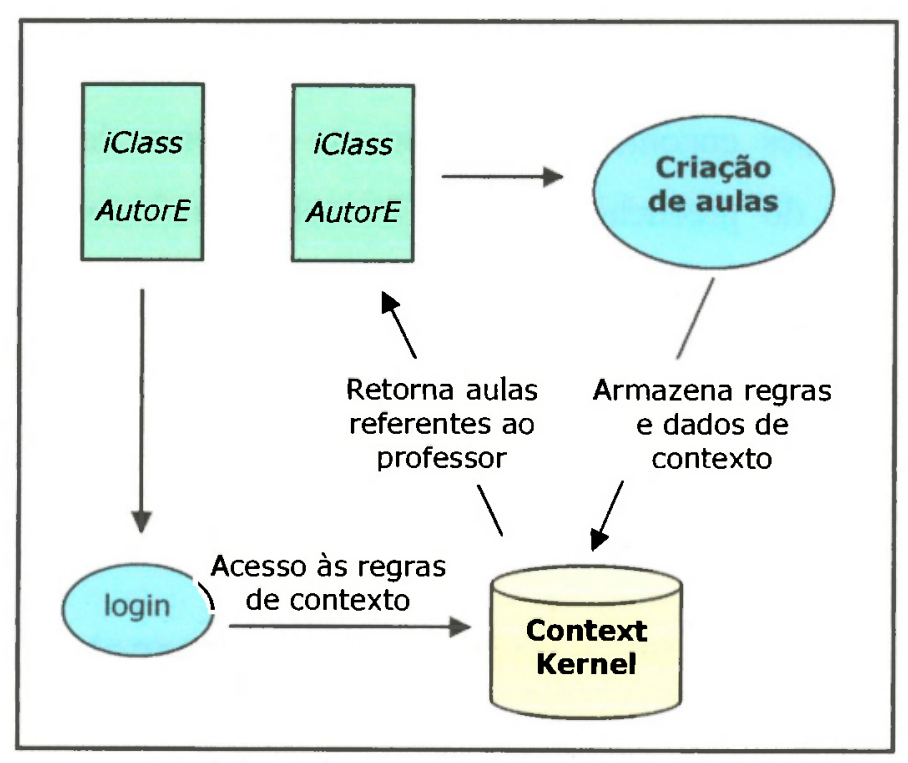

Figura 6.14: Integração entre os serviços.

${ }^{27}$ Essa implementação conta com contribuições feitas pelo mestrando Carlos Henrique Odenique Jardim e do doutorando Renato de Freitas Bulcão Neto. reponsáveis pela implementação do AutorE e Context Kernel atualmente [Bulcão Neto et. al., 2004a; Bulcão Neto et. al., 2004b]. 
$\mathrm{Na}$ integração do iClass com o Context Kernel, as modificações feitas para a integração foram as seguintes:

1) Na preparação das sessões de captura, feita pelo sistema de autoria AutorE que faz parte do iClass, o login passou a consultar o banco de dados do Context Kernel, que antes era baseada no banco de dados do iClass.

A Figura 6.15 ilustra um fragmento XML da consulta ao banco de dados quando o usuário se loga. O sistema pergunta "que curso a professora de login renatapg oferece nas terças-feiras (dia em que o usuário logou) na sala intermídia”. A Figura 6.16 mostra o resultado retornado, indicando que é o curso SCE-8886.

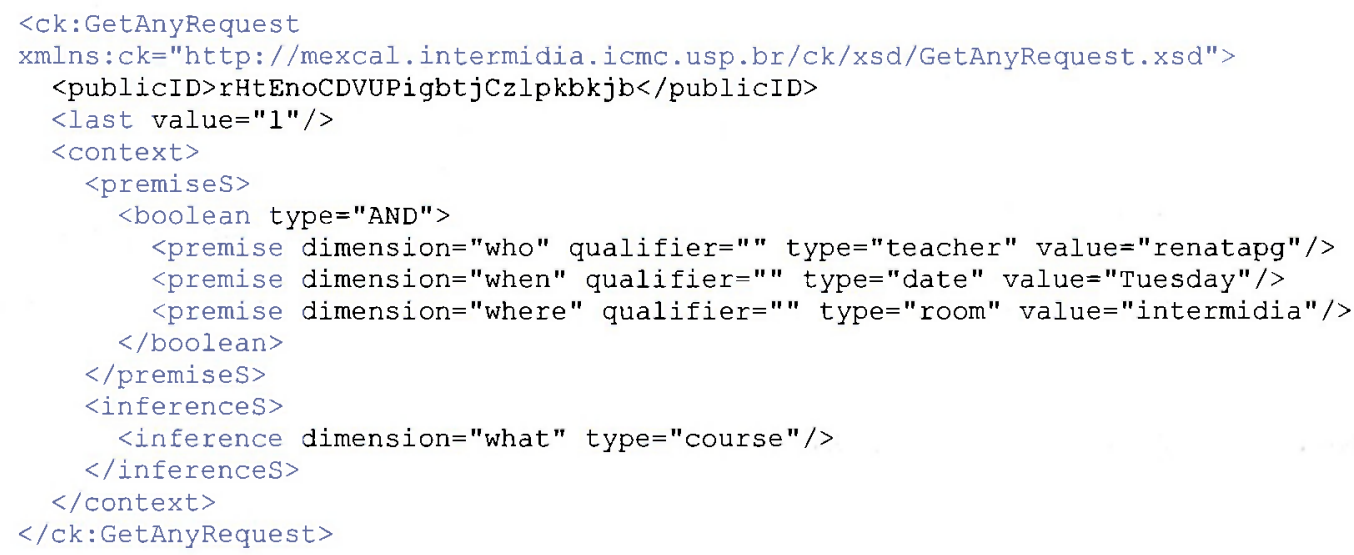

Figura 6.15: Fragmento XML de consulta ao Context Kernel.

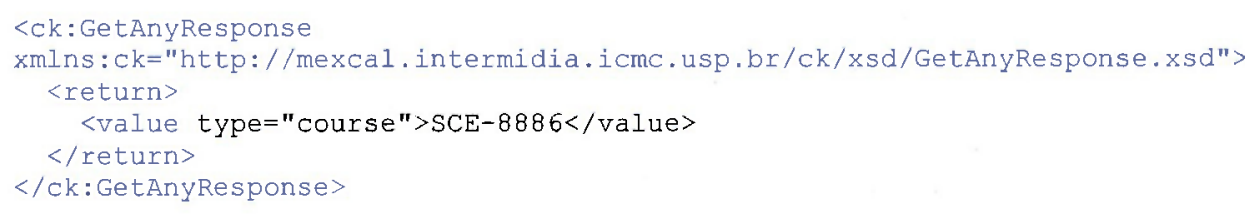

Figura 6.16: Fragmento XML do resultado retornado.

A Figura 6.17 exibe a interface no AutorE/iClass após o usuário ter logado, mostrando os cursos e as aulas daquele determinado período do dia. O sistema também fornece a opção de mostrar todas as aulas de determinado professor. Uma mudança positiva, já que o sistema demorava em exibir todas as matérias de todos os professores, além dos dados não serem relevantes. Como a interface continua a mesma, não será mostrada, pois somente o modo consulta ao banco foi alterada. 


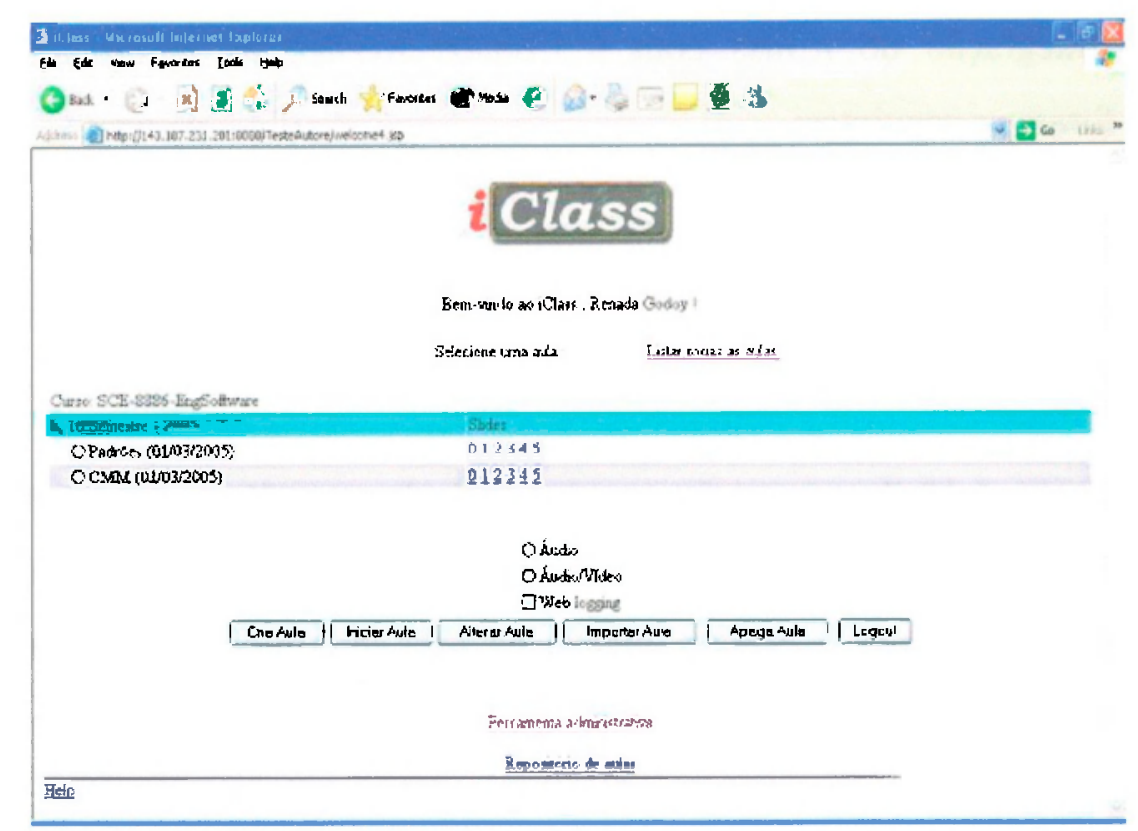

Figura 6.17:Interface no AutorE/iClass, mostrando os cursos e as aulas de determinado periodo do dia.

2) Uma outra mudança foi que, ao criar uma aula, as informações referentes a essa aula agora estão sendo armazenadas no Context Kernel através de regras de contexto e dados de informações. A Figura 6.18 ilustra um fragmento XML que será armazenado no Context Kernel após a criação de uma aula e a Figura 6.19 mostra a confirmação do resultado. A Figura 6.20 ilustra uma regra XML que também será armazenado no Context Kernel após a criação de uma aula, referente à armazenação da URL da Coteia.

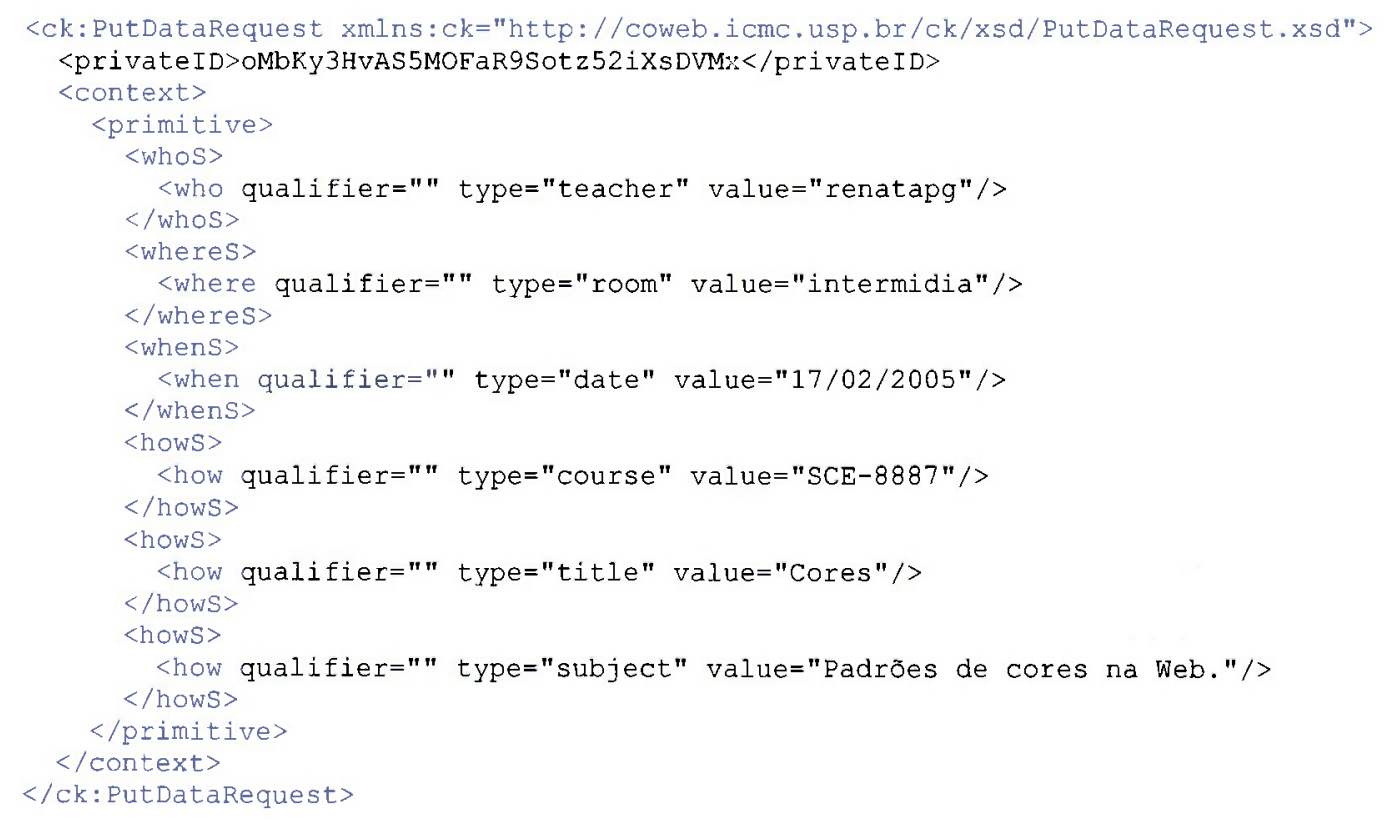

Figura 6.18: Fragmento XML que será armazenado no Context Kernel. 
Renata Paciência Godoy - Dissertação de Mestrado - Pós-Graduação - ICMC/USP - São Carlos

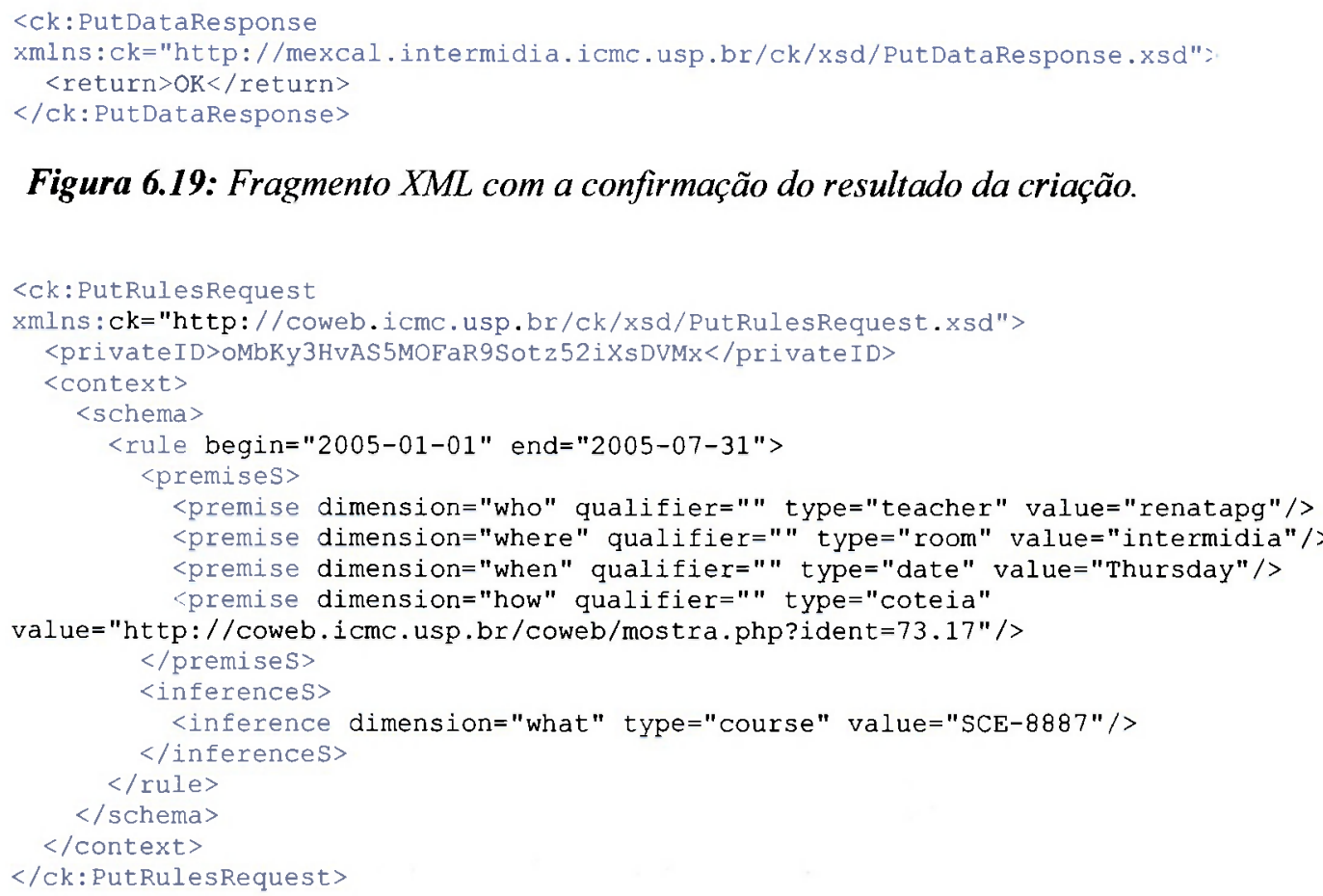

Figura 6.19: Fragmento XML com a confirmação do resultado da criação.

$<c k$ :PutRulesRequest

xmlns: ck="http://Coweb.icmc.usp.br/ck/xsd/PutRulesRequest.xsd">

<privateID>OMbKY3HvAS5MOFaR9Sotz52iXsDVMx</privateID>

<context>

$<$ schema

$<$ rule begin="2005-01-01" end="2005-07-31">

$<$ premises

$<$ premise dimension="who" qualifier="" type="teacher" value="renatapg" />

<premise dimension="where" qualifier=" " type="room" value="intermidia"/>

<premise dimension="when" qualifier=" type="date" value="Thursday"/>

value="http:///coweb.icmc.usp.br/coweb/mostra.php?ident=73.17"/

$</$ premises $>$

<inference dimension="what" type="course" value="SCE-8887"/> $</$ inferences

$</$ ck:PutRulesRequest $>$

Figura 6.20: Regra XML que será armazenado no Context Kernel, referente a URL da Coteia.

A Figura 6.21 exibe a interface no AutorE/iClass para a criação da aula. Vale notar que o "assunto", preenchido no formulário, será inserido no Context Kernel como um dado na dimensão how.

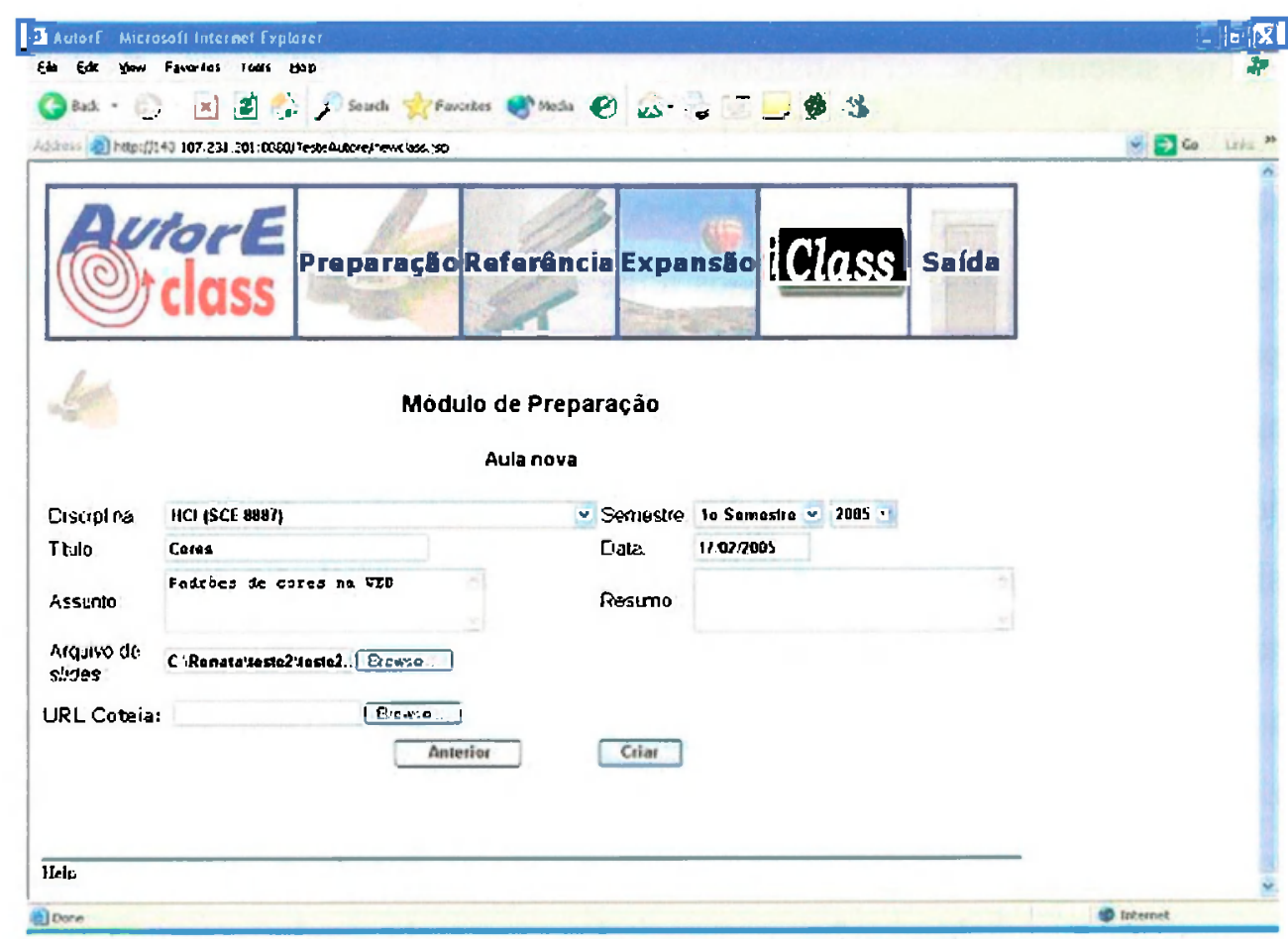

Figura 6.21: Interface no AutorE/iClass para a criação da aula. 
Renata Paciência Godoy Dissertação de Mestrado-Pós-Graduação ICMC/USP-São Carlos

\subsubsection{Vantagens e Limitações}

A integração do Context Kernel com o iClass apresenta uma grande vantagem, pois: através do uso das informações de contexto, permite-se que a aplicação (no caso o iClass para a criação de aulas) se adapte à necessidade especifica do usuário (mostra somente as aulas do próprio usuário num determinado período de tempo), além de proporcionar que as ferramentas fiquem mais automatizadas.

Quanto às limitações, encontramos algumas relacionadas à integração do C'ontext Kernel com o iClass durante a implementação. A primeira é na questão de não termos sensores para obtermos a localização (dimensão de contexto where) do usuário em um determinado ambiente. A solução encontrada foi associarmos a dimensão de contexto where a um lugar fixo, que convenhamos, acaba não sendo tão ubíquo assim.

A segunda limitação é na questão da dimensão de contexto when, pois o C'ontext Kernel armazena as informações de tempo especificadas em dias da semana, não tendo como obtê-las por horário. A solução encontrada foi fazcr a seleção da dimensão when com uma janela de tempo para resolver o problema.

\subsection{Consideraçōes Finais}

Com a inclusão das funcionalidades do padrão $S C O R M$ ao iClass, qualquer conteúdo armazenado no sistema pode ser transformado $\mathrm{cm}$ objeto de aprendizagem. Esses objetos de aprendizagem ampliam o uso do material, pois, como são criados a partir dos slides dados numa determinada aula, os professores podem criar objetos de estudo com as informações mais relevantes de cada aula, provendo aos alunos uma ênfase no material de estudo. Essas novas capacidades ampliam o poder de utilização do sistema $i$ Class, reusado como objeto de aprendizagem.

Fica claro como cada vez mais é importante a construção (e no caso aqui, a expansão) de dispositivos e aplicações para suportar a captura automatizada de experiências ao vivo. Esses sistemas, integrados com o uso de informações de contexto através do Context Kernel, permitem que essas ferramentas sejam cada vez mais adaptadas à situação do usuário, já que fornecem somente as informações de interesse do mesmo. A implementação então, possibilitou a incorporação de metadados à informação capturada de maneira que quaisquer metadados possam ser padronizados e associados, tanto de modo automático, como sob demanda do usuário. 


\section{Conclusões}

Uma caractcrística importante de aplicações de computação ubíqua é a utilização de informações de contexto para especializar os serviços prestados aos usuários. Sistemas de captura e acesso, outro tema importante da área de computação ubíqua, utilizam aplicações Web para fornecer visualização das informações capturadas. Uma lacuna identificada $\mathrm{cm}$ relação a aplicações de captura e acesso é que, muitas vezes, tais aplicações são desenvolvidas sem atenção para um possível reuso, por parte de outras aplicações, do material capturado. Por exemplo, com o aumento das pesquisas provocadas pelo crescimento das aplicações de $e$ learning, ensino à distância e utilização de objetos de aprendizagem, uma importante demanda é a associação de metadados à informação capturada por sistemas de captura e acesso do domínio de ensino-aprendizagem, de modo a viabilizar o intercâmbio e reuso das informações capturadas.

Neste trabalho foram realizadas especificações que, partindo de informações capturadas pelo sistema iClass, permitem a criação de objetos de aprendizagem de acordo com o padrão SCORM tanto de modo automático como manual. No primeiro caso, metadados associados a informações de contexto são obtidos automaticamente a partir do Context Kernel. No segundo caso, informações adicionais podem ser incluídas explicitamente pelo usuário a partir de um conjunto de formulários que, especificados de acordo com o padrão SCORM, contém metadados considerados relevantes dada a utilização usual do sistema iClass. 
Com o desenvolvimento de objetos de aprendizagem e a extensão de informações capturadas no iClass, torna-se possível fornecer auxílio para implantação e utilização destes sistemas no cenário de educação nacional, que vem passando por um processo de grande expansão atrelado ao andamento de grandes projetos na área como o TIDIA-Aprendizagem Eletrônica ${ }^{28}$ e dos programas de educação a distancia (EAD) nas universidades.

\subsection{Contribuições}

Algumas contribuições podem ser identificadas sob o ponto de vista do projeto. Com relação aos objetivos gerais do trabalho, as principais contribuições são:

- Criação de um mecanismo que permite a incorporação de metadados à informação capturada de modo que quaisquer metadados manipulados sejam padronizados;

- Criação de um mecanismo que permite a incorporação de metadados à informação capturada de modo que metadados possam ser associados de modo automático a permitir intercâmbio;

- Criação de um mecanismo que permite a incorporação de metadados à informação capturada de modo que metadados possam ser adicionados sob demanda do usuário.

As principais contribuições sob o ponto de vista do processo de criação de objetos de aprendizagem são:

- Possibilidade de incorporação de metadados de maneira automática e sob demanda do usuário;

- Utilização de Web services no contexto educacional:

- Possibilidade de criação de objetos de aprendizagem baseadas no padrão SCORM, através da extensão do sistema iClass;

- Possibilidade de reuso dos objetos de aprendizagem, já que estão sendo padronizados;

\footnotetext{
${ }^{28} \mathrm{http} / /$ tidia-ae.incubadora.fapesp.br/portal
} 
Renata Paciência Godoy - Dissertação de Mestrado - Pós-Graduação - KCMC/USP - São Carlos

- Geração dinâmica de conteúdo para a Web por meio de conteúdo $X M L$, através do framework Apache Cocoon;

- O serviço é ainda bastante extensível, podendo scr adequado a novas tecnologias e necessidades do projeto InCA-SERVE.

Com relação à integração dos serviços iClass e Context Kernel, as principais contribuições são:

- Permite que a aplicação iClass de adapte a necessidade do usuário, já que utiliza informações de contexto;

- Possibilidade de incorporação de metadados de mancira automática;

- Integração e troca de informações na Web no contexto de aplicações de captura e acesso, e cientes de contexto.

\subsection{Trabalhos Futuros}

O trabalho realizado apresenta algumas limitações, muitas das quais podem ser tratadas com a continuidade do trabalho. Algumas possibilidades de atividades a screm realizadas, como conseqüência do trabalho já rcalizado, são:

- No processo de criação de objetos de aprendizagem, o preenchimento do formulário referente aos metadados pode ser melhorado, associando-se mais informações de contexto existentes iClass que não estão sendo utilizadas, bem como uma maior reutilização nas informações obtidas através do Context Kernel;

- Ainda no processo de criação, poderiam-se criar objetos de aprendizagem automaticamente tanto de uma aula inteira com os metadados default, sem a necessidade de qualquer preenchimento de formulário; bem como, de um curso completo de determinada matéria;

- Utilização de outras informações armazenadas pelo iClass, além das imagens (texto dos slides, endereços de páginas Web visitadas durante a aula, etc.); 
- A extensão do processo de criação de objetos de aprendizagem. Atualmente, a ferramenta só disponibiliza a criação de objetos de aprendizagem. Como trabalho futuro, pode ser investigada a exportação desse material para repositórios públicos de objetos de aprendeizagem;

- Melhoria da usabilidade na interface de criação de objeto de aprendizagem;

- Criação de uma versão do sistema em português;

- Extensões com informações de contexto where e when, que hoje tem limitações no Context Kernel;

- Extensão na integração dos sistemas, como por exemplo, da ferramenta Coteia.

\subsection{Considerações finais}

Esta dissertação corresponde a uma contribuição para a área de computação ubíqua, identificando a importância do reuso de informações capturadas por aplicações de captura e acesso e propondo a associação de metadados a essas informações - tanto de forma automática, com a exploração de informações de contexto, como de forma manual, com a utilização de interfaces Web. Para exemplificar essa proposta, o trabalho envolveu a associação de metadados ao sistema iClass padronizadas em SCORM (Sharable Content Object Reference Model), fazendo uso de informações de contexto obtidas do Context Kernel.

Além disso, foram abordados alguns conceitos na área de metadados, objetos de aprendizagem e informações de contexto, sobre os quais as implementações realizadas se baseiam. Apresentou-se a área de computação ubíqua, enfocando as aplicações de captura e acesso e aplicações ciente de contexto, no qual a implementação esteve inserida. 


\section{Apêndice A}

\section{Empacotamento do Conteúdo SCORM}

Este apêndice é bascado no estudo do SCORM CAM versão 1.3 [SCORM, 2004]. Através desse estudo e das necessidades do projeto, a autora desenvolveu a parte do projeto referente às especificações do pacote de conteúdo conforme detalhado neste capítulo. Uma véz que um conteúdo de aprendizado ć projetado e construído, há a necessidade de tornar esse contcúdo disponível para estudantes, repositórios ou Sistemas de Gerenciamento de Aprendizado (LMSs).

A proposta do Pacote de Conteúdo é disponibilizar um padrão para trocar conteúdo de aprendizado entre diferentes sistemas ou ferramentas, provendo a descrição da estrutura ou organização e o comportamento para uma colcção de conteúdo de aprendizado. Para isto, foi designada a especificação do conteúdo de empacotamento IMS para prover esse padrão, que disponibiliza um modelo comum de entrada / saída que qualquer sistema pode suportar.

O conteúdo de empacotamento SCORM é um conjunto de orientações e requisitos específicos que adere estritamente às especificações do conteúdo de empacotamento IMS, além de prover requisitos adicionais e orientação de implementação para empacotar Assets, SC.OS e organização de contcído.

Este capílulo é organizado da seguinte maneira: Na Seção $\Lambda .1$. são delinidos os componentes e os conceitos fundamentais que lidam com o Pacote de Conteúdo. A Seção A.2 apresenta os componentes de um Manifesto, que delinem a estrutura do Pacote de Conteúdo do Manifesto. A Seção A.3 define o processo de construção do Pacote de Conteúdo e o arquivo do Manifesto, descrevendo os componentes XML do manifesto e os requisitos para usar esses componentes. 


\section{A.1 Componentes do Pacote de Conteúdo}

Esta seção contém uma descrição dos Pacotes de Conteúdo, a nomenclatura que descreve esses pacotes e sua constituição. O escopo da especificação do conteúdo de empacotamento IMS é focalizado em definir interoperabilidade entre sistemas que desejam importar, exportar, agregar e desagregar pacotes de conteúdo. Um Pacote de Conteúdo IMS contém dois componentes principais:

- Um documento XML descrevendo a estrutura do conteúdo e os recursos associados ao pacote, denominado arquivo manifesto (imsmanifest. xml);

- Os arquivos físicos que fazem parte do pacote de conteúdo.

A Figura A.1 é um diagrama conceitual que ilustra os componentes do Pacote de Conteúdo IMS

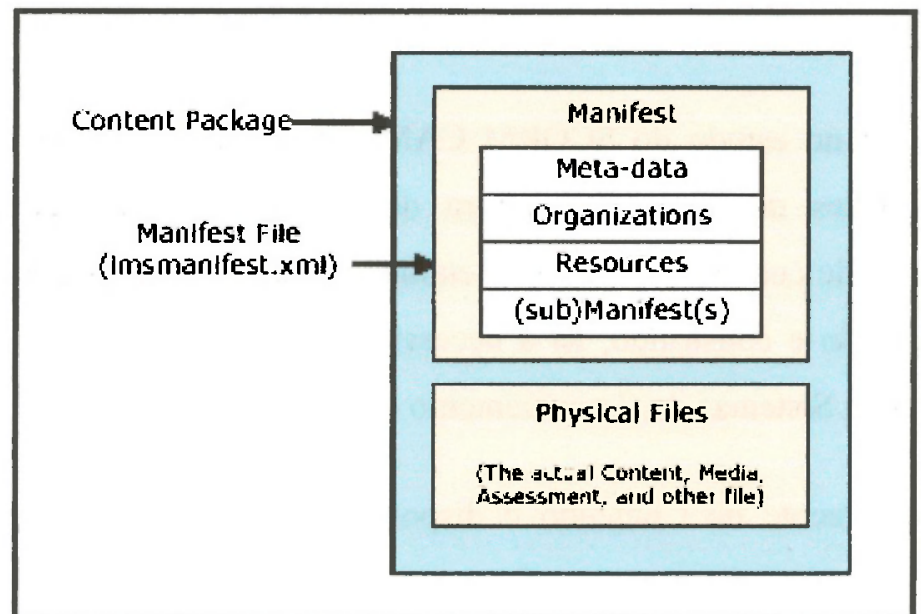

Figura A.I - Diagrama conceitual do Pacote de conteúdo [SCORM, 2004]

\section{A.1.1 Pacote de Conteúdo}

Um Pacote de Conteúdo representa uma unidade de aprendizado. A unidade de aprendizado pode fazer parte de um curso que tem relevância instrutiva fora da organização do curso ou pode ser entregue independentemente, como uma parte de um curso, um curso inteiro ou como uma coleção de cursos.

\section{A.1.2 Manifesto}

Um Manifesto é um documento XML que contém um inventário estruturado do conteúdo do pacote. Depois de empacotar uma coleção de cursos, Pacote de Conteúdo terá que ser desagregado para ser entregue aos estudantes em um sistema de execução LMS. 
Renata Paciência Godoy - Dissertação de Mestrado - Pós-Graduação - ICMC/USP - São Carlos

A regra geral é que um Pacote de Conteúdo sempre contém um único Manifesto que pode conter um ou mais (sub) Manifestos. O Manifesto principal sempre descreve o Pacote de Conteúdo e os (sub) Manifestos aninhados descrevem conteúdo como "curso", "objeto instrutivo" ou outro. O Manifesto deve atender às seguintes exigências, como definido pela especificação do Pacote de Conteúdo IMS:

- O arquivo do manifesto deve ter nome imsmani fest. $\mathrm{xml}$;

- O imsmanifest.xml e qualquer um dos seus arquivos de controle, como DTD e XSD, deverão estar na raiz do pacote de conteúdo;

- Todos os requisitos definidos no Pacote de Conteúdo do IMS de Especificação de Ligação XML, qualquer restrição e exigências adicionais para o ligamento IMS, como definido na Seção A.3: Construindo Pacotes de Conteúdo.

\section{A.1.3 Arquivo de Intercâmbio de Pacote (PIF)}

O Arquivo de Intercâmbio de Pacote (PIF) é uma ligação dos componentes do Pacote de Conteúdo na forma de um arquivo comprimido. O PIF contém o imsmanifest.xml, todos os arquivos de controle e os recursos referenciados no Pacote de Conteúdo (aqueles contidos no pacote de conteúdo). O SCORM recomenda que o Pacote de Conteúdo seja criado como PIF de acordo com a RFC 1951 [IETF, 1996a], que exige o formato .zip.

\section{A.2 Componentes do Manifesto}

A Figura A.2 mostra o arquivo Manifesto, que é composto de quatro seções principais: metadados, organizações, recursos e (sub) Manifesto(s).

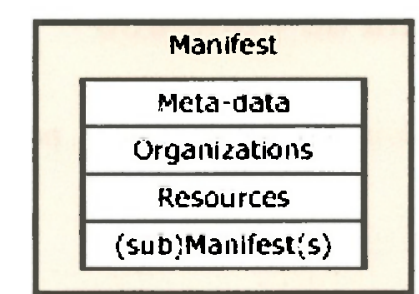

Figura A.2 - Componentes de um Manifesto [SCORM, 2004].

\section{A.2.1 Meta-data}

Metadados são definidos como dados sobre dados. Esses metadados possibilitam a pesquisa e a descoberta do próprio pacote de conteúdo, além de um mecanismo para descrever as características do pacote de conteúdo. 


\section{A.2.2 Organizações}

O componente Organizações é usado para descrever como o conteúdo é organizado dentro do Pacote de Conteúdo. Pode conter um ou mais componentes Organização, cada um descrevendo uma estrutura particular para o conteúdo do pacote. A versão atual da especificação do Pacote de Conteúdo IMS define uma maneira de organização do conteúdo, na forma de uma árvore ou hierarquia.

\section{A.2.2.1 Organizações de Conteúdo Múltiplo}

A especificação do Pacote de Conteúdo IMS separa recursos de aprendizado da maneira que esses recursos são organizados, permitindo um ou mais usos do mesmo recurso dentro de contextos diferentes ou usos. Para entregar o Pacote de Conteúdo a um estudante em um LMS, deve haver pelo menos uma organização de conteúdo.

\section{A.2.2.2 Organização do Conteúdo}

A Organização do Conteúdo descreve como o Pacote de Conteúdo é organizado para uso. É como um tipo de índice para os recursos no pacote, além de ser usada como um modo para descrever uma hierarquia de atividades de aprendizagem que exploram os recursos de aprendizagem. Para qualquer atividade definida em uma Organização de Conteúdo, o desenvolvedor pode ou não definir comportamentos e regras específicas.

Organizações de Conteúdo fornecem meios para representar a estrutura de coleções de recursos de aprendizagem. No contexto do SCORM, é o I MS que é responsável pela entrega do conteúdo de acordo com as prescrições da organização do conteúdo.

\section{A.2.2.3 Representando Estrutura de Conteúdo}

A Organização de Conteúdo SCORM inclui componentes para definir diferentes aspectos de uma estrutura de conteúdo:

- Hicrarquia do Conteúdo: representa uma organização lógica para os recursos de aprendizagem ou atividades que usam esses recursos;

- Metadados: componente opcional, com dados sobre uma atividade definida na organização do conteúdo;

- Seqüienciamento, Seqüenciamento Adaptável e Navegação: prescrições opcionais podem ser embutidas na organização do conteúdo se o desenvolvedor quiser controlar qual recurso de 
aprendizagem será apresentado ao estudante. Devido ao escopo do trabalho, não detalharemos esse item.

O modelo de agregação SCORM é neutro sobre a complexidade do conteúdo, o número de níveis hierárquicos de uma unidade particular de instrução e a metodologia instrutiva empregada.

\section{A.2.2.3.1 Hierarquia de Conteúdo}

Uma coleção de recursos de aprendizagem pode ser organizada em uma hierarquia, que pode ser representada como uma Organização de Conteúdo. Outra maneira para organizar recursos de aprendizagem é definir uma hierarquia de atividades que especificam recursos para prover uma experiência de aprendizagem específica.

A especificação do Pacote de Conteúdo IMS define um conjunto de termos que são usados na representação da Hierarquia de Conteúdo. A estrutura hierárquica é uma árvore aninhada de elementos Item, onde a raiz é o elemento Organização. Um elemento Item pode referenciar um elemento Recurso, que descreve um recurso de aprendizagem específico para ser lançado quando o Item é usado como uma atividade, como mostra a Figura A.3.

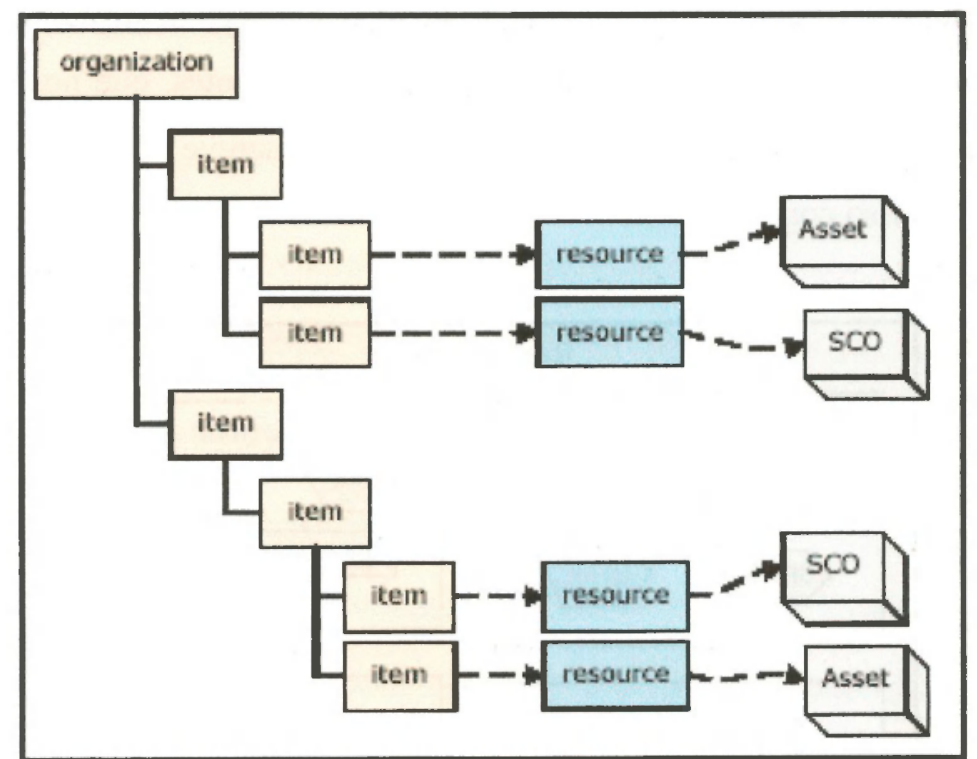

Figura A.3-Terminologia de Hierarquia de Conteúdo IMS [SCORM, 2004].

SCORM e a Especificação de Sequenciamento Simples IMS [IMS, 2003] são perfis da especificação do conteúdo de empacotamento IMS que possuem restrições. Uma é que somente Itens folha (Item que não têm filho) possam referenciar um recurso de aprendizagem. Outra é que uma Organização deve conter pelo menos um Item. Além disso, o SCORM requer que um recurso de aprendizagem seja de um de dois tipos: ou um SCO ou um Recurso. 


\section{A.2.2.3.2 Metadados}

Quando um recurso de aprendizagem é criado com a intenção de se tornar reutilizável, é apropriado descrevê-lo com metadados, que permitem que o recurso de aprendizagem possa ser encontrado quando armazenado em um Pacote de Conteúdo ou em um Repositório. Isto torna o recurso de aprendizagem mais reutilizável, pois a pessoa pode inspecionar só o metadado, decidindo reusá-lo sem ter que inspecionar o próprio recurso. Quando o uso do recurso de aprendizagem é definido como parte de uma estratégia de aprendizagem, podem ser usados metadados adicionais para descrever a atividade que usa o recurso.

Se há alguma chance do Pacote de Conteúdo ser modificado, reorganizado ou desagregado para o reuso em algum momento futuro, então faz sentido prover metadados para todo elemento que poderá ser reusado ou precisará ser interpretado.

\section{A.2.3 Recursos}

O componente Recurso de um Manifesto pode descrever recursos externos ou arquivos físicos localizados no pacote. Esses arquivos podem ser mídias, texto ou objetos de avaliação. Agrupamentos conceituais e relacionamentos entre arquivos podem ser representados dentro do componente Recurso. Na Figura A.4 um único Recurso é composto de vários componentes, que no SCORM são simples Assets, listados como Arquivos dentro do recurso. O Recurso descreve ainda a parte física (inventário de componentes) do recurso como um todo.

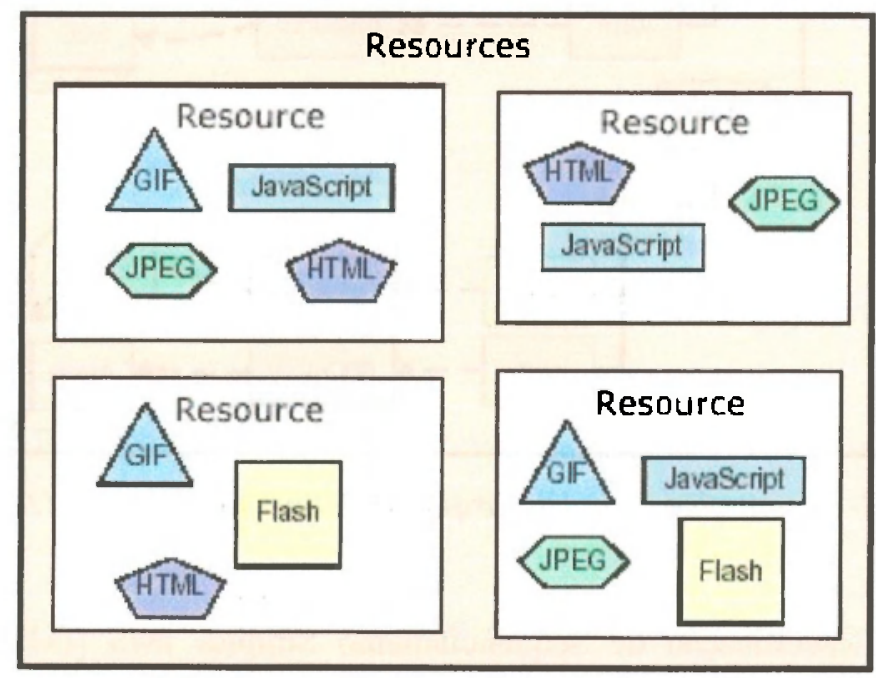

Figura A.4 - Recursos do Manifesto [SCORM, 2004]. 


\section{A.2.4 Arquivos Fisicos}

() componente Arquivos Físicos representa os arquivos referenciados no componente Recurso. Esses arquivos podem ser arquivos locais contidos de fato dentro do pacote de conteúdo, ou podem ser arquivos externos referenciados por uma URI.

\section{A.3 Construindo o Pacote de Conteúdo}

Esta seçâo apresenta os requisitos para construir os pacotes de conteúdo SCORM e o XML de ligação para a especificação do conteúdo de empacotamento IMS, além de definir os requisitos para cada aplicação do pacote de conteúdo SCORM.

\section{A.3.1 Arquivo Manifesto}

Esta seção define os requisitos para a construção do arquivo imsmani fest.xml, que estrutura um Pacote de Conteúdo. Se o Pacote de Contcúdo pode ser entregue para o usuário final, então o Manifesto também deve conter informações sobre como o conteúdo é organizado. Os tipos de dados c formatos dos elementos são definidos pelos tipos de dados de XML Schema [W3C, 2001].

Devido à extensão do trabalho, serão apresentados somente os elementos e atributos obrigatórios e que foram julgados importantes para o desenvolvimento do projeto. $\Lambda$ Figura A.5 mostra a composição básica do arquivo imsmani fest. xml.

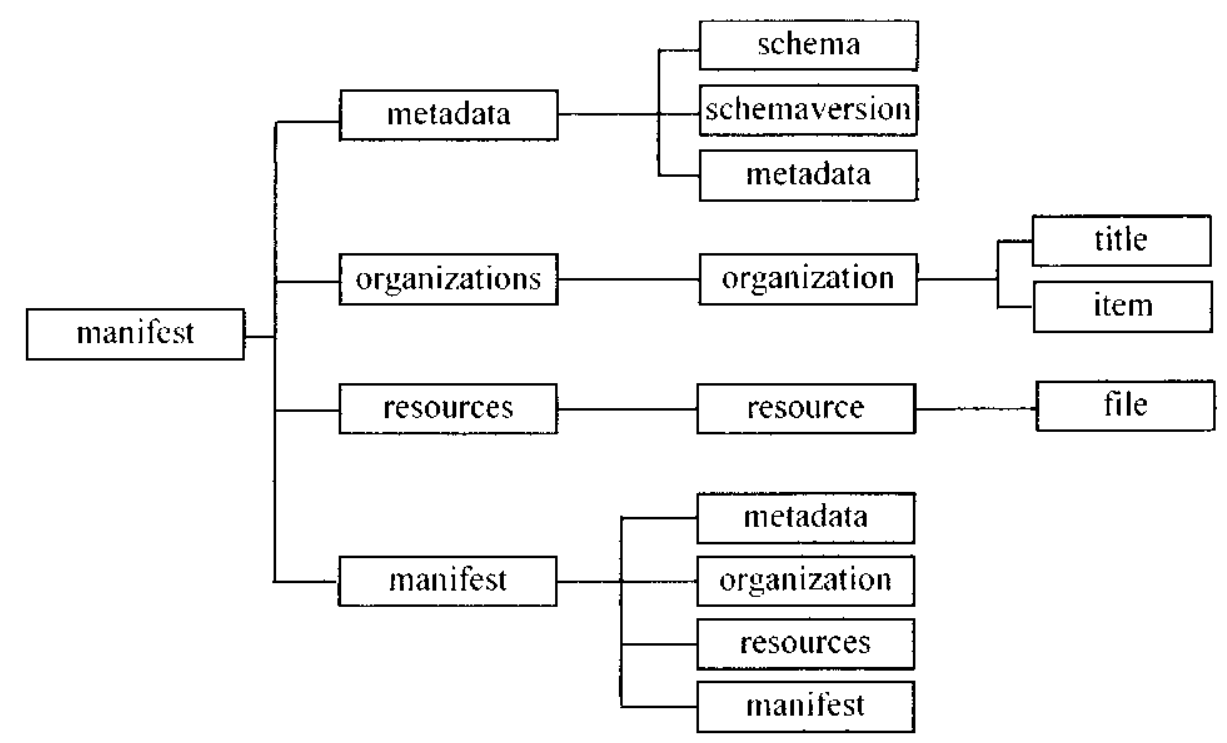

Fìura A.5 - Composição do arquivo imsmanifest. xmI . 


\section{A.3.1.1 Elemento <manifest>}

$O$ elemento <manifest> representa uma unidade instrutiva reusável que encapsula metadados, Organizações e Recursos. Ele é o nó raiz do arquivo imsmanifest.xml. Ocorrências de outros elementos <manifest> são usadas para compartilhar arquivos, metadados e organizações estruturais para agregação, desagregação e reuso. Esses elementos fĩlhos <manifest> são referenciados como (sub) Manifests, mas não estaremos entrando em detalhes, pois no desenvolvimento do projeto determinamos o uso de somente um manifesto, ficando o desenvolvimento da utilização de (sub)Manifests para trabalhos futuros.

Qualquer declaração deve ser feita dentro do elemento <manifest $>$. O elemento <manifest> contém os atributos:

- Identifier: identifica o manifesto e é único. O atributo é provido pelo autor ou pela ferramenta de autoria durante o desenvolvimento do manifesto. É representado por um ID do XML Schema [W3C, 2001];

- Version: identifica a versão do manifesto. É usado para distinguir entre manifestos com o mesmo identificador. É representado por uma string de até 20 caracteres através do XML Schema [W3C, 2001].

O clemento <manifest> contém os seguintes clementos filhos:

- <metadata $>$

- <organizations>

- <resources $>$

- $<$ manifest $>$

\section{Exemplo:}

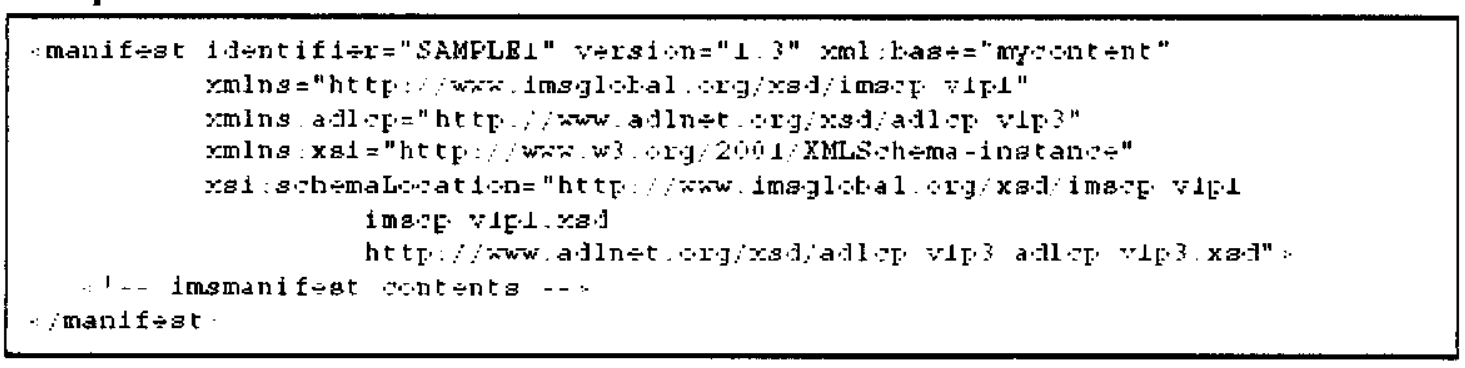

\section{A.3.1.1.1 Elemento <metadata $>$}

O elemento <metadata> contém metadados que descrevem o Manifesto e informações relevantes que descrevem o Pacote de Conteúdo como um todo. O elemento $<$ metadata $>$ contém os elementos: 
- <schema>: descreve o esquema que define e controla o Manifesto. É representado por uma cadeia de caracteres do XML Schema [W3C, 2001], seguindo um vocabulário restrito que contém a palavra reservada: ADL SCORM (indica que o pacote é construído de acordo com os requisitos definidos pelo SCORM);

- <schemaversion>: descreve a versão do esquema. É representado por uma cadeia de caracteres do XML Schema [W3C, 2001], seguindo um vocabulário restrito que contém a palavra reservada: CAM 1.3 (indica que o pacote é construído de acordo com os requisitos definidos pelo SCORM CAM versão 1.3);

- $\{$ metadados $\}$ : Os metadados devem ser inseridos dentro do Manifesto usando um esquema apropriado de metadados, como o esquema LOM [IEEE LTSC, 2002], que será apresentado no Apêndice B. Há alguns tipos de mecanismos para inserir metadados no manifesto, como:

- definindo um nome em um elemento XML com um prefixo específico;

\section{Exemplo:}

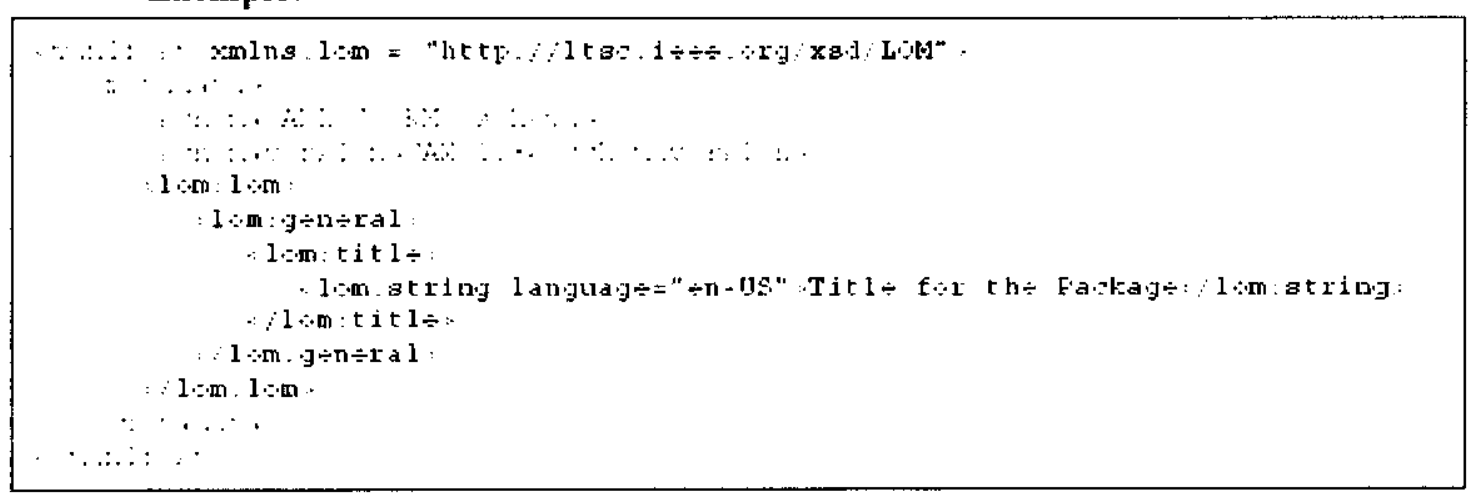

- definindo u m nome cm um elemento XML sem um prefixo;

Exemplo:

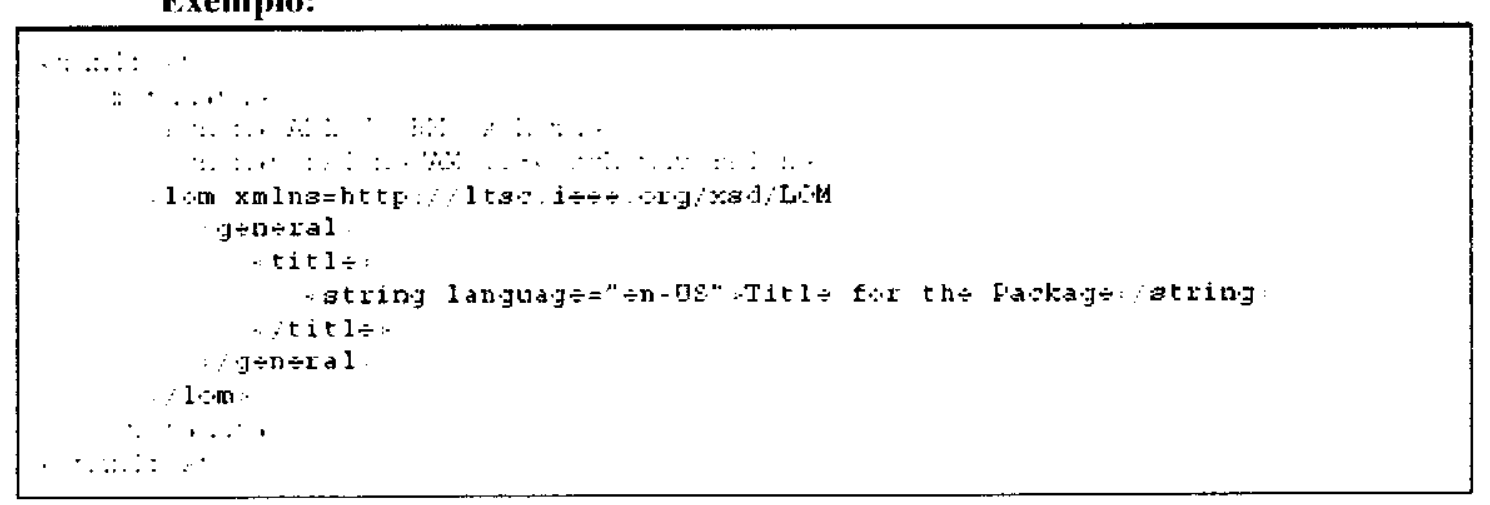

- através do elemento <location> que provê uma maneira de descrever a localizaçăo de onde o metadado pode ser encontrado. 
Exemplo:

\begin{tabular}{|c|}
\hline 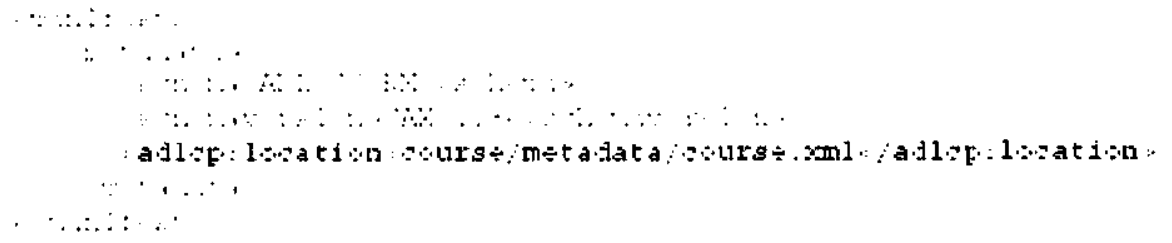 \\
\hline
\end{tabular}

Um exemplo que mostra o uso do elemento <metadata> seria:

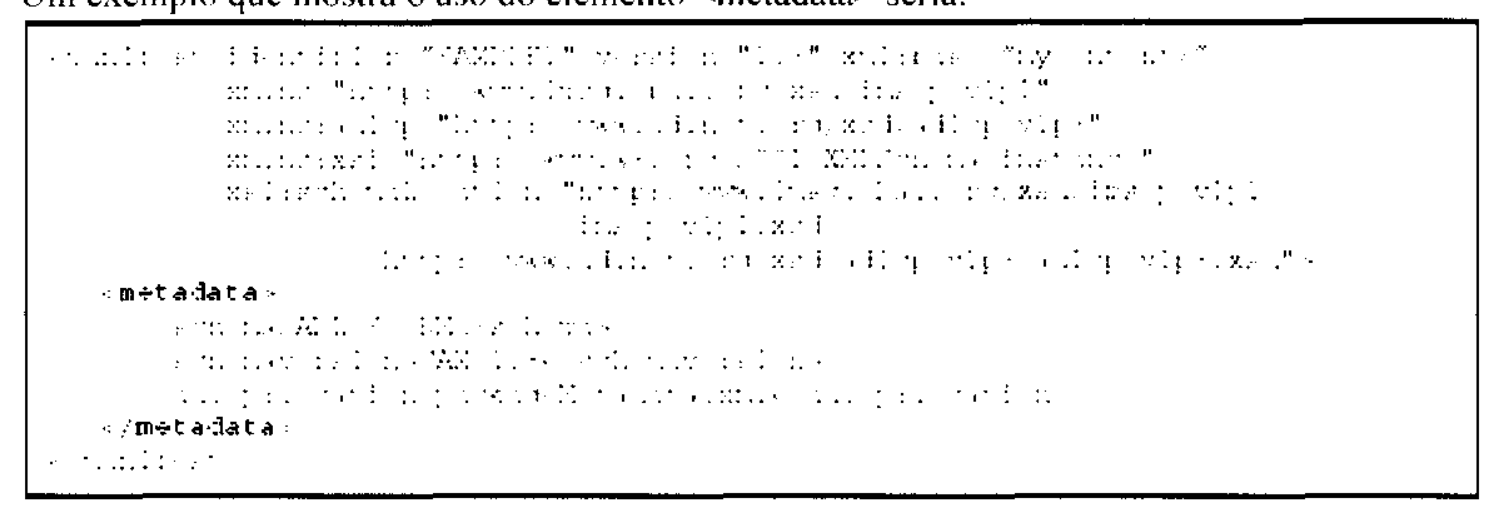

\section{A.3.1.1.2 Elemento <organizations>}

O elemento <organizations> descreve uma ou mais estruturas ou Organizações para o pacote. Ouando for construir um Pacote de Conteúdo SCORM, este elemento deve conter pelo menos um subelemento <organization>. O elemento <organizations> contém o atributo:

- Default: identifica a organização default para usar. O valor deste elemento deve referenciar o atributo identifier do elemento <organization> ou o atributo identifier do elemento <manifest>. É representado por um IDREF através do XML Schema [W3C, 2001];

O elemento <organization> contém o elemento filho:

- <organization>

Exemplo:

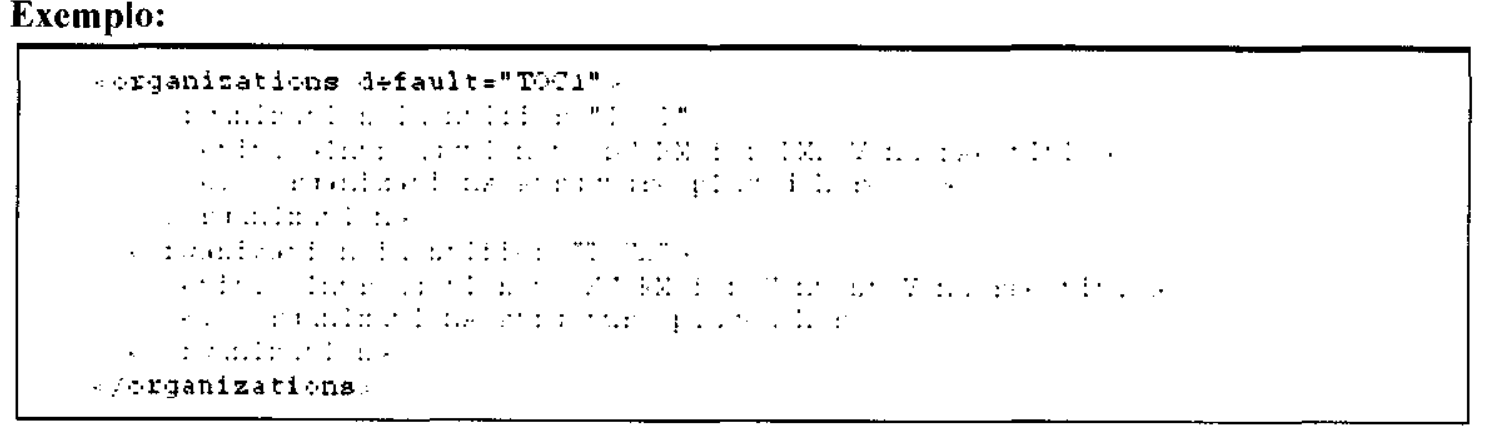




\section{A.3.1.1.2.1 Elemento <organization>}

O elemento <organization> descreve uma organização hierárquica. O conteúdo da organização pode ser uma aula, módulo, curso, capítulo, entre outros. O elemento <organization> contém o atributo:

- Identifier: é o identificador da organização que é único dentro do Manifesto. O valor é dado pelo autor ou pela ferramenta de autoria, sendo representado por um ID de XML Schema [W3C, 2001]

O elcmento <organizations> contém o elemento filho:

- <title>: descreve o título da Organização. Pode ser usado para ajudar o usuário a decidir qual organização escolher. Dependendo do que a organização estiver descrevendo, o título pode ser, por excmplo, um curso, módulo ou aula. É representado por uma cadeia de até 200 caracteres de XML Schema [W3C, 2001];

- <item>: é um nó que descreve a estrutura hierárquica da organização, que pode ser aninhado e repetido com outros elementos $<\mathrm{item}>\mathrm{em}$ qualquer número de níveis. O elemento $<$ item> representa uma Atividade na organização do conteúdo. O elemento <item> por sua vez, contém o atributo:

- Identificr: é o identificador para o item que é único dentro do manifesto, sendo representado por um ID de XML Schema [W3C, 20011;

O elemento <item $>$ contém os elementos filhos:

o <title>: descreve o título do item. I: representado por uma cadeia de até 200 caracteres de XML Schema [W3C, 2001].

Exemplo:

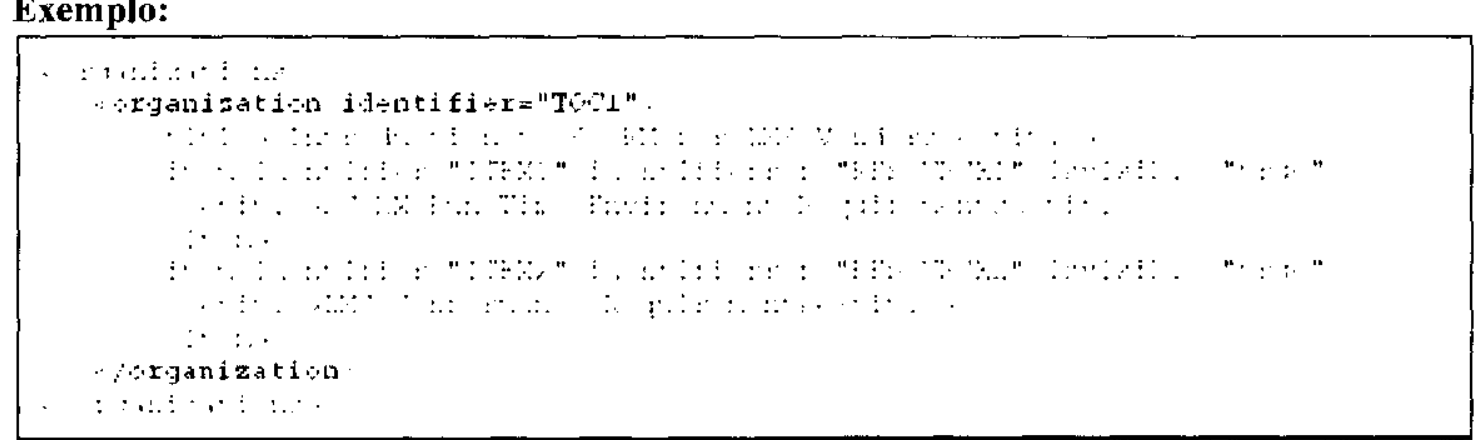

\section{A.3.1.1.3 Elemento <resources>}

O elemento <resources> é uma coleção de referencias para recursos. O elemento <resources> contém o elemento filho:

- $<$ resource $>$ 


\section{A.3.1.1.3.1 Elemento $<$ resource $>$}

O elemento <resource> é a referência para o Recurso. Há dois tipos primários de Recursos definidos dentro do SCORM: SCOS e Assets. O elemento <resource> contém os atributos:

- Identifier: é o identificador do recurso que é único dentro do escopo que contém o arquivo manifesto. $\mathrm{O}$ valor é dado pelo autor ou pela ferramenta de autoria, sendo representado por um ID de XML Schema [W3C, 2001];

- Type: indica o tipo de Recurso, que deve ser setado para webcontent.

- adlcp:scormType: define o tipo de recurso SCORM, que deve ser setado para SCO ou Asset;

- href: referencia a URL que representa o ponto de entrada do recurso. É representado por uma cadeia de até 2000 caracteres de XML. Schema [W3C, 2001].

O elemento <resource> contém os elementos filhos:

- <file>: uma lista de arquivos do qual o recurso depende. Pode ser repetido se necessário para cada arquivo de um dado recurso. $O$ elemento <file> por sua vez, contém o atributo:

- href: identifica a localização do arquivo, sendo representado por uma cadeia de de até 2000 caracteres de XMI. Schema [W3C, 2001].

\section{Exemplo:}

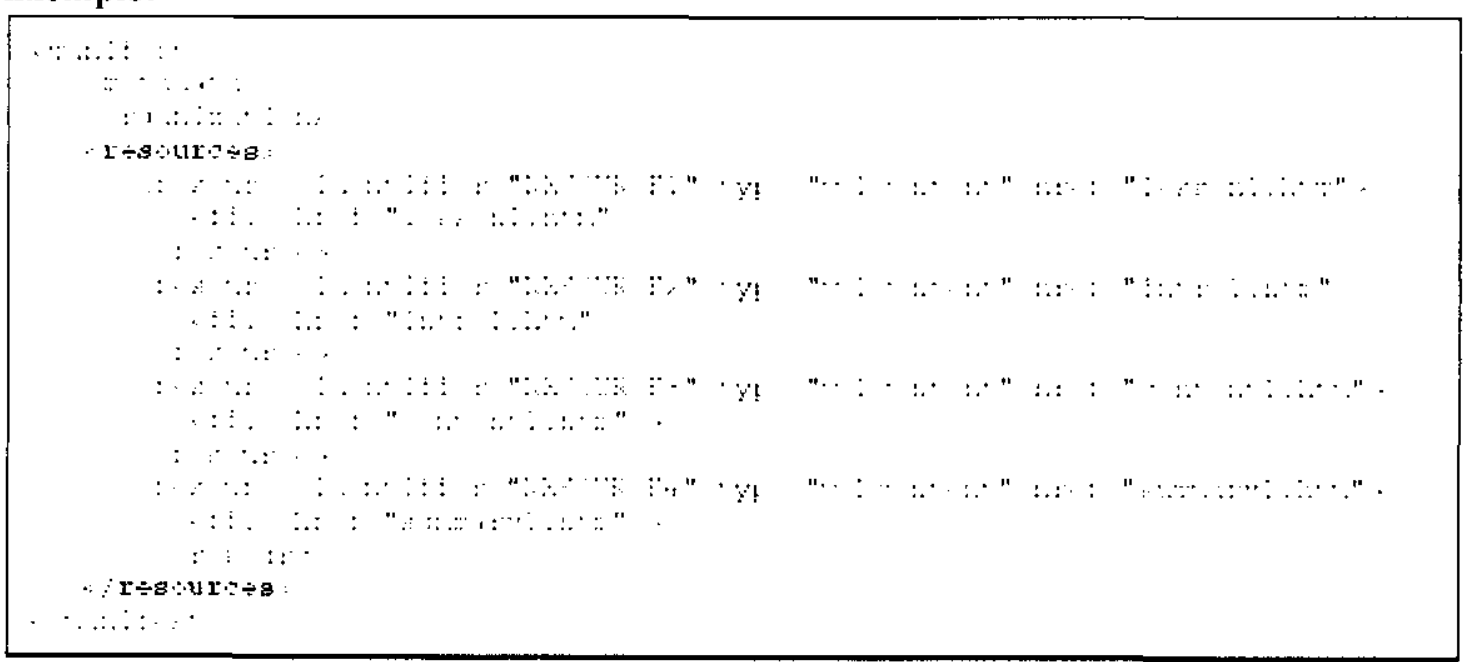




\section{Apêndice B Especificações dos Metadados SCORM}

Este apêndice apresenta quais foram as especificações dos metadados adotadas nos trabalhos de modelagem e implementação desta dissertação, baseadas no estudo do SCORM CAM versão 1.3 [SCORM, 2004]. O perfil da aplicação SCORM definida aqui, referencia diretamente o IEEE Standard for Learning Object Metadata (LOM) [IEEE LTSC, 2002] e o IEEE Standard for Extensible Markup Language (XML) Binding for Learning Object Metadata Data Model [IEEE LTSC, 2004] Através desse estudo e das necessidades do projeto, a autora desenvolvcu a parte do projeto referente às especificações dos metadados segundo os requisitos c condições estabelecidas a seguir.

\section{B.1 Elemento <lom>}

Todos os metadados devem ter a instância <lom> como nó principal. Esse nó começa a descrever os metadados usados para descrever o componente SCORM. O nó <lom $>$ possui nove categorias, que podem aparccer em qualquer ordem. Qualquer declaração deve ser feita dentro do elemento <lom $>$, incluindo qualquer atributo que seja considerado extensão de metadados.

Verificando a multiplicidade, nota-se que o elemento $<\mathrm{lom}>$ deve aparecer somente uma vez dentro dos metadados. $O$ elemento $<$ lom $>$ contém os seguintes elementos filhos:

- $\quad$ general $>$

- $<$ lifeCycle $>$

- $<$ metaMetadata $>$

- <technical $>$

- <educational> 
- $\quad$ rights $>$

- $\quad<$ relation>

- <annotation>

- <classification>

\section{Exemplo:}

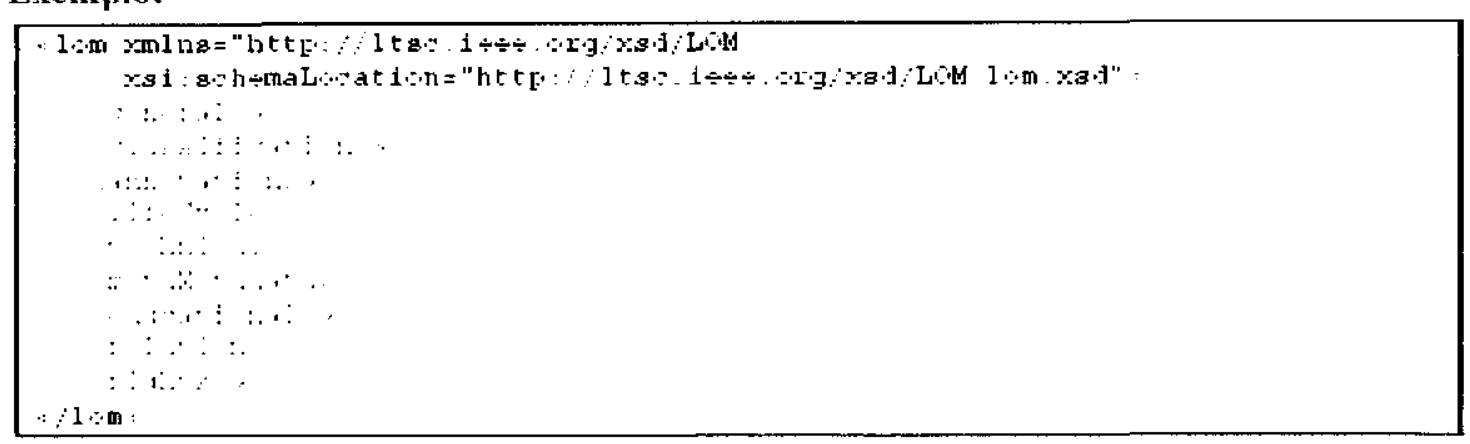

\section{B.2 Elemento <general>}

A categoria <general > agrupa informações que descrevem um recurso como um papel. Um recurso nesse caso é um componente SCORM, que pode ser um Asset, SCO, Activity ou Content Organization. Essa informação geral às vezes é vista como uma informação chave que descreve um componente particular. O elemento <general $>$ deve aparecer somente uma vez dentro do elemento $<$ lom $>$ e contém os seguintes elementos filhos:

- <identifier>

- $<$ title $>$

- <language $>$

- <description>

- <keyword $>$

- <coverage $>$

- <structure

- <aggregationLevel>

\section{B.2.1 Elemento <identifier>}

O clemento <identifier> representa um mecanismo para determinar um identificador único do componente SCORM. Isso é importante quando lidamos com várias etapas do desenvolvimento do conteúdo de aprendizagem, como versão e manutenção, por exemplo.

Através da multiplicidade, notamos que o elemento é obrigatório e pode ser repetido (até dez vezes), permitindo que os componentes possam ter vários identificadores. No sistema, é dada a opção 
Renata Paciência Godoy -- Dissertação de Mestrado-Pós-Graduação-ICMC/USP - São Carlos

padrão obtida através do sistema iClass que o usuário pode estar modificando, além de outras duas possibilidades de criação de metadados. O elemento <identifier> possui os seguintes elementos filhos:

- <catalog $>$ - Elemento opcional.

- <entry $>$ - Elemento obrigatório.

Exemplo:

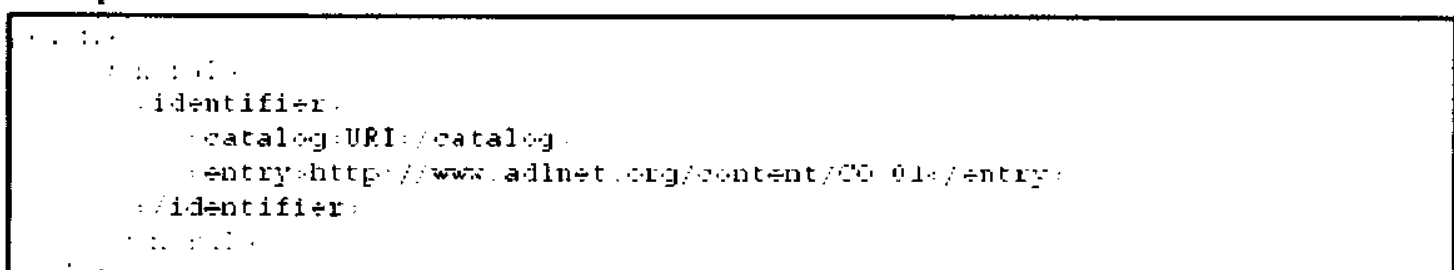

\section{B.2.1.1 Elemento <catalog>}

O elemento $<$ catalog $>$ representa o nome do identificador ou esquema usado para criar e gerenciar a entrada. Existem alguns tipos de sistemas para catálogo, como os que seguem:

- URI: Universal Resource Identifier;

- URN: Universal Resource Name

- DOl: Digital Object Identifier;

- ISBN: International Standard Book Numbers;

- ISSN: International Standard Serial Numbers

Apesar de o elemento <catalog> ser opcional, o elemento <entry> (elemento filho de <identifier>) é obrigatório, o que faz com que o elemento em discussão torne-se obrigatório também, já que ele representa o tipo de esquema usado no elemento <entry>. No sistema, é dada a opção padrão e outras duas possibilidades de criação de metadados. A opção padrão é obtida através do sistema iClass em que o elemento <catalog> assume o valor de "URI" e o usuário pode modificar esse valor

\section{B.2.1.2 Elemento <entry>}

Esse elemento representa o valor do identificador do objeto de aprendizagem, ou seja, apresenta o valor referente ao esquema escolhido no elemento <calalog. $>$. O valor de <entry> na implementação realizada será representado como um CharacterString Data Type [ISO/IEC, 2000] com até 1000 caracteres e deve aparecer somente uma ve $z$ dentro do elemento <identifier $>$. No sistema, é dada a opção padrão e outras duas possibilidades de criação de metadados. A opção padrão é obtida através do sistema iClass $\mathrm{cm}$ que o elemento <entry> assume a URL que indica a localização do objeto de aprendizagem que está sendo criado. Esse valor pode ser modificado pelo usuário. 


\section{B.2.2 Elemento <title>}

Representa o nome dado ao objeto de aprendizagem, sendo representado por LangString Data Type [IEEE LTSC, 2002], com até 1000 caracteres. O elemento $<$ title $>$ deve aparecer somente uma vez dentro do elemento <general $>$. Na implementação realizada, é dada a opção padrão obtida através do sistema iClass assumindo o valor do título da aula, o qual o usuário pode estar modificando.

\section{Exemplo:}

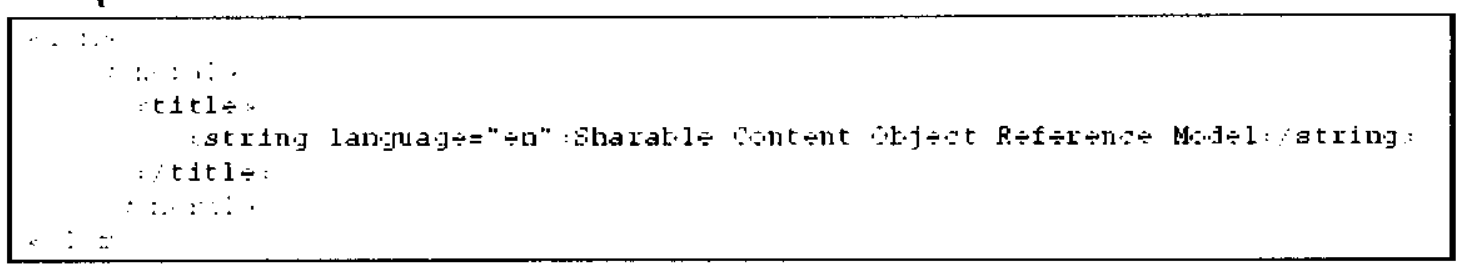

\section{B.2.3 Elemento <language>}

Representa a linguagem primária ou linguagens usadas dentro do componente SCORM para a comunicação com o usuário. Através da multiplicidade, notamos que o elemento é opcional e pode ser repetido (até dez vezes), permitindo que os componentes descritos possam suportar múltiplas linguagens. $\mathrm{Na}$ implementação realizada foi adotado o português como linguagem padrão e única. Apesar de o elemento ser opcional, como o valor será sempre o mesmo ("pt"), decidiu-se por deixar o elemento <general $><$ language> nas especificações dos metadados SCORM. Não colocamos à disposição do usuário a criação de mais instâncias.

\section{Exemplo:}

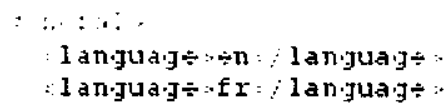

\section{B.2.4 Elemento <description>}

Representa a descrição textual do componente SCORM que está sendo descrito pelo metadado. É representado como um elemento Langstring Data Type [IEEE LTSC, 2002], com até 2000 caracteres e pode ser repetido (até dez vezes), permitindo que os componentes possam ter várias descrições. No entanto, na implementação realizada colocamos a disposição do usuário apenas a criação de uma única instância. 


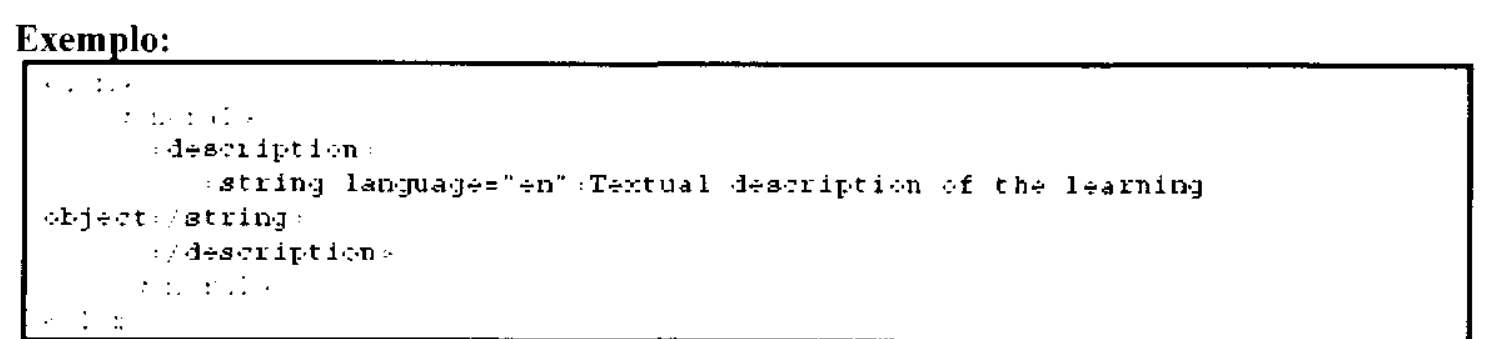

\section{B.2.5 Elemento <keyword>}

Deve ser usado para definir palavras chaves comuns ou frases que descrevam o objeto de aprendizagem. O elemento é representado por um elemento LangString Data Type [IEEE LTSC, 2002], com até 1000 caracteres. O elemento pode ter múltiplas instâncias (até dez) no caso de mais de uma palavra chave ser necessária. No sistema, é oferecida uma opção padrão e outras duas possibilidades de criação de metadados. A opção padrão é obtida através do sistema $i$ Class assumindo o valor do título da aula, que o usuário pode estar modificando.

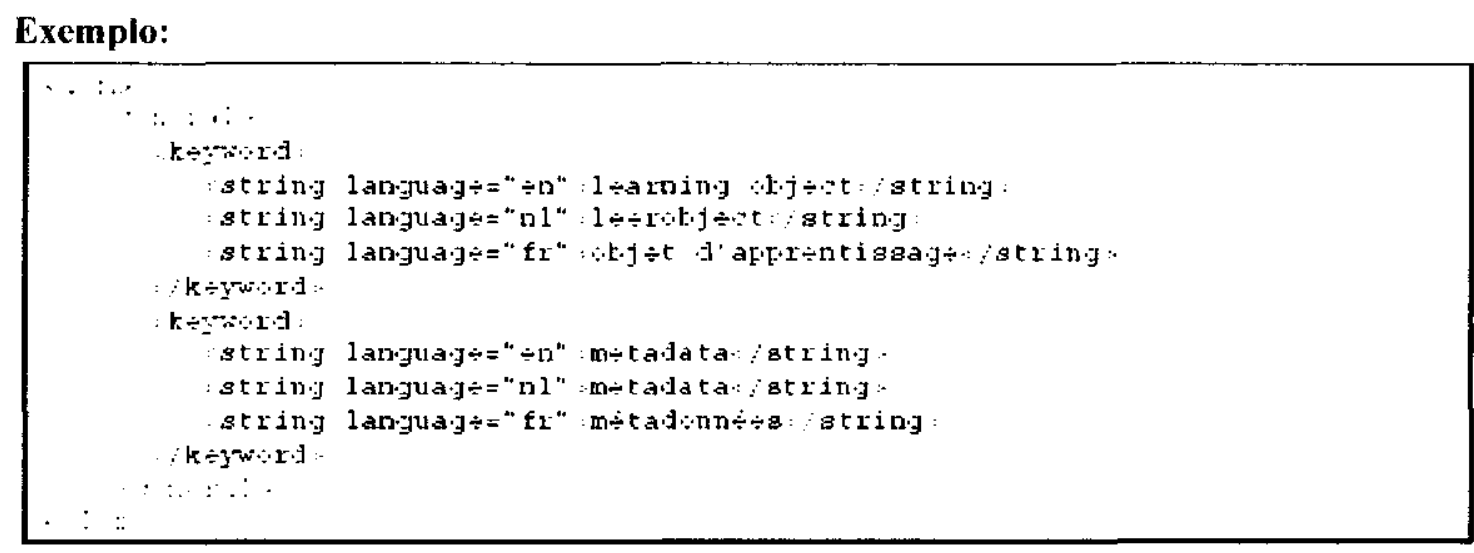

\section{B.2.6 Elemento <coverage>}

Sendo o elemento opcional, decidiu-se por não usá-lo, pois o uso foi considerado desnccessário, já que descreve o tempo, cultura, geografia ou região em que os componentes SCORM são aplicados. Entretanto, em trabalho futuros, deve-se reconsiderar o uso deste elemento.

\section{B.2.7 Elemento <structure>}

Através da multiplicidade, notamos que esse elemento é opcional. Porém foi considerado válido o uso, já que deve ser usado para descrever a estrutura organizacional do componente SCORM. É representado por palavras reservadas presentes em um vocabulário restrito definido pelo Vocabulary Data Type [IEEE LTSC, 2002], cujo conjunto válido é: 
Renata Paciência Godoy-Dissertação de Mestrado Pós-Graduação ICMC/USP-São Carlos

- atomic: um objeto que ć indivisível;

- collection: um conjunto de objetos sem especifico relacionamento entre eles (no sistema, essa opção é a padrão);

- network: um conjunto de objetos com relacionamentos que não são especificos;

- hierarchical: um conjunto de objetos cujos relacionamentos podem ser representados por uma estrutura de árvore;

- linear: um conjunto de objetos que são completamente ordenados.

\section{Exemplo:}

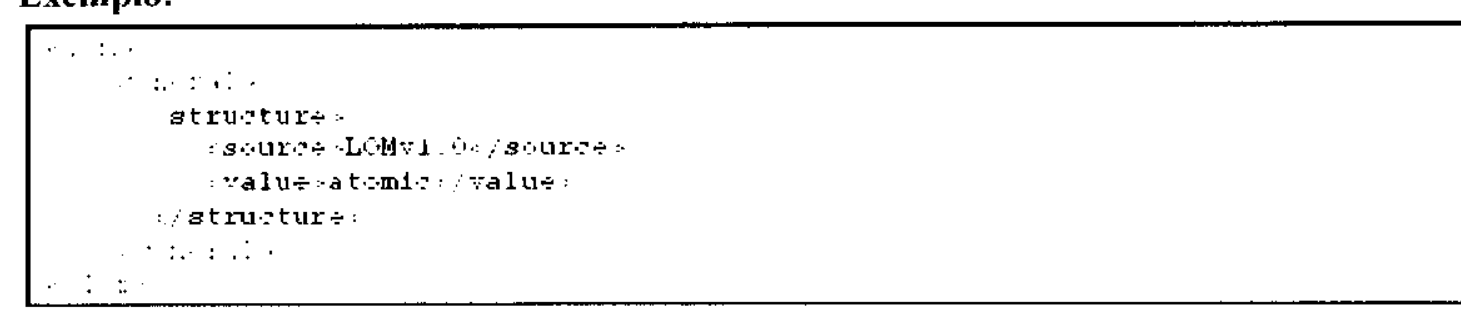

\section{B.2.8 Elemento <aggregationLevel>}

Através da multiplicidade, notamos que esse elemento é opcional. Porém foi considerado válido o uso. descrevendo a granularidade funcional do objeto de aprendizagem, de grande uso no contexto de ensino. É representado por palavras reservadas presentes em um vocabulário restrito definido pelo Vocabulary Data Type [IEEE LTSC, 2002], cujo conjunto válido é:

- 1: o menor nivel de agregação, como por exemplo, fragmentos ou dados de mídia;

- 2: uma coleção de objetos de aprendizagem do nível 1, por exemplo, uma aula;

- 3: uma coleção de objetos de aprendizagem do nível 2, por exemplo, um curso;

- 4: o maior nivel de agregação, como por exemplo, um conjunto de cursos que permitem uma certificação.

No contexto do sistema, os valores 3 e 4 não estão sendo usados, já que descrevem um curso ou conjunto deles. Portanto, são oferecidas as opções 1 e 2, onde o valor padrão é o 1 . Em uma futura versão, deve ser possivel criar um objeto de aprendizagem como, por exemplo, um curso todo, considerando-se o uso dos outros valores descartados nessa versão.

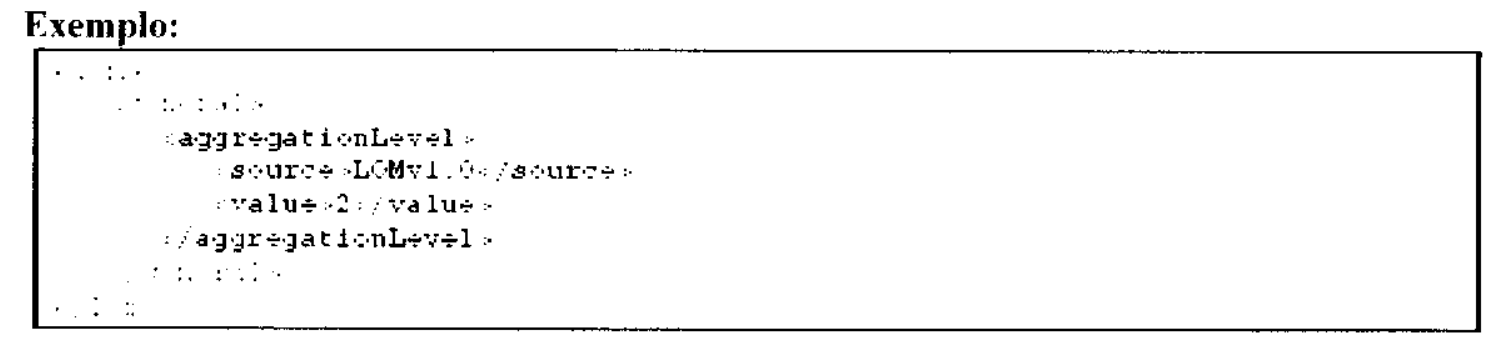

Exemplo: 


\section{B.2.9 Exemplo com todos os elementos filhos do elemento <general>}

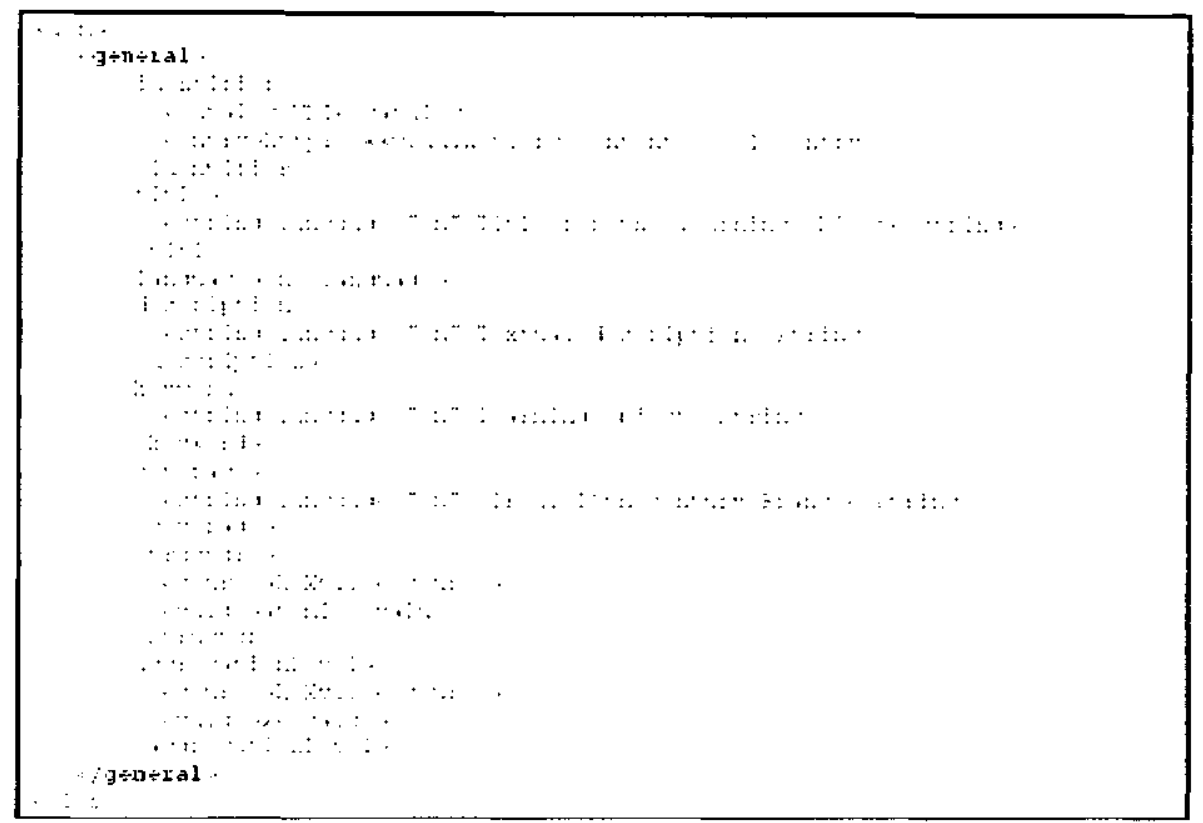

\section{B.3 Elemento <lifeCycle>}

Agrupa as categorias relatadas ao ciclo de vida e ao estado atual do componente SCORM, e aqueles que afetaram o componente durante sua evolução. Os tipos de informaçôes colctados nessa categoria incluem o status do componente (estado final ou draft), o identificador da versão, e uma lista de individuos e/ou organizaçōes que afetaram o componente de uma maneira ou outra. $O$ elemento $<$ lifeCycle> deve aparecer somente uma vez dentro do elemento <lom> e contém os seguintes elementos filhos:

- <version $>$

- $<$ status $>$

- <contribute>

\section{B.3.1 Elemento <version>}

Deve descrever a edição / versão do componente SCORM. Um componente pode ter várias versões ou edições durante seu tempo de vida. Ė representado pclo elemento LangString Data Type [IEEE LTSC, 2002], com até 50 caracteres e deve aparecer somente uma vez dentro do elemento $<$ lifeCycle $>$. No sistema, foi adotado como "1.0" o valor padrão do elemento, que o usuário pode modificar se desejar.

Exemplo:

$\therefore \quad \cdots:$

$\div \mathrm{r} s \mathrm{i} \because \mathrm{n}$

string lanjuajo="ثto 1 " alpha string

$\therefore \quad \cdots$ 


\section{B.3.2 Elemento <status>}

Deve descrever o status completo ou condição do componente SCORM. Um componente pode ter vários status durante seu ciclo de vida. Verificando a multiplicidade, nota-se que o elemento <status> deve aparecer somente uma vez dentro do elemento <lifeCycle>. É representado por palavras reservadas presentes em um vocabulário restrito definido pelo Vocabulary Data Type [IEEE LTSC, 2002], cujo conjunto válido é:

- draft: o componente está em desenvolvimento de acordo com o desenvolvedor; padrão);

- final: o componente está pronto de acordo com o desenvolvedor (no sistema, essa opção é a

- revised: o componente foi revisado desde sua última versão:

- unavailable: a informação do status não está disponível.

\section{Exemplo:}

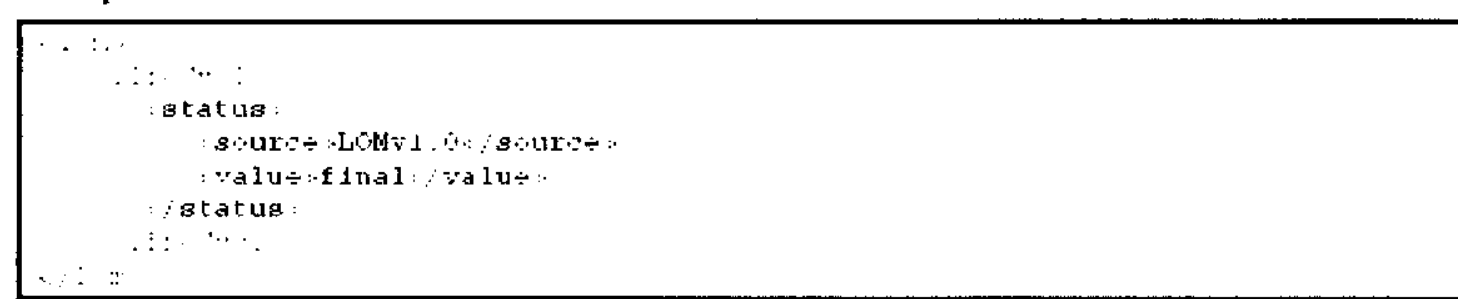

\section{B.3.3 Elemento <contribute>}

Esse elemento deve ser usado para descrever essas entidades que têm contribuído para o estado do componente SCORM durante seu ciclo de vida (como por exemplo: criação, edição, publicações). $O$ elemento <contribute> possibilita a captura de todos esses indivíduos ou organizações envolvidas.

Através da multiplicidade notamos que esse elemento é opcional, podendo ter até trinta instâncias no caso de mais contribuições serem necessárias. Nesse caso, deixamos o uso de acordo com o usuário, já que não é obrigatório. Na implementação realizada, são dadas duas opções padrões obtidas através do serviço Context Kernel que fornece as <entity>s responsáveis pelo <contribute>, além de outra possibilidade de preenchimento do elemento <contribute>. O usuário pode modificar esses valores padrões e criar mais uma entidades para o elemento.

O elemento $<$ contribute $>$ possui os seguintes elementos filhos:

- <role >- obrigatório se o elemento <contribute> for usado:

- <entity> - obrigatório se o elemento <contribute> for usado;

- <date>-opcional se o elemento <contribute $>$ for usado. 


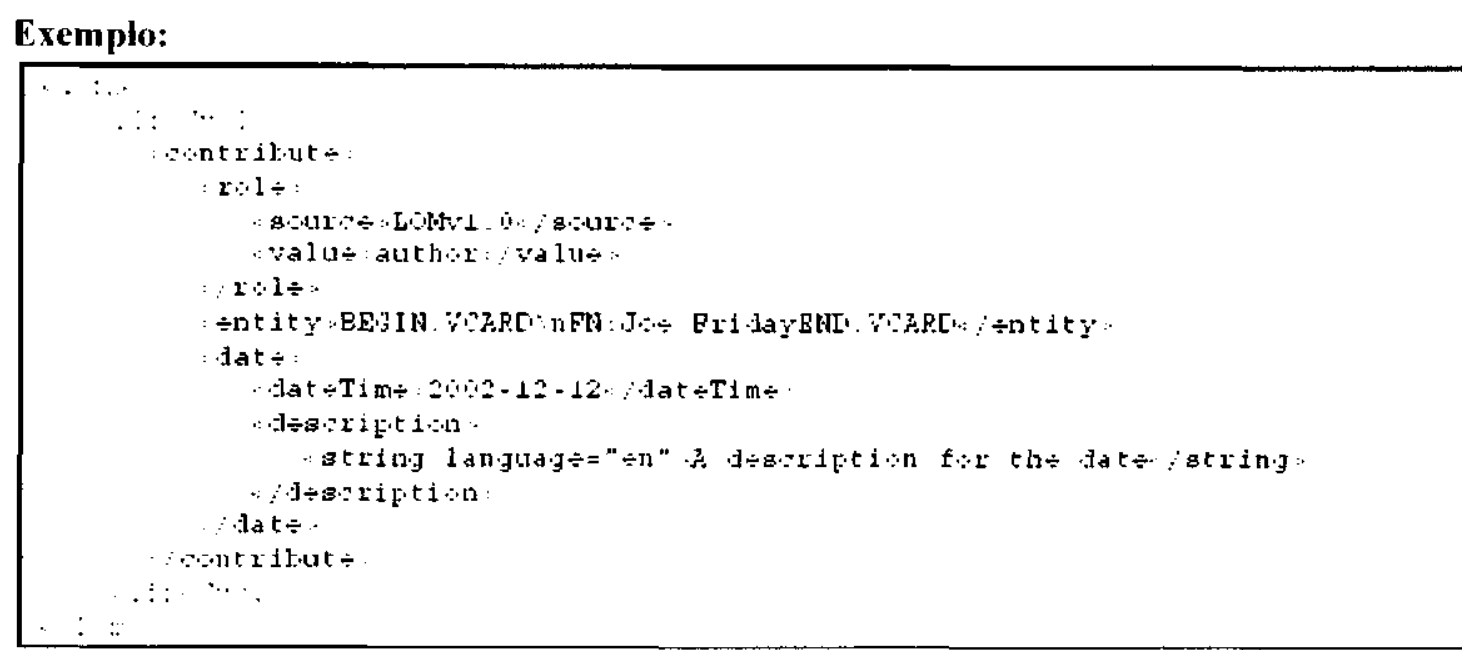

\section{B.3.3.1 Elemento <role>}

Obrigatório se o elemento <contribute> for usado. Define o tipo de contribuição feito pelo contribuidor (identificado pelo elemento <entity>) no desenvolvimento do componente SCORM. O IEEE [IEEE LTSC, 2002] definiu um conjunto de papéis típicos que são envolvidos no ciclo de vida do componente, representados por palavras reservadas presentes $\mathrm{cm}$ um vocabulário, cujo conjunto válido é:

- author

- publisher

- unknown

- initiator

- terminator
- validator

- editor

- graphical designer

- technical implementer

- content provider
- technical validator

- educational validator

- script writer

- instructional designer

- subject matter expert

Na implementação realizada, para o elemento filho <role> do elemento <contribute $>$ são dadas duas opções padrões, uma em cada elemento <contribute $>$. Para o primeiro <contribute>, o valor do elemento <role> padrão é "author", e para o segundo, "educational validator". O usuário pode estar modificando esses valores, além de poder criar outro <contribute> e assim, criar um novo elemento $<$ role $>$.

\section{B.3.3.2 Elemento <entity>}

Obrigatório se o elemento <contribute> for usado. Define a(s) entidade(s) que podem ter contribuído durante o desenvolvimento do ciclo de vida do componente SCORM. É representado pelo elemento CharacterString Data Type [ISO/IEC, 2000] com até 1000 caracteres, onde todos os valores das entidades devem ser representados no formato $v$ Card Data Type [IETF, 1998]. 
O padrão fornece a criação de até quarenta instâncias para determinada <role> mas na implementação feita, atualmente são oferecidas três opções. Os valores para cada elemento $<$ contribute > <entity> padrões (que são dois) são obtidos pelo serviço Context Kernel que, através da dimensão de contexto who (informando o professor que ministra a aula) fornece os elementos <entity> responsáveis pelos elementos <contribute>. O sistema ainda permite que esses valores possam ser alterados, além de poder criar mais duas outras <entity $>$ para o elemento.

\section{B.3.3.3 Elemento <date>}

Identifica a data que a contribuição foi feita pela entidade. $O$ elemento < date $>$ contém dois elementos filhos:

- <datetime> - E representado pelo elemento DateTime Data Type [ISO, 2000], que é pego automaticamente do sistema;

- <description> - Sendo esse elemento opcional, decidiu-se por não usá-lo, pois o uso foi considerado desnecessário, já que representa a descrição textual da data.

\section{B.3.4 Exemplo com todos os elementos filhos do elemento <lifeCycle>}

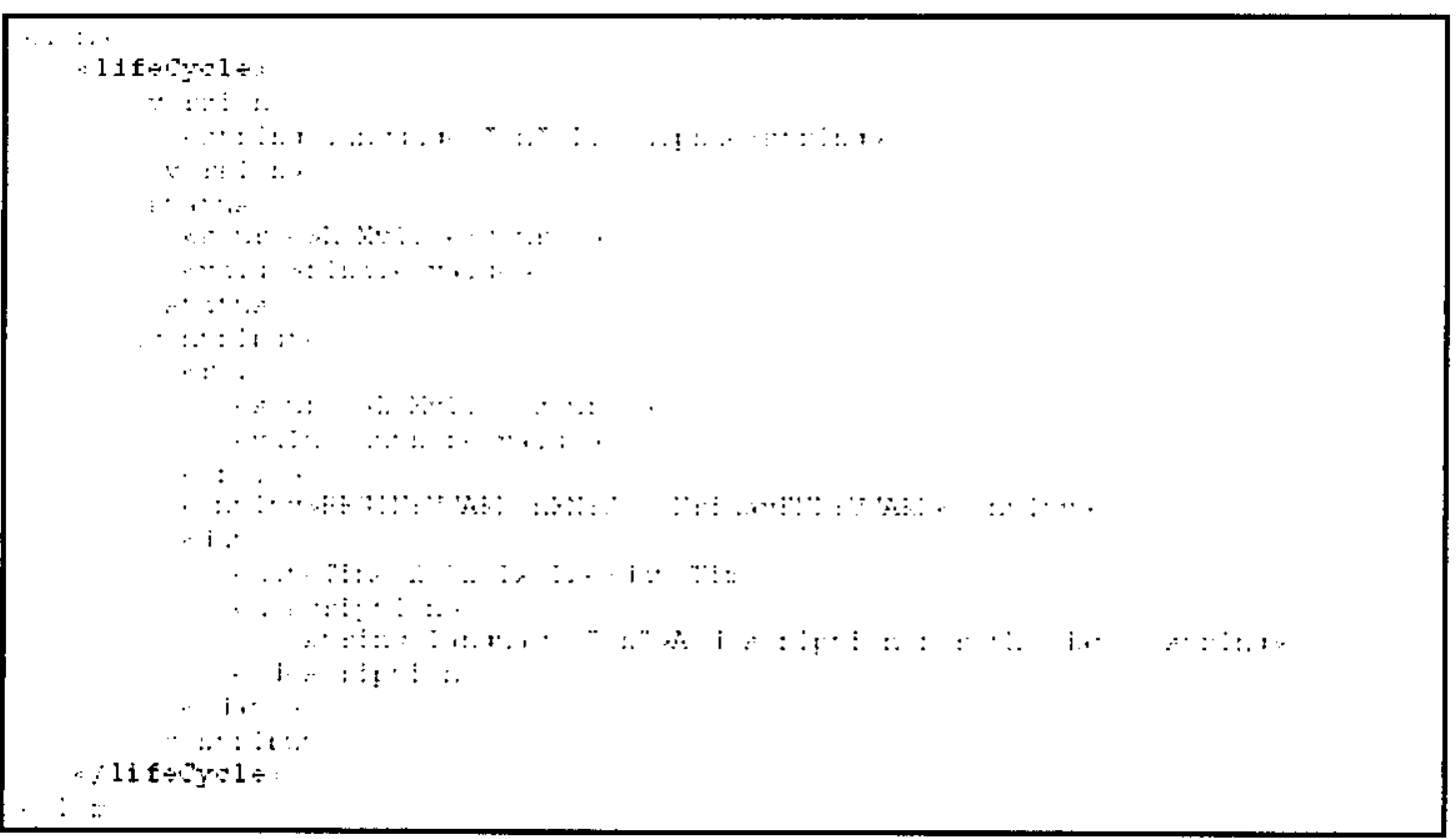

\section{B.4 Elemento <metaMetadata $>$}

Descreve como uma instância de metadados pode ser identificada, quem criou a instância, como, quando e com quais referências. O elemento deve aparecer somente uma vez dentro do elemento $<$ lom> e contém os seguintes elementos filhos: 
- <identifier $>$

- <contribute $>$

- <metadataSchema>

- <language $>$

\section{B.4.1 Elemento <identifier>}

O elemento <identifier> representa um mecanismo para determinar um identificador único do metadado que descreve o componente SCORM. A multiplicidade, os elementos filhos e as características dentro do sistema, já foram apresentados na Seção B.2.1.

\section{Exemplo:}

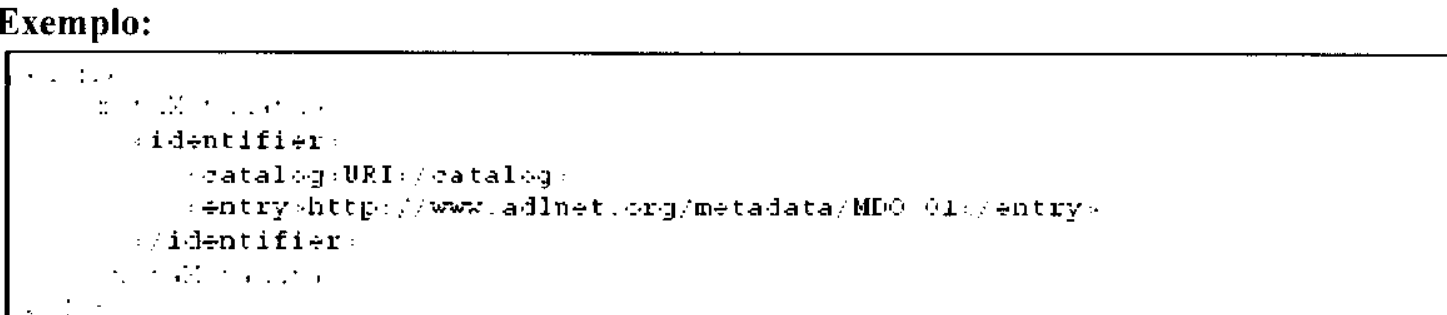

\section{B.4.2 Elemento <contribute>}

O elemento <contribute> deve ser usado para descrever essas entidades, como pessoas e organizações que têm afetado o estado da instância do metadado durante o desenvolvimento do seu ciclo de vida. A multiplicidade, os elementos filhos e as características dentro do sistema já foram apresentados na Seção B.3.3. A diferença é que a implementação realizada fornece a criação de duas instâncias (e não três como na Seção B.3.3) e o conjunto válido de palavras reservadas apresentado no vocabulário do elemento filho $<$ role $>$ é:

- creator (adotada no sistema como padrão)

- validator

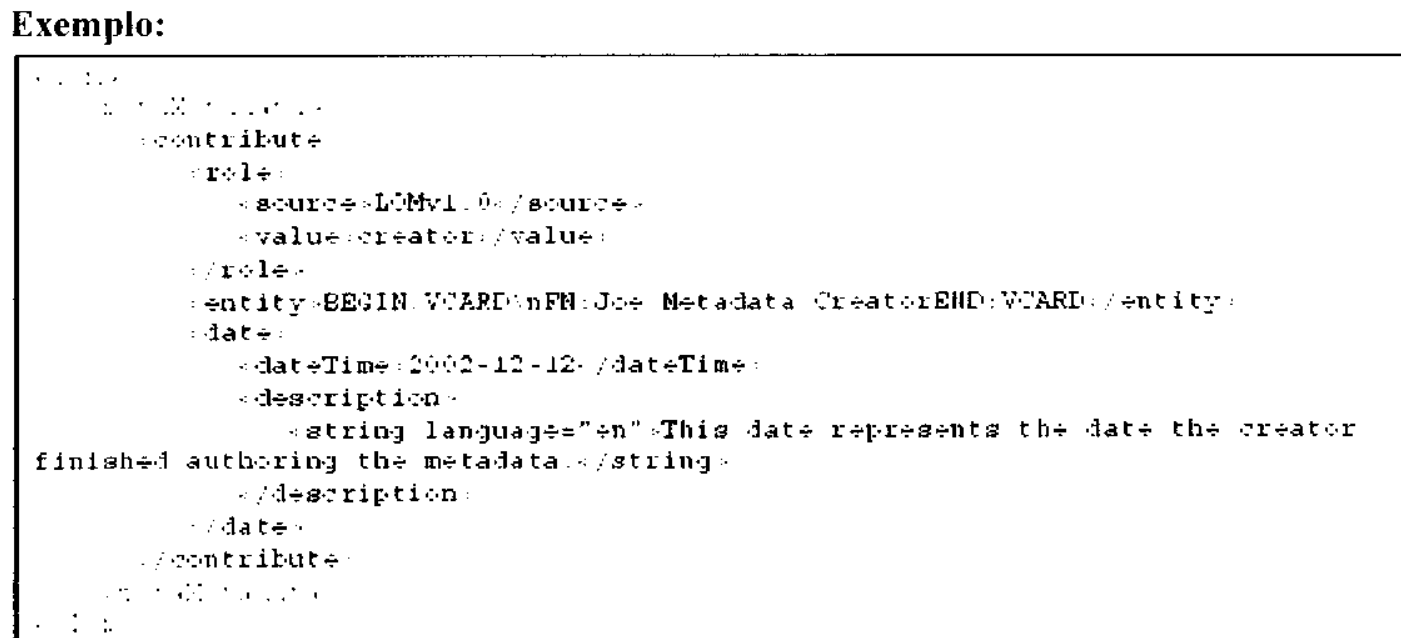




\section{B.4.3 Elemento <metadataSchema>}

Representa o nome e versão da especificação usada para criar a instância metadado. Para todos metadados SCORM, a instância deve estar em conforme com ambos requisitos do LOM e do SCORM CAM versão 1.3. Devido a isto, o SCORM precisa que pelo menos os seguintes esquemas metadados sejam documentados em todas as instâncias metadados:

- LOMv1.0: Indica que o esquema LOM Versão 1.0 são usados;

- SCORM_CAM_v1.3: Indica que o perfil da aplicação SCORM CAM Versão 1.3 Mctadados foram seguidas.

Se mais esquemas metadados são relevantes, eles também devem ser listados, podendo chegar a dez. No projeto não colocamos à disposição do usuário a criação de mais instâncias, colocando as duas instâncias obrigatórias como default.

\section{Exemplo:}

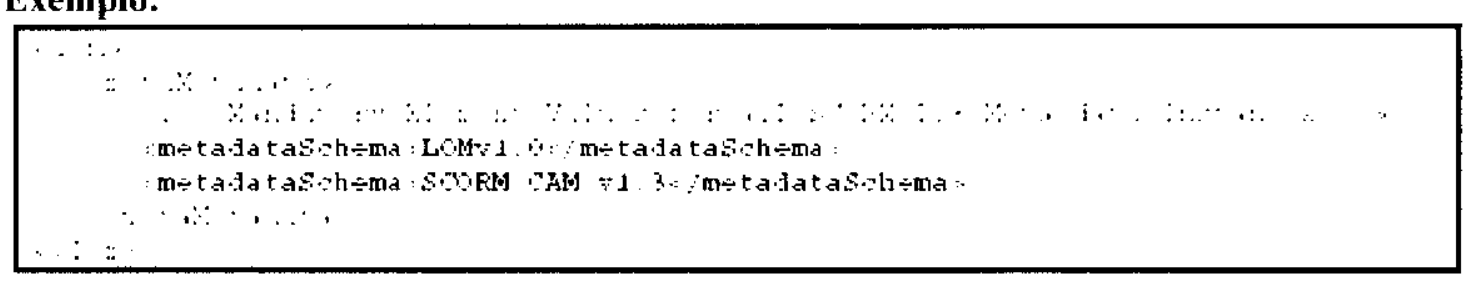

\section{B.4.4 Elemento <language>}

Apresentado na Seção B.2.3

\section{B.4.5 Exemplo com todos os elementos filhos do elemento <metaMetadata>}

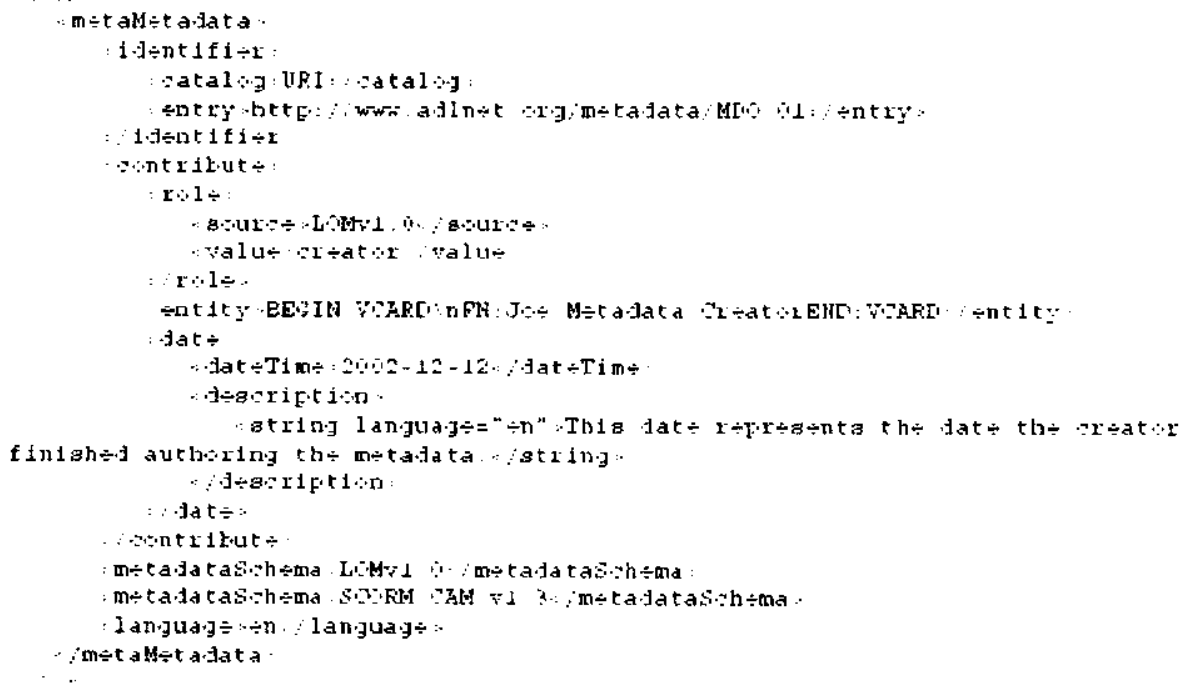




\section{B.5 Elemento <technical>}

A categoria <technical> descreve todas as caracteristicas técnicas e requisitos para o componente SCORM. Verificando a multiplicidade, nota-se que o elemento <technical> deve aparecer somente uma vez dentro do elemento <lom>. O elemento <technical > contém os seguintes elementos fillos:

- $<$ format $>$

- $<$ size $>$

- <location>

- <requirement>

- <installation Remarks $>$

- <otherPlatformRequirements $>$

- <duration $>$

\section{B.5.1 Elemento <format>}

O elemento < format> representa os tipos de dados técnicos de todos os componentes usados na preparação do componente SCORM. Este elemento é usado para identificar qualquer software necessário para acessar e usar o componente. E representado pelo elemento CharacterString Data Type [ISO/IEC, 2000], com até 500 caracteres e deve ser do tipo MIME baseado no registro IANA [IETF, 1996b] ou string literal não digital.

Através da multiplicidade, notamos que o elemento pode ser repetido até 40 vezes, permitindo que as características técnicas possam ter vários formatos. No sistema permite-se o elemento possa ser repetido três vezes. São dadas duas opções padrões. uma com o valor de "text/html"e outra "video/jpeg" que o usuário pode estar modificando, além de outra possibilidade de preenchimento para a criação de metadados.

\section{Exemplo:}

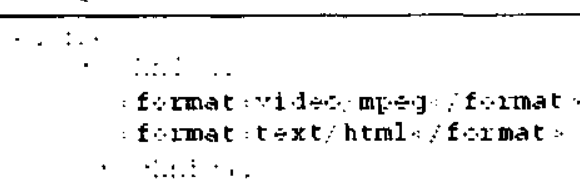

\section{B.5.2 Elemento <size>}

Obtemos esse elemento automaticamente. já que representa o tamanho digital do componente SCORM em bytes. É representado por CharacterString Data Type [ISO/IEC, 2000], com até 30 caracteres.

Exemplo:

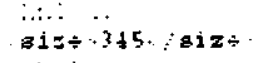


Renato Paciência (jodoy - Dissertação de Mestrado-Pós-(jraduação-ICMC/USP - São Carlos

\section{B.5.3 Elemento <location>}

Obtemos esse elemento automaticamente através do sistema iClass que informa a URL da localização do componente SCORM descrito pelo metadado.

\section{B.5.4 Elemento <requirement>}

Expressa a capacidade técnica necessária para usar o componente SCORM. Vendo a multiplicidade, notamos que esse elemento é opcional. Aqui fica a cargo do usuário o uso ou não desse elemento. Pode ter múltiplas instâncias, chegando até 40 itens. $\mathrm{Na}$ implementação realizada só damos opção da criação de duas instâncias < requeriment>. O elemento < requeriment > contém o elemento fillho:

- <orComposite>

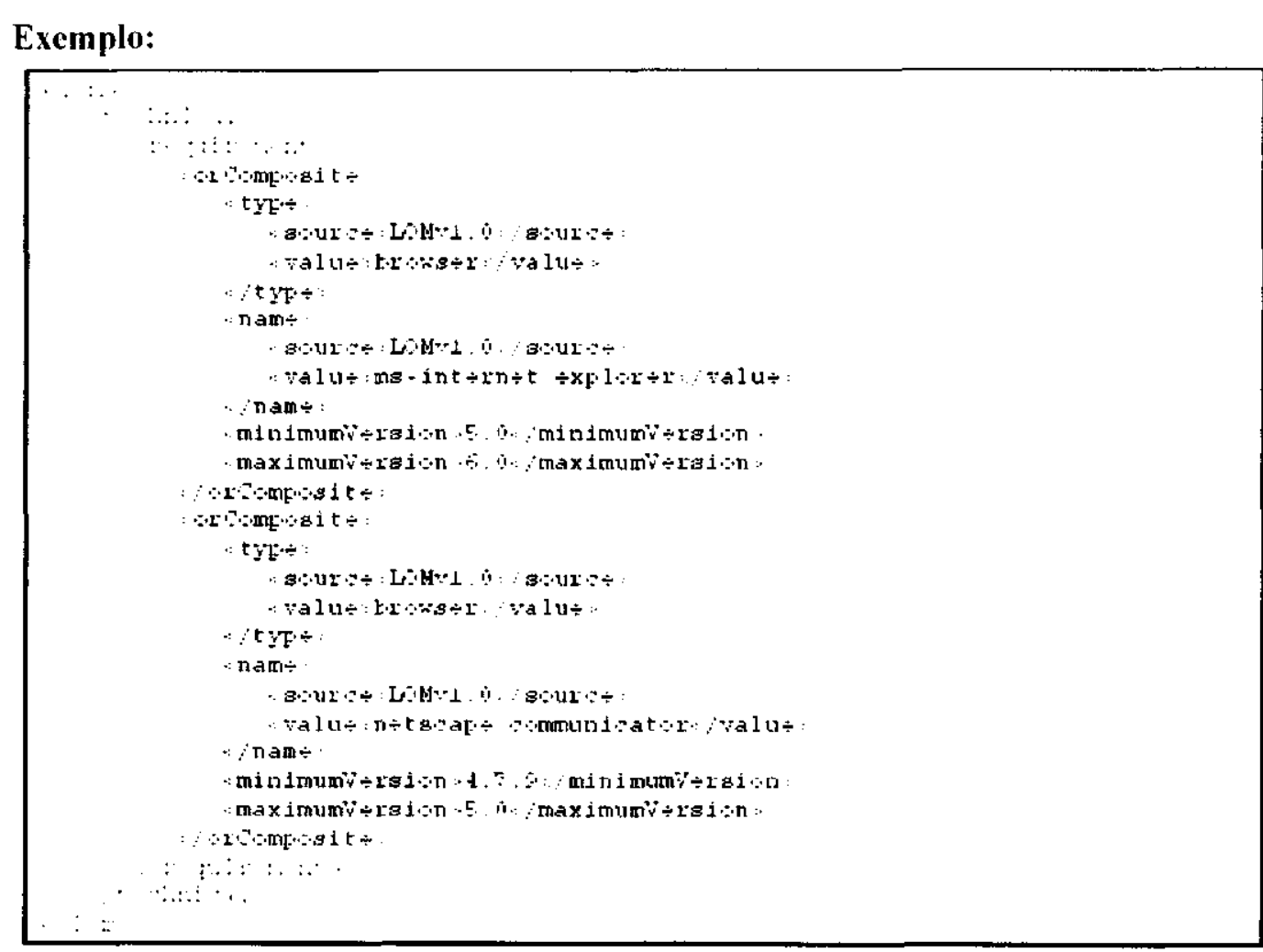

\section{B.5.4.1 Elemento <orComposite>}

Representa um simples requisito. Através da multiplicidade, notamos que esse elemento é opcional. Porém, se o usuário optou por estar utilizando o elemento <requeriment>, deverá utilizar o elemento $<$ orComposite>. Pode ter múltiplas instâncias (usando o conector lógico "OR") chegando até quarenta itens, porém, no sistema só damos opção da criação de duas instâncias. O clemento <orComposite> contém os seguintes elementos filhos: 
- <type>

- <name $>$

- <minimumVersion>

- <maximumVersion>

\section{B.5.4.1.1 Elemento <type>}

O elemento <type> representa a tecnologia necessária para usar o componente SCORM, como por exemplo, hardware, softwarc e rede. É representado por palavras reservadas presentes em um vocabulário restrito definido pelo Vocabulary Data Type [IEEE 1 TSC, 2002], cujo conjunto válido é:

- operating system

- browser

O sistema disponibiliza duas opções padrões que podem ou não serem modificadas pelo usuário, sendo que cada uma delas representa cada elemento <requeriment> (que o sistema disponibiliza duas opções) e assume o valor das palavras reservadas presentes no conjunto de vocabulário: "operating system" e "browser".

\section{B.5.4.1.2 Elemento <name>}

Representa o nome da tecnologia necessária para usar o componente SCORM. O valor usado nesse elemento depende do valor identificado pelo elemento <valuc $>$. O sistema possibilita ao usuário escolher até dois valores para o elemento $<$ name $>$, que representa o valor identificado pelo elemento $<$ type $>$.

O IEEE [IEEE I,TSC, 2002] definiu um conjunto de valores que são representados por palavras reservadas em um vocabulário. O conjunto válido de palavras reservadas para o elemento $<$ requirement $>$.<orComposite $>$. $<$ name $>$ é:

$\begin{array}{ll}\text { Se } & \text { type }>=\text { "operating system" } \\ \text { - pc-dos } & \bullet \text { any } \\ \text { - ms-windows } & \bullet \text { netscape communicator } \\ \text { - macos } & \bullet \text { ms-internet explorer } \\ \text { - unix } & \bullet \text { opera } \\ \text { - multi-os } & \bullet \text { amaya } \\ \text { - none } & \end{array}$




\section{B.5.4.1.3 Elemento <minimumVersion>}

Sendo o elemento opcional, decidiu-se por não usá-lo, pois o uso foi considerado desnecessário, já que representa a menor versão possível da tecnologia necessária para usar o componente SCORM.

\section{B.5.4.1.4 Elemento <maximumVersion>}

Sendo o elemento opcional, decidiu-se por não usá-lo no sistema, pois o uso foi considerado desnecessário, já que representa a maior versão possível da tecnologia necessária para usar o componente SCORM.

\section{B.5.5 Elemento <installationRemarks>}

É usado para representar qualquer instrução específica em como instalar o componente SCORM. $\dot{\mathrm{E}}$ representada por LangString Data Type [IEEE LTSC, 2002], com até 1000 caracteres. Vendo a multiplicidade, notamos que esse elemento é opcional, ficando a cargo do usuário o usa ou não. $\mathrm{O}$ sistema fornece uma opção padrão representada por uma frase especificando instruções de instalação, que o usuário pode ou não modificar.

Exemplo:

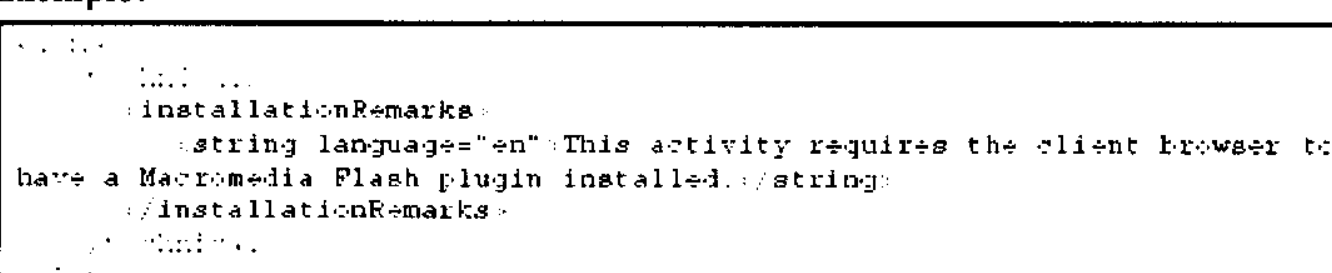

\section{B.5.6 Elemento <otherPlatformRequirements>}

É usado para representar informações sobre outros softwares e hardwares necessários para o componente SCORM, que não podem ser representados nos elementos técnicos. É representada por LangString Data Type [IEEE LTSC, 2002], com até 1000 caracteres. Vendo a multiplicidade, notamos que esse elemento é opcional, ficando a cargo do usuário o uso ou não desse elemento.

\section{Exemplo:}

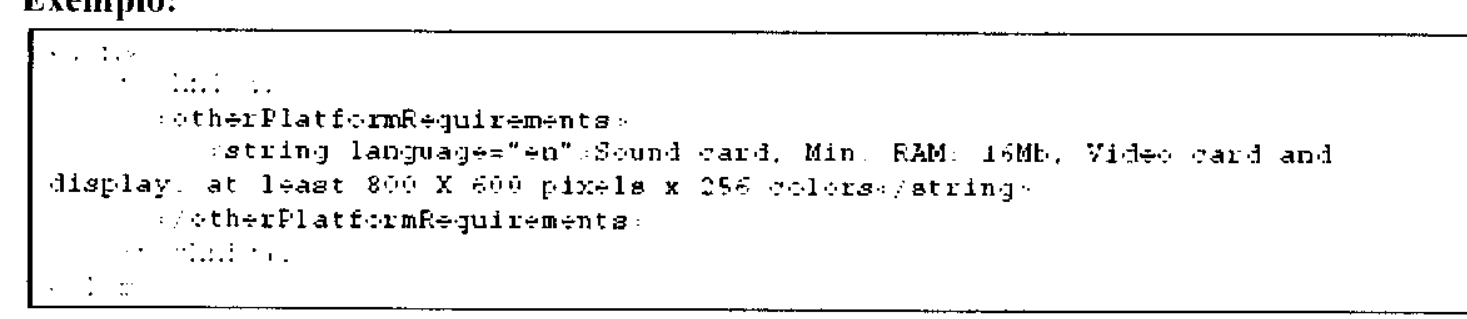


Renata Paciência Godoy Dissertação de Mestrado-Pós-Graduação-ICMC/USP - São Carlos

\section{B.5.7 Elemento <duration>}

Sendo o elemento opcional, optou-se por não usá-lo, já que representa o tempo contínuo de duração de um componente SCORM (útil para sons, filmes ou simulações). Entretanto, em trabalho futuros, devese reconsiderar o uso.

\section{B.5.8 Exemplo com todos os elementos filhos do elemento <technical>}

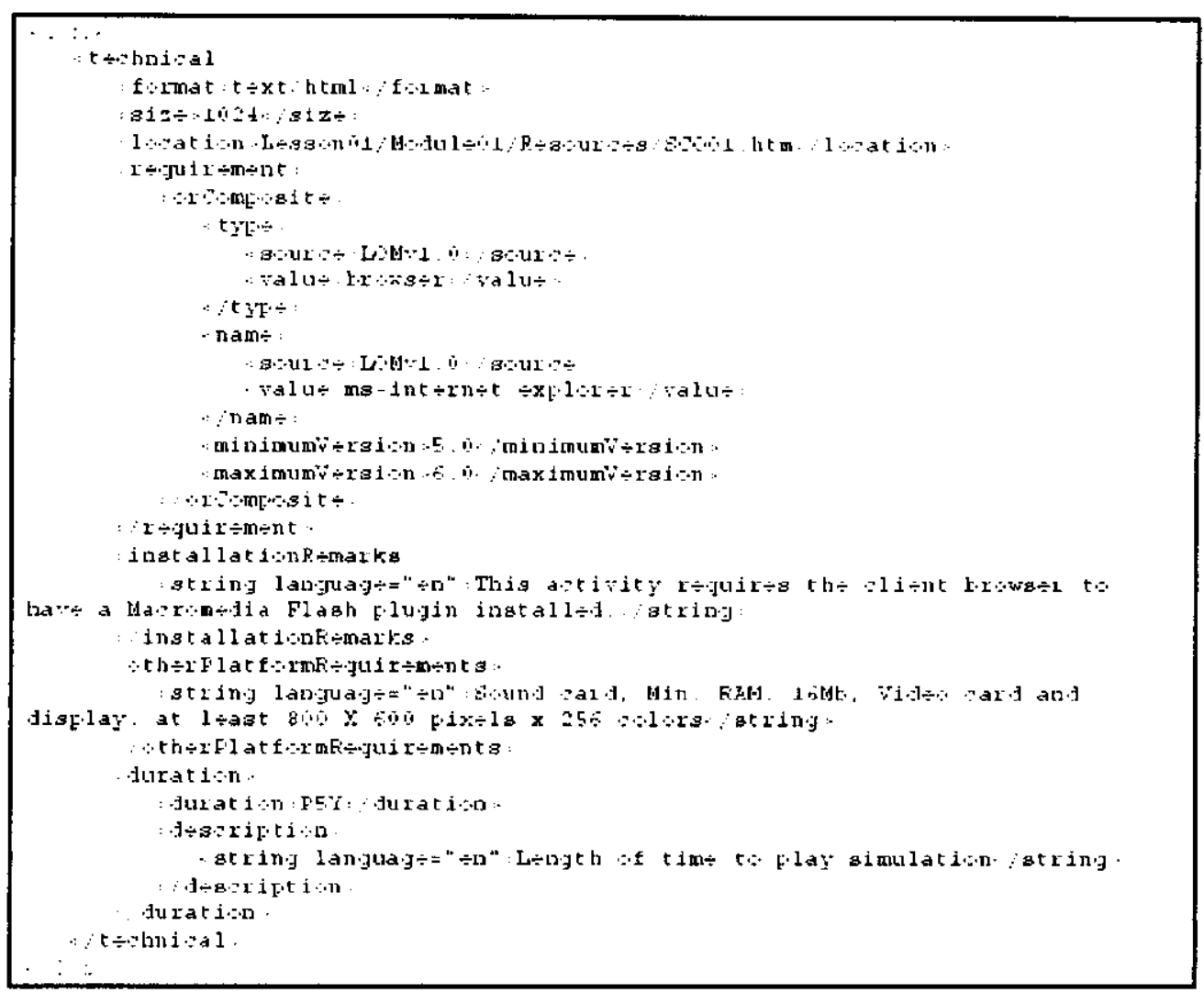

\section{B.6 Elemento <educational>}

Essa categoria descreve as características chaves educacionais ou pedagógicas do componente SCORM, sendo usada por professores, gerentes, autores e estudantes.

Através da multiplicidade, notamos que esse elemento é opcional e todos os elementos filhos também são opcionais. Apesar disso, o elemento <educacional $>$ e quase todos elementos filhos (com exceção do <typicalAgeRange>, <semanticDensity> e <typicalLearningTime >) foram considerados obrigatórios no sistema, pois são elementos de importância fundamental, dado que o trabalho se foca no contexto educacional

Pode ter múltiplas instâncias, chegando até cem itens, embora o sistema só ofereça a opção da criação de uma única instância. O elemento <educational> contém os seguintes elementos filhos: 
- <interactivityType >

- $<$ learningResourceType $>$

- <interactivityLevel>

- <semanticDensity>

- $\quad$ intendedEndUserRole>

- $<$ context $>$
- <typical $\Lambda$ geRange>

- <difficulty >

- <typicalLearningTime $>$

- <description>

- <language $>$

\section{B.6.1 Elemento <interactivityType>}

Representa o modo dominante de aprendizado suportado pelo componente SCORM. O IEEE [IEEE LTSC, 2002] definiu um conjunto de valores que são representados por palavras reservadas em um vocabulário, cujo conjunto válido é:

- active: aprendizado ativo, que diretamente introduz ação produtiva pelo estudante (aprendendo fazendo);

- expositive: aprendizado expositivo, quando o trabalho do estudante consiste principalmente em entender o conteúdo exposto a ele (aprendizado passivo) (no sistema, essa opção é adotada como padrão);

- mixed: $\Lambda$ mistura dos tipos active e expositive de interatividade.

\section{Exemplo:}

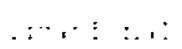

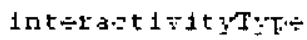

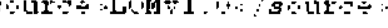

value-mlx-d: valu

int $\dot{\text { ractivityTy }}$

i. $\cdot \cdots: \ldots$ :

\section{B.6.2 Elemento <learningResourceType>}

Representa o tipo específico do componente SCORM. Através da multiplicidade, notamos que o elemento pode ser repetido (até dez vezes), permitindo descrever completamente os tipos de recursos usados pelo componente. No sistema, é fornecida a opção padrão "slide" que o usuário pode modificar, além de outras duas possibilidades para a criação da instância <learningResourceType > $O$ IEEE [IEEE LTSC, 2002] definiu um conjunto de valores que são representados por palavras reservadas em um vocabulário, cujo conjunto válido é:

- exercise

- simulation

- questionnaire
- graph

- index

- slide
- exam

- experiment

- problem statement 


$\begin{array}{lll}\text { - diagram } & - \text { table } & \bullet \text { self assessment } \\ \text { - figure } & \bullet & \text { narrative text }\end{array}$

Exemplo:

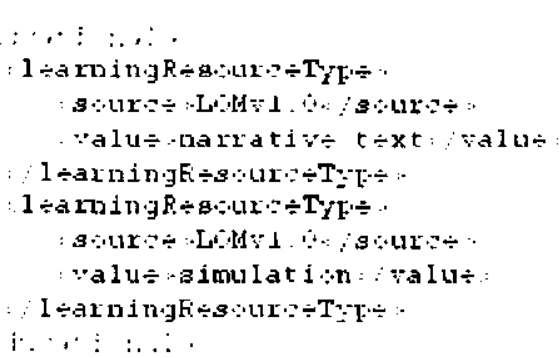

\section{B.6.3 Elemento <interactivityLevel>}

Representa o nível de interatividade que caracteriza o componente SCORM. Nesse contexto, interatividade refere-se ao nível que o usuário pode influenciar no aspecto ou ambiente do componente. O IEEE [IEEE LTSC, 2002] definiu um conjunto de valores que são representados por palavras reservadas em um vocabulário. O conjunto válido de palavras reservadas é:

- very low (valor padrão assumido pelo sistema)

- low

- medium

- high

- very high

Exemplo:

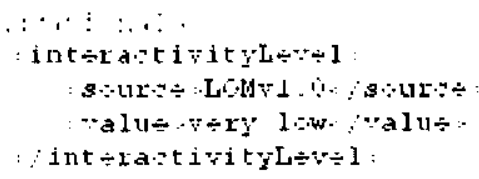

\section{B.6.4 Elemento <semanticDensity>}

Representa o nivel semântico do componente SCORM. A densidade semântica do componente SCORM pode ser estimada em termos de tamanho, ou no caso de recursos como áudio ou vídeo, duração. Esse elemento não foi considerado obrigatório, ficando a cargo do usuário o uso ou não desse elemento. O IEEE [IEEE LTSC, 2002] definiu um conjunto de valores que são representados por palavras reservadas em um vocabulário. O conjunto válido de palavras reservadas é: 
Renata Paciência Godoy - Dissertação de Mestrado Pós-Graduação ICMC/USP - São Carlos

- very low (valor padrão assumido pelo sistema)

- low

- medium

- high

- very high

Exemplo:

. $\because \vdots: \ldots \therefore$

g-mant $1:[\div$ nsit

sotur $\div$ LOd 1 . 6 sour

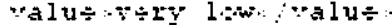

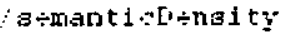

i. $\cdot \cdots: \ldots$

\section{B.6.5 Elemento <intendedEndUserRole>}

Identifica o(s) usuário(s) principal(is) para que o componente SCORM foi designado. Vendo a multiplicidade, notamos que o elemento pode ser repetido em até 10 vezes, permitindo que múltiplos elementos sejam usados, sendo que o usuário/papel mais dominante deve vir primeiro. No sistema, é fornecida a opção padrão "Icarner" que o usuário pode estar modificando, além de outra possibilidade de preenchimento para a criação de metadados. O IEEE [IEEE LTSC, 2002] definiu um conjunto de valores que são representados por palavras reservadas em um vocabulário, cujo conjunto válido é:

- teacher

- author

- learner (valor padrão assumido pelo sistema)

- manager

\section{Exemplo:}

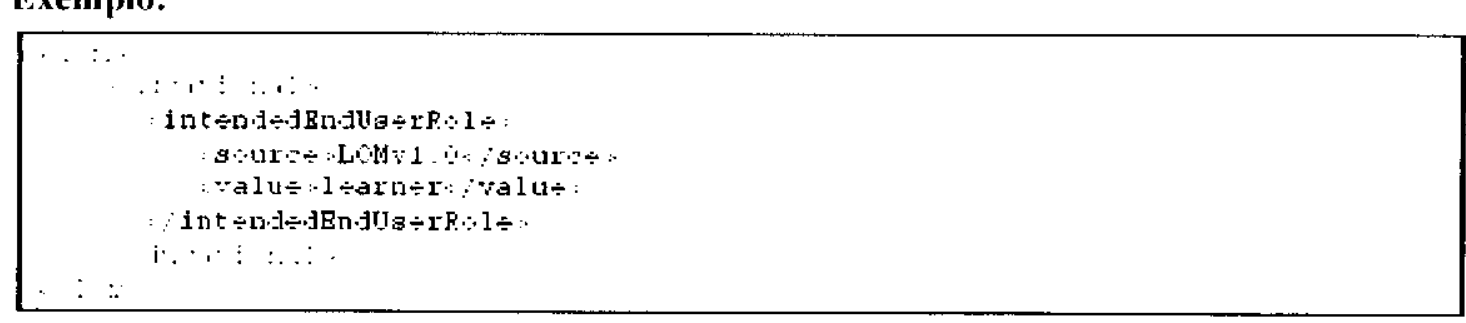

\section{B.6.6 Elemento <context>}

Representa o principal ambiente dentro do qual o aprendizado e o uso do componente SCORM é utilizado. Vendo a multiplicidade, notamos que o elemento pode ser repetido até dez vezes, permitindo que múltiplos elementos sejam usados. No sistema, é fornecida a opção padrão "higher education" que 
o usuário pode modificar, além de outra possibilidade de criação da instância do elemento <context>. O IEEE [IEEE LTSC, 2002] definiu um conjunto de valores que são representados por palavras reservadas em um vocabulário. O conjunto válido de palavras reservadas é:

- school

- higher education (assume o valor padrão no sistema)

- training

- other

\section{Exemplo:}

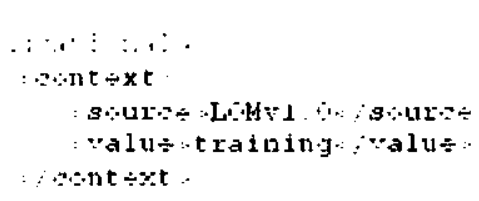

B.6.7 Elemento <typicalAgeRange>

O elemento foi desnecessário, já que representa a idade do típico usuário final

\section{B.6.8 Elemento <difficulty>}

Representa o quão dificil é o trabalho com o componente SCORM. O alvo lípico pode ser caracterizado pelo elemento <context $>$. O IEEE [IEEE LTSC, 2002] definiu um conjunto de valores que são representados por palavras reservadas em um vocabulário, cujo conjunto válido é:

- $\quad$ very easy (assume o valor padrão no sistema)

- easy.

- medium

- difficult

- very difficult

Exemplo:

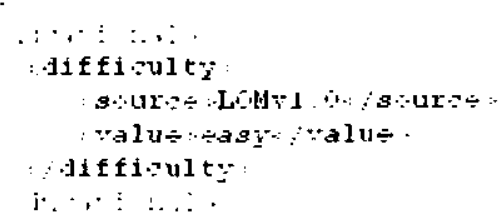




\section{B.6.9 Elemento <typicall_earningTime>}

Representa o tempo aproximado gasto para trabalhar com o componente SCORM. O alvo típico pode ser caracterizado pelo elemento $<$ context $>$. O elemento <typicall earningTime $>$ contém os seguintes elementos filhos:

- <duration>: É representado por Duration Data Type [ISO, 2000]. O elemento não foi considerado obrigatório, ficando a cargo do usuário o uso ou não.

- <description>: O elemento foi considerado desnecessário.

\section{Exemplo:}

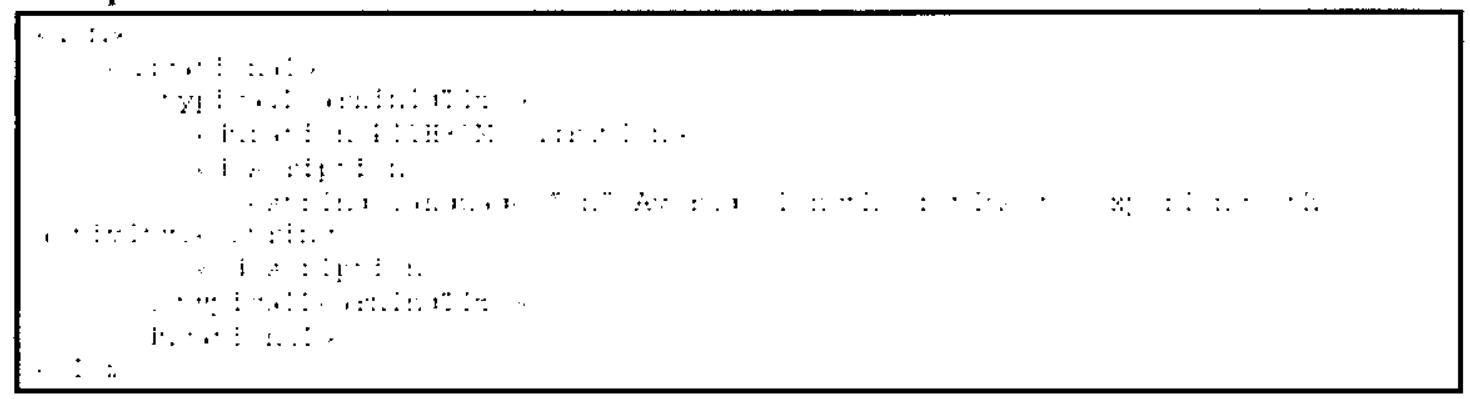

\section{B.6.10 Elemento <description>}

Empregado para descrever como o componente SCORM deve ser usado. Embora o elemento possa ter múltiplas instâncias (até dez), o sistema disponibiliza a criação de apenas uma. $O$ elemento é representado por LangString Data Type [IEEE LTSC, 2002], com até 1000 caracteres.

\section{Exemplo:}

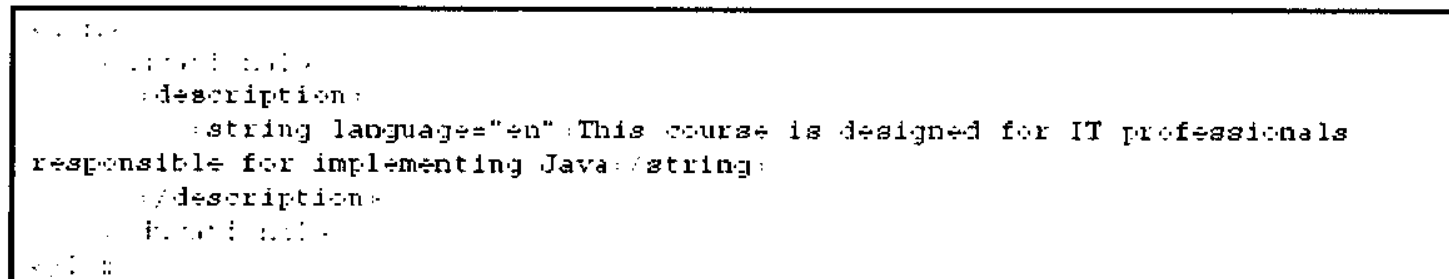

\section{B.6.11 Elemento <language>}

Apresentado na Seção B.2.3. 


\section{B.6.12 Exemplo com todos os elementos filhos do elemento <educational>}

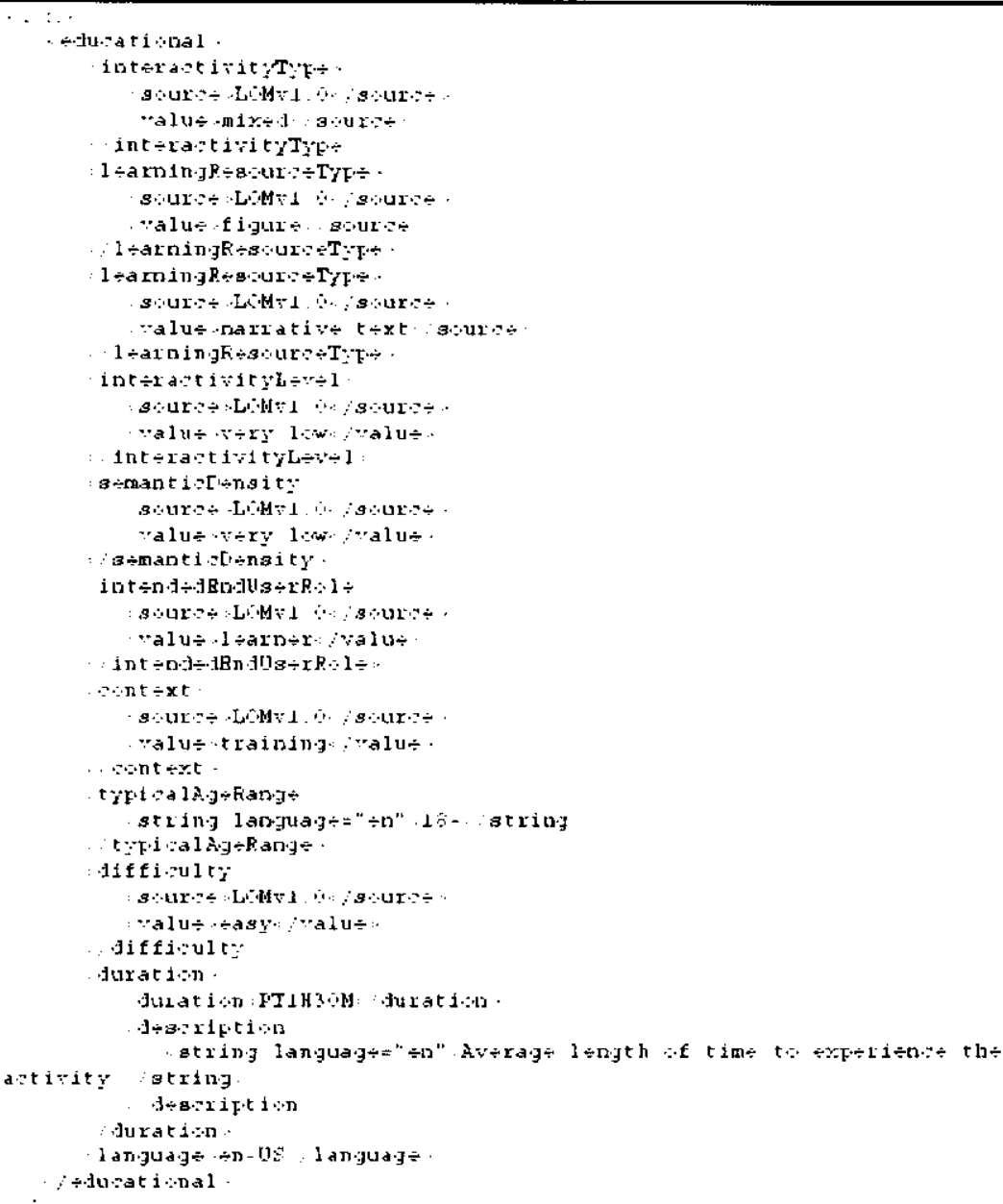

\section{B.7 Elemento <rights>}

Descreve os direitos de propriedade intelectuais e condições de uso do componente SCORM. Deve ser usado para descrever quaisquer e todos direitos do componente, como por exemplo, custo por uso e direitos de cópia. O elemento <rights $>$ deve aparecer somente uma vez dentro do elemento <lom> e contém os seguintes elementos filhos:

- $\langle\cos t>$

- <copyrightAndOtherRestrictions >

- <description>

\section{B.7.1 Elemento <cost $>$}

Representa se o componente SCORM requer ou não algum tipo de pagamento. Verificando a multiplicidade, nota-se que o elemento $<$ cost $>$ deve aparecer somente uma vez dentro do elemento $<$ rights>. O elemento é representado por um vocabulário definido pelo Vocabulary Data Type [IEEE 
Renata Paciência (jodoy - Dissertação de Mestrado-Pós-Graduação ICMC/USP - São Carlos

LTSC, 2002], que são representados por palavras reservadas em um conjunto de valores. O conjunto válido de palavras reservadas é:

- yes

- no (assume o valor padrão do sistema)

Exemplo:

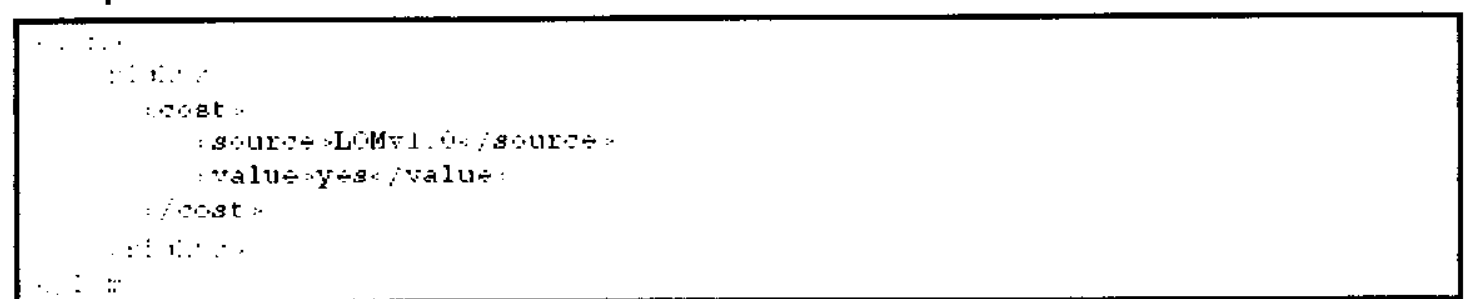

\section{B.7.2 Elemento <copyrightAndOtherRestrictions>}

Descreve se o "copyright" ou outras restrições se aplicam ao uso do componente SCORM. O elemento <copyrightAndOtherRestrictions> deve aparecer somente uma vez dentro do elemento < rights> e é representado por um vocabulário definido pelo Vocabulary Data Type [IEEE LTSC, 2002], que são representados por palavras reservadas em um conjunto de valores. O conjunto válido de palavras reservadas é:

- yes

- no (valor default assumido pelo sistema)

Exemplo:

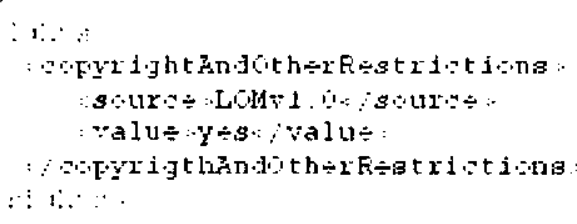

B.7.3 Elemento <description>

Permite comentários sobre as condições de uso do componente SCORM. O elemento é representado por LangString Data Type [IEEE LTSC, 2002], com até 1000 caracteres. Como o elemento é opcional, fica a cargo do usuário o uso ou não desse elemento. $O$ sistema fornece uma opção padrão (que pode ou não ser modificada pelo usuário) representada por uma frase especificando quem contatar e em que endereço eletrônico, no caso de informações adicionais. Essas informações são obtidas pelo serviço Context Kernel através de dimensões de contexto. 
Exemplo:

$\therefore: \therefore$

$1 \div \operatorname{sic} i \mathrm{i}$ t $\mathrm{s}$

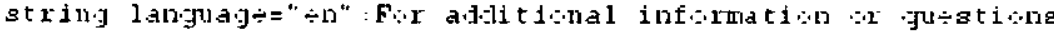

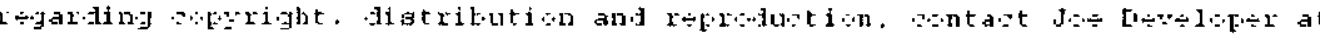

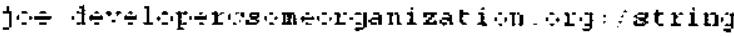

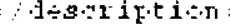

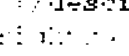

\section{B.7.4 Exemplo com todos os elementos filhos do elemento <rights>}

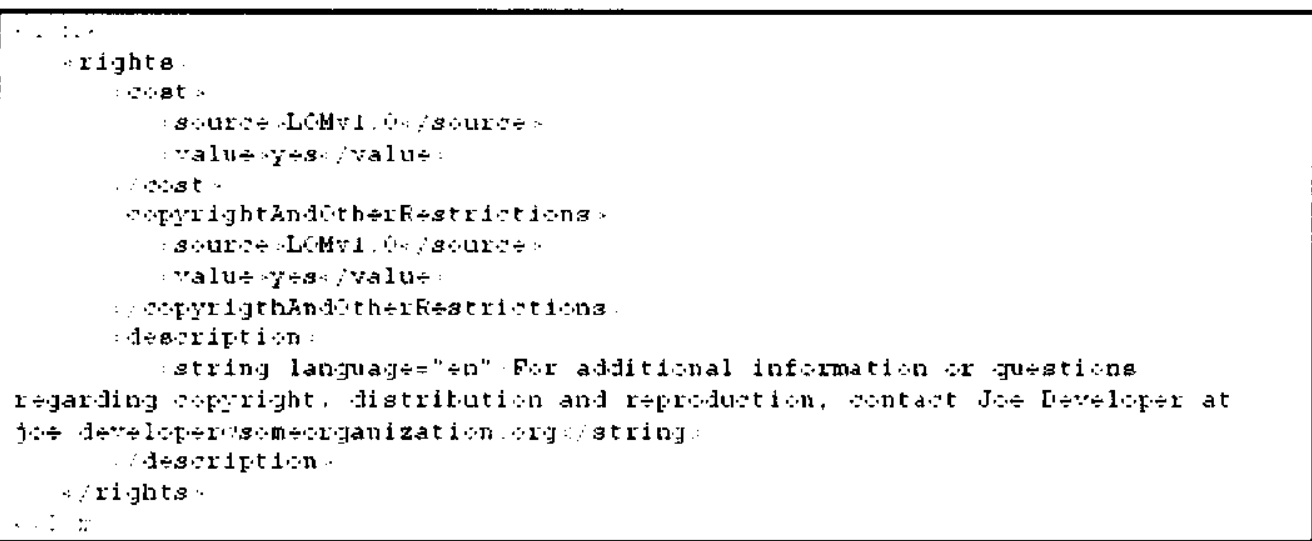

\section{B.8 Elemento <relation>}

Define o relacionamento entre o componente SCORM c outros componentes, se existir. Vendo a multiplicidade, notamos que esse clemento é opcional. Aqui fica a cargo do usuário o uso ou não desse elemento. $O$ elemento <relation> pode ser repetido para definir múltiplos relacionamentos, criando várias instâncias dessa categoria, chegando até 100 itens. No sistema disponibiliza-se a opção de criação de quatro instâncias < relation $>$.

No sistema, são dadas duas opções padrões, uma obtida através do serviço Context Kernel e outra através o serviço iClass. O usuário pode modificar esse valor padrão e criar mais duas outras entidades para o elemento. $O$ elemento $<$ relation $>$ contém os seguintes elementos filhos:

- $<$ kind $>$

- <resource $>$

\section{B.8.1 Elemento <kind >}

Descreve a natureza do relacionamento entre o componente SCORM e o componente identificado pelo recurso. Através da multiplicidade, notamos que esse elemento é opcional. O elemento é representado 
Renata Paciència Godoy Dissertação de Mestrado Pós-Graduação-ICMC/USP - São Carlos

por um vocabulário definido pelo Vocabulary Data Type [IEEE LTSC, 2002], que é representado por palavras reservadas em um conjunto de valores. O conjunto válido de palavras reservadas é:

- Ispartof

- haspart

- isversionof

- hasversion
- Isformatof

- hasformat

- references

- isreferencedby
- isbasedon

- isbasisof

- requires

- isrequiredby

No sistema, são dadas duas opções padrões, cada uma para cada elemento < relation> criado. A primeira, obtida através do serviço Context Kernel assume como valor "references" e a segunda, obtida através do serviço iClass, recebe o valor "ispartof". Há ainda a possibilidade de o usuário estar criando mais duas outras entidades $<$ kind $>$, cada uma referente ao elemento $<$ relation $>$.

Exemplo:

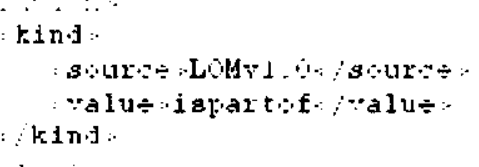

\section{B.8.2 Elemento <resource>}

Descreve o objetivo do componente SCORM que seu relacionamento referencia. Através da multiplicidade, notamos que esse elemento é opcional e pode ter múltiplas instâncias, chegando até 100 itens. No projeto só damos opção da criação de uma única instância <resource> para cada elemento $<\mathrm{kind}>$. O clemento $<$ resource $>$ contém os seguintes elementos filhos:

- <identifier>

- $<$ description $>$

\section{Fxemplo:}

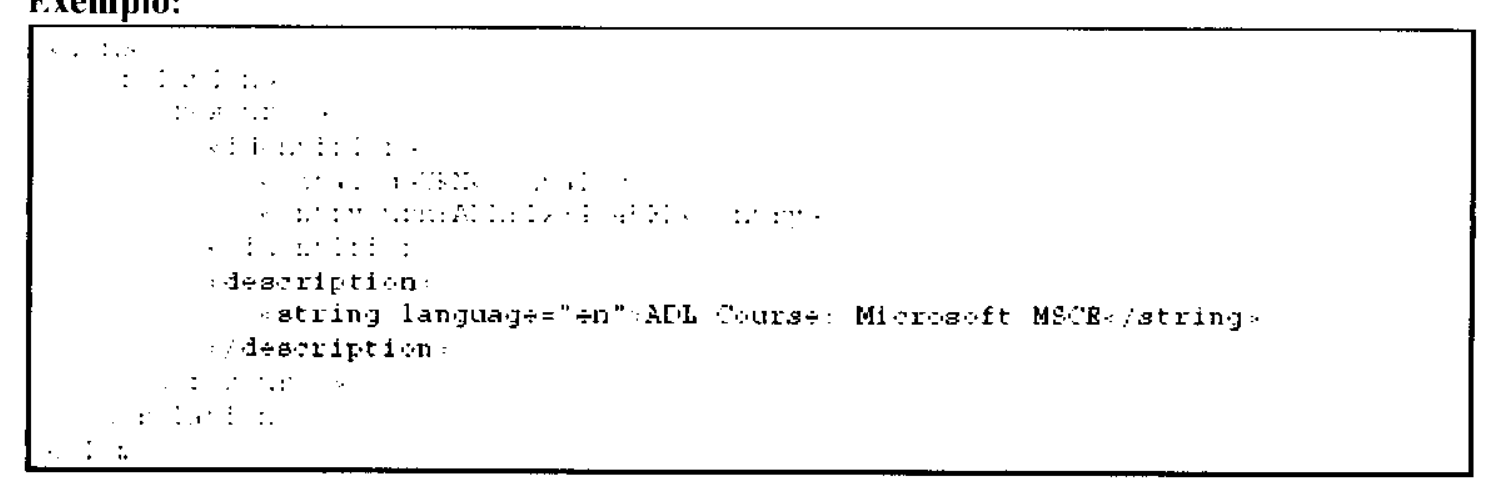




\section{B.8.2.1 Elemento <identifier>}

O elemento <identifier> representa um mecanismo para determinar um identificador único do objetivo do componente SCORM. A multiplicidade e os elementos filhos já foram apresentados na Seção B.2.1.

No sistema, são dadas duas opções padrões, cada uma para cada elemento <relation>. A primeira, obtida por meio do serviço Context Kernel assume o valor da URL referente à página da aula na CoTéa através de dimensões de contexto. A outra é obtida através do serviço iClass assumindo o valor da URL referente à página da aula. Ambos os valores são armazenados no elemento filho <entry>. Há ainda a possibilidade de o usuário estar criando mais duas outras entidades <identifier>. cada uma referente ao elemento <kind $>$, que por sua vez, faz parte do elemento <relation>.

\section{B.8.2.2 Elemento <description>}

O elemento <description> descreve o objetivo do componente SCORM. I: representado como um elemento LangString Data Type [IEEE LTSC, 2002], com até 1000 caracteres. O clemento é opcional, ficando a cargo do usuário o uso ou não.

\section{B.8.3 Exemplo com todos os elementos filhos do elemento <relation>}

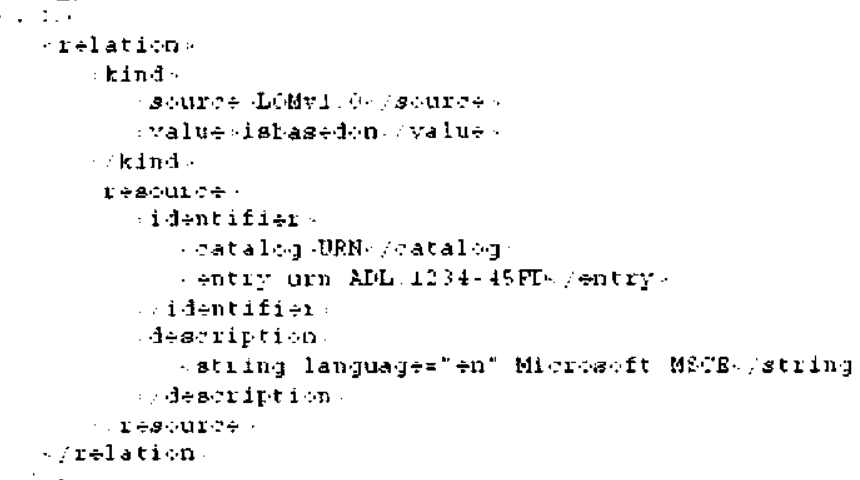

\section{B.9 Elemento <annotation>}

Provê comentários no uso educacional do componente SCORM e informações de quando e por quem os comentários foram criados. Iissa categoria possibilita que educadores possam compartilhar suas avaliações dos componentes SCORM e sugestões de uso.

Através da multiplicidade, notamos que esse elemento é opcional e pode ter múltiplas instâncias, chegando até trinta itens. Porém no sistema só foi adotada uma instância, que é a default, 
obtida por meio do serviço Context Kernel através de informações de contexto. $O$ elemento <annotation> contém os seguintes elementos filhos:

- $<$ entity $>$

- $<$ date $>$

- $<$ description $>$

\section{B.9.1 Elemento <entity>}

Identifica a entidade ou entidades que criaram as anotações. É representado pelo elemento CharacterString Data Type [ISO/IEC, 2000$]$ com até 1000 caracteres, onde todos os valores das entidades devem ser representados no formato vCard Data Type [IETF, 1998]. O elemento é opcional, ficando a critério do usuário o uso.

O sistema fornece um valor padrão obtido pelo serviço Context Kernel que através da dimensão de contexto who (informando o professor que ministra a aula) fornece a <entity> responsável pela <annotation>, que pode ou não ser modificado pelo usuário.

Exemplo:

$$
\begin{aligned}
& \therefore \therefore \cdot \cdots \quad: \quad
\end{aligned}
$$

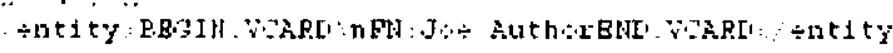

$$
\begin{aligned}
& \text {, } \ldots \text {. : : : . }
\end{aligned}
$$

\section{B.9.2 Elemento <date>}

Apresentado na Seção B.3.3.3

\section{B.9.3 Elemento <description>}

Deve ser usado para representar o conteúdo da anotação. O elemento é representado por LangString Data Type [IEEE LTSC, 2002], com até 1000 caracteres. Como o elemento é opcional, fica a cargo do usuário o uso ou não desse elemento. $O$ sistema fornece uma opção padrão representada por uma frase, cujo conteúdo é obtido por meio do serviço Context Kernel que através da dimensão de contexto como who, where, when e what fornecem as informações necessárias para a descrição da anotação.

Exemplo:

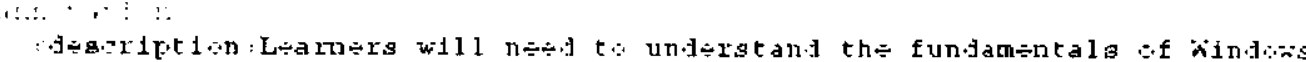
frow

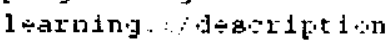

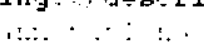




\section{B.9.4 Exemplo com todos os elementos filhos do elemento <annotation>}

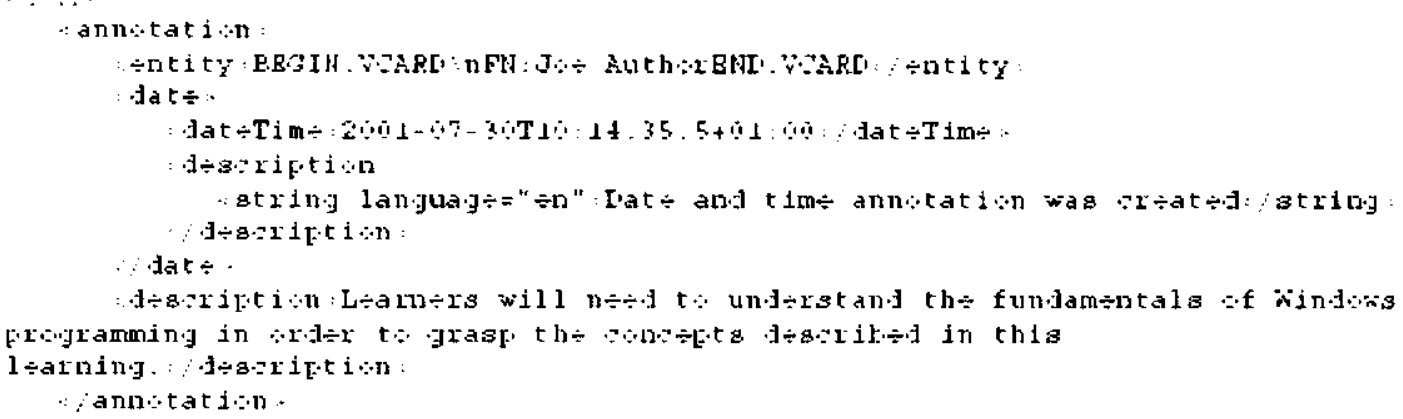

\section{B.10 Elemento <classification>}

Essa categoria descreve onde o componente SCORM se classifica no sistema. O elemento é opcional e pode ter até quarenta instâncias para definir classificações múltiplas. Nesse caso, deixamos o uso de acordo com o usuário, já que não é obrigatório. $\mathrm{Na}$ implementação realizada é oferecida somente a criação de uma instância. $O$ elemento <classification> possui os seguintes elementos filhos:

- <purpose >

- <taxonPath>

- <description>

- $<$ keyword $>$

\section{B.10.1 Elemento <purpose>}

Define propostas para a classificação do componente SCORM. Sendo o elemento opcional, fica a critério do usuário sobre o uso. No sistema, ć oferecida uma opção padrão com o valor "educational objective"que o usuário pode estar modificando, além de poder criar outras duas instâncias. É representado por palavras reservadas presentes em um vocabulário restrito definido pelo Vocabulary Data Type [IEEE LTSC, 2002], cujo conjunto válido é:

- Discipline

- idea

- prerequisite
- educational objective

- accessibility restrictions

- educational level
- skill level

- security level

- competency 


\section{Exemplo:}

$\therefore::: \cdot \cdot::$

: F-11rm $8 \div$

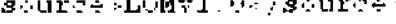

valu-:akill: : valu:

Fu $2 \mathrm{2} \cdots \mathrm{8} \div$

\section{B.10.2 Elemento <taxonPath>}

Sendo o elemento opcional, decidiu-se por não usá-lo, pois o uso não foi considerado relevante, já que descreve o caminho taxonômico em um específico sistema de classificação, onde cada nível sucessivo é um refinamento na definição do nível de procedimento.

\section{B.10.3 Elemento <description>}

Sendo o elemento opcional, decidiu-se por não usá-lo, pois o uso foi considerado desnecessário, já que contém a descrição do componente SCORM relativo ao propósito declarado (<purpose>).

\section{B.10.4 Elemento <keyword>}

Contém palavras chaves e frases do componente relativo ao propósito declarado (<purpose>) na classificação específica, como disciplina, idéia, nível de habilidade, objetivo educacional, entre outros. O elemento é representado por LangString Data Type [IEEE LTSC, 2002], com até 1000 caracteres.

Através da multiplicidade notamos que esse elemento é opcional, podendo ter várias instâncias (até 40) no caso de ser usada para definir várias palavras chaves. Nesse caso, deixamos o uso de acordo com o usuário, já que não é obrigatório.

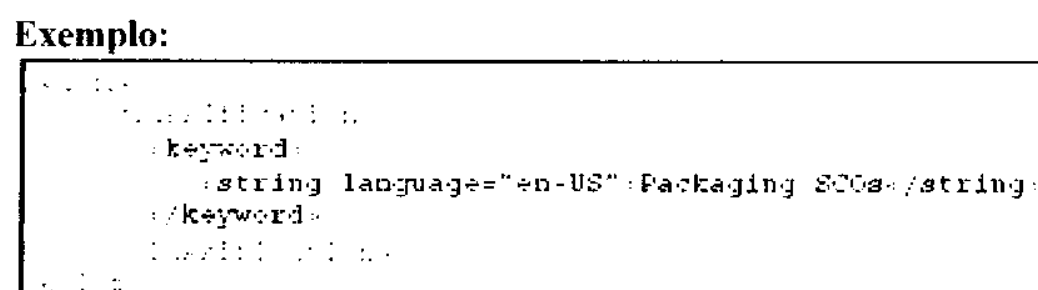




\section{B.10.5 Exemplo com todos os elementos filhos do elemento <classification>}

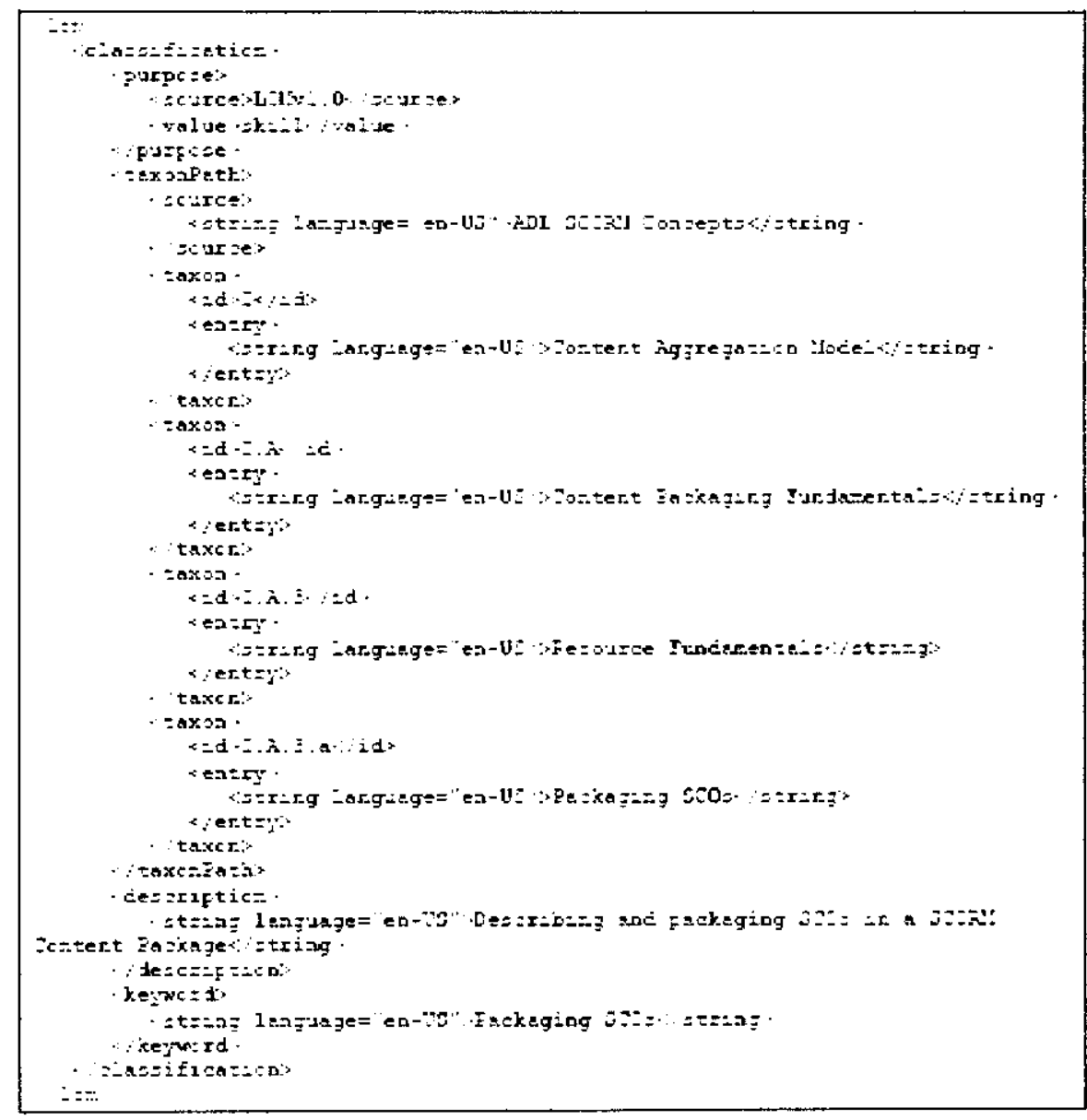


Renata Paciência Godov - Dissertação de Mestrado - Pós-Graduação- KCMC/USP - São Carlos 


\section{Referências Bibliográficas}

[Abowd, 1999a] $\Lambda$ bowd, G. D. Software engineering issues for ubiquitous computing. In: Proceedings of the $21^{\text {st }}$ International Conference on Software Engineering, pages 75-84, May 1999. Los Angeles, CA. ACM Press.

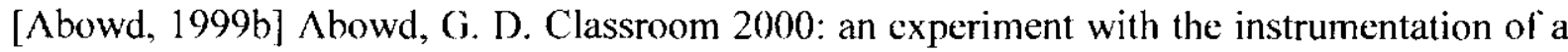
living educational environment. IBM Systems Journal, Vol. 38, $\mathrm{n}^{\circ} 4$, pages 508-530, October 1999.

[Abowd \& Mynatt, 2000] Abowd, G. D.; Mynatt, E. D. Charting past, present, and future research in ubiquitous computing. ACM Transactions on Computer-Human Interaction ('TOCHI), Vol. 7, n 1 , pages 29-58, March 2000.

[Abowd et al., 1997] Abowd, G. D.; Atkson, C. G.; I long, J.; Long, S.; Kooper, R.; Pinkerton M. Cyberguide: a mobile context-aware tour guide. ACM Wireless Networks, vol. 3, n 5 , pages $421-433,1997$.

[Abowd et al., 2002] Abowd, G. D.; Mynatt, E. D.; Rodden, T. The Human Experience. IEEF Pervasive Computing, vol. 1, $\mathrm{n}^{\circ} 1$, pages 48-57, January/March 2002.

[Andrade et. al, 2004a] Andrade, A. R.; Munson, E. V.; Pimentel, M. G. P.. Engineering web applications with XMI and XSLT. In: WebMedia\&LA-Web 2004 Joint Conference, 2004. Proceedings of the WebMedia\&LA-Web 2004 Joint Conference, 2004. v. 1. p. 1 8 .

[Andrade et. al, 2004b] Andrade, A. R.; Munson, E. V.; Pimentel, M. G. P.. A document based approach to the generation of Web applications. In: ACM Symposium on Document Engineering, 2004. Proceedings of the ACM Symposium on Document Enginecring 2004, 2004. v. 1. p. 45-47.

[Arruda Jr. \& Pimentel, 2001] Arruda Jr, C. R. E.; Pimentel, M. G. C. Projeto e implementação de um sistema colaborativo de edição. Revista Eletrônica de Iniciação Científica da Sociedade Brasileira de Computação (REIC - SBC), Ano 1, vol. 1, n 2 , Novembro 2001.

Disponível em: 
http://www.sbc.org.br/reic/edicoes/2001e2/cientificos/ProietoeImplementacaodeumSist emaColaborativodeEdicao.pdt, visitado em 18 de janeiro de 2004.

[Arruda Jr et al. 2002] Arruda Jr, C. R. E., Izeki, C. A., Pimentel, M. G. C. CoTeia: Uma ferramenta colaborativa de edição baseada na Web. In Proceedings of the 8th Brazilian Symposium on Multimedia and Hypermedia Systems, pages 371-374, Fortaleza, Brazil.

[Arruda Jr., 2003] Arruda Jr., C. R. E. Context Kernel: um Web Service para as cinco dimensões de informação de contexto. Dissertação de Mestrado, Instituto de Ciências Matemáticas e de Computação da USP, São Carlos - SP, 85 folhas, Maio 2003.

[Arruda Jr. et. al., 2003] Arruda, C. R. E.; Bulcão, R. F.; Pimentel, M. G. C.. Open contextaware storage as a Web Service. In: Ist International Workshop on Middleware for Pervasive and Ad Hoc Computing (MPAC), 2003. ACM/IFIP/USENIX Middleware 2003 Companion, 2003. v. 1. p. 81-87.

[Aware Home, 2003] Aware Home. Available online in http://www.cc.gatech.edu/fcelahri, visitado em 24 de janeiro de 2005.

[Baldochi et. al., 2002] Baldochi, L. A.; Cattelan, R. G.; Troung, K. N.; Pimentel, M. G. C.. Automatic Generation of Capture and Access Applications. In: Simpósio Brasileiro em Sistemas Multimídia e Hipermídia, 2002, Fortaleza,CE. Anais do Simpósio Brasileiro em Sistemas Multimídia e Hipermídia'2002, 2002. v. 1. p. 100-115.

[Baldochi et. al., 2003] Baldochi, L. A.; Cattelan, R. G.; Pimentel, M. G. C.. Building a Middleware Infrastructure for Capture and Access Applications. In: Seminário Integrado de Software and Hardware, 2003, Campinas. Anais, 2003. v. 1. p. 1-15.

[Baldochi et. al., 2004] Baldochi, L. A.; Andrade, A. R.; Cattelan, R. G.; Pimentel, M. G. C.. Architecture and components for capture and access applications. In: WebMedia\&LAWeb 2004 Joint Conference, 2004. Proceedings of the WebMedia\&LA-Web 2004 Joint Conference, 2004. v. 1. p. 1-8.

[Barrit \& Lewis, 2000] Barrit, C.; Lewis, D.. Reusable Learning Object Strategy: Definition, Creation Process, and Guidelines for Building. Version 3.1. E-learning at CISCO Systems. Available online in: http://www.cisco.com/, visitado em 10 de Janeiro de 2005.

[Böhm \& Rakow, 1994] Böhm, K.; Rakow, T. C.. Metadata for Multimedia Documents. In ACM SIGMOD Record, Special Issue on Metadata for Digital Media, vol.23, $\mathrm{n}^{\circ} 4$, pages 21-26, December 1994.

[Brotherton et al., 1999] Brotherton, J. A.; Abowd, G. D.; Troung, K. N. Supporting Capture and Access Interfaces for Informal and Opportunistic Meetings. GVU Center, Georgia Institute of Technology, Technical Report GIT-GVU-99-06. January 1999. Available online in: http://www.cc.gatech.edu/gvu/reports/1999/, acessado em 12 de Janeiro de 2005.

[Brown, 1996] Brown, P. J. The stick-e document: a framework for creating context-aware applications. In: Proceedings of Electronic Publishing 96, Palo Alto, U.S., pages 259272, January 1996.

[Bulcão Neto, 2001] Bulcão Neto, R. F. Wls: um serviço aberto de ligaçöes hipermídia para Web baseado em xml. Dissertação de Mestrado, Instituto de Ciências Matemáticas e de Computação da USP, São Carlos - SP, Outubro 2001.

[Bulcão et. al., 2004a] Bulcão, R. F.; Jardim, C.H.O.; Guerreiro, J.A.C.; Pimentel, M. G. C.. A Web Service Approach for Providing Context Information to CSCW Applications. 
Renata Paciência Godoy - Dissertação de Mestrado - Pós-Graduação - ICMC/USP - São Carlos

In: WebMedia\&LA-Web 2004 Joint Conference, 2004. Proceedings of the WebMedia\&LA-Web 2004 Joint Conference, 2004. v. 1. p. 1-8.

[Bulcão et. al., 2004b] Bulcão, R. F.; Jardim, C.H.O.; Guerreiro, J.A.C.; Lobato, D. C.; Pimentel, M. G. C.. A Context-based Web Service Approach to Communities of Practice. In: Semish 2004, 2004. Anais do Congresso da Sociedade Brasileira de Computacao, 2004. v. 1. p. 1-15.

[Burrell et al., 2002] Burrell, J.; Gay, G. K.; Kubo, K.; Farina, N. Context-aware computing: A test case. In Proceedings of the International Conference on Ubiquitous Computing, pages 1-15, September/October 2002.

[Cattelan et al., 2003a] Cattelan, R. G.; Andrade, A. R.; Rocha, C. F. P.; Pimentel, M. G. C. iClass: um sistema para captura e acesso de sessões em ambiente educacional. Revista Eletrônica de Iniciação Científica da Sociedade Brasileira de Computação (REIC $\mathrm{SBC}$ ), Ano 3, vol. 3, $\mathrm{n}^{\circ}$ 1, 19 páginas, Março 2003. Disponível em: http://www.sbc.org.br/reicledicoes/2003el/cientificos/iClassUmSistemaParaCapturaEAcessoDeSessoesEmAmbienteEducacional:pdf, visitado em 17 de Janeiro de 2005

[Cattelan et al., 2003b] Cattelan, R. G.; Baldochi, L. A.; Pimentel, M. G. C.. Experiences on building capture and access applications. In: Simpósio Brasileiro de Sistemas Multimídia e Web, 2003, Salvador. Anais, 2003. v. 1. p. 213-228.

[Cattelan et al., 2003c] Cattelan, R. G.; Baldochi, L. A.; Pimentel, M. G. C.. Processing and Storage Middleware Support for Capture and Access Applications. In ACM/IFIP/USENIX International Middleware Conference 2003, 2003, Rio de Janeiro. Companion to the conference proceedings, 2003. v. 1. p. 1-1.

[Cattelan, 2004] Cattelan, R. Construção de aplicações de captura e acesso baseada em recorrência de funcionalidades. Dissertação de Mestrado, ICMC-USP, 100 páginas. Disponivel em: http://www.teses.usp.br/teses/disponiveis/55/55134/tde-06052004180541 publico/dissertacao:pdf, visitado em 15 de dezembro de 2004.

[CISCO, 2003] Reusable Learning Object Authoring Guidelines: How to Build Modules, Lessons, and Topics. E-learning at CISCO Systems. Available online in: http://www.cisco.com/application/pdf/en/us/guest/netsol/ns460/c654/cdccont 0900aecd 800eb905:pdf, visitado em 21 de março de 2005.

[DCMI, 2003a] DCMI Metadata Terms. DCMI Recommendation, Dublin Core Metadata Initiative. Available online in: http://dublincore.org/documents/dcmi-terms/, visitado em 15 de fevereiro de 2005 .

[DCMI, 2003b] Dublin Core Metadata Element Set, Version 1.1: Reference Description DCMI Recommendation, Dublin Core Metadata Initiative. Available online in: http://dublincore.org/documents/dces/. visitado em 14 de fevereiro de 2005.

[Dey \& Abowd, 2000a] Dey, A. K.; Abowd, G. D. Towards a Better Understanding of Context and Context Awareness. In: Proceedings of CHI 2000 Workshop on the What Who, Where, When, and How of ContextAwareness. 12 pages, April 2000. Available online in: http://www.cc. gatech.edu/gvu/reports/2000/abstracts/00-18. html. visitado em 14 de fevereiro de 2005 . 
[Dey \& Abowd, 2000b] Dey, A. K.; Abowd, G. D. The Context Toolkit: Aiding the Development of Context-Aware Applications. Proceedings of the Workshop on Software Engineering for Wearable and Pervasive Computing, June 2000.

[Dey, 2001] Dey, A. K. Understanding and Using Context, Personal UbiComp, vol. 5, $\mathrm{n}^{\circ} 1$, pages 4-7, 2001.

[Dey et al., 1999] Dey, A. K.; Abowd, G. D.; Futakawa, M.; Salber, D. The Conference Assistant: Combining Context-Awareness with Wearable Computing. In: the Proceedings of the $3^{\text {iu }}$ International Symposium on Wearable Computers (ISWC '99), San Francisco, CA, pages 21-28, October 20-21, 1999.

[Duval \& Hodgins, 2003] Duval, E.; Hodgins, W.. A LOM Research Agenda. WWW2003 Conference, 20-24 May 2003, Budapest, Hongary. Available online in: http://www2003.org/cdrom/papers/alternate/P659/p659-duval.html.html. visitado em 24 de janeiro de 2004.

[Duval \& Verbert, 2004] Duval, E.; Verbert, K.. Towards a global architecture for learning objects: a comparative analysis of learning object content models. Proceedings of the ED-MEDIA 2004 World Conference on Educational Multimedia, Hypermedia and Telecommunications (Cantoni, L. and McLoughlin, C., eds.), pages 202-208.

[Gilliland-Swetland, 2000] Gilliland-Swetland, A.. Introduction to Metadata: Pathways to Digital Information, chapter Setting the Stage. Los Angeles, California: Getty Education Institute for the Arts. Available online in: http://www.getty.edu/research/institute/standards/intrometadatal, visitado em 21 de fevereiro de 2004.

[Harrison et al., 1998] Harrison, B. L.; Fishkin, K.; Gujar, A.; Mochon, C.; Want, R. The Design and Use of Squeezable Computers: $\mathrm{Na}$ Exploration of Manipulative User Interfaces. In: CHI 1998 Conference Proceedings, ACM Press, pages 74-75, April 1998.

[Hess et al., 2002] Hess, C. K.; Román, M.; Campbell, R. H. Building applications for ubiquitous computing environments. In Proceedings of the International Conference on Pervasive Computing, pages 16-29, August 2002.

[Hillmann, 2003] Hillmann, D.. Using Dublin Core. Available online in: http://dublincore.org/documents/usageguide/, visitado em 16 de fevereiro de 2005.

[Hong \& Landay, 2001] Hong, J. I.; Landay, J. A. An infrastructure approach to contextaware computing. Human-Computer Interaction (HCI) Journal, vol. 16, $\mathrm{n}^{\circ} 2-3,2001$

[Hauptmann, 2004] Hauptmann, A. G.; Gao, J.; Yan, R.; Qi, Y.; Yang, J.; Wactlar, H. D. Automated Analysis of Nursing Home Observations, Carnegie Mellon University, Pervasive Computing, vol. $3, \mathrm{n}^{\circ}$ 2, pages 15-21, April-June 2004

[IEEE LTSC, 2002] IEEE 1484.12.1:2002 Draft Standard for Learning Object Metadata (LOM). Draft Standard, IEEE Learning Technology Standards Committee. Available online in: http://tsc.ieee.org/wg/12/files/LOM $1484121 \mathrm{vl}$ Final Draft.pdf, visitado em 14 de janeiro de 2005.

[IEEE LTSC, 2004] IEEE 1484.12.3/D2 Draft Standard for Extensible Markup Language (XML) Schema Definition Language Binding for Learning Object Metadata. Draft Standard, IEEE Learning Technology Standards Committee. Available online in: http://ltsc.ieee.org/wgl2/files/lEEE 1484_12 03 d2, visitado em 14 de janeiro de 2005. 
[IETF, 1996a] IETF RFC 1951 DEFLATE Compressed Data Format Specification version 1.3, May 1996. Available online in: http://www. ietf.org/rfc/rfcl 1951 .txt. visitado em 14 de janeiro de 2005.

[IETF, 1996b] RFC 2048:1998. Request For Comments, Internet Engineering Task Force Available online in: http://www.ietf.org/rfc/rfc2048.txt, visitado em 14 de janeiro de 2005.

[IETF, 1998] RFC 2426:1998 vCard MIME Directory Profile. Request For Comments, Internet Engineering Task Force. Available online in http://www.ietf.org/rfc/rfc2426.txt. visitado em 14 de janeiro de 2005.

[IMS, 2003] IMS Simple Sequencing Behavior and Information Model vl.0 Final Specification, IMS Global Learning Consortium, Inc., March 2003 Available online in http://www.imsproject.org/, visitado em 19 de janeiro de 2005.

[Ip et al., 2001] Ip, A., Morrison, I.; Currie, M.. What is a learning object, technically? WebNet 2001 (World Conference on the WWW and Internet), Orlando,Florida, AACE.

[Ishii \& Ullmer, 1997] Ishii, H.; Ullmer, B. Tangible Bits: Towards Seamless Interfaces between People, Bits and Atoms. In: CHI 1997 Conference Proceedings, ACM Press, pages 234-241, March 1997.

[ISO, 2000]. ISO Standard 8601:2000 Data elements and interchange formats - Information interchange - Representation of dates and times. ISO International Standard, International Organization for Standardization.

[ISO/IEC, 2000] Information Technology - Universal multiple-octet coded character set -Part 1: Architecture and basic multilingual plane. ISO/IEC Final Draft International Standard 10646-1:2000. International Organization for Standardization/International Electrotechnical Commission.

[ISO, 2003] ISO Standard 15836:2003 Information and documentation - The Dublin Core metadata element set. ISO International Standard, International Organization for Standardization. Available online in: http://www. niso.org/international/SC4/n515.pdf. visitado em 19 de janeiro de 2005.

[Izeki, 2001] Izeki, C. A. Anotações colaborativas como hiperdocumentos de primeira classe na Web semântica. Dissertação de Mestrado, Instituto de Ciências Matemáticas e de Computação da USP, São Carlos - SP, 2001.

[Johanson et al., 2002] Johanson, B.; Fox, A.; Winigrad,T. The Interative Workspaces Project: Experiences with ubiquitous computing rooms. IEEE Pervasive Computing, vol.1 $\mathrm{n}^{\circ}$ 2, pages 71-78, April-June 2002.

[Kashyap et al., 1995] Kashyap, V.; Shah, K.; Sheth, A.. Metadata for building the multimedia path quilt. In Multimedia Database System: Issues and Research Directions. pages 297 -319, Springer-Verlag New York.

[L'Allier et al., 1995] L'Allier, J. J.; Miles, K. W.; Welsh, S. H.. The NETg Mastery Test Strategy. Available online in: http://www.netg.com/demodownloads/, visitado em $22 \mathrm{de}$ fevereiro de 2005.

[L'Allier, 1997] L'Allier, J. J.. A Frame of Reference: NETg's Map to Its Products, Their Structures and Core Beliefs. Available online in: http://www.netg.com/demodownloads/, visitado em 22 de fevereiro de 2005 . 
[Macedo et al., 2001] Macedo, A. A.; Bulcão Neto, R. F.; Pimentel, M. G. C. Autoria colaborativa na Web: Experiências e reflexões sobre a CoWeb. Revista Brasileira de Informática na Educação, (9), págs 9-25.

[Moura et. al., 1998] Moura, A. M. C.; Campos, M. L. M.; Barreto, C. M. A survey on metadata for describing and retrieving Internet resources. World Wide Web Journal, volume 1 (4), 221-240.

[Mynatt \& Tran, 2002] Mynatt. E. D.; Tran, Q. T. Cook's Collage: Two Exploratory Designs. Position paper for the Technologies for Families Workshop at CHI 2002, pages 20-25, Minneapolis, MN, April 2002.

[Muller \& Ottmann, 2000] Muller, R.; Ottmann, T.. The Authoring on the Fly" system for automated recording and replay of (tele)presentations. Multimedia Systems Journal, vol. $8, \mathrm{n}^{\circ} 3$, pages $158-176,2000$.

[Oviatt, 1999] Oviatt, S.. Ten myths of multimodal iteraction. Communications of ACM, vol. 42, $\mathrm{n}^{\circ} 11$, pages 74-81, November 1999.

[Pimentel \& Abowd 1999] Pimentel, M. G. C.; G. D. Abowd. Development and understanding of automated capture enviroments to support long-term use. Projeto de cooperação internacional aprovado junto ao ProTeM-Cc-Cnpq/Brasil e ao NSF/EUA, 1999.

[Pimentel et. al., 2001] Pimentel, M. G. P.; Abowd, G. D.; Ishiguro, Y.; Kerimbaev, B.; Guzdial, M.. Supporting Long-term Educational Activities through Dynamic Web Interfaces. Interacting With Computers, England, v. 13, p. 353-374, 2001.

[Pimentel et. al, 2003] Pimentel, M. G. C.; Sante, D. G.; Bulcão Neto, R. F.. Preparing and Extending Capture-based Documents. In: 2nd International Information and Telecommunication Technologies Symposium, 2003, Florianópolis. Proceedings of I2TS'2003, 2003. v. 1. p. 1-8.

[Qu \& Nejdl, 2002] Qu, C.; Nejdl, W.. Towards Interoperability and Reusability of Learning Resources: a SCORMconformant Courseware for Computer Science Education. In Proceedings of the 2nd IEEE International Conference on Advanced Learning Technologies (IEEE ICALT 2002), Sept. 2002.

[Ribas, 2004] Ribas, H. M. B.. Geração de metadados SCORM para documentos de aula do iclass. Monografia de Projeto de Graduação, Instituto de Ciências Matemáticas e de Computação da USP, São Carlos - SP, Dezembro 2004.

[Ritcher et. al., 2001] Richter, H.; Abowd, G. D.; Geyer, W.; Fuchs, L.; Daijavad, S.; Poltrock, S.. Integrating meeting capture within a collaborative team environment. In Proceedings of the International Conference on Ubiquitous Computing, pages $123-138$, Atlanta, GA, USA.

[Rocha, 2004] Rocha, C. F. P. Anotações com pdas: extensão da área de escrita e integração com o projeto inca-serve. Dissertação de Mestrado, Instituto de Ciências Matemáticas e de Computação da USP, São Carlos - SP, 79 folhas, Abril 2004.

[Rodden et al.,1998] Rodden, T.; Cheverest, K.; Davies, N.; Dix, A. Exploiting Context in HCI design for Mobile Systems. In: Workshop on Human Computer Interaction with Mobile Devices, pages 12-17, May 1998. 
[Ryan et al., 1997] Ryan, N.; Pascoe, J.; Morse, D. Enhanced Reality Fieldwork: The contextaware archeological assistant. In: Computing Applications in Archaeology. V. Gaffney, M. van Leusen and S. Exxon (editors), 1997.

[Salber et al., 1999] Salber, D.; Dey, A. K.; Abowd, G. D. The Context Toolkit: Aiding the development of context-enabled applications. In Proceedings of the Conference on Human Factors in Computing Systems, pages 434-441, May 1999.

[Sante, 2003] Sante, D. Autore: suportando autoria evolucionária em ambientes de captura. Dissertação de Mestrado, Instituto de Ciências Matemáticas e de Computação da USP, São Carlos - SP, 87 folhas, Maio 2003.

[Sante et al., 2003] Sante, D. G.; Pimentel, M. G. C.; Fortes, R. P. M.. Preparing and Extending capture-based documents. In: Simpósio Brasileiro de Sistemas Multimídia e Hipermídia, 2003, Salvador. Anais, 2003. v. 1. p. 507-507.

[Schilit \& Theimer, 1994] Schilit, B. N.; Theimer, M. M. Disseminating Active Map Information to Mobile Hosts, IEEE Network, vol. 8, $\mathrm{n}^{\circ}$ 5, pages 22-32, September 1994.

[Schilit et al., 1993] Schilit, B. N.; Adams, N.; Gold, R.; Tso, M.; Want, R. The ParcTab mobile computing system. In Proceedings of the Workshop on Workstation Operating Systems, pages 34-39, October 1993.

[SCORM, 2004] SCORM Content Aggregation Model (CAM) Version 1.3, Technical report, Advanced Distributed Learning, January 2004. Available online in: http://www.adlnet.org/, visitado em 23 de março de 2005.

[Shi et. al., 2003] Shi, Y.; Xie, W.; Xu, G.; Shi, R.; Chen, E.; Mao, Y.; Liu, F.. The smart classroom: Merging technologies for seamless tele-education. IEEE Pervasive Computing, vol 2, $\mathrm{n}^{\circ} 2$, pages 47-55, 2003.

[Shmandt \& Arons, 1985] Shmandt, C.; Arons, B. PhoneSlave: A graphical telecommunications interface. In: Proceedings of the Society for Information Display, vol. 26, $\mathrm{n}^{\mathrm{o}} 1$, pages 79-82, 1985.

[Siewiorek, 2002] Siewiorek, D. P. New frontiers of Application Design. Communication of the ACM, vol.45, $n^{\circ} 12$, pages 79-82, December 2002.

[Stal, 2002] Stal, M. Web Services: beyond component-based computing. Communications of the ACM, vol. 45, $\mathrm{n}^{\circ} 10$, pages 71-76, October 2002.

[Truong et al., 2001] Truong, K. N.; Abowd, G. D.; Brotherton, J. A. Who, What, When, How: Design issues of capture \& access applications. In: Proceedings of the International Conference on Ubiquitous Computing, pages 209-224, Atlanta, GA, 2001.

[Truong \& Abowd, 2002] Truong, K. N.; Abowd, G. D.. Enabling the generation, preservation \& use of records and memories of everyday life. In Proceeding of CHI.

[Truong \& Abowd, 2004] Truong, K. N.; Abowd, G. D.. Inca: A software infrastructure to facilitate the construction and evolution of ubiquitous capture \& access applications. In Proceedings of Pervasive 2004: The Second International Conference on Pervasive Computing, April.

[Yau et al., 2002] Yau, S. S.; Karim, F.; Wang, Y.; Wang, B.; Gupta, S. K. S. Reconfigurable context-sensitive middleware for pervasive computing. IEEE Pervasive Computing, vol. $1, \mathrm{n}^{\mathrm{o}} 3$, pages 33-40, July-September 2002. 
[Wagner, 2002] Wagner, E. D.. Steps to Creating a Content Strategy for Your Organization. The e-Learning Developers' Journal, October 2002.

[Want et al., 1992] Want, R.; Hopper, A.; Falcao, V.; Gibsons, J. The active badge location system. ACM Transactions on Information Systems, vol. 10, pages91-102, January 1992.

[Want et al., 1995] Want, R.; Schilit, B.; Adams, N.; Gold, R.; Petersen, K.; Goldberg, D.; Ellis, J.; Weiser, M. The ParcTab Ubiquitous Computing Experiment, Xerox Parc Technical Report CSL-95-1, Xerox Palo Alto Research Center, March 1995.

[Weiser, 1991] Weiser, M. The computer for the $21^{\text {st }}$ century, Scientific American, vol. 265, $\mathrm{n}^{\circ} 3$, pages 94-104, September 1991.

[Wiley, 2000] Wiley, D. A.. Connecting learning objects to instructional design theory: A definition, a metaphor, and a taxonomy. In D. A. Wiley (Ed.), The Instructional Use of Learning Objects. Available online in: http://reusability.org/read/chapters/wiley.doc, visitado em 28 de março de 2005.

[Wiley et al., 2000] Wiley, D.; Gibbons, A. S.; Recker, M.. A Reformulation of the Issue of Learning Object Granularity and Its Implications for the Design of Learning Objects (Vol. 2001). http://reusability.org/granularity.pdf, visitado em 28 de março de 2005.

[Wiley, 2002] Wiley, D.. Learning objects - a definition. In A. Kovalchick \& K. Dawson (Eds.) Educational Technology: An Encyclopedia. Santa Barbara: ABC-CLIO.

[W3C, 2001] XML Schema Part 2: Datatypes. W3C Recommendation, World Wide Web Consortium, May 2001. Available online in: http://www.w3.org/TR/xmlschema-2/. visitado em 15 de fevereiro de 2005.

[W3C, 2002] Web Service Activity. W3C Recommendation, World Wide Web Consortium, Available online in http://www.w3.org/2002/ws, visitado em 15 de fevereiro de 2005. 


\section{Glossário}

ASSET (recurso): é o objeto (item) mais básico de um recurso de aprendizagem. Assets são representações eletrônicas de mídia, como texto, imagens, som, objetos de conteúdo ou qualquer fragmento de dados que podem ser feitos por um cliente $W e b$ e apresentados ao usuário (estudante, professor, monitor, etc). Mais de um asset pode ser agrupado para construir outros assets.

JSP: JavaServer Pages. É uma tecnologia para criar páginas Web com programação em Java, compostas de código IITML/XML. Com JSP pode-se criar aplicações Web executáveis em vários servidores $\mathrm{Web}$, de múltiplas plataformas.

LMS: Learning Management Systems. É um software que automatiza o gerenciamento dos eventos de treinamento, com funcionalidades projetadas para entregar, localizar, informar e gerenciar o conteúdo de aprendizagem, o progresso e as interações do estudante.

MANIFESTO: é um documento XMI. que contém um inventário estruturado do conteúdo do pacote. Depois de empacotar uma coleção de cursos, esse pacote de conteúdo terá que ser desagregado para ser entregue aos usuários em um sistema de execução LMS.

METADADOS: é um termo que é compreendido de diferentes maneiras pelas comunidades profissionais que projetam, criam, descrevem, preservam e usam sistemas de informação, que quer dizer "dados sobre dados". Metadado pode ser entendido como qualquer objeto de informação em qualquer nível de agregação.

PACOTE (de conteúdo): Um pacote representa uma unidade de aprendizado. A unidade de aprendizado pode fazer parte de um curso que tem relevância instrutiva fora da organização do curso e pode ser entregue independentemente, como uma parte de um curso, um curso inteiro ou como uma coleção de cursos.

RDF: Resource Description Framework. Trata-se de uma especificação normalmente baseada em XML que tem como objetivo automatizar e ampliar recursos para a internet através da representação de informações. 
SCO: Sharable Content Obiect. E uma coiecao ae um ou mas assets trecurs:. ıepresentam um unico recurso ae aprenaizagem, atem de ser o mais baixo nivei de granularidade de um rccurso de aprendizagem.

SMIL: Synchronized Multimedia Integration Language. Possibilita a autoria de apresentações audiovisual interativas. SMIL é tịicamente usado em apresentações multimídia que integram streaming de áudio e vídeo com imagens, texto ou qualquer outro tipo de mídia.

URL: Uniforme Resource Locator. Um termo informal associado com o esquema URI (Uniform Resource Identifier) popular: http, ftp, mailto, etc.

XHTML: Extensible HyperText Markup Language. E uma família de tipos de documentos baseados no padrão XML e módulos que reproduzem e estendem o HTML.

XML: Extensible Markup Language. E uma meta-linguagem simples e flexível, utilizada na definição de linguagens para estruturação de hiperdocumentos. E considerada evolução de HTML, por permitir acesso e manipulação da estrutura e semântica do hiperdocumento. E um importante padrão para intercâmbio de dados na Web e em qualquer outra aplicação.

XSL: Extensible Stylesheet Language. E uma linguagem para expressar folhas de estilo. Utiliza XSLT mais a descrição de um conjunto de Objetos de Formatação e Propriedades de Formatação.

XSLT: XSL Transformations. E uma linguagem para descrever como transformar um documento XML (representado como uma árvore) em outro documento (outra árvore).

XSP: A linguagem XSP é o centro da tecnologia Cocoon, baseado em XML para Web, publicado em Java e uma das sete partes do Projeto Apache XML. O XSP é usado para construir conteúdo XMI dinâmico e não necessita de esforços para aprender uma linguagem de programação. 